\title{
THE POTENTIAL OF PLANT GROWTH-PROMOTING BACTERIA TO ENHANCE RHIZOREMEDIATION OF DIESEL FUEL-CONTAMINATED SITES
}

\author{
Dissertation \\ for the award of the degree \\ "Doctor rerum naturalium" (Dr.rer.nat.) \\ of the Georg-August-Universität Göttingen
}

within the doctoral program Biology

of the Georg-August University School of Science (GAUSS)

submitted by

Michael Onyedika EZE

from Opi, Nigeria

Göttingen, 2021 


\section{Thesis Committee}

Prof. Dr. Rolf Daniel, Department of Genomic and Applied Microbiology, Institute of Microbiology and Genetics, Georg-August-Universität Göttingen, Germany

Prof. Simon George, Department of Earth and Environmental Sciences, Macquarie University, Sydney, Australia

PD. Dr. Michael Hoppert, Department of General Microbiology, Institute of Microbiology and Genetics, Georg-August-Universität Göttingen, Germany

\section{Members of the Examination Board}

Reviewer: $\quad$ Prof. Dr. Rolf Daniel, Department of Genomic and Applied Microbiology, Institute of Microbiology and Genetics, GeorgAugust-Universität Göttingen, Germany

Second Reviewer: Prof. Simon George, Department of Earth and Environmental Sciences, Macquarie University, Sydney, Australia

\section{Further Members of the Examination Board}

PD. Dr. Michael Hoppert, Department of General Microbiology, Institute of Microbiology and Genetics, Georg-August-Universität Göttingen, Germany

Prof. Dr. Jörg Stülke, Department of General Microbiology, Institute of Microbiology and Genetics, Georg-August-Universität Göttingen, Germany

Prof. Dr. Volker Thiel, Geobiology, Geoscience Centre, Georg-August-Universität Göttingen, Germany

Prof. Dr. Kai Heimel, Department of Molecular Microbiology and Genetics, Institute of Microbiology and Genetics, Georg-August-Universität Göttingen, Germany 


\section{Declaration}

I hereby certify that this thesis entitled "The potential of plant growth-promoting bacteria to enhance rhizoremediation of diesel fuel-contaminated sites" is being submitted to GeorgAugust-Universität Göttingen, Germany and Macquarie University, Sydney, Australia in accordance with the Cotutelle agreement dated 10 October 2018.

To the best of my knowledge and belief, the thesis contains no material previously published or written by another person except where due reference is made in the thesis itself.

Michael O. Eze

Göttingen, April 2021 


\section{Dedication}

This dissertation is gratefully dedicated to my loving wife

\section{Gloria Eze}

who offered unflinching support and encouragement through thick and thin, and especially during the past three years of my doctoral journey. Thank you for always believing in me, and for being $100 \%$ confident in my ability to get this research done!

And to our beloved children

\section{Manaen and Persis}

both of whom cheered me up when I was discouraged, and often made me forget my worries. 


\section{Acknowledgements}

"A tree cannot make a forest." How often we hear those words! That is also true with any doctoral research. Without the guidance, support and encouragement of certain individuals, this dissertation would not have been possible.

First and foremost, I would like to thank the Almighty God, Jehovah, the source of life, wisdom and knowledge. My profound gratitude goes to my Australian supervisors Prof. Simon George and Prof. Grant Hose, both of whom constantly guided me through my doctoral study. Simon's willingness to always proofread my applications for research grants motivated me to carry out many academic exploits, resulting in more than 15 national and international awards during my three years of study. Yes, he reinforced my wings to fly high! In addition, both Simon and Grant showed great concern for my social wellbeing and that of my family, with several get-togethers, oftentimes involving the entire family. My little boy fondly remembers how he played with a cute little python during one dinner in Simon's house.

I would like to thank my German supervisors, Prof. Dr. Rolf Daniel and PD. Dr. Michael Hoppert. They and their research teams proved to be a loving and supportive family during our stay in Germany. Prof. Dr. Volker Thiel is especially thanked for granting me access to the Geobiology facility of Georg-August University of Goettingen.

I must express my appreciation for the support I received from friends and colleagues especially the Organic Geochemistry group in Macquarie University and the Applied Microbiology group in Georg-August University of Goettingen. I will run out of space if I were to list them by name.

Many thanks are due to Macquarie University and the Commonwealth Government of Australia for supporting my study by providing me with an international Research Training Program (iRTP) Scholarship. Similarly, I am grateful to the German Academic Exchange Service (DAAD) for providing me with a DAAD Scholarship to enable my research in Germany.

I am very thankful to my parents and parents-in-law for their tender concern for my young family. Their constantly keeping in touch with their grandchildren was so reassuring to the kids. Finally, I am deeply indebted to my darling wife (pet-named "My Love") and our son, Manaen, for their love, encouragement and sacrifices. They provided moral boost during my many science communication events, such as the 2018 Falling Walls Lab Australia at the Australian Academy of Science in Canberra. They also accompanied me to Germany, sacrificing the warmth of Sydney at the altar of European winters. How glad we were to welcome to the world our little "angel” named Persis during our stay in Germany! I love you all dearly!

Michael O. Eze 


\begin{abstract}
Crude oil and fuel spillages are the most persistent environmental menace resulting from oil and gas exploration, production and utilisation. The United States Environmental Protection Agency (US EPA) estimated that rehabilitation can cost over \$US1 million per hectare. Traditional solutions for remediation are expensive and environmentally unfriendly. Consequently, more cost-effective and eco-friendly remediation technologies are needed.

The use of plants to clean up contaminated sites is a cost-effective and an environmentallyfriendly approach. However, the toxicity of petroleum hydrocarbons to most plants, coupled with the slow rate of natural attenuation limits the effectiveness of this approach. Therefore, the identification of hydrocarbon tolerant plants and the isolation of microbial consortium and isolates capable of plant growth promotion and hydrocarbon degradation is crucial to the success of plant-based remediation techniques. This is the crux of this research.

In the first part, I examine how ethanol addition to diesel fuel affects the leaching potentials of diesel fuel hydrocarbons. Since rhizoremediation of hydrocarbons depends largely on rhizodegradation of contaminants by the root-associated microbiome, the leaching of petroleum hydrocarbons beyond the rooting zones of plants may limit the effectiveness of this process as a reclamation strategy. The results revealed that while 5\% (by volume) ethanol addition had a limited effect on aromatic hydrocarbons, $10 \%$ ethanol addition resulted in the elution of all classes of aromatic hydrocarbons studied beyond a $90 \mathrm{~cm}$ column. This revealed the need for choosing plants with adequate rooting system for an effective rhizoremediation of organic contaminants.
\end{abstract}

Secondly, through phytotoxicity bioassays, I selected Medicago sativa as the most suitable species for rhizoremediation of diesel fuel. Dose-response analysis revealed that increasing diesel fuel concentrations in the soil generally led to a monotonically-decreasing biomass in all other studied plant species $(\mathrm{P}<0.001)$, with EC10 values $( \pm \mathrm{SE})$ ranging from $0.36 \pm 0.18 \mathrm{~g} / \mathrm{kg}$ to $12.67 \pm 2.13 \mathrm{~g} / \mathrm{kg}$. On the other hand, hydrocarbons had a statistically significant hormetic influence on $M$. sativa $(f=3.90 \pm 1.08$; $\mathrm{P}<0.01)$. Interestingly, exposure to diesel fuel contaminated soil up to $10 \mathrm{~g} / \mathrm{kg}$ did not affect the viability of $M$. sativa seeds, although time to seed emergence was delayed. These factors position $M$. sativa as the most-promising plant species for microbially-enhanced rhizoremediation of diesel fuel.

In the third part of the research, I successfully isolated a bacterial consortium and single isolates that can metabolize diesel fuel hydrocarbons as their sole carbon and energy source, while promoting the growth of host plants. In addition, I elucidated the genes and metabolic pathways involved in these reactions. I also reconstructed a number of metagenome-assembled genomes, 
many of which contained genes putatively involved in hydrocarbon degradation, with potentials for bioremediation application.

Finally, I examined the rhizoremediation effectiveness of $M$. sativa inoculated with either the consortium or M. sativa inoculated with Paraburkholderia tropica single isolate. The results indicated that $M$. sativa-P. tropica symbionts successfully enhanced the rhizodegradation of diesel fuel hydrocarbons. The geochemical analysis of residual hydrocarbons revealed that the combined action of $M$. sativa and P. tropica resulted in $96 \%$ degradation of the total diesel fuel hydrocarbons within 60 days. Biodegradation was further confirmed using parameters such as $\mathrm{nC}_{17} /$ pristane, $\mathrm{nC}_{18} /$ phytane, $\mathrm{nC}_{16} /$ nor-pristane and total petroleum hydrocarbons/unresolved complex mixture ratios. Molecular analysis of biodegradation revealed that the polycyclic aromatic hydrocarbon components of the diesel fuel were almost completely degraded by the plant-microbe symbionts.

I am confident that the results of this research will revolutionize the way diesel spills and other organic contaminants are cleaned up, and facilitate the reclamation of petroleum contaminated sites. 


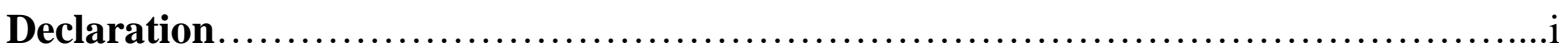

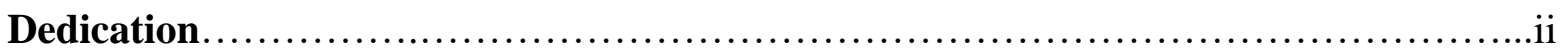

Acknowledgements.............................................................

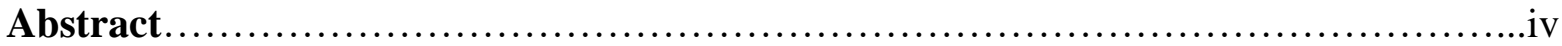

Table of contents...............................................................

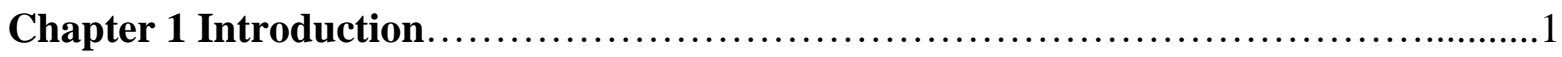

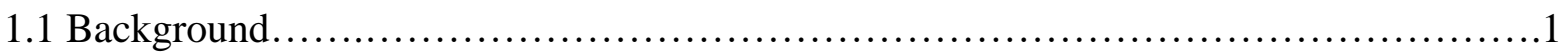

1.2 Aim and objectives.........................................................

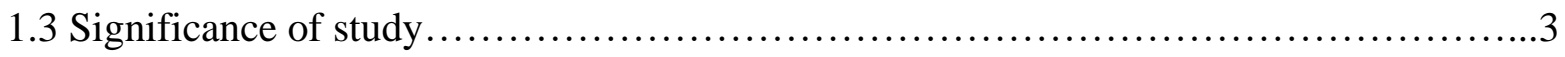

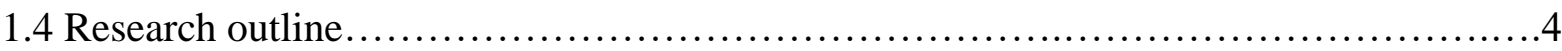

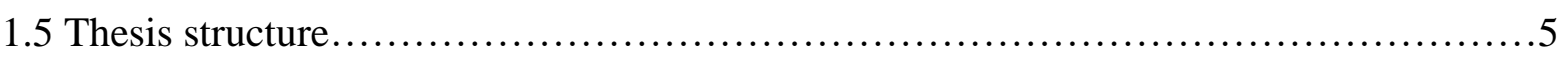

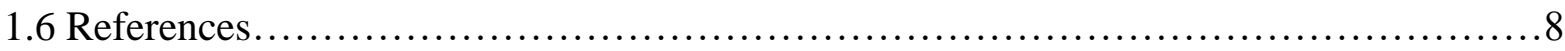

Chapter 2 Ethanol-blended petroleum fuels: implications of co-solvency for phytotechnologies............................................................ 10

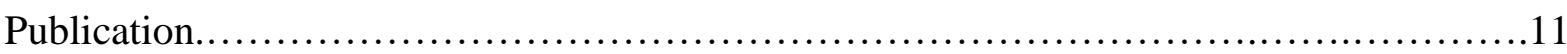

Chapter 3 Dose-response analysis of diesel fuel phytotoxicity on selected plant species..20

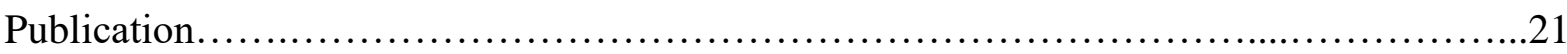

Chapter 4 Assessing the effect of diesel fuel on the seed viability and germination of Medicago sativa using the event-time model...................................29

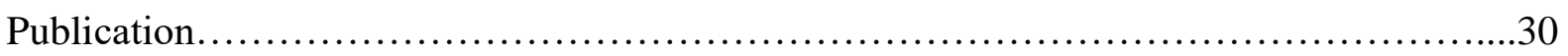

Chapter 5 Metagenome assembly and metagenome-assembled genome sequences from a historical oil field located in Wietze, Germany ................................... 39

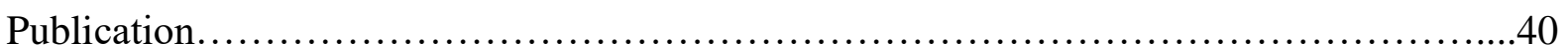

Chapter 6 Diversity and metagenome analysis of hydrocarbon-degrading bacterial consortium from asphalt lakes located in Wietze, Germany .......................42

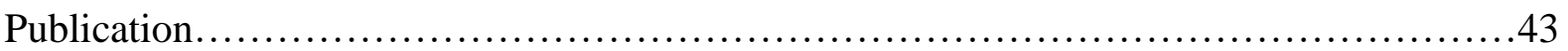


Supplemental information to Chapter 6.

Chapter 7 Metagenomic insight into the plant growth-promoting potential of a dieseldegrading bacterial consortium for enhanced rhizoremediation application............71

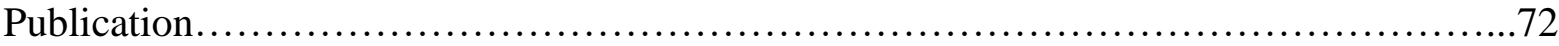

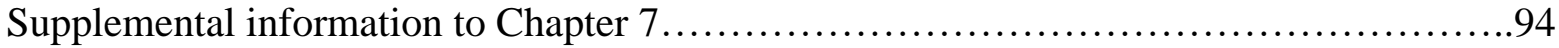

Chapter 8 Exploiting synergistic interactions of Medicago sativa L. and Paraburkholderia tropica for enhanced biodegradation of diesel fuel hydrocarbons...................98

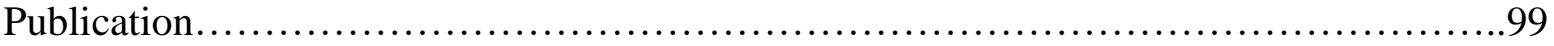

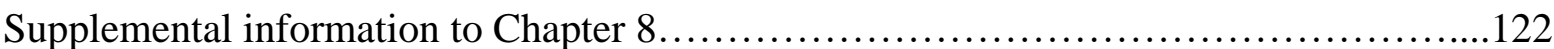

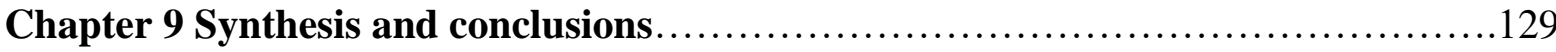

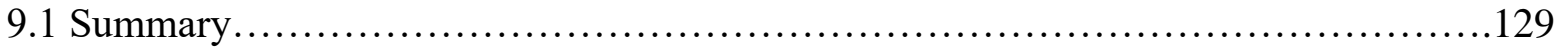

9.2 Outlook and suggestions for future research..................................... 131

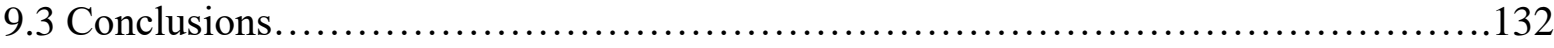

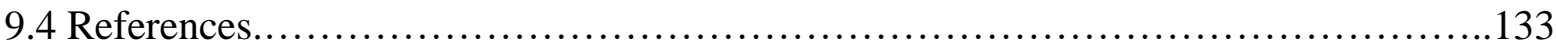

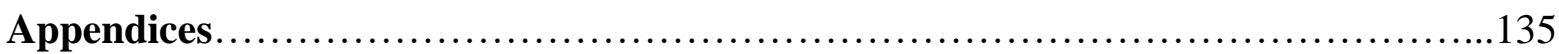

Appendix A. RSC HOT Article Award........................................... 135

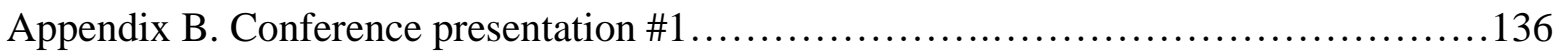

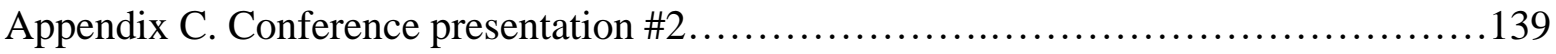

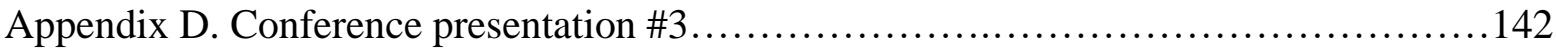

Appendix E. Curriculum Vitae..................................................... 144 


\section{Chapter 1}

\section{Introduction}

\subsection{Background}

The negative impact of oil pollution on the environment has precipitated legitimate concerns in the last decade. Globally, oil spillage is the most significant environmental threat resulting from oil and gas operations. Spills have occurred due to corrosion, human error and equipment failure, with negative impacts to humans, animals and the environment. Although large-scale aquatic spills easily attract public attention, the majority of spills have occurred on land, with long-lasting ecological impacts on terrestrial biota (Duffy et al., 1980).

The international community has realized the potential impact of hydrocarbon contamination on the environment and seriously seeks to address it through various conventions such as the United Nations Conference on Environment and Development (UNCED). Consequently, the reclamation of contaminated sites is on the agenda of many countries. For example, on 2nd June 2016, the Federal Government of Nigeria launched \$1 Billion Ogoniland clean-up and restoration programme in harmony with the recommendations made by the United Nations Environment Programme (UNEP).

Diesel fuel-polluted sites are difficult to remediate because diesel is less volatile and has less biodegradable characteristics compared to petrol (gasoline) spills (ATSDR, 1995). Traditional methods of remediation, such as excavation and relocation of contaminants to landfills, are expensive and usually impractical because of the amount of soil involved. In addition, these methods are environmentally unfriendly as they impact on soil matrix and associated microbiomes. As a result, more cost-effective and eco-friendly remediation techniques are being explored. One of the emerging strategies is the use of plants to extract, mitigate, and stabilise contaminants, which is categorised as "phytoremediation", and which can also assist in reforestation (Cunningham et al., 1995; Macek et al., 2000; Mench et al., 2009; Al-Baldawi et al., 2015).

In most cases, plants growing in polluted sites exhibit a measure of tolerance to existing contaminants. However, some researchers have observed that even plants that are tolerant to the prevailing environmental contaminants often remain stunted in the presence of contaminants, and remove only small quantities of contaminants per plant (Glick, 2003; PilonSmits and Freeman, 2006). To obtain more efficient degradation of organic compounds, plants depend on their associated microorganisms (Pilon-Smits and Freeman, 2006). Sadly, native 
microbes exhibit slow growth rate and low metabolic activities, thereby limiting the effectiveness of natural attenuation (Abdulsalam et al., 2011; Jiang et al., 2016). Therefore, the success of bioremediation primarily depends on optimising biodegradation through the inoculation of plant growth-promoting rhizobacteria (PGPR) capable of utilizing hydrocarbons as their major carbon and energy source.

Rhizoremediation involves the degradation of contaminants in the rhizosphere by rootassociated microorganisms (Allamin et al., 2020). This approach involves some plant-microbe beneficial interactions in which root exudates (amino and fatty acids, sugars, vitamins, nucleotides) provide hydrocarbon-degrading rhizobacteria with the needed nutrients for their metabolic activities (Kuiper et al., 2004). On the other hand, these bacteria stimulate the growth of host plants through plant growth-promoting processes, including, but not limited to, nitrogen fixation, phosphate solubilization, siderophore transport, indoleacetic acid and pyrroloquinoline quinone syntheses (Lobo et al., 2019). This synergistic relationship that enhances biomass production, tolerance of plants to unfavourable soil conditions, regular nutrient flow and continuous biodegradation of contaminants, has been described as the ecological driver of rhizoremediation (Rohrbacher and St-Arnaud, 2016).

In view of the foregoing, there is a growing interest in enhancing rhizoremediation through the inoculation of microbial consortia or isolates with the right metabolic abilities (Garrido-Sanz et al., 2018; Garrido-Sanz et al., 2019). Unfortunately, the majority of research work has focussed only on hydrocarbon-degrading microbes (Di Martino et al., 2012; Abed et al., 2014; Ali et al., 2020), with very few studies targeted at organisms capable of both plant growth promotion and hydrocarbon degradation (Dias et al., 2019). In addition, there is a scarcity of literature on single bacterial isolates with both capabilities. By combining microbial metagenomics, culture techniques and organic geochemical approaches, this study examines the potential of isolated consortia and single bacterial isolates to enhance plant growth promotion and petroleum hydrocarbon degradation. Specifically, this study is the first attempt to examine the synergistic interactions of Medicago sativa L. and Paraburkholderia tropica for enhanced rhizoremediation of diesel fuel-contaminated soils.

I am confident that the results from this study will form a basis for state-of-the-art biotechnological innovation in soil reclamation, and will hopefully revolutionize the way oil spills and other environmental contaminants are cleaned up. 


\subsection{Aim and Objectives}

The central aim of this research is to harness the synergistic interactions between plants and microbes and develop the right plant-microbe pairs (systems) for a more efficient clean-up of diesel fuel spills, and by extension other petroleum hydrocarbon contaminants.

Specific objectives include:

- Screening of selected plant species for hydrocarbon tolerance.

- Isolation of hydrocarbon-degrading bacterial consortium and single species from crude oil-contaminated sites.

- Functional (meta)genome analyses of bacterial consortium and single species for their potentials for plant growth promotion and hydrocarbon degradation.

- Greenhouse-based study of the effectiveness of Medicago sativa L. and/or isolated consortium and single species for enhanced rhizoremediation.

\subsection{Significance of Study}

The motivation for this study stems from many diverse but complementary observations, which highlights the significance of the expected research outcome.

- Traditional solutions for remediation of petroleum contaminated soils such as excavation are very expensive and environmentally unfriendly. The United States Environmental Protection Agency (US EPA) estimated that rehabilitation can cost over \$US1 million per hectare using excavation and landfill incineration (USEPA, 2000). By comparison, adopting plant-based remediation techniques can result in a cost saving of 50 to $80 \%$ over traditional alternatives (USEPA, 2001).

- Native plants that are relatively tolerant to environmental contaminants often remain stunted and exhibit low metabolic activities, thereby removing only small quantities of contaminants (Pilon-Smits and Freeman, 2006). By identifying effective plant growthpromoting and hydrocarbon-degrading bacteria, I hope to overcome this challenge.

- With more stringent regulations to mitigate oil-related environmental damage, and more penalties (fines) imposed on defaulting organisations, it makes environmental and economic sense to innovate and adopt the most efficient remediation technologies.

- This study presents a well-augmented remediation technique that will drive any policy measure by Federal Governments to combat environmental pollution. 


\subsection{Research Outline}

The $\mathrm{PhD}$ research consists of four separate but interconnected projects (Figure 1.1), with each contributing to the achievement of my central aim.

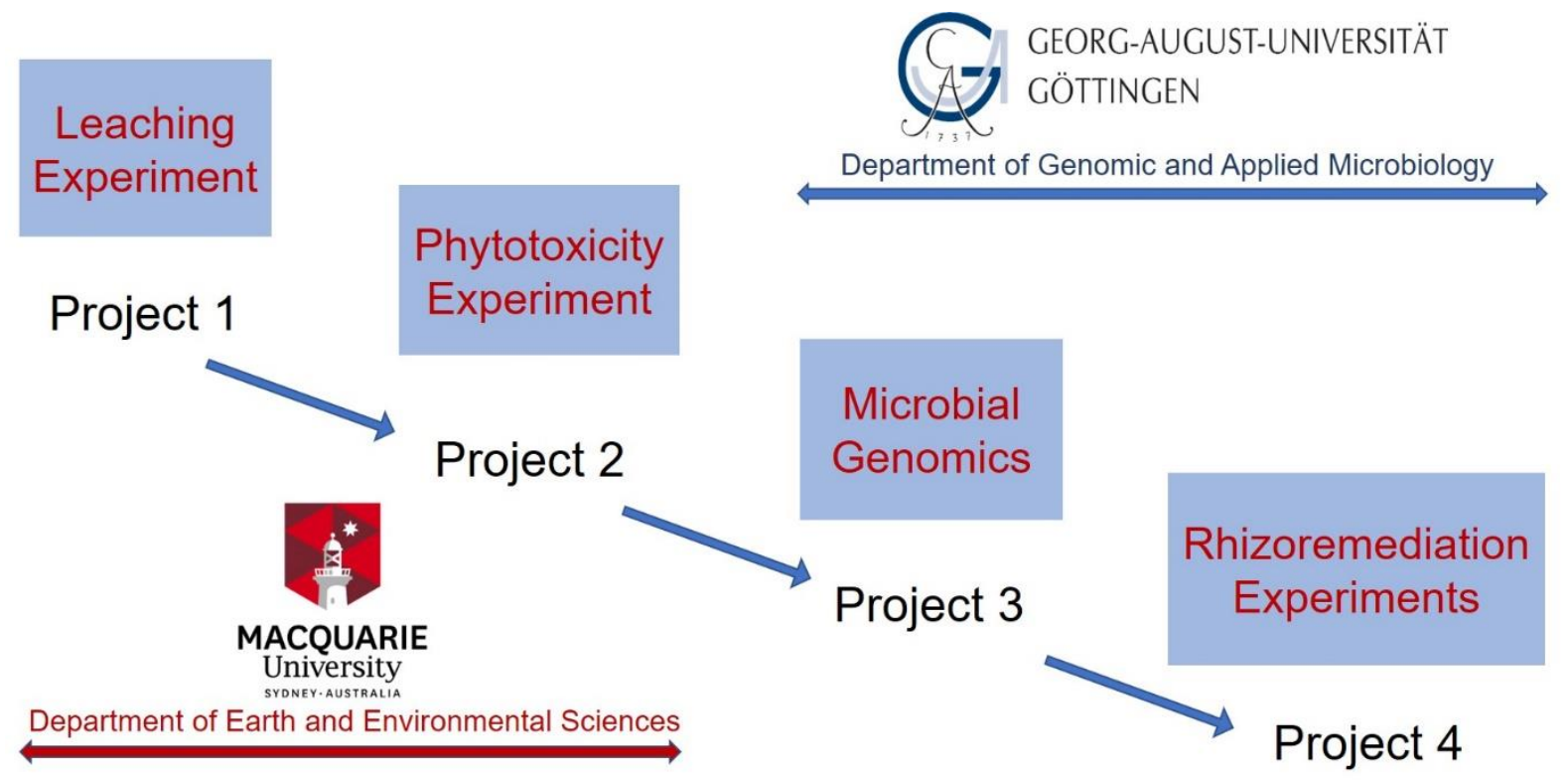

Figure 1.1. The conceptual research diagram showing precedence of activities for this study.

The first part of the research was a leaching experiment designed to understand the effect of ethanol addition on the leaching potentials of petroleum hydrocarbons. Since rhizoremediation of hydrocarbons depends largely on rhizodegradation of contaminants by the root-associated microbiome, the leaching of petroleum hydrocarbons beyond the rooting zones of plants may limit the effectiveness of this process as a reclamation strategy. The second project is a phytotoxicity experiment through which I examined the tolerance of selected plant species to hydrocarbon toxicity. This enabled the identification of the most suitable plant species for rhizoremediation of diesel fuel. The first two projects were conducted at Macquarie University, Sydney, Australia.

The third project involved the isolation of bacterial consortia and single species followed by comparative (meta)genome analysis of their plant growth-promoting and hydrocarbondegrading potentials. Finally, a greenhouse-based rhizodegradation experiment was carried out to assess the capability of the isolated consortium and single bacterial species for effective reclamation of diesel fuel-contaminated soils. Geochemical analysis of residual soils provided a confirmatory test for the degradation of diesel fuel hydrocarbons. These experiments were performed at Georg-August University of Goettingen, Germany. 


\subsection{Thesis Structure}

The thesis is divided into nine chapters.

Chapter 1 introduces the main aim, objectives, and significance of this research. It also outlines the nature of the different part of the research that were carried out at each of the two institutions that are part of the cotutelle agreement.

Chapters 2-8 constitute the results of the seven different but interconnected projects that make up the overall thesis. These findings are organised into seven independent research papers, the majority of which are already published in Q1 peer-reviewed journals. Specifically:

Chapter 2 shows how ethanol addition to diesel fuel affects the leaching potentials of diesel fuel hydrocarbons. Since phytoremediation of hydrocarbons depends largely on rhizodegradation of contaminants by the root-associated microbiome, the leaching of petroleum hydrocarbons beyond the rooting zones of plants may limit the effectiveness of this process as a reclamation strategy for ethanol-blended fuel spills. Hence, these results are vital in selecting suitable phytoremediating plant(s). The preliminary results were given as an oral presentation at the $20^{\text {th }}$ Australian Organic Geochemistry Conference in Canberra, Australia in December 2018. Another part of the results was presented as a poster at the SETAC Europe $29^{\text {th }}$ Annual Meeting in Helsinki, Finland in May 2019. The complete results were published in RSC Advances. Happily, the article was selected for and featured in 2020 RSC Advances HOT Articles.

Eze, M.O. and George, S.C. (2020) Ethanol-blended petroleum fuels: implications of cosolvency for phytotechnologies. RSC Advances 10, 6473-6481.

https://doi.org/10.1039/C9RA10919F

Chapter 3 presents the results of a phytotoxicity bioassay experiment through which I examined the hydrocarbon tolerance of various plant species. Based on these results, I selected Medicago sativa as the most suitable species for rhizoremediation of diesel fuel since it exhibited the highest tolerance to hydrocarbon toxicity among all the studied plants. Part of these results was presented at the American Association of Petroleum Geologists' 2019 International Conference and Exhibition (AAPG 2019 ICE) for which I was awarded the Carlos Walter M. Campos Memorial Award for Best International Student Paper. My presentation was also published in AAPG Search and Discovery (Article \#80708). The entire results were published in the journal Chemosphere.

Eze, M.O., George, S.C., Hose, G. (2021) Dose-response analysis of diesel fuel phytotoxicity on selected plant species. Chemosphere 263, 128382.

https://doi.org/10.1016/j.chemosphere.2020.128382 
Chapter 4 adds more details about the effect of diesel fuel on seed viability and the germination rate of Medicago sativa. The results from this study together with those presented in chapter 3 indicate that $M$. sativa is the most-promising plant species for microbially-enhanced rhizoremediation of diesel fuel. The results were published in Plants.

Eze, M.O., Hose, G.C., George, S.C. (2020) Assessing the effect of diesel fuel on the seed viability and germination of Medicago sativa using the event-time model. Plants 9, 1062. https://doi.org/10.3390/plants9091062

Chapter 5 is an omics data set of metagenomes and metagenome-assembled genomes from a former crude oil borehole in Wietze, Germany. Wietze is the site of the first commercial crude oil exploration in Germany (Craig et al., 2018). The results provided preliminary understanding of the potential microbes for hydrocarbon degradation. This was published in Microbiology Resource Announcements.

Eze M.O., Lütgert S.A., Neubauer H., Balouri A., Kraft A.A., Sieven A., Daniel R., Wemheuer B. (2020). Metagenome assembly and metagenome-assembled genome sequences from a historical oil field located in Wietze, Germany. Microbiology Resource Announcements 9, e00333-20. https://doi.org/10.1128/MRA.00333-20

Chapter 6 is a detailed study of the diversity and metagenome analysis of hydrocarbondegrading consortia isolated from three different sites in the historic oil-contaminated field in Wietze, Germany. This detailed analysis provided insight into the genes and coding DNA sequences involved in the degradation of petroleum hydrocarbons. These results were published in bioRxiv.

Eze, M.O., Hose, G.C., George, S.C., Daniel, R. (2021). Diversity and metagenome analysis of hydrocarbon-degrading bacterial consortium from asphalt lakes located in Wietze, Germany. bioRxiv. https://doi.org/10.1101/2021.03.25.436929

Chapter 7 is a metagenome study of plant growth-promoting potentials of the isolated hydrocarbon-degrading consortium. This is crucial since the goal is to identify microorganisms with both hydrocarbon-degrading (Chapter 6) and plant growth-promoting (Chapter 7) potentials. Thus Chapter 7 perfectly complements the results of Chapter 6. Additionally, through a greenhouse-based study, I examined the rhizoremediation efficiency of Medicago sativa inoculated with one of the isolated consortia. These results have been published in bioRxiv. 
Eze, M.O., Thiel, V., Hose, G.C., George, S.C., Daniel, R. (2021). Metagenomic insight into the plant growth-promoting potential of a diesel-degrading bacterial consortium for enhanced rhizoremediation application. bioRxiv. https://doi.org/10.1101/2021.03.26.437261

Chapter 8 shows the results of a study of the full genomes of selected bacterial species to identify the most effective bacterial isolates for microbially-enhanced rhizoremediation. Since consortia are often difficult to reproduce, the identification of specific single bacterial isolates capable of enhancing both plant growth promotion and hydrocarbon degradation will expand the range of bacteria available for biotechnological applications. This chapter further presents a pot-based study of rhizoremediation through the inoculation of Medicago sativa with the most promising single bacterial isolate (Paraburkholderia tropica). The results were published in bioRxiv.

Eze, M.O., Thiel, V., Hose, G.C., George, S.C., Daniel, R. (2021). Exploiting synergistic interactions of Medicago sativa L. and Paraburkholderia tropica for enhanced biodegradation of diesel fuel hydrocarbons. bioRxiv. doi: https://doi.org/10.1101/2021.03.30.437699

Chapter 9 concludes with a summary of the main findings of this $\mathrm{PhD}$ thesis. 


\subsection{References}

Abdulsalam, S., Bugaje, I. M., Adefila, S. S., \& Ibrahim, S. (2011). Comparison of biostimulation and bioaugmentation for remediation of soil contaminated with spent motor oil. Int. J. Environ. Sci. Technol. 8, 187-194. doi:10.1007/BF03326208

Abed, R. M. M., Al-Sabahi, J., Al-Maqrashi, F., Al-Habsi, A., \& Al-Hinai, M. (2014). Characterization of hydrocarbon-degrading bacteria isolated from oil-contaminated sediments in the Sultanate of Oman and evaluation of bioaugmentation and biostimulation approaches in microcosm experiments. Int. Biodeterior. Biodegradation 89, 58-66. doi:https://doi.org/10.1016/j.ibiod.2014.01.006

Al-Baldawi, I. A., Abdullah, S. R. S., Anuar, N., Suja, F., \& Mushrifah, I. (2015). Phytodegradation of total petroleum hydrocarbon (TPH) in diesel-contaminated water using Scirpus grossus. Ecol. Eng. 74, 463-473. doi:https://doi.org/10.1016/j.ecoleng.2014.11.007

Ali, N., Dashti, N., Khanafer, M., Al-Awadhi, H., \& Radwan, S. (2020). Bioremediation of soils saturated with spilled crude oil. Sci. Rep. 10, 1116. doi:10.1038/s41598-01957224-x

Allamin, I. A., Halmi, M. I. E., Yasid, N. A., Ahmad, S. A., Abdullah, S. R. S., \& Shukor, Y. (2020). Rhizodegradation of petroleum oily sludge-contaminated soil using Cajanus cajan increases the diversity of soil microbial community. Sci. Rep. 10, 4094. doi:10.1038/s41598-020-60668-1

ATSDR (1995). Toxicological profile for fuel oils. U.S. Department of Health and Human Services, Agency for Toxic Substances and Disease Registry, United States.

Craig, J., Gerali, F., MacAulay, F., \& Sorkhabi, R. (2018). The history of the European oil and gas industry (1600s-2000s). Geological Society, London, Special Publications, 465, 1. doi:10.1144/SP465.23

Cunningham, S. D., Berti, W. R., \& Huang, J. W. (1995). Phytoremediation of contaminated soils. Trends Biotechnol. 13, 393-397. doi:https://doi.org/10.1016/S0167$\underline{7799(00) 88987-8}$

Di Martino, C., López, N. I., \& Raiger Iustman, L. J. (2012). Isolation and characterization of benzene, toluene and xylene degrading Pseudomonas sp. selected as candidates for bioremediation. Int. Biodeterior. Biodegradation 67, 15-20. doi:https://doi.org/10.1016/j.ibiod.2011.11.004

Dias, G. M., de Sousa Pires, A., Grilo, V. S., Castro, M. R., de Figueiredo Vilela, L., \& Neves, B. C. (2019). Comparative genomics of Paraburkholderia kururiensis and its potential in bioremediation, biofertilization, and biocontrol of plant pathogens. MicrobiologyOpen 8, e00801. doi:10.1002/mbo3.801

Duffy, J. J., Peake, E., \& Mohtadi, M. F. (1980). Oil spills on land as potential sources of groundwater contamination. Environ. Int. 3, 107-120. doi:https://doi.org/10.1016/0160-4120(80)90045-8

Garrido-Sanz, D., Manzano, J., Martín, M., Redondo-Nieto, M., \& Rivilla, R. (2018). Metagenomic analysis of a biphenyl-degrading soil bacterial consortium reveals the 
metabolic roles of specific populations. Front. Microbiol. 9, 232.

doi:10.3389/fmicb.2018.00232

Garrido-Sanz, D., Redondo-Nieto, M., Guirado, M., Pindado Jiménez, O., Millán, R., Martin, M., \& Rivilla, R. (2019). Metagenomic insights into the bacterial functions of a dieseldegrading consortium for the rhizoremediation of diesel-polluted soil. Genes 10, 456. doi:10.3390/genes10060456

Glick, B. R. (2003). Phytoremediation: synergistic use of plants and bacteria to clean up the environment. Biotechnol. Adv. 21, 383-393. doi:https://doi.org/10.1016/S07349750(03)00055-7

Jiang, Y., Brassington, K. J., Prpich, G., Paton, G. I., Semple, K. T., Pollard, S. J. T., \& Coulon, F. (2016). Insights into the biodegradation of weathered hydrocarbons in contaminated soils by bioaugmentation and nutrient stimulation. Chemosphere 161, 300-307. doi:https://doi.org/10.1016/j.chemosphere.2016.07.032

Kuiper, I., Lagendijk, E. L., Bloemberg, G. V., \& Lugtenberg, B. J. J. (2004).

Rhizoremediation: a beneficial plant-microbe interaction. Mol. Plant Microbe Interact. 17, 6-15. doi:10.1094/MPMI.2004.17.1.6

Lobo, C. B., Juárez Tomás, M. S., Viruel, E., Ferrero, M. A., \& Lucca, M. E. (2019). Development of low-cost formulations of plant growth-promoting bacteria to be used as inoculants in beneficial agricultural technologies. Microbiol. Res. 219, 12-25. doi:https://doi.org/10.1016/j.micres.2018.10.012

Macek, T., Macková, M., \& Káš, J. (2000). Exploitation of plants for the removal of organics in environmental remediation. Biotechnol. Adv. 18, 23-34. doi:https://doi.org/10.1016/S0734-9750(99)00034-8

Mench, M., Schwitzguébel, J.-P., Schroeder, P., Bert, V., Gawronski, S., \& Gupta, S. (2009). Assessment of successful experiments and limitations of phytotechnologies: contaminant uptake, detoxification and sequestration, and consequences for food safety. Environ. Sci. Pollut. Res. 16, 876. doi:10.1007/s11356-009-0252-z

Pilon-Smits, E. A. H., \& Freeman, J. L. (2006). Environmental cleanup using plants: biotechnological advances and ecological considerations. Front. Ecol. Environ. 4, 203-210. doi:10.1890/1540-9295(2006)004[0203:ECUPBA]2.0.CO;2

Rohrbacher, F., \& St-Arnaud, M. (2016). Root exudation: the ecological driver of hydrocarbon rhizoremediation. Agronomy 6, 19. doi:10.3390/agronomy6010019

USEPA (2000). EPA/600/R-99/107: Introduction to Phytoremediation. United States Environmental Protection Agency.

USEPA (2001). EPA 542-R-01-006: Brownfields Technology Primer: Selecting and Using Phytoremediation for Site Cleanup. United States Environmental Protection Agency. 


\title{
Chapter 2
}

\section{Ethanol-blended petroleum fuels: implications of co-solvency for phytotechnologies}

\author{
Michael O. Eze* and Simon C. George
}

Department of Earth and Environmental Sciences, MQ Marine Research Centre, Macquarie University, Sydney, NSW 2109, Australia.

*Correspondence: michael.eze@ @dr.mq.edu.au

RSC Advances 10, 6473-6481. https://doi.org/10.1039/C9RA10919F

\section{Relationship to the Overall Thesis}

Phytoremediation of hydrocarbons depends largely on the rhizodegradation of contaminants by the root-associated microbiome. Since oxygenates such as ethanol can impact on the solubility of petroleum hydrocarbons by serving as co-solvents, it is vital that the effect of this process on the leaching ability of petroleum fuels be understood. To this end, this chapter examines the effect of ethanol on the leaching potentials of diesel fuel hydrocarbons. This understanding is helpful not only for selecting suitable plants for rhizoremediation of diesel fuel, but also for other plant-based remediation approaches where oxygenated organics are the target pollutants.

\section{Author Contributions}

Conceived and designed the study: MOE and SCG

Performed the experiments: MOE

Analysed the data: MOE

Wrote the paper: MOE and SCG 


\section{RSC Advances}

\section{PAPER}

Check for updates

Cite this: RSC Adv., 2020, 10, 6473

\section{Ethanol-blended petroleum fuels: implications of co-solvency for phytotechnologies}

\begin{abstract}
Michael O. Eze (D)* and Simon C. George (D)
In recent decades, there has been increasing interest in the use of ethanol-blended fuels as alternatives to unblended fossil fuels. These initiatives are targeted at combating $\mathrm{CO}_{2}$ and particulate matter emissions, as these oxygenates leave behind a lesser carbon footprint. Noble as it may appear, this innovation is not without attendant ugly consequences. One major implication is the effect of co-solvency on the applicability of various forms of phytotechnologies for contaminant removal. By means of gas chromatography-mass spectrometry, this research investigated the effect of diesel fuel ethanol addition on the leaching potentials of petroleum hydrocarbons. Since phytoremediation of hydrocarbons depends largely on rhizodegradation of contaminants by the root-associated microbiome, the leaching of petroleum hydrocarbons beyond the rooting zones of plants may limit the effectiveness of this process as a reclamation strategy for ethanol-blended fuel spills. The analyses presented in this paper highlight the need for energy scientists to carefully consider the environmental impacts of ethanolblended innovations holistically.
\end{abstract}

Received 25th December 2019 Accepted 3rd February 2020

DOI: $10.1039 /$ c9ra10919f

rsc.li/rsc-advances toxic effects of pollutants. Depending on the pollutant type (elemental or organic), there are several mechanisms (accumulation or extraction, degradation, filtration, stabilisation and volatilisation) involved in phytoremediation. Elemental pollutants (toxic heavy metals and radionuclides) are mostly removed by extraction, transformation and sequestration. On the other hand, organic pollutants (hydrocarbons and chlorinated compounds) are predominantly removed by degradation, rhizoremediation, stabilisation and volatilisation, with mineralisation being possible when some plants such as willow and alfalfa are used..$^{17,18}$

As a strategy, and especially in comparison to removal and relocation of contaminants, phytoremediation is inexpensive. The US EPA has indicated that implementing this technology may result in cost savings of 50 to $80 \%$ over traditional methods. ${ }^{1,2}$ Benefits from successful approaches of phytoremediation include healthier soil, promoting and sustaining indigenous microbial communities that are essential for long-term bioremediation of the soil, and creation of a more pleasing landscape, compared with ugly contaminated areas. ${ }^{19}$ Other advantages of phytoremediation include low cost, environmental friendliness, the possibility of large-scale operations, low installation and maintenance costs, conservation of soil structure, prevention of erosion, and control of the leaching of pollutants. ${ }^{\mathbf{2 0 , 2 1}}$ Moreover, following phytoremediation, there might be improved soil fertility due to the input of organic matter. ${ }^{22}$

Despite the numerous advantages of phytoremediation, it has its own limitations. One major limitation is root depth. For this technique to achieve its desired objective, the contaminants of interest must be within the rooting zones of plants.
Department of Earth and Environmental Sciences, $M Q$ Marine Research Centre, Macquarie University, Sydney, NSW 2109, Australia. E-mail: michael.eze@hdr.mq. edu.au 
Nonetheless, many contaminants migrate vertically within the soil matrix, thereby making them inaccessible to plant roots. Compounding this problem is the addition of oxygenates such as ethanol and methyl-tertiary-butyl ether (MTBE) to fuels, so as to reduce vehicular emissions to the atmosphere. These additives, although beneficial in reducing atmospheric pollution, may increase the leaching potentials of organic contaminants due to the co-solvency of petroleum hydrocarbons and by the provision of a preferential substrate for microbial utilisation. ${ }^{23}$

Ethanol-fuel mixtures have an "E" and a number, which describe the percentage of ethanol by volume in the mixture. For example, "E10" refers to a $10 \%$ by volume ethanol and $90 \%$ by volume diesel mixture. Ethanol-diesel mixtures range from E5 to E85, with E10 being the most common. Alternative blends in many countries, especially Brazil and the United States of America, include ethanol-biodiesel mixtures. This increasing shift from unblended petroleum-derived diesel to ethanolblended diesel may pose significant challenges to the success of phytoremediation and the rehabilitation of diesel fuel contaminated sites, owing to the co-solvency caused by the ethanol. Therefore, the environmental implications of ethanol additives to diesel fuel must be thoroughly investigated. This is the motivation for this research.

\section{Experimental}

\section{Stability of ethanol blends}

Diesel was obtained from a Shell service station in Sydney, Australia. To determine the categories of ethanol-diesel fuel blends to be used for this study, the stability of ethanol-blended diesel fuels at $20{ }^{\circ} \mathrm{C}$ were examined without the use of stabilising additives. To do this, three different blends (E5, E10 and E20) were prepared in addition to the unblended diesel (E0), and their miscibility was observed. The E5 and E10 blends gave stable (homogenous) mixtures (Fig. 1), indicating that ethanol is soluble in diesel fuel up to $10 \%$ by volume. On the other hand, E20 gave a heterogeneous (two-phase) mixture, as shown by phase separation and a boundary layer (red pointer). This indicates that at $20 \%$ by volume, ethanol is not completely miscible with diesel. Thus, the preparation of E20 diesel and other higher blends requires the use of stabilisers. This observation agrees with other research work on the stability of

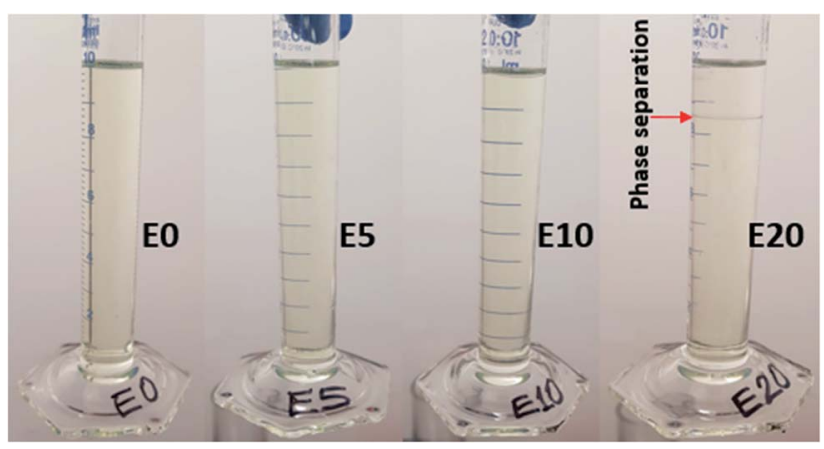

Fig. 1 Stability of four ethanol blends at $20^{\circ} \mathrm{C}$. ethanol-blended diesels. ${ }^{24,25}$ In view of this, even though all four blends were examined, this study focused primarily on the E0, E5 and E10 blends, which are both the most stable and most common ethanol-diesel fuel blends.

\section{Leaching column set-up}

The movement of diesel fuel was followed in a lab-based study of a $90 \mathrm{~cm}$ sand column packed in a polyethylene column of $15 \mathrm{~cm}$ diameter, with the effect of ethanol addition on this movement investigated. Four columns representing E0, E5, E10 and E20 were set up and eluted with deionised water (Fig. 2). To prepare the column, the method used by Adam et al. ${ }^{23}$ was adopted with some modifications.

Polyethylene drain pipes were cut into sections (L $10 \mathrm{~cm} \times$ ID $13 \mathrm{~mm}$ ). The sections were sealed together using waterproof tape to provide an airtight seal at the joins. Nine sections were fitted together to create a column $90 \mathrm{~cm}$ in length. Each column was filled with the same mass of extracted and baked river sand $(200 \mathrm{~g})$ to ensure that the same packing density was maintained. The choice of river sand was necessary to provide low organic matter content. After sieving to remove $>2 \mathrm{~mm}$ gravel, the soil textural class was determined using laser diffractometer at the sediment analysis laboratory, Macquarie University. The textural class is sand ( $97.5 \%$ sand, $2.5 \%$ silt and $0.02 \%$ clay), with a mode of medium sand $(450 \mu \mathrm{m})$, and $1.18 \%$ organic matter content by loss on ignition (Fig. 2). To ensure accurate results, two major factors that affect soil total petroleum hydrocarbon content, namely biodegradation and volatilisation, were controlled. First, the sand was twice extracted using an accelerated solvent extractor (ASE300) and dichloromethane (DCM) : methanol $(9: 1)$. It was then baked at $500{ }^{\circ} \mathrm{C}$ for 24 hours. This was necessary in order to remove all naturally occurring organic compounds and extraneous matter in the sand, as well as to prevent any possible biodegradation of the diesel fuel by microbial enzymes within the leaching column. The bottom section of the column was fitted with a fine nylon mesh to cover the lower end to prevent the sand from escaping, but allowing the leachate to freely drain away. An extra section was placed on the top of the column to provide a collar for the water reservoir. The column was run at a temperature of about $20{ }^{\circ} \mathrm{C}$ to prevent volatilisation.

$5 \mathrm{~mL}$ of each blend was added by pipette to the respective columns. The diesel fuel was allowed to penetrate into the sand for approximately 30 minutes. After this time, $20 \mathrm{~mL}$ of water was poured in to wet the column. Then $200 \mathrm{~mL}$ of water was added through a $250 \mathrm{~mL}$ funnel. This acted as a reservoir, allowing a constant supply of water to leach through the column for ten days. The flow rate was a factor of gravity and the density of the sand packed column.

\section{Extraction of diesel from the medium (sand and leachates)}

After ten days, the four columns were dismantled one section at a time, and a sand subsample was taken from each section of each column. Total extractable diesel fuel in each subsample was obtained through solvent extraction (DCM : methanol (9:1)) using the ASE300. Since the sand used for the column 


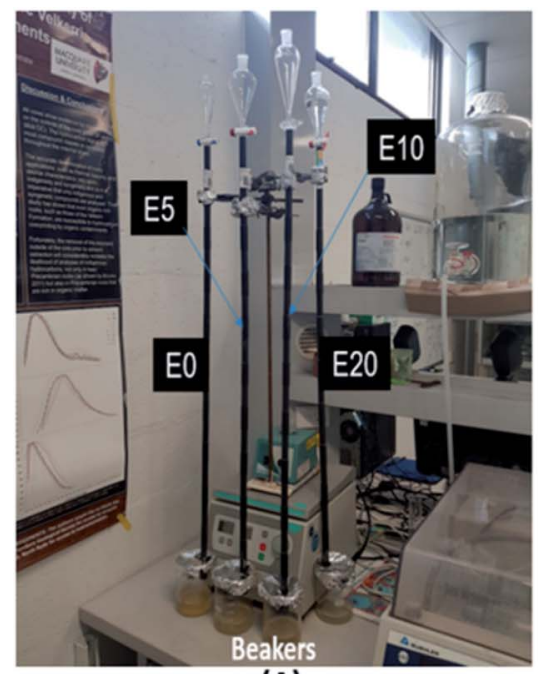

(A)

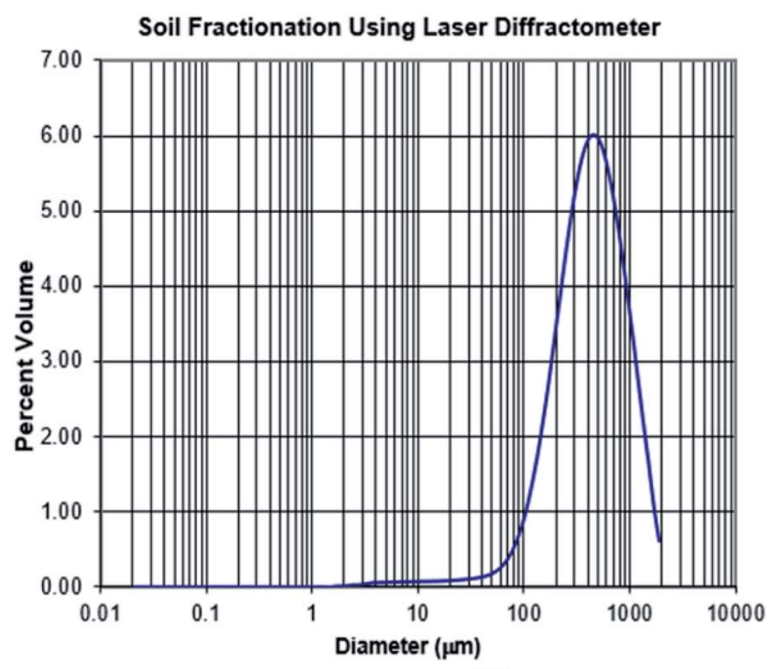

(B)

Fig. 2 Leaching column set-up (A), and soil textural class determination using laser diffractometer (B).

experiment was initially extracted and baked, it was possible to determine the diesel component of each section of the column gravimetrically.

The leachate from each column was collected in beakers. Since the aqueous leachates contained diesel fuel hydrocarbons, three with ethanol as a co-solvent, it was necessary to first compare various standard extraction ISO and USEPA methods ${ }^{26-28}$ to determine the appropriate solvent for most effective diesel fuel recovery. This was achieved by carrying out several back-filtration experiments on ethanol-diesel-water mixtures of known volumes using different solvents and solvent mixtures (such as DCM, $n$-hexane : DCM mixtures, etc.). From the results obtained, only the $4: 1 n$-hexane : DCM mixture (a modification of ISO $9377-1$ method $^{26}$ ) gave almost $100 \%$ diesel fuel recovery for a single extraction. This may be attributed to the chemistry of the diesel fuel, as diesel fuel contains a high percentage of $n$-alkanes which are highly soluble in $n$-hexane. ${ }^{29}$ The molecular composition of diesel fuel may make possible the use of an appropriate $n$-hexane : DCM mixture without the possible loss of $\mathrm{C}_{8}$ to $\mathrm{C}_{13}$ hydrocarbons during the solvent removal process ${ }^{30}$ - a common problem with $n$-hexane alone..$^{26,29}$ These methods will be examined further with the goal of determining the most effective (more extracts) and most efficient (lower frequency) method for liquid-liquid extraction of diesel-water mixtures. However, repeated extractions using DCM alone gave very similar results to single extraction using the $4: 1 n$-hexane : DCM mixture. Since this method is already documented in literature, repeated liquid-liquid extraction using DCM was used to isolate diesel fuel hydrocarbons from the aqueous leachates. ${ }^{31,32}$ This method followed the Environmental Protection Agency (EPA) Method 3510C. ${ }^{28}$

\section{Molecular analysis of the leachates using GC-MS}

Molecular analysis of both the pure diesel and the leachates was carried out using gas chromatography-mass spectrometry (GCMS), following EPA Method 8270D. ${ }^{33}$ This was carried out using the Pegasus 4D instrument in the Organic Geochemistry laboratory, Macquarie University, Sydney according to the procedure by Flannery and George. ${ }^{34}$ Samples from each leachate were analysed using a two dimensional gas chromatograph (Agilent 7890A) operating in one dimension, coupled to a Pegasus time-of-flight-mass spectrometer (GCxGCToFMS). Fractions $(1 \mu \mathrm{L})$ were injected through a split/splitless injector operating at $310{ }^{\circ} \mathrm{C}$ in splitless mode onto a J\&W DB5MS column ( $60 \mathrm{~m} \times 0.25 \mathrm{~mm}$ i.d., $0.25 \mathrm{~mm}$ film thickness) coated with modified $5 \%$ phenyl $95 \%$ methyl silicone, with $\mathrm{He}$ as the carrier gas. The temperature programme was: $40{ }^{\circ} \mathrm{C}(2$ min) to $310{ }^{\circ} \mathrm{C}$ at $4{ }^{\circ} \mathrm{C} \mathrm{min}^{-1}$, then held for $45 \mathrm{~min}$. Peak areas were integrated using LECO Chromatof software.

\section{Results and discussion}

\section{Leaching of diesel fuel through the column}

The results from the $90 \mathrm{~cm}$ leaching columns indicate that ethanol addition influenced the vertical movement of diesel fuel. Fig. 3A shows the percentage distribution of extractable diesel fuel along the column for the four blends of diesel fuels. The topmost $10 \mathrm{~cm}$ sections of each column had higher percentages of diesel fuel than the sections immediately below. This can be explained by the fact that this section is the first point of contact onto which the diesel hydrocarbons would be easily adsorbed. Little migration of diesel fuel was observed in the E0 blend, with the extractable amount decreasing down the column from $15 \%$ in the top section to $8.4 \%$ at a depth of $90 \mathrm{~cm}$. After the top section, the percentage diesel fuel in the E5 column gradually increased from a low of $9.3 \%$ at $20 \mathrm{~cm}$ to a maximum of $12.3 \%$ at $70 \mathrm{~cm}$ depth, after which it gradually decreased again. On the other hand, after the first $10 \mathrm{~cm}$ top section, the E10 column experienced a continuous increase in percentage extractable diesel fuel beyond $10 \mathrm{~cm}$, with the peak percentage occurring at $90 \mathrm{~cm}$ depth (Fig. 3A). This is a strong indication of the effect of co-solvency on hydrocarbon 

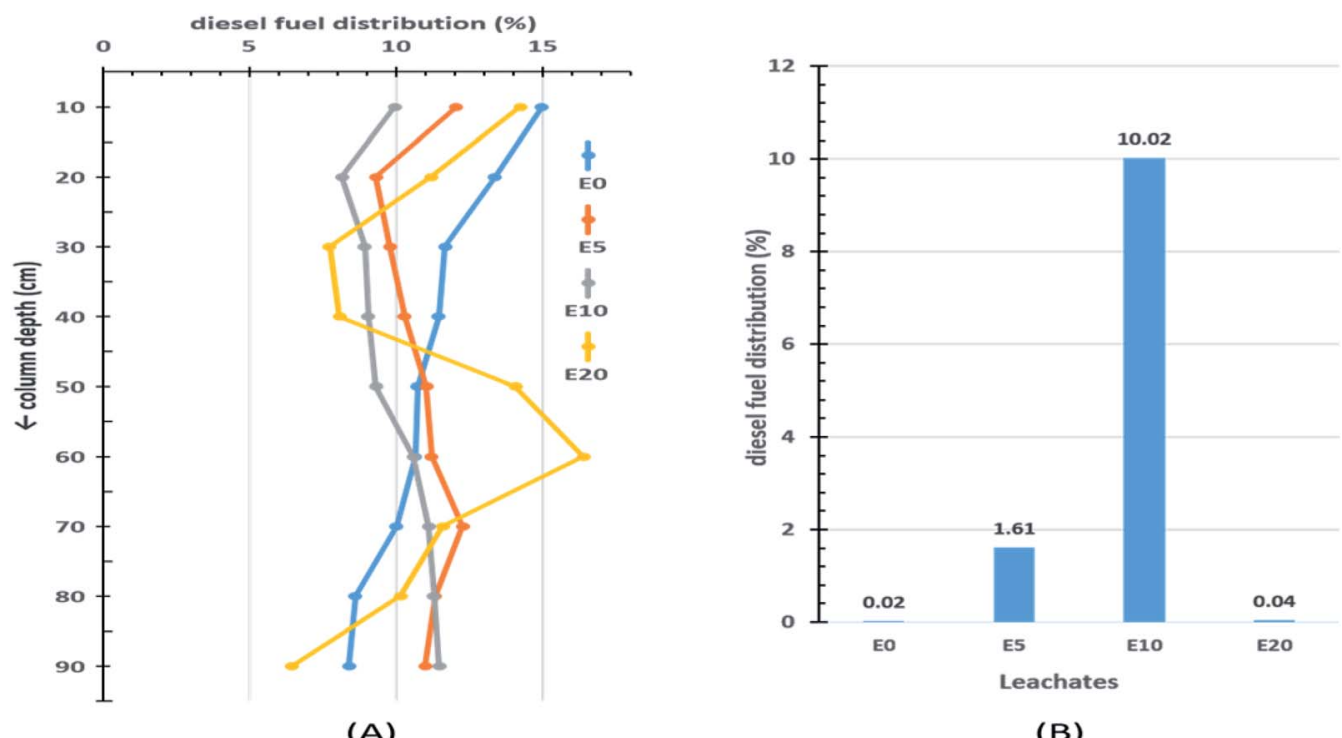

(B)

Fig. 3 Percentage distribution of diesel fuel in $90 \mathrm{~cm}$ sand columns (A) and in leachates (B).

migration. The E20 blend exhibited an irregular pattern. This can be attributed to the lack of homogeneity in the E20 mixture, which consequently limits co-solvency and thereby reduces the amount of diesel fuel hydrocarbons in the aqueous layer.

The effect of ethanol addition on the leaching potential of diesel fuel was more evident when the amount of extractable diesel fuel in each leachate was examined (Fig. 3B). Of the four column leachates, the E10 leachate recorded the highest amount of diesel fuel fraction $(10.02 \%)$, and the E0 the least $(0.02 \%)$.

Table 1 gives a brief summary of the percentage distribution of extractable diesel fuel with four depth divisions $(x)$ corresponding to $(0-30 \mathrm{~cm}),(30-60 \mathrm{~cm}),(60-90 \mathrm{~cm})$ and the leachates. The deeper two divisions $(>60 \mathrm{~cm})$ accounted for almost half $(44 \%)$ of the diesel fraction in the E10 column, $36 \%$ in the E5 column, but only $27 \%$ and $28 \%$ in the E0 and E20 columns, respectively. This is a clear indication of the effect of co-solvency on the leaching potentials of ethanol-blended fuels.

\section{Effect of ethanol on vertical migration of petroleum hydrocarbons}

To better understand the effect of ethanol-based co-solvency on the movement of petroleum hydrocarbons, the leachate from

Table 1 Percentage extractable diesel fuel with increasing depth for the unblended diesel (E0) and the three ethanol blends with diesel (E5, E10, E20)

\begin{tabular}{lllll}
\hline & \multicolumn{4}{l}{ Percentage distribution } \\
\cline { 2 - 5 } Column depth $(\mathrm{cm})$ & E0 & E5 & E10 & E20 \\
\hline $0 \leq x \leq 30$ & 40.1 & 31.2 & 27.1 & 33.2 \\
$30<x \leq 60$ & 32.9 & 32.6 & 29.0 & 38.6 \\
$60<x \leq 90$ & 27.1 & 34.6 & 33.9 & 28.2 \\
Leachates $(90<x)$ & 0.02 & 1.61 & 10.02 & 0.04
\end{tabular}

each column was examined for the presence of both aliphatic and aromatic hydrocarbons using GC-MS. Fig. 4-8 give an overview of this effect as shown by mass chromatograms selective for $n$-alkanes $(\mathrm{m} / z \mathrm{57})$ and some aromatic hydrocarbons ( $\mathrm{C}_{2}$ alkylnaphthalenes, $m / z$ 156; methylphenanthrenes, $m$ / $z$ 192; biphenyl, $m / z 154 ; \mathrm{C}_{2}$ alkylbiphenyls, $\mathrm{m} / \mathrm{z} 182$ ) detected in the leachates from each column. These data show that ethanol addition strongly affected the vertical migration of diesel fuel hydrocarbons.

The amount of $n$-alkanes detected in the E0 leachate is very low, but a considerable quantity is present in the E5 leachate, with a maxima at $\mathrm{C}_{16}$ (Fig. 4). More significant was the E10 leachate, in which virtually all the $n$-alkanes in the diesel fuel were leached by $10 \%$ by volume ethanol.

The GC-MS chromatograms of the aromatic hydrocarbons reveal that the effects of ethanol on these were more pronounced in the E10 leachate. For example, no alkylnaphthalene was detected in the E0 leachate (Fig. 5). In the E5 leachate, low concentrations of only 2,7-dimethylnaphalene, coeluting 1,3- and 1,7-dimethylnaphthalene, and 1,6-dimethylnaphthalene were detected. On the other hand, several alkylnaphthalenes ranging from 2-ethylnaphthalene to 1,2dimethylnaphthalene were detected in the E10 leachate (Fig. 5). Similarly, whereas methylphenanthrenes were not detected in the E0 leachate (Fig. 6), very limited amounts of all four isomers were detected in the E5 leachate. Conversely, 10\% ethanol in diesel (E10) caused considerable leaching of all alkylphenanthrenes including the methylphenanthrenes from beyond the $90 \mathrm{~cm}$ column into the leachate (Fig. 6).

An increase in the ethanol content of the diesel fuel led to an increase in the leaching potential of substituted biphenyls (Fig. 7). Ethanol content of the diesel fuel had a differential effect on the amount of ethylbiphenyls and dimethylbiphenyls eluted, with the largest amount of these hydrocarbons present in the E10 leachate (Fig. 7). 

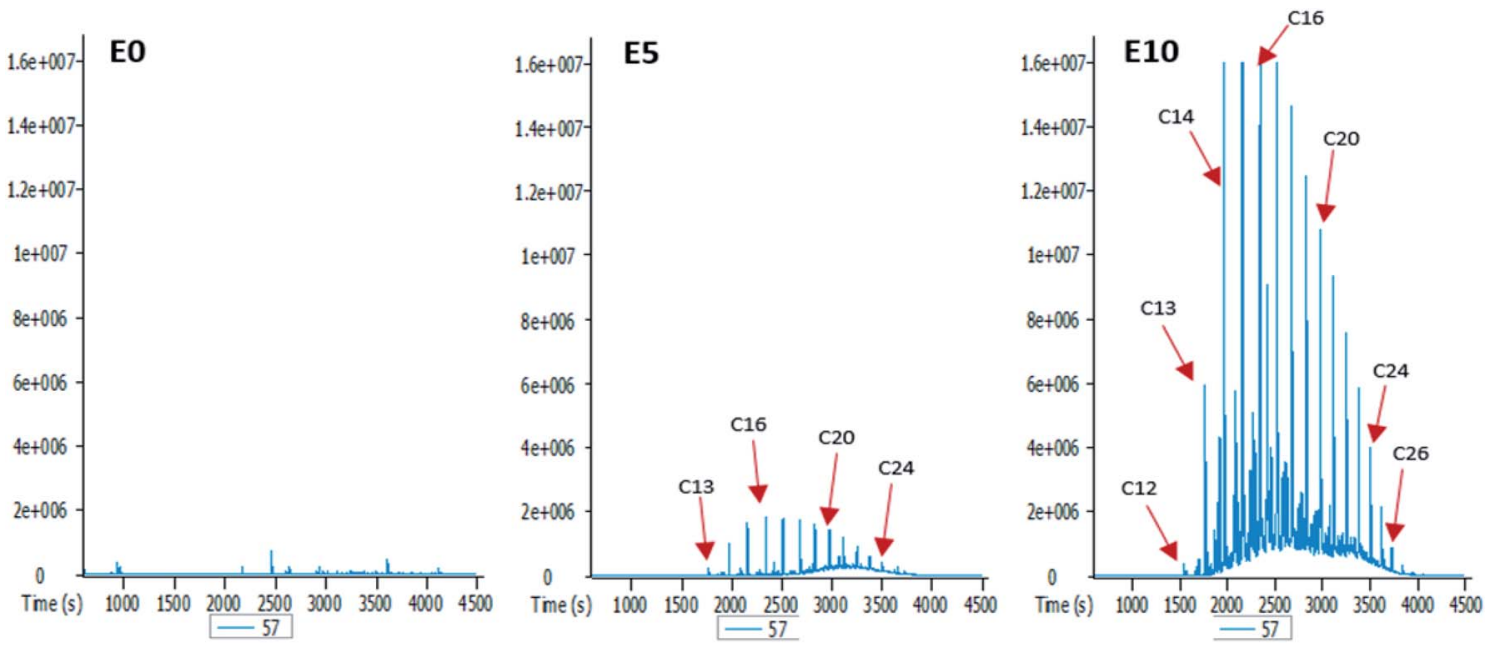

Fig. 4 Partial $\mathrm{m} / \mathrm{z} 57$ mass chromatograms of the E0, E5 and E10 leachates, showing identification of a homologous series of $n$-alkanes [E0: unblended diesel fuel; E5: diesel fuel containing 5\% ethanol (v/v); E10: diesel fuel containing $10 \%$ ethanol (v/v); Cx: $n$-alkanes containing $x$ number of carbon atoms].

Interestingly, a prior study examined the effect of ethanol on the leaching ability of individual hydrocarbons independently, and not in their form as a mixture. ${ }^{23}$ The current study is the first to use GC-MS to examine the effect of ethanol content on the leaching potentials of diesel fuel hydrocarbons as a complete mixture.

From the results obtained, it is evident that the addition of ethanol to diesel fuel has a direct impact on the leaching potential of diesel fuel hydrocarbons. While $5 \%$ by volume of ethanol had a very limited effect on the vertical movement of aromatic hydrocarbons, its effect on aliphatic hydrocarbons are consequential, as shown by the presence of significant amounts of $n$ alkanes in the E5 leachate (Fig. 4). Therefore, ethanol content had more impact on aliphatic hydrocarbons than it did on aromatic hydrocarbons. This is not unexpected since the solubility of petroleum hydrocarbons under room temperature decreases with increasing molecular weight and aromaticity (high stability). ${ }^{35,36}$ This also explains why for polycyclic aromatic hydrocarbons (PAHs), the lighter aromatic hydrocarbons such as alkylnaphthalenes (Fig. 5) eluted more efficiently from the column than the heavier ones such as alkylphenanthrenes (Fig. 6). In addition, an increase in diesel fuel ethanol content from $5 \%$ to $10 \%$ by volume considerably increased the amount of aromatic hydrocarbons that eluted from the columns. This can be seen from the difference between the amounts of the aromatic hydrocarbons eluted from the E5 column and those eluted from the E10 column. This can be explained by the fact that ethanol breaks the surface tension of repellent soil, allowing increasing penetration. ${ }^{23,37}$ Thus, with increasing ethanol content the co-solvency of these hydrocarbons increases, making them more available in the aqueous phase, and consequently more susceptible to leaching.
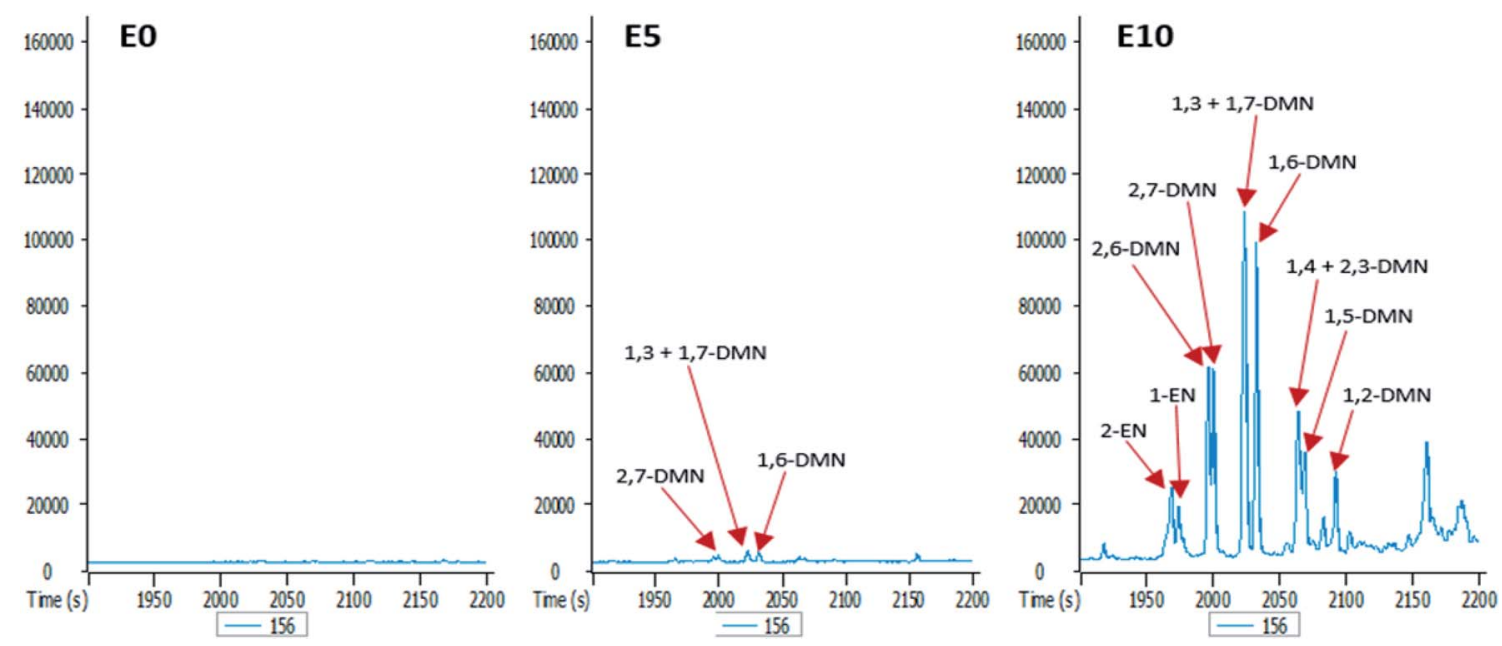

Fig. 5 Partial m/z 156 mass chromatograms of the EO, E5 and E10 leachates showing identification of $\mathrm{C}_{2}$ alkylnaphthalenes [EN: ethylnaphthalene; DMN: dimethylnaphthalene; E0: unblended diesel fuel; E5: diesel fuel containing 5\% ethanol (v/v); E10: diesel fuel containing 10\% ethanol $(\mathrm{v} / \mathrm{v})]$. 

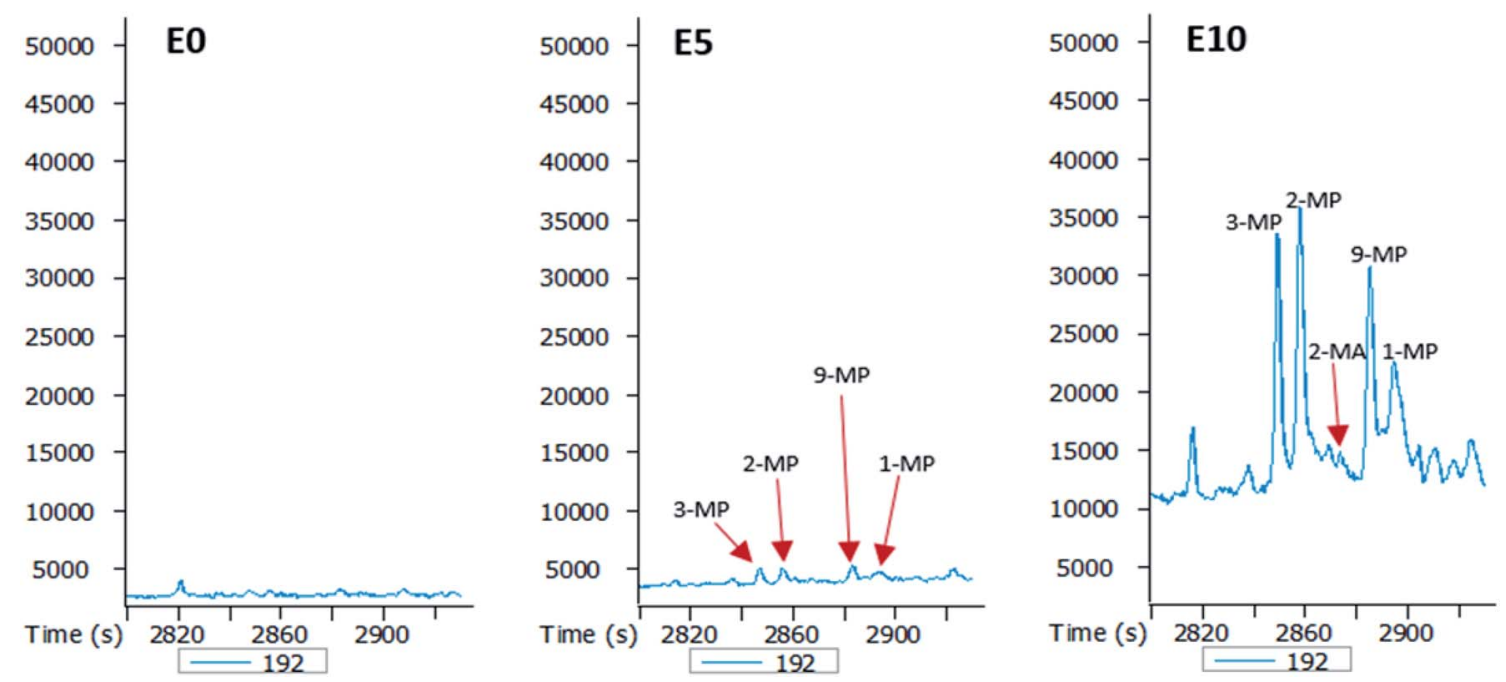

Fig. 6 Partial $\mathrm{m} / \mathrm{z} 192$ mass chromatograms of the EO, E5 and E10 leachates showing identification of methylphenanthrenes (MP) [EO: unblended diesel fuel; E5: diesel fuel containing 5\% ethanol (v/v); E10: diesel fuel containing 10\% ethanol (v/v)].

In the absence of stabilisers, co-solvency drops when ethanol content exceeds $10 \%$ by volume..$^{24,25}$ This agrees with the results of this study, as shown by the mass chromatograms of the leachate from the E20 column (Fig. 8). This leachate contains some $n$-alkanes with a higher molecular maxima $\left(\mathrm{C}_{20}\right)$ than raw diesel, and no aromatic hydrocarbons. This is because solubility of ethanol in petroleum hydrocarbons significantly drops at $20 \%$ by volume, thereby creating a biphasic solution with an ethanol phase containing small amounts of hydrocarbons. Since ethanol is the co-solvent for water and hydrocarbons, this immiscibility at $20 \%$ ethanol volume is responsible for the observed drop in the hydrocarbon content of the E20 leachates.

\section{Implications for phytotechnologies}

Phytotechnology is the direct use of living plants for in situ bioremediation of contaminated environments, such as soils. ${ }^{2,38}$ As a "green" technology, phytotechnology is one of the important prospects for sustainable development. ${ }^{39}$ Phytoremediation does not require transportation of contaminated soils and requires less labour, is less expensive and has a lower carbon footprint (based on the amount of $\mathrm{CO}_{2}$ emitted) than traditional techniques of remediation. ${ }^{40}$ Current rehabilitation costs can total over $\$ 1$ million per hectare, and some studies have indicated that implementing phytoremediation may result in a cost savings of 50 to $80 \%$ over traditional technologies. ${ }^{1}$

However, phytoremediation of hydrocarbons depends primarily on rhizoremediation, which involves the breakdown of contaminants in soil as a result of microbial activity at the roots. ${ }^{41-43}$ This involves a series of plant-microbe interactions which can have potential negative implications for ethanolbased co-solvency, when petroleum hydrocarbons are leached beyond the rooting zones of plants.

Rhizosphere microorganisms generally live under conditions of "nutrient starvation" and are thus constantly looking
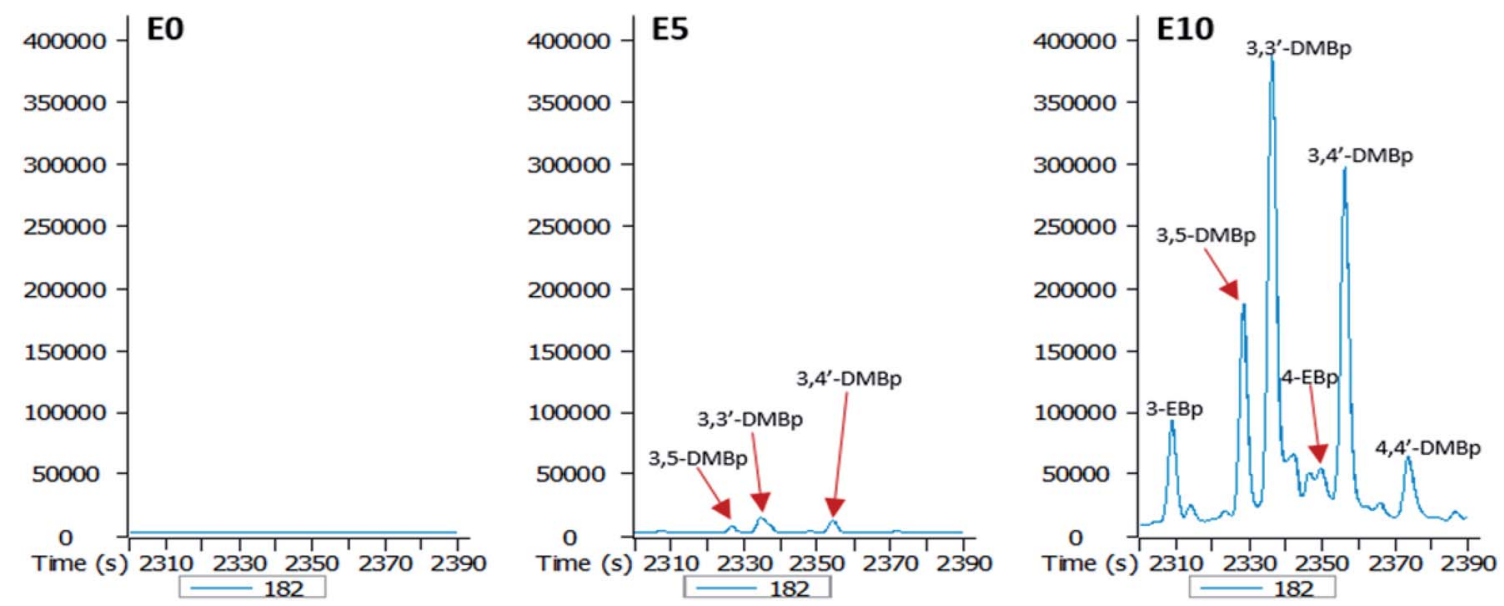

Fig. 7 Partial m/z 182 mass chromatograms of the E0, E5 and E10 leachates showing identification of $C_{2}$ alkylbiphenyls [DMBp: dimethylbiphenyl; EBp: ethylbiphenyl; E0: unblended diesel fuel; E5: diesel fuel containing 5\% ethanol (v/v); E10: diesel fuel containing 10\% ethanol (v/v)]. 

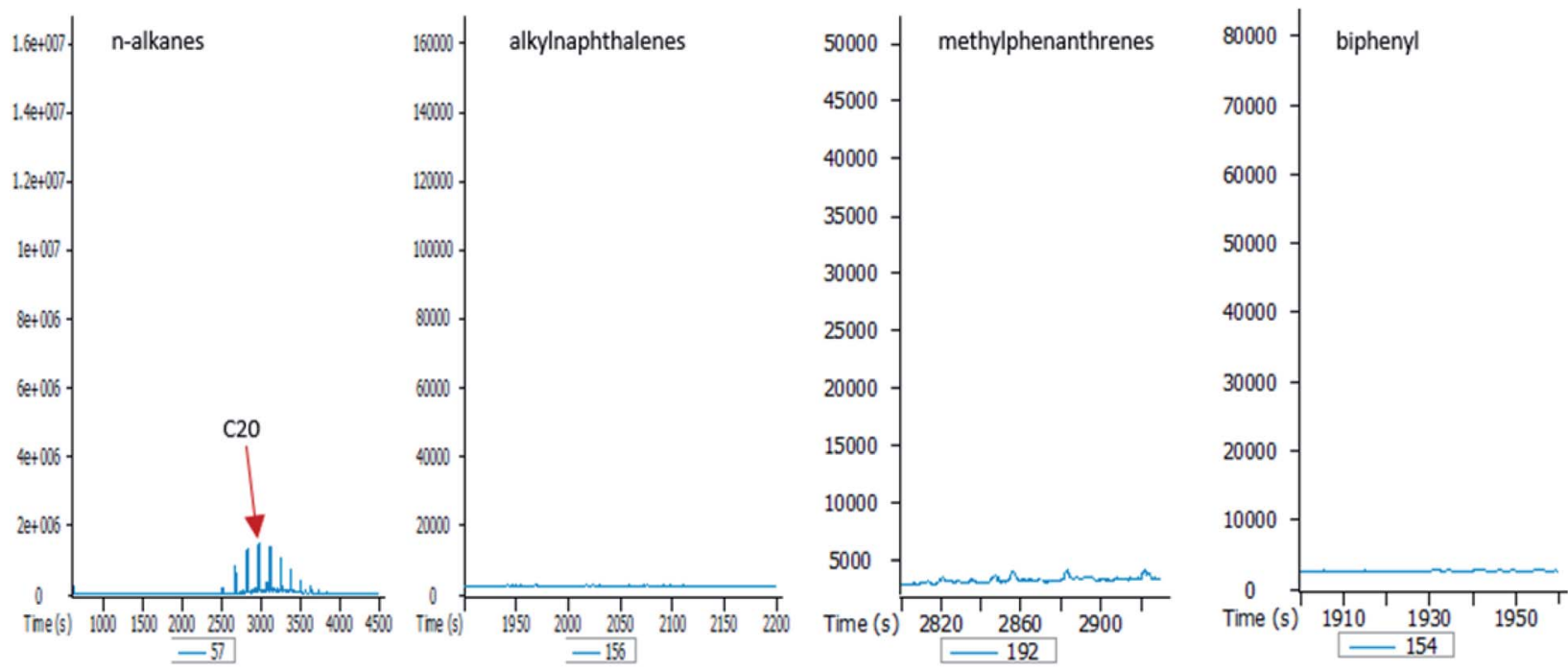

Fig. 8 Partial mass chromatograms ( $\mathrm{m} / \mathrm{z} 57,156,192$ and 154$)$ of the E20 leachates, showing limited ( $n$-alkanes) or no elution of diesel fuel hydrocarbons $\left(C_{2}\right.$ alkylnaphthalenes, methylphenanthrenes, biphenyl). E20: diesel fuel containing $20 \%$ ethanol (v/v).

for nutrients. The most important nutrient sources excreted by roots are organic acids (citric, malic, succinic, oxalic and pyruvic acid), carbohydrates (glucose, xylose, fructose, maltose, sucrose, ribose), amino acids, fatty acids, proteins, enzymes, nucleotides and vitamins. ${ }^{\mathbf{4 4 - 4 8}}$ Microorganisms have developed sensory systems (chemotaxis) that guide them to these roots-secreted components in order to provide the necessary nutrition and energy for their survival and reproduction. ${ }^{49}$ As a result, the rhizosphere is up to 100 times richer in microbial density than bulk soil. ${ }^{50-53}$ This phenomenon is called "the rhizosphere effect". ${ }^{5-56}$ Previous studies have shown that the quantity and quality of root exudates are determined by the cultivar, plant species, developmental stage, various environmental factors (soil type, $\mathrm{pH}$, temperature, nutrient availability), and the presence of microorganisms. ${ }^{45,57-61}$ Thus, root exudates affect not only the microbial population but also its diversity.

Plants and microorganisms have co-evolved so that each can take advantage of their association. In contaminated soil, the contaminant distribution gradient is negatively correlated with the gradient of root exudates, with the lowest hydrocarbon concentration, and the highest root exudate and microbial concentration, mostly at the root tips and at sites of lateral branching. ${ }^{53,60,62-64}$ Corgie et $a .^{\mathbf{4 2}}$ reported that phenanthrene biodegradation reached $86 \%$ in the first $3 \mathrm{~mm}$ from the roots, $48 \%$ between 3 and $6 \mathrm{~mm}$, and $36 \%$ between 6 and $9 \mathrm{~mm}$. They observed a parallel bacterial gradient, where high numbers of heterotrophs and PAH-degrading bacteria were close to the roots. Similarly, in the rhizosphere of perennial ryegrass (Lolium perenne) growing in a petroleum hydrocarbon contaminated soil, the highest rates of hydrocarbon degradation and the microbial degraders were mainly found within $3 \mathrm{~mm}$ of the root surface. ${ }^{65}$

Plants may directly improve degradation via the root exudation of enzymes, such as laccases, phenol oxidases and peroxidases, which catalyse the oxidation of various hydrocarbons and degrade them into intermediate products. ${ }^{53,62}$ However, microbial-derived enzymatic breakdown is considered to be the primary pathway for petroleum hydrocarbon degradation..$^{33}$

Furthermore, many secondary plant metabolites exuded by roots such as flavonoids, are structurally similar to aromatic hydrocarbons. ${ }^{\mathbf{6 6}, 67}$ This structural analogy may improve hydrocarbon degradation by stimulating co-metabolic processes, which involves the oxidation/mineralisation of petroleum hydrocarbons molecules that do not support plant growth, such as benzo- $\alpha$-pyrene, ${ }^{68}$ in the presence of other growth supporting root exudates. ${ }^{69,70}$ Co-metabolism seems to be the primary process underlying degradation of recalcitrant hydrocarbons. ${ }^{18,71}$

Since most plants employed in phytotechnologies (such as legumes and grasses) possess limited rooting depths with root density decreasing with increasing depth, these results reveal that ethanol addition to diesel fuel will significantly limit the effectiveness of phytoremediation as a reclamation strategy for soils contaminated with ethanol-blended diesel spills. In addition, since soil microbial diversity and population depend on root exudation, the efficiency of rhizodegradation of petroleum hydrocarbons will be negatively affected by enhanced leaching of the hydrocarbons owing to ethanol addition. This will also be the case with other innovative variants of phytotechnologies such as genetically-modified phytoremediation.

In view of the foregoing, it is evident that it is not enough to limit environmental concerns to atmospheric and particulate matter emissions. Energy and environmental policy experts must take a holistic view of energy-related innovations, taking into consideration other potential implications as they relate to other aspects of the environment, in this case, soil and underground water. More so, the effect of such innovations on other sustainable initiatives such as soil contaminant clean-up and restoration should be carefully considered. 


\section{Conclusions}

Ethanol-blended petroleum fuels are becoming increasingly common and utilised. These fuels are targeted at combating atmospheric pollution, as their oxygenates leave behind lesser carbon footprints. Noble as this may appear, this innovation is not without attendant consequences. This research has demonstrated that the addition of ethanol to diesel fuels can significantly affect the leaching potentials of petroleum hydrocarbons. This effect was seen in both aliphatic and aromatic hydrocarbons. While 5\% (by volume) ethanol addition had a limited effect on aromatic hydrocarbons, $10 \%$ ethanol addition resulted in the elution of all class of aromatic hydrocarbons studied beyond the $90 \mathrm{~cm}$ column. Even the more stable polycyclic aromatic hydrocarbons such as alkylnaphthalenes and alkylphenanthrenes, which are otherwise highly insoluble in water, were eluted through the E10 column. This shows the ability of ethanol to enhance co-solvency of hydrocarbons as well as break the surface tension of repellent soil, allowing increasing penetration. This observation is significant considering the persistence of these classes of hydrocarbons in the environment and their toxicity to humans when these contaminants make their way into the underground water table.

The analyses presented in this paper highlight potential implications for the successes of phytotechnologies. Since phytoremediation of hydrocarbons depends largely on rhizodegradation of contaminants by the root-associated microbiome, the leaching of petroleum hydrocarbons beyond the rooting zones of plant will definitely limit the effectiveness of this approach as a reclamation strategy for ethanol-blended diesel spills. Thus, it is imperative that energy scientists and policy makers carefully consider the resultant environmental impacts of ethanol-blended innovations holistically.

\section{Conflicts of interest}

There are no conflicts to declare.

\section{Acknowledgements}

The authors would like to thank the Commonwealth Government of Australia and Macquarie University for supporting this research project by providing an international Research Training Program (iRTP) scholarship to ME (allocation number: 2017561). This research was conducted in the Organic Geochemistry Laboratory, Department of Earth and Environmental Sciences, and MQ Marine Research Centre, Macquarie University, Sydney, the support of which is gratefully acknowledged.

\section{References}

1 USEPA, EPA 542-R-01-006, 2001.

2 USEPA, EPA/600/R-99/107, 2000.

3 T. Dalton and D. Jin, Mar. Pollut. Bull., 2010, 60, 1939-1945.

4 X. Hong, W. Chen and L. Zhang, Procedia Environ. Sci., 2010, $2,49-56$.
5 B. Hassler, in Environmental Governance of the Baltic Sea, ed. M. Gilek, M. Karlsson, S. Linke and K. Smolarz, Springer International Publishing, Cham, 2016, pp. 125-146, DOI: 10.1007/978-3-319-27006-7_6.

6 S. D. Cunningham, W. R. Berti and J. W. Huang, Trends Biotechnol., 1995, 13, 393-397.

7 T. Macek, M. Macková and J. Káš, Biotechnol. Adv., 2000, 18, 23-34.

8 M. McGuinness and D. Dowling, Int. J. Environ. Res. Public Health, 2009, 6, 2226-2247.

9 N. Weyens, D. van der Lelie, S. Taghavi and J. Vangronsveld, Curr. Opin. Biotechnol., 2009, 20, 248-254.

10 B. R. Glick, Biotechnol. Adv., 2003, 21, 383-393.

11 M. Mench, J. Vangronsveld, P. Bleeker, A. Ruttens, W. Geebelen and N. Lepp, in Phytoremediation of MetalContaminated Soils, ed. J.-L. Morel, G. Echevarria and N. Goncharova, Springer Netherland, Dordrecht, 2006, pp. 109-190.

12 E. A. H. Pilon-Smits and J. L. Freeman, Front Ecol. Environ., 2006, 4, 203-210.

13 W. H. O. Ernst, Geochemistry, 2005, 65, 29-42.

14 C. C. Azubuike, C. B. Chikere and G. C. Okpokwasili, World J. Microbiol. Biotechnol., 2016, 32, 180.

15 J. H. Lee, Biotechnol. Bioprocess Eng., 2013, 18, 431-439.

16 Z. Wang, Y. Xu, J. Zhao, F. Li, D. Gao and B. Xing, J. Hazard. Mater., 2011, 190, 677-685.

17 R. B. Meagher, Curr. Opin. Plant Biol., 2000, 3, 153-162.

18 I. Kuiper, E. L. Lagendijk, G. V. Bloemberg and B. J. J. Lugtenberg, Mol. Plant-Microbe Interact., 2004, 17, 615.

19 M. O. Mendez and R. M. Maier, Rev. Environ. Sci. Bio/ Technol., 2008, 7, 47-59.

20 B. Van Aken, Curr. Opin. Biotechnol., 2009, 20, 231-236.

21 H. Ali, E. Khan and M. A. Sajad, Chemosphere, 2013, 91, 869881.

22 M. Mench, J.-P. Schwitzguébel, P. Schroeder, V. Bert, S. Gawronski and S. Gupta, Environ. Sci. Pollut. Res., 2009, 16, 876 .

23 G. Adam, K. Gamoh, D. G. Morris and H. Duncan, Sci. Total Environ., 2002, 286, 15-25.

24 K. R. Gerdes and G. J. Suppes, Ind. Eng. Chem. Res., 2001, 40, 949-956.

25 M. Lapuerta, O. Armas and R. García-Contreras, Fuel, 2007, 86, 1351-1357.

26 ISO:9377-1, 2000.

27 ISO:9377-2, 2000.

28 USEPA, Method 3510C, 1996.

29 USEPA, Method 1664, Revision B, 2010.

30 M. Ahmed and S. C. George, Org. Geochem., 2004, 35, 137155.

31 I. A. Al-Baldawi, S. R. S. Abdullah, N. Anuar, F. Suja and I. Mushrifah, Ecol. Eng., 2015, 74, 463-473.

32 A. Lohi, M. Alvarez Cuenca, G. Anania, S. R. Upreti and L. Wan, J. Hazard. Mater., 2008, 154, 105-111.

33 USEPA, Method 8270D, 1998.

34 E. N. Flannery and S. C. George, Org. Geochem., 2014, 77, 115-125. 
35 L. C. Price, J. Pet. Geol., 1981, 4, 195-223.

36 M. C. Davis, P. W. Fedick, D. V. Lupton, G. S. Ostrom, R. Quintana and J.-D. Woodroffe, RSC Adv., 2019, 9, 2289122899.

37 P. M. King, Soil Res., 1981, 19, 275-285.

38 E. Pilon-Smits, Annu. Rev. Plant Biol., 2005, 56, 15-39.

39 D. E. Salt, R. D. Smith and I. Raskin, Annu. Rev. Plant Physiol. Plant Mol. Biol., 1998, 49, 643-668.

40 N. Das and P. Chandran, Biotechnol. Res. Int., 2011, 1-13.

41 F. Rohrbacher and M. St-Arnaud, Agronomy, 2016, 6, 1-27.

42 S. C. Corgié, E. J. Joner and C. Leyval, Plant Soil, 2003, 257, 143-150.

43 Y. Yang, D. Ratté, B. F. Smets, J. J. Pignatello and D. Grasso, Chemosphere, 2001, 43, 1013-1021.

44 C. Bertin, X. Yang and L. A. Weston, Plant Soil, 2003, 256, 6783.

45 D. V. Badri and J. M. Vivanco, Plant Cell Environ., 2009, 32, 666-681.

46 L. Lioussanne, M. Jolicoeur and M. St-Arnaud, Soil Biol. Biochem., 2008, 40, 2217-2224.

47 K. Narasimhan, C. Basheer, V. B. Bajic and S. Swarup, Plant Physiol., 2003, 132, 146.

48 B. Lugtenberg, in Principles of Plant-Microbe Interactions: Microbes for Sustainable Agriculture, ed. B. Lugtenberg, Springer International Publishing, Cham, 2015, pp. 7-15, DOI: 10.1007/978-3-319-08575-3_3.

49 E. J. Joner and C. Leyval, Environ. Sci. Technol., 2003, 37, 2371-2375.

50 J. M. Lynch and J. M. Whipps, Plant Soil, 1990, 129, 1-10.

51 L. Marilley and M. Aragno, Appl. Soil Ecol., 1999, 13, 127-136.

52 G. A. Kowalchuk, D. S. Buma, W. de Boer, P. G. L. Klinkhamer and J. A. van Veen, Antonie van Leeuwenhoek, 2002, 81, 509.

53 B. C. Martin, S. J. George, C. A. Price, M. H. Ryan and M. Tibbett, Sci. Total Environ., 2014, 472, 642-653.

54 W. Cheng and D. C. Coleman, Soil Biol. Biochem., 1990, 22, 781-787.

55 T. A. Anderson, E. A. Guthrie and B. T. Walton, Environ. Sci. Technol., 1993, 27, 2630-2636.
56 M. Nie, Q. Yang, L.-F. Jiang, C.-M. Fang, J.-K. Chen and B. Li, Biol. Lett., 2010, 6, 811-814.

57 A. Gransee and L. Wittenmayer, J. Plant Nutr. Soil Sci., 2000, 163, 381-385.

58 B. W. Hütsch, J. Augustin and W. Merbach, J. Plant Nutr. Soil Sci., 2002, 165, 397-407.

59 M. B. Leigh, J. S. Fletcher, X. Fu and F. J. Schmitz, Environ. Sci. Technol., 2002, 36, 1579-1583.

60 G. Neumann, in Nutrient Cycling in Terrestrial Ecosystems, ed. P. Marschner and Z. Rengel, Springer Berlin Heidelberg, Berlin, Heidelberg, 2007, pp. 123-157, DOI: 10.1007/978-3540-68027-7_5.

61 K. Xue, L. Wu, Y. Deng, Z. He, J. Van Nostrand, P. G. Robertson, T. M. Schmidt and J. Zhou, Appl. Environ. Microbiol., 2013, 79, 1284.

62 Y. Gao, Y. Yang, W. Ling, H. Kong and X. Zhu, Soil Sci. Soc. Am. J., 2011, 75, 1694-1703.

63 P. Marschner, D. Crowley and Z. Rengel, Soil Biol. Biochem., 2011, 43, 883-894.

64 W. Ling, H. Dang and J. Liu, J. Soils Sediments, 2013, 13, 677685.

65 S. C. Corgié, T. Beguiristain and C. Leyval, Appl. Environ. Microbiol., 2004, 70, 3552.

66 A. C. Singer, in Phytoremediation Rhizoremediation, ed. M. Mackova, D. Dowling and T. Macek, Springer Netherlands, Dordrecht, 2006, pp. 5-21, DOI: 10.1007/978-1-4020-49994_2.

67 H. P. Bais, C. D. Broeckling and J. M. Vivanco, in Secondary Metabolites in Soil Ecology, ed. P. Karlovsky, Springer Berlin Heidelberg, Berlin, Heidelberg, 2008, pp. 241-252, DOI: 10.1007/978-3-540-74543-3_11.

68 R. A. Kanaly and R. Bartha, Environ. Toxicol. Chem., 1999, 18, 2186-2190.

69 J. S. Fletcher and R. S. Hegde, Chemosphere, 1995, 31, 30093016.

70 E. Yergeau, S. Sanschagrin, C. Maynard, M. St-Arnaud and C. W. Greer, ISME J., 2014, 8, 344-358.

71 S. D. Cunningham and W. R. Berti, In Vitro Cell. Dev. Biol.: Plant, 1993, 29, 207-212. 


\section{Chapter 3}

\section{Dose-response analysis of diesel fuel phytotoxicity on selected plant species}

Michael O. Eze ${ }^{\mathrm{a} b *}$, Simon C. George ${ }^{\mathrm{a}}$, Grant C. Hose ${ }^{\mathrm{c}}$

aDepartment of Earth and Environmental Sciences and MQ Marine Research Centre, Macquarie University, Sydney, NSW 2109, Australia.

bepartment of Genomic and Applied Microbiology and Goettingen Genomics Laboratory, Georg-August University of Goettingen, 37077 Göttingen, Germany.

'Department of Biological Sciences, Macquarie University, Sydney, NSW 2109, Australia.

*Correspondence: meze@gwdg.de

Chemosphere 263, 128382. https://doi.org/10.1016/j.chemosphere.2020.128382

\section{Relationship to the Overall Thesis}

This chapter presents a phytotoxicity bioassay experiment through which I examined the hydrocarbon tolerance of various plant species. This is a crucial step in the selection of potential rhizoremediating plants.

\section{Author Contributions}

Conceived and designed the study: MOE, SCG and GCH

Performed the experiments: MOE

Analysed the data: MOE

Wrote the paper: MOE, SCG and GCH 


\title{
Dose-response analysis of diesel fuel phytotoxicity on selected plant species
}

\author{
Michael O. Eze ${ }^{\text {a, b, }{ }^{*}, \text { Simon C. George }}{ }^{a}$, Grant C. Hose ${ }^{\mathrm{c}}$ \\ a Department of Earth and Environmental Sciences and MQ Marine Research Centre, Macquarie University, Sydney, NSW, 2109, Australia \\ ${ }^{\mathrm{b}}$ Department of Genomic and Applied Microbiology and Goettingen Genomics Laboratory, Georg-August University of Goettingen, Germany \\ c Department of Biological Sciences, Macquarie University, Sydney, NSW, 2109, Australia
}

\section{H I G H L I G H T S}

- Hormesis cannot be ignored in plant ecotoxicology research.

- Diesel fuel had a concentrationdependent monotonic impact on most species, but had a hormetic effect on Medicago sativa.

- An appropriate dose-response model is crucial for the accurate assessment of hormesis in plants.

- A wrong statistical model leads to a wrong interpretation of the potential of species for environmental remediation.

\section{A R T I C L E I N F O}

\section{Article history:}

Received 16 August 2020

Received in revised form

13 September 2020

Accepted 17 September 2020

Available online 19 September 2020

Handling Editor: A. Gies

\section{Keywords:}

Dose-response analysis

Bioassay

Phytotoxicity

Diesel fuel

Hormesis

\section{G R A P H I C A L A B S T R A C T}

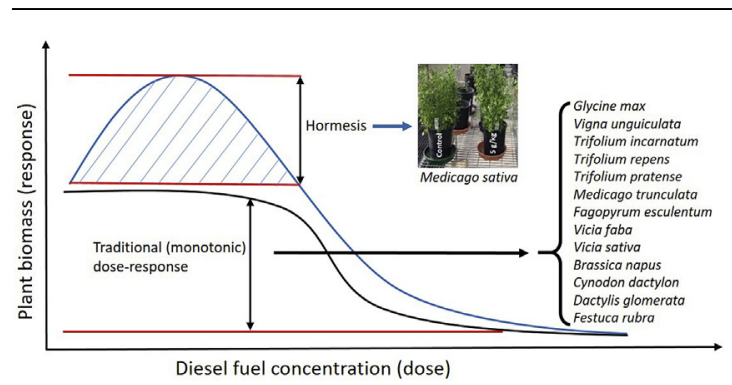

\begin{abstract}
A B S T R A C T
As an ecotoxicological tool, bioassays are an effective screening tool to eliminate plants sensitive to the contaminant of interest, and thereby reduce the number of plant species requiring further study. We conducted a bioassay analysis of fifteen plant species to determine their tolerance to diesel fuel toxicity. Dose-response analysis revealed that increasing diesel fuel concentrations in the soil generally led to a monotonically decreasing biomass in 13 species $(P<0.001)$, with EC10 values $( \pm$ SE) ranging from $0.36 \pm 0.18 \mathrm{~g} / \mathrm{kg}$ to $12.67 \pm 2.13 \mathrm{~g} / \mathrm{kg}$. On the other hand, hydrocarbons had a statistically significant hormetic influence on Medicago sativa $(f=3.90 \pm 1.08 ; P<0.01)$. The EC10 and EC50 values $( \pm \mathrm{SE})$ from the fitted hormetic model were $15.33 \pm 1.47 \mathrm{~g} / \mathrm{kg}$ and $26.89 \pm 2.00 \mathrm{~g} / \mathrm{kg}$, respectively. While previous studies have shown M. sativa's tolerance of hydrocarbon toxicity, this is the first attempt to describe diesel fuel-induced hormesis in M. sativa using the Cedergreen-Ritz-Streibig model. This study thus shows that hormesis cannot be ignored in plant toxicology research, and that when present, an appropriate statistical model is necessary to avoid drawing wrong conclusions.
\end{abstract}

(C) 2020 Elsevier Ltd. All rights reserved.

\footnotetext{
* Corresponding author. Department of Earth and Environmental Sciences and MQ Marine Research Centre, Macquarie University, Sydney, NSW, 2109, Australia.

E-mail address: meze@gwdg.de (M.O. Eze).
}

\section{Introduction}

Globally, oil spillage is the most significant environmental threat resulting from oil and gas operations. For example, in 1989 the Exxon Valdez oil spill released 42 million litres of crude oil, resulting in the contamination of approximately $2000 \mathrm{~km}$ of shorelines in the Gulf of Alaska (Bragg et al., 1994). Although large- 
scale aquatic spills readily attract public attention, the majority of oil and fuel spills have occurred on land, with long-lasting ecological impacts (Duffy et al., 1980; Errington et al., 2018). The toxicity of petroleum hydrocarbons to human and animal life, coupled with the slow rate of natural attenuation has led to increasing interest in the discovery of effective remediation techniques (Dean, 1985; McKee and White, 2013).

The remediation of contaminated soils is a multibillion dollar a year global industry (Cunningham and Berti, 1993). Most often, remediation is based on either ex situ (excavation and offsite) treatment or in situ (on site) remediation approaches. Due to the prohibitive cost and environmental impacts of traditional strategies, a high proportion of contaminated sites are either left as is or their rehabilitation is delayed. Thus, other cheaper and eco-friendly alternatives are required. Plant-based remediation techniques are considered to be an effective and affordable "green technology" for reclaiming soils contaminated with petroleum hydrocarbons (McLntyre and Lewis, 1997; Rohrbacher and St-Arnaud, 2016).

Rhizoremediation relies on the tolerance of plants to contaminant toxicity and the degradation of contaminants in the rhizosphere. Under a variety of environmental conditions, vegetation has been shown to particularly enhance microbial degradation rates of organic chemical residues in soils (Anderson et al., 1993; Reilley et al., 1996; Corgié et al., 2003, 2004). This is due to plant's ability to exude nutrients such as sugars and amino acids from its roots that support specific, beneficial bacterial assemblages (Berendsen et al., 2012, 2018). In addition, root exudates can stimulate bacterial behaviours vital for the synthesis of degradative enzymes, as well as regulate plant-microbe interactions by recruiting plant growth promoting rhizobacteria such as nitrogen-fixers or phosphate solubilizers (Benizri et al., 2002; Baudoin et al., 2003; Butler et al., 2003; Broeckling et al., 2008). These are processes vital for tolerance and rhizoremediation of environmental contaminants. Several studies have thus identified root exudation as the most important driver responsible for rhizodegradation of organic contaminants (Yoshitomi and Shann, 2001; Joner et al., 2002; Da Silva et al., 2006; Phillips et al., 2012; Martin et al., 2014).

There is strong evidence that the quantity and quality of root exudates are determined by the cultivar, plant species, developmental stage, and various environmental factors (Viebahn et al., 2005; Badri and Vivanco, 2009; Xue et al., 2013). Similarly, the microbial assemblages that root exudates foster, can be specific to the plant species, and even the strain (Lioussanne et al., 2008; Micallef et al., 2009). It appears that, from the reservoir of microbial diversity that the bulk soil comprises, plant roots select specific microorganisms to prosper in the rhizosphere (Miethling et al., 2000; Siciliano et al., 2003; Berg et al., 2006; Berendsen et al., 2012). This consequently enhances the ability of host plants to withstand contaminant toxicity. Since different plant species exhibit different responses to environmental toxicants, it is highly beneficial to screen plants for their ability to withstand contaminant toxicity. Bioassays as screening tools helps to eliminate plants sensitive to the target contaminant, thereby reducing the number of plant species requiring large-scale studies (Kirk et al., 2002; Chouychai et al., 2007). Equally important is the accurate analysis of phytotoxicity through the use of appropriate dose-response models (Ritz, 2010). These are all important parameters when selecting plants suitable for phytoremediation.

There is increasing evidence that plants can exhibit biphasic dose-response (hormetic) behaviours, characterized by contrasting responses to low and high concentrations of contaminants, with often stimulatory effects of contaminants at low doses (Agathokleous et al., 2018). Unfortunately, species-specific hormesis in plant research remains underexplored. Therefore, the aim of this research is to explore the response (including hormetic response) of selected plant species to diesel fuel phytotoxicity and to analyse plants' responses through the use of appropriate doseresponse models. This research is vital to enhance our understanding of the response of plants to chemical stress, especially those caused by toxic hydrocarbons.

\section{Materials and methods}

\subsection{Soil preparation for bioassay}

The soil used for this experiment was "turf underlay" obtained from Australian Native Landscapes Pty, Sydney. Turf underlay is made from a mixture of screened sand, soil, and composted organics. It is blended with a natural fertiliser additive to help roots properly grow and stay long during all times of year, including the winter months. The soil was sieved using a 2-mm sieve to remove unwanted large particles. The soil textural class is dominantly sand ( $86.2 \%$ sand, $5.1 \%$ silt and $8.7 \%$ clay), with $9.3 \%$ organic matter content by loss on ignition and $0.18 \%$ total nitrogen content. The soil was then air-dried until a constant weight is achieved. Different concentrations of diesel fuel contaminated soils $(0 \mathrm{~g} / \mathrm{kg}, 5 \mathrm{~g} / \mathrm{kg}$, $10 \mathrm{~g} / \mathrm{kg}, 20 \mathrm{~g} / \mathrm{kg}, 30 \mathrm{~g} / \mathrm{kg}, 40 \mathrm{~g} / \mathrm{kg}, 50 \mathrm{~g} / \mathrm{kg}$ and $100 \mathrm{~g} / \mathrm{kg}$ of soil) were prepared by spiking $2 \mathrm{~kg}$ of soil samples with appropriate amounts of diesel fuel. The diesel fuel used was petroleum diesel (also called petrodiesel), as opposed to synthetic diesel or biodiesel, and was obtained from a Shell service station in Sydney. The chemical composition is predominantly saturated hydrocarbons $\left(C_{10}\right.$ to $C_{25}$ n-alkanes, iso- and cyclo-alkanes) and some aromatic hydrocarbons (e.g. alkylnaphthalenes and alkylbenzenes). The spiked soils were first mixed manually by hand (using gloves), followed by a thorough mixing using a Sanfine portable electric $1800 \mathrm{~W}$ soil mixing machine (Model No. SF-HM1401/1401 S). The mixing was performed for 15 min per pot ( $2 \mathrm{~kg}$ soil) with a break and manual shaking after every 5 min to achieve complete homogeneity.

\subsection{Determination of seed viability}

The triphenyltetrazolium chloride (TTC) test has been developed to provide a rapid estimate of seed viability (Van Waes and Debergh, 1986; Adam and Duncan, 2002). TTC is a clear, water soluble compound (a salt) which is reduced by respiring tissues to yield triphenylformazan (TPF), a water-insoluble red pigment. Thirty seeds of each species were subjected to the TTC test as follows. Each batch of seeds was placed in a beaker containing $50 \mathrm{~mL}$ of $1 \%$ TTC, prepared by dissolving $1 \mathrm{~g}$ of TTC in $100 \mathrm{~mL}$ distilled water. The beakers were covered and placed in an incubator at $30^{\circ} \mathrm{C}$ for $1 \mathrm{~h}$. Following incubation, the liquid was decanted and the seeds were rinsed with distilled water until the water was clear. The seeds were blotted with dry towel and the colour was observed. The seeds were classified into two categories according to their colour development, namely: "red/pink" and "no colour", corresponding to "viable" and "not viable", respectively.

\subsection{Plant growth experiment}

Following the results of the TTC test, phytotoxicity assays were carried out using a series of pot experiments in a greenhouse using seeds from viable seed bags. The plant species studied included 12 legumes (Glycine max, Vigna unguiculata, Trifolium incarnatum, Trifolium repens, Trifolium pratense, Medicago truncatula, Medicago sativa, Fagopyrum esculentum, Vicia faba, Vicia sativa, Brassica napus, Cassia rotundifolia) and three grasses (Cynodon dactylon, Dactylis glomerata, Festuca rubra).

For each plant species, 10 viable seeds were placed in pots each containing $2 \mathrm{~kg}$ of control soil or contaminated soils of different 
concentrations $(0,5,10,20,30,40,50$ and $100 \mathrm{~g}$ diesel $/ \mathrm{kg}$ soil). Pots were watered twice a week for a period of 90 days. During this period, measurements such as shoot heights (in mean values of plants per pot) were taken every two weeks to determine species relative growth rate. Height growth was measured from the shoot tip to the base of stem following the methods of Chen et al. (2002). In addition, visual assessments of the plant leaves were made per plant per pot every two weeks to assess for the presence or absence of chlorosis. After three months, each plant was harvested, the shoots and roots were washed under tap water, oven-dried at $70{ }^{\circ} \mathrm{C}$ until a constant weight was achieved, and then their dry biomass weight was obtained.

\subsection{Statistical analysis and modelling}

\subsubsection{Log-logistic model}

All statistical analyses were carried out using the "doseresponse curve" package in $\mathrm{R}$ ( $\mathrm{R}$ Core Team, 2018). A large number of dose-response model functions are built-in to drc (Ritz et al., 2015). These models are parameterized using a unified structure, with a coefficient $b$ denoting the steepness of the dose-response curve, $c$ and $d$ the lower and upper asymptotes or limits of the response respectively, and $e$, which reflects the point of inflection and equates to the effective dose ED50 or EC50 in some models (Ritz, 2010). The present study used the $d r m($ ) function in the package $d r c$ to model the effect of diesel fuel exposure on plant biomass. As in the methods of Hose et al. (2016), a series of 3parameter response curves including log-logistic, Weibull, lognormal and hormetic curves were fit to the data, and the best fitting model based on Akaike information criterion were chosen. Log-logistic models are the most used dose-response models (Ritz et al., 2015). The four-parameter log-logistic model corresponds to the model function:

$\boldsymbol{f}(\boldsymbol{x},(\boldsymbol{b}, \boldsymbol{c}, \boldsymbol{d}, \boldsymbol{e}))=\boldsymbol{c}+\frac{\boldsymbol{d}-\boldsymbol{c}}{1+\exp [\boldsymbol{b}\{\log (\boldsymbol{x})-\log (\boldsymbol{e})\}]}$

However, in most biological experiments, all test organisms die at high contaminant concentrations. This was also true in this study. Hence, it is desirable to fix the lower asymptote $c$ at 0 . This results in a three-parameter log-logistic model as follows:

$\boldsymbol{f}(\boldsymbol{x},(\boldsymbol{b}, \boldsymbol{d}, \boldsymbol{e}))=\frac{\boldsymbol{d}}{1+\exp [\boldsymbol{b}\{\log (\boldsymbol{x})-\log (\boldsymbol{e})\}]}$

One benefit of fixing $c$ at 0 on biological or toxicological grounds is improved precision of the remaining parameter estimates, as the information content of the model has been enhanced (Ritz, 2010). The concentrations causing $10 \%$ and $50 \%$ reductions in biomass of the test population (the EC10 and EC50 values) were extrapolated from the fitted curves. Analyses were based on nominal soil hydrocarbon concentrations.

\subsubsection{Modelling hormesis: Cedergreen-Ritz-Streibig model}

Traditionally, dose-response models are based on strictly monotonic functions, which are either strictly decreasing from a maximum control response at zero dose to a lower limit at infinite dose, or are strictly increasing from no effect at zero dose to maximum effect at infinite dose, depending on whether it is the response or the effect that is being assessed. These functions therefore cannot be used to model dose responses that exhibit initial response stimulation, known as hormesis (Cedergreen et al., 2005), a phenomenon that has gained increased recognition (Calabrese and Baldwin, 2003; Agathokleous, 2018).

To overcome these limitations, Cedergreen et al. (2005) developed a new empirical model that can describe and test for hormetic responses in all types of dose-response data, irrespective of their slope. This model is known as the Cedergreen-Ritz-Streibig model and is described by the equation:

$\boldsymbol{f}(\boldsymbol{x})=\boldsymbol{c}+\frac{\boldsymbol{d}-\boldsymbol{c}+\boldsymbol{f} \exp \left(-1 /\left(\boldsymbol{x}^{\alpha}\right)\right)}{1+\exp [\boldsymbol{b}\{\log (\boldsymbol{x})-\log (\boldsymbol{e})\}]}$

This model allows the calculation of the concentration of the maximum hormetic response, the size and significance of this response, as well as effective doses (EDx). The ability of the Cedergreen-Ritz-Streibig model to enable the determination of effective doses is its major advantage over earlier models (Cedergreen et al., 2005). A statistical test for the presence of hormesis is equal to the test of $f=0$, where $f$ is the rate of hormetic effect or growth stimulation at doses close to zero (Brain and Cousens, 1989; Cedergreen et al., 2005).

\subsubsection{Relative growth rate}

Relative growth rate was calculated for the three most tolerant taxa identified from the concentration response experiments. We chose plants in the $5 \mathrm{~g} / \mathrm{kg}$ diesel fuel contaminated soils, since this reflected the lowest tolerable concentrations in our study. The classical approach to relative growth rate measurements makes use of dry mass, which requires destructive harvesting (Hunt, 1990; Alameda and Villar, 2012). However, this method is often associated with certain biases, owing to some variations in plant weight among individuals (Hoffmann and Poorter, 2002). Since dry weight biomass often correlates well with plant height, we assessed relative growth rate in terms of the mean values of shoot heights per pot. This approach is similar to that adopted by Chen et al. (2002). For statistical analysis, we employed the generalized logistic model with lower asymptote $c=0$, since height at $t_{0}=0$ (Fresco, 1973; Gregorczyk, 1991; Szparaga and Kocira, 2018).

\section{Results}

\subsection{Biomass response}

Of the 12 legumes (Glycine max, Vigna unguiculata, Trifolium incarnatum, Trifolium repens, Trifolium pratense, Medicago truncatula, Medicago sativa, Fagopyrum esculentum, Vicia faba, Vicia sativa, Brassica napus, Cassia rotundifolia) and three grasses (Cynodon dactylon, Dactylis glomerata, Festuca rubra) tested, only C. rotundifolia failed to germinate even at low concentrations of diesel fuel. This was not unexpected since the initial viability test performed on seed bags gave percentage viability of $32 \%$ for C. rotundifolia and $>90 \%$ for other seed species. Therefore, C. rotundifolia was excluded from further analysis.

With the exception of $M$. sativa, growth of all plant species showed monotonic behaviour in the presence of diesel fuel contamination, with decreasing biomass at increasing diesel fuel concentrations, as exemplified in Fig. 1 for D. glomerata and T. pratense.

\subsection{Relative growth rate}

When grown in $5 \mathrm{~g} / \mathrm{kg}$ diesel fuel contaminated soils, $M$. sativa had the highest relative growth rate ( \pm standard error) of the three species $(0.08 \pm 0.01 \mathrm{~cm} /$ day $)$, followed by $V$. faba $(0.07 \pm 0.01 \mathrm{~cm} /$ day) and G. $\max (0.06 \pm 0.01 \mathrm{~cm} /$ day $)$ (Fig. 2).

Chlorosis is a condition in which leaves produce insufficient chlorophyll, leading to pale or yellow colouration of the leaves and eventual death unless chlorophyll production is restored (Pallardy, 2008). Visual assessments of the plant leaves were performed to assess the presence of chlorosis in selected plants (Fig. 3). With the 

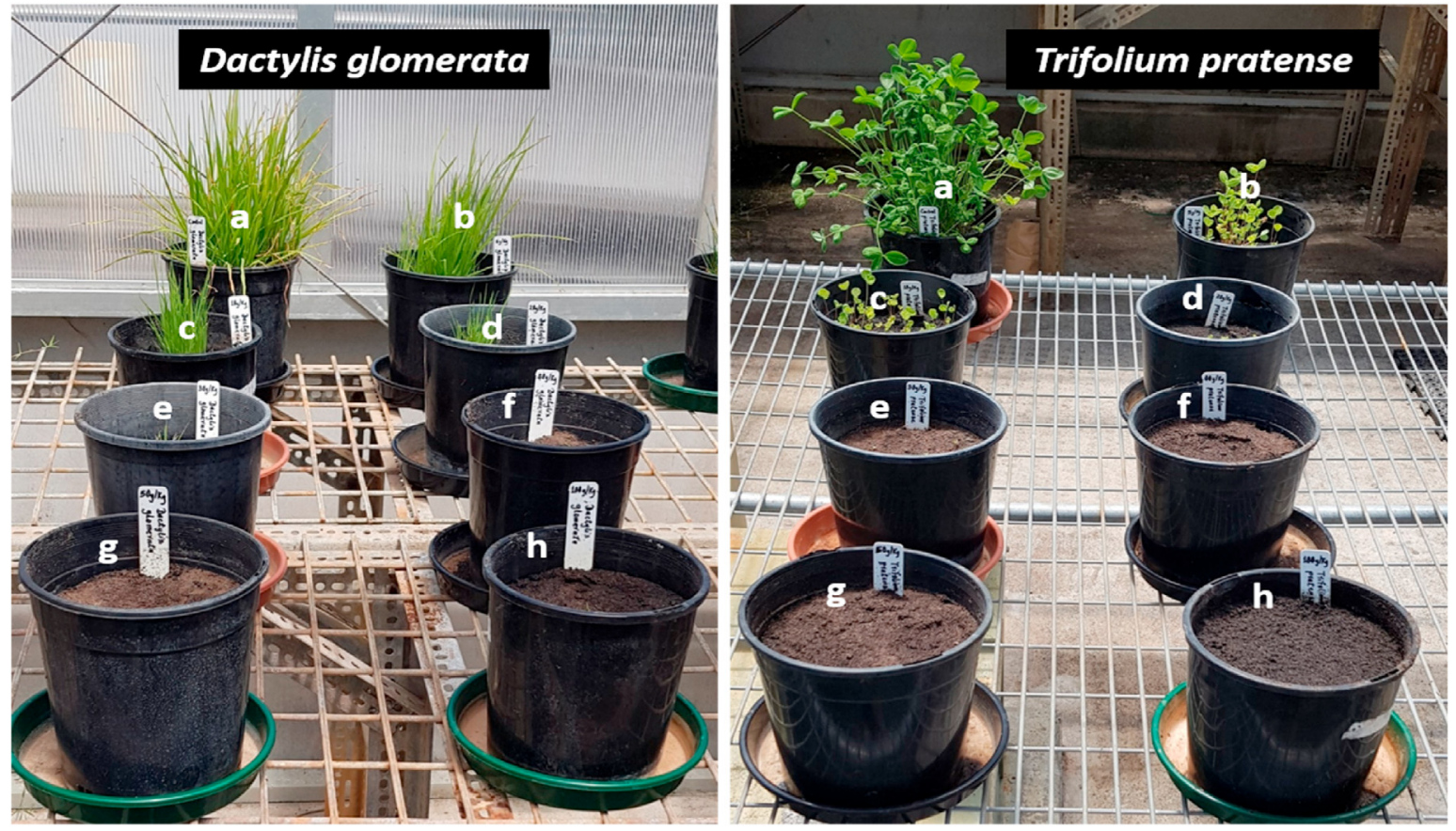

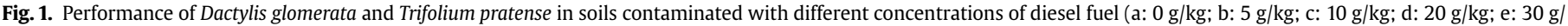
kg; f: $40 \mathrm{~g} / \mathrm{kg} ; \mathrm{g}$ : $50 \mathrm{~g} / \mathrm{kg} ; \mathrm{h}: 100 \mathrm{~g} / \mathrm{kg}$ ).

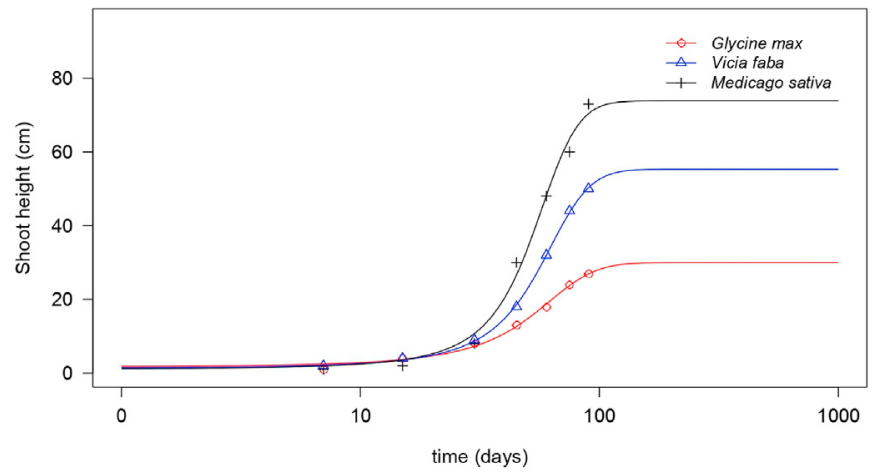

Fig. 2. Generalized logistic model showing the growth rate of three plants grown in $5 \mathrm{~g} / \mathrm{kg}$ diesel fuel contaminated soils. The growth rate was measured in terms of shoot height $(\mathrm{cm})$ attained with time (days).

exception of M. sativa, all the plants grown in diesel fuel contaminated soils showed the presence of chlorosis at different stages of their growth. For example, by week 3, V. unguiculata and B. napus in $20-50 \mathrm{~g} / \mathrm{kg}$ diesel fuel contaminated soils began to show signs of chlorosis, and by week 6 , they began to die. This indicates their high sensitivity to diesel fuel. In contrast, the appearance of chlorosis in $V$. faba corresponded with increasing soil diesel fuel concentrations, with first occurrence in $V$. faba plants growing in $50 \mathrm{~g} / \mathrm{kg}$ in week 6 . By week 8 chlorosis had occurred in all $V$. faba plants growing in $10-50 \mathrm{~g} / \mathrm{kg}$ contaminated soils.

\subsection{Dose-response analysis}

A 3-parameter log-logistic model provided the best fit for the responses of all taxa (Table 1, Fig. 4), except for M. sativa for which the concentration response was best described by the CedergreenRitz-Streibig model (Table 1, Fig. 5). The Cedergreen-Ritz-Streibig model suggests a hormetic response for $M$. sativa, in which biomass increased relative to the control at low hydrocarbon concentrations (Fig. 5). The statistical test for the presence of hormesis was significant $(f=3.90 \pm 1.08, P<0.01)$ for $M$. sativa indicating hormesis. As shown in Table 1, tolerance to diesel fuel varied from one species to another. For example, while some species (such as $B$. napus and $T$. repens) could not survive beyond $20 \mathrm{~g} / \mathrm{kg}$ concentrations, others such as G. max and $V$. faba continued to produce biomass at diesel fuel concentrations in the range of $5-50 \mathrm{~g} / \mathrm{kg}$. None of the plants survived in soils containing $100 \mathrm{~g} / \mathrm{kg}$ diesel fuel.

As shown in Table 1, the effect of diesel fuel on plant species was species-specific. For example, there was a marked difference in ECX values between $M$. sativa and $M$. truncatula, and between T. incarnatum and T. pratense. Among the species studied, $M$. sativa had the highest EC10 $( \pm$ SE) value of $15.33 \pm 1.47 \mathrm{~g} / \mathrm{kg}$, while T. incarnatum had the lowest EC10 $( \pm$ SE) value of $0.36 \pm 0.18 \mathrm{~g} / \mathrm{kg}$. The three plants with the highest EC50 $( \pm \mathrm{SE})$ values were $G$. max $(36.94 \pm 1.97 \mathrm{~g} / \mathrm{kg}), \quad$. faba $(31.25 \pm 2.86 \mathrm{~g} / \mathrm{kg})$ and M. sativa $(26.89 \pm 2.00)$ (Table 1). On this basis, these three species were further assessed for their relative growth rates.

\section{Discussion}

In this study, grasses and legumes were selected as they are often the best candidates for phytoremediation (USEPA, 2001). Grasses are potentially useful for phytoremediation because of their extensive and fibrous root system (Binet et al., 2000), while legumes are suitable because of their intrinsic ability to obtain nitrogen through their symbiotic relationships with Rhizobia (USEPA, 2000). The results of our study show that diesel fuel in soil impacts biomass production of potential phytoremediating plants, and that the nature and extent of this impact is plant species-specific. The findings of this research also highlight the need to employ appropriate statistical models in the analysis of phytotoxicity assay results, so as to reduce the chances of drawing wrong conclusions.

A major objective of this study was to establish how various concentrations of diesel fuel in soil affect the survival and biomass 

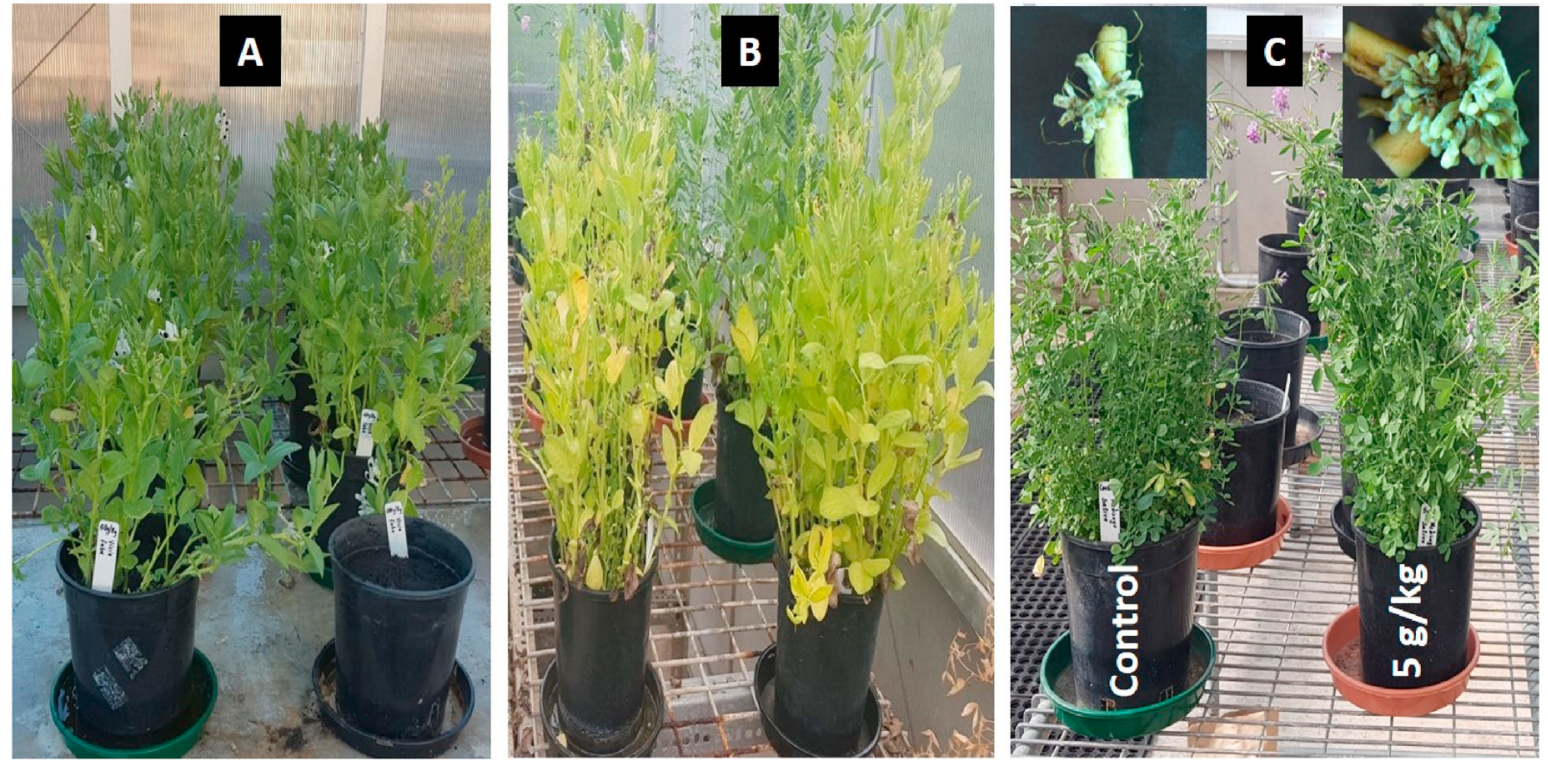

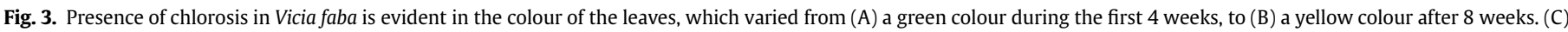

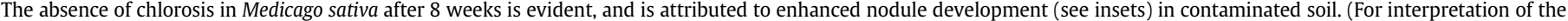
references to colour in this figure legend, the reader is referred to the Web version of this article.)

Table 1

Toxicity of diesel fuel to different plant species.

\begin{tabular}{lllll}
\hline \multirow{2}{*}{ Legumes } & Species & EC10 & EC50 & Model \\
& Glycine max & $12.67(2.13)$ & $36.94(1.97)^{* * *}$ & LL.3 \\
& Vicia faba & $5.05(1.44)$ & $31.25(2.86)^{* * *}$ & LL.3 \\
& Vicia sativa & $5.07(1.15)$ & $21.28(1.96)^{* * *}$ & LL.3 \\
& Vigna unguiculata & $2.24(0.85)$ & $14.50(2.41)^{* * *}$ & LL.3 \\
& Medicago sativa & $15.33(1.47)$ & $26.89(2.00)^{* * *}$ & CRS.4a \\
& Medicago truncatula & $0.87(0.20)$ & $4.19(0.41)^{* * *}$ & LL.3 \\
& Trifolium incarnatum & $0.36(0.18)$ & $3.02(0.65)^{* * * *}$ & LL.3 \\
& Trifolium pratense & $2.35(0.50)$ & $7.73(0.80)^{* * *}$ & LL.3 \\
& Trifolium repens & $2.86(0.38)$ & $7.06(0.43)^{* * *}$ & LL.3 \\
& Brassica napus & $1.89(0.57)$ & $5.00(0.59)^{* * * *}$ & LL.3 \\
& Fagopyrum esculentum & $0.59(0.32)$ & $6.53(1.49)^{* * * *}$ & LL.3 \\
Grasses & Cynodon dactylon & $3.10(0.46)$ & $9.35(0.71)^{* * *}$ & LL.3 \\
& Dactylis glomerata & $3.00(0.49)$ & $10.26(0.83)^{* * *}$ & LL.3 \\
& Festuca rubra & $4.40(1.70)$ & $11.58(2.04)^{* * *}$ & LL.3 \\
\hline
\end{tabular}

EC10 and EC50 values indicate the concentrations of diesel fuel $(\mathrm{g} / \mathrm{kg})$ that caused a $10 \%$ and $50 \%$ reduction in biomass production of each species, respectively. Values in parentheses indicate standard errors. LL.3 = 3-parameter Log-logistic model; CRS.4a = Cedergreen-Ritz-Streibig model; Significant code: '***’ $P<0.001$.

production of the studied plants. Regression analysis (Fig. 4) shows that the effect of diesel fuel on plant biomass production is speciesspecific. For example, while the three species of Trifolium were sensitive to diesel fuel, the impact of diesel fuel on the species varied (Fig. 4, Table 1). Similar observations were made for Medicago and Vicia species. In general, increases in diesel fuel concentrations in the soil led to a highly statistically significant $(P<0.001)$ monotonic decrease in the biomass of 13 species, as shown by the sigmoidal curves (Fig. 4). This observation is consistent with previous research on other plant species (Adam and Duncan, 2003; Chouychai et al., 2007). On the other hand, diesel fuel in the soil at $5 \mathrm{~g} / \mathrm{kg}$ concentrations enhanced nodule development and consequently biomass production in $M$. sativa, resulting in a hormetic response (Fig. 5). The statistical test for the presence of hormesis is equal to the test of $f=0$, where $f$ is the rate of hormetic effect. Interestingly, our resulting hormetic model gave $f=3.90 \pm 1.08$, denoting an inverted U-shaped hormetic curve which is statistically significant at $P<0.01$. On this basis, we calculated effective concentrations of diesel fuel in terms of EC10 and EC50.

For log-logistic curves for the other species, EC10 values ranged from $0.36 \pm 0.18 \mathrm{~g} / \mathrm{kg}$ for $T$. incarnatum to $12.67 \pm 2.13 \mathrm{~g} / \mathrm{kg}$ for G. max, while EC50 values ranged from $3.02 \pm 0.65 \mathrm{~g} / \mathrm{kg}$ for T. incarnatum to $36.94 \pm 1.97 \mathrm{~g} / \mathrm{kg}$ for $\mathrm{G}$. $\max$. For the hormetic curves, care is required since the value of $e$ provides a lower bound of the EC50 value. The EC10 and EC50 values from our fitted hormetic model were $15.33 \pm 1.47 \mathrm{~g} / \mathrm{kg}$ and $26.89 \pm 2.00 \mathrm{~g} / \mathrm{kg}$ respectively. Hence, $M$. sativa and G. max had the highest EC10 and EC50 values, respectively. Our goal was to identify species with high EC values and high biomass. As G. $\max , V$. faba and M. sativa had high EC values (high tolerance) and high biomass, this suggests that they are suitable species for rhizoremediation.

Our study also reveals that errors in fitting statistical models can lead to wrong conclusions. For example, describing the effect of diesel fuel on M. sativa using log-logistic model produces EC10 and EC50 values of $11.83 \pm 2.67 \mathrm{~g} / \mathrm{kg}$ and $25.13 \pm 2.51 \mathrm{~g} / \mathrm{kg}$. These are lower than the actual EC10 and EC50 values extrapolated from the hormetic curves. Hydrocarbon-induced hormesis was first observed in plants about a century ago (Agathokleous et al., 2020a), and more recent studies have shown that $M$. sativa is tolerant to hydrocarbon toxicity (Chekol and Vough, 2001; Sun et al., 2011; Hamdi et al., 2012; Marchand et al., 2016, 2018; Panchenko et al., 2017). However, this paper is the first attempt to describe diesel fuel-induced hormesis in M. sativa using the Cedergreen-RitzStreibig model. This is important since traditionally, doseresponse models, such as the log-logistic model or the lognormal and Weibull models, are based on strictly monotonic functions and therefore cannot be used to model dose responses that exhibit initial response stimulation (Brain and Cousens, 1989; Cedergreen et al., 2005), a phenomenon that has gained increased recognition (Calabrese and Baldwin, 2003; Calabrese and Blain, 2005; Wiegant et al., 2012). An adequate understanding of species-specific hormesis in plant biology is vital for establishing toxicological thresholds, and for determining the suitability of plant species for hydrocarbon remediation purposes.

Examination of the existing literature suggests that in many biological studies, hormesis is the norm rather than the exception. 


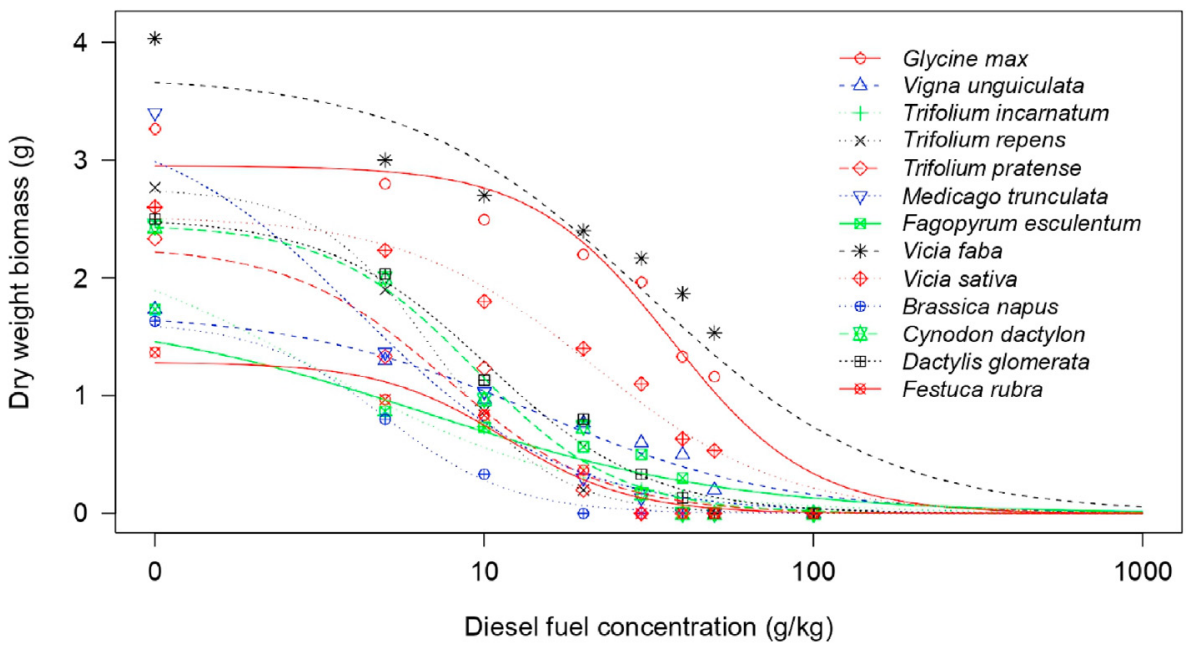

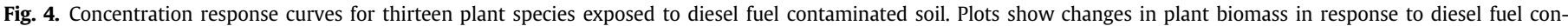
centration, with curves modelled using a 3-parameter log-logistic model.

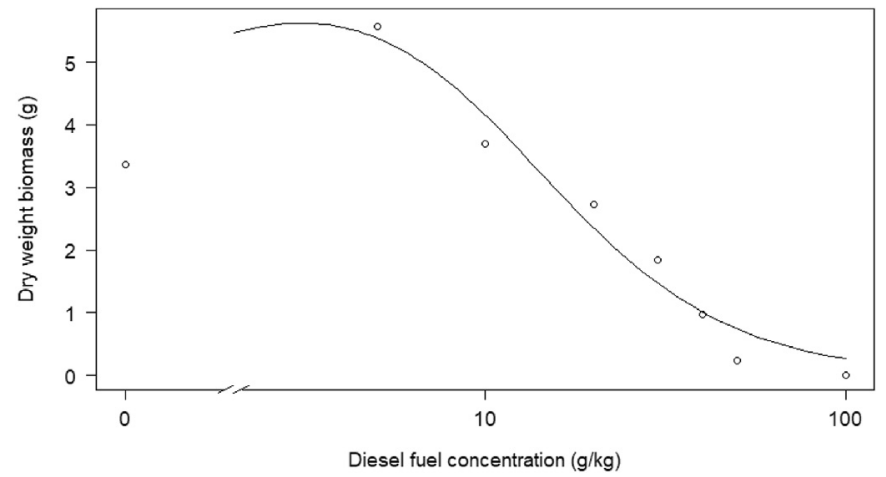

Fig. 5. A plot of the hormetic influence of diesel fuel in the soil on the biomass of Medicago sativa in glasshouse bioassays using the Cedergreen-Ritz-Streibig model.

Various substances generally classified as toxicants have been found to be beneficial to living organisms at low doses, indicating that dosage is an important determinant of toxicity. Although organic and inorganic substances such as petroleum hydrocarbons and heavy metals are considered phytotoxic, increasing evidence suggests that they impact positively on plant growth at low doses (Muszyńska and Labudda, 2019; Carvalho et al., 2020; Shahid et al., 2020). An evaluation of thirty-three plant species and over twenty stress-inducing agents revealed this stimulatory effect is related to the influence of stressors on chlorophyll production at low concentrations (Agathokleous et al., 2020b). The results of our study revealed that the stimulatory (or inhibitory) effect of diesel fuel is species-specific, as shown in the case of Medicago, Vicia and Trifolium species (Table 1). For example, while $M$. truncatula gave a decreasing monotonic response to diesel fuel, $M$. sativa exhibited a highly significant hormetic response in the order of $165 \%$ of control (maximal mean value), a value that is in agreement (although slightly higher) with the maximum median values of $150-160 \%$ reported in many hormetic studies (Agathokleous et al., 2020b). It should be noted, however, that it was not possible to investigate all varieties within the genera studied, as this would require numerous genotypes of each species. Additionally, different doses of diesel fuel (especially concentrations lower than $5 \mathrm{~g} / \mathrm{kg}$ ) might induce hormesis in species that did not show hormesis in this study.

To obtain a more accurate picture of survival and tolerance in phytotoxicity assays, relative growth rates of plants in the presence of contaminants should also be determined. From EC50 values alone, one may conclude that G. max offers the best potential for rhizoremediation. However, an examination of relative growth rate (RGR; cm/day) reveals that G. $\max$ has the lowest RGR $(0.06 \pm 0.01)$ when compared to those of $M$. sativa $(\mathrm{RGR}=0.08 \pm 0.01)$ and $V$. faba $(\mathrm{RGR}=0.07 \pm 0.01)$. In addition, $M$. sativa had the highest value of the upper asymptote $(d=73.84 \pm 2.98 ; P<0.001)$, while $G$. max had the lowest value $(d=30.02 \pm 4.19 ; P<0.001)$ among the three species. Considering the fact that M. sativa, G. $\max$ and $V$. faba can generally grow to heights of $1 \mathrm{~m}, 1.2 \mathrm{~m}$ and $1.8 \mathrm{~m}$ respectively, our results indicate that G. $\max$ and $V$. faba were highly sensitive to petroleum hydrocarbons. This observation thus places $M$. sativa as the best species in terms of toxicity tolerance and consequently rhizoremediation potential.

Finally, our examination highlights the need for extended test duration for bioassays to enable the observation of such indicators of phytotoxicity as chlorosis. In ecotoxicology research, chlorosis in plants is a strong indication of toxicity of contaminants, be it organic or inorganic, to plant tissues (Sanderson et al., 1997; Edward, 1998; Sağlam et al., 2016). The determination of chlorosis through visual observations is crucial in our choice of plants with tolerance to phytotoxicity. The presence of chlorosis in most of the studied plants was evident from morphological observations (Fig. 3). Our results revealed that by the fourth week, the majority of the species had already shown signs of chlorosis. Additionally, a few species such as $V$. faba did not show any sign of chlorosis within the first four weeks, but these signs began to appear from the sixth week onward (Fig. 3b). In contrast, plants in the controls did not show any signs of chlorosis, implicating the diesel fuel contamination as being responsible. Medicago sativa on the other hand did not manifest any sign of chlorosis in any treatment (Fig. 3c). Microscopic examination of the roots of the studied plants revealed enhanced nodule development and microbial colonisation of the $M$. sativa roots (Fig. $3 c$ insets). Nitrogen fixation by associated rhizobacteria may therefore be responsible for enhanced biomass production and for the absence of chlorosis (Kozlowski and Pallardy, 1997; Kirkby, 2005; Scherer, 2005).

Traditional methods of assessing chlorosis are by spectrophotometric or colorimetric analyses, following extraction of pigments from leaves (Wickliff and Aronoff, 1962). However, in view of the destructive nature of this method, we recommend the more recent 
non-destructive vision-based approaches using reflectance and transmittance as base parameters (Liang et al., 2017; Pérez-Patricio et al., 2018). Finally, our results underscore the need to extend plant bioassay research beyond the first couple of weeks to enable sufficient time to assess chlorosis, either through visual observation or other non-destructive techniques.

\section{Conclusions}

Bioassays are an effective ecotoxicological tool to screen the sensitivity of plants to contaminants, and to reduce the number of plant species required for further studies. Our screening of 15 plant species reveals that diesel fuel in soil is toxic to most plants, and the magnitude of this effect increases with diesel fuel concentrations in the soil. While all other studied plants gave a monotonically decreasing biomass with increasing diesel fuel concentrations, $M$. sativa had a hormetic curve, indicating that diesel fuel at low concentrations stimulated growth. A combination of parameters points to M. sativa as possessing the highest phytotoxicity tolerance and potential for the rhizoremediation of diesel fuel contaminated sites. Finally, this study demonstrated the importance of choosing the appropriate statistical model for the analysis of phytotoxicity.

\section{Author contributions}

M.O.E., S.C.G. and G.C.H. conceived and designed the study; M.O.E., S.C.G. and G.C.H. acquired, analysed and interpreted the data; M.O.E. drafted the manuscript, while S.C.G. and G.C.H. revised it.

\section{Declaration of competing interest}

The authors declare that they have no known competing financial interests or personal relationships that could have appeared to influence the work reported in this paper.

\section{Acknowledgements}

The authors would like to thank the Commonwealth Government of Australia and Macquarie University, Sydney for supporting this research project by providing an international Research Training Program (iRTP) scholarship to the first author (Allocation Number: 2017561). This research was conducted at the Plant Growth Facility, Macquarie University, Sydney, Australia. We thank the two anonymous journal reviewers whose helpful comments significantly improved this manuscript.

\section{References}

Adam, G., Duncan, H., 2002. Influence of diesel fuel on seed germination. Environ. Pollut. 120, 363-370.

Adam, G., Duncan, H., 2003. The effect of diesel fuel on common vetch (Vicia sativa L.) plants. Environ. Geochem. Health 25, 123-130.

Agathokleous, E., 2018. Environmental hormesis, a fundamental non-monotonic biological phenomenon with implications in ecotoxicology and environmental safety. Ecotoxicol. Environ. Saf. 148, 1042-1053.

Agathokleous, E., Barceló, D., Tsatsakis, A., Calabrese, E.J., 2020a. Hydrocarboninduced hormesis: 101 years of evidence at the margin? Environ. Pollut. 265, 114846.

Agathokleous, E., Feng, Z., Peñuelas, J., 2020b. Chlorophyll hormesis: are chlorophylls major components of stress biology in higher plants? Sci. Total Environ. $726,138637$.

Agathokleous, E., Kitao, M., Calabrese, E.J., 2018. Environmental hormesis and its fundamental biological basis: rewriting the history of toxicology. Environ. Res. $165,274-278$

Alameda, D., Villar, R., 2012. Linking root traits to plant physiology and growth in Fraxinus angustifolia Vahl. seedlings under soil compaction conditions. Environ. Exp. Bot. 79, 49-57.

Anderson, T.A., Guthrie, E.A., Walton, B.T., 1993. Bioremediation in the rhizosphere. Environ. Sci. Technol. 27, 2630-2636.
Badri, D.V., Vivanco, J.M., 2009. Regulation and function of root exudates. Plant Cell Environ. 32, 666-681.

Baudoin, E., Benizri, E., Guckert, A., 2003. Impact of artificial root exudates on the bacterial community structure in bulk soil and maize rhizosphere. Soil Biol. Biochem. 35, 1183-1192.

Benizri, E., Dedourge, O., Dibattista-Leboeuf, C., Piutti, S., Nguyen, C., Guckert, A., 2002. Effect of maize rhizodeposits on soil microbial community structure. Appl. Soil Ecol. 21, 261-265.

Berendsen, R.L., Pieterse, C.M.J., Bakker, P.A.H.M., 2012. The rhizosphere microbiome and plant health. Trends Plant Sci. 17, 478-486.

Berendsen, R.L., Vismans, G., Yu, K., Song, Y., de Jonge, R., Burgman, W.P., Burmølle, M., Herschend, J., Bakker, P.A.H.M., Pieterse, C.M.J., 2018. Diseaseinduced assemblage of a plant-beneficial bacterial consortium. ISME J. 12, 1496-1507.

Berg, G., Opelt, K., Zachow, C., Lottmann, J., Götz, M., Costa, R., Smalla, K., 2006. The rhizosphere effect on bacteria antagonistic towards the pathogenic fungus Verticillium differs depending on plant species and site. FEMS (Fed. Eur. Microbiol. Soc.) Microbiol. Ecol. 56, 250-261.

Binet, P., Portal, J.M., Leyval, C., 2000. Fate of polycyclic aromatic hydrocarbons $(\mathrm{PAH})$ in the rhizosphere and mycorrhizosphere of ryegrass. Plant Soil 227, 207-213.

Bragg, J.R., Prince, R.C., Harner, E.J., Atlas, R.M., 1994. Effectiveness of bioremediation for the Exxon Valdez oil spill. Nature 368, 413-418.

Brain, P., Cousens, R., 1989. An equation to describe dose responses where there is stimulation of growth at low doses. Weed Res. 29, 93-96.

Broeckling, C.D., Broz, A.K., Bergelson, J., Manter, D.K., Vivanco, J.M., 2008. Root exudates regulate soil fungal community composition and diversity. Appl. Environ. Microbiol. 74, 738.

Butler, J.L., Williams, M.A., Bottomley, P.J., Myrold, D.D., 2003. Microbial community dynamics associated with rhizosphere carbon flow. Appl. Environ. Microbiol. 69, 6793.

Calabrese, E.J., Baldwin, L.A., 2003. Toxicology rethinks its central belief. Nature 421, 691-692.

Calabrese, E.J., Blain, R., 2005. The occurrence of hormetic dose responses in the toxicological literature, the hormesis database: an overview. Toxicol. Appl. Pharmacol. 202, 289-301.

Carvalho, M.E.A., Castro, P.R.C., Azevedo, R.A., 2020. Hormesis in plants under Cd exposure: from toxic to beneficial element? J. Hazard Mater. 384, 121434.

Cedergreen, N., Ritz, C., Streibig, J.C., 2005. Improved empirical models describing hormesis. Environ. Toxicol. Chem. 24, 3166-3172.

Chekol, T., Vough, L.R., 2001. A study of the use of Alfalfa (Medicago sativa L.) for the phytoremediation of organic contaminants in soil. Remed. J. 11, 89-101.

Chen, S., Li, J., Fritz, E., Wang, S., Hüttermann, A., 2002. Sodium and chloride distribution in roots and transport in three poplar genotypes under increasing $\mathrm{NaCl}$ stress. For. Ecol. Manag. 168, 217-230.

Chouychai, W., Thongkukiatkul, A., Upatham, S., Lee, H., Pokethitiyook, P., Kruatrachue, M., 2007. Phytotoxicity assay of crop plants to phenanthrene and pyrene contaminants in acidic soil. Environ. Toxicol. 22, 597-604.

Corgié, S.C., Beguiristain, T., Leyval, C., 2004. Spatial distribution of bacterial communities and phenanthrene degradation in the rhizosphere of Lolium perenne $\mathrm{L}$. Appl. Environ. Microbiol. 70, 3552.

Corgié, S.C., Joner, E.J., Leyval, C., 2003. Rhizospheric degradation of phenanthrene is a function of proximity to roots. Plant Soil 257, 143-150.

Cunningham, S.D., Berti, W.R., 1993. Remediation of contaminated soils with green plants: an overview. In: Vitro Cellular \& Developmental Biology - Plant, vol. 29, pp. 207-212.

Da Silva, M.L.B., Kamath, R., Alvarez, P.J.J., 2006. Effect of simulated rhizodeposition on the relative abundance of polynuclear aromatic hydrocarbon catabolic genes in a contaminated soil. Environ. Toxicol. Chem. 25, 386-391.

Dean, B.J., 1985. Recent findings on the genetic toxicology of benzene, toluene, xylenes and phenols. Mutat. Res. 154, 153-181.

Duffy, J.J., Peake, E., Mohtadi, M.F., 1980. Oil spills on land as potential sources of groundwater contamination. Environ. Int. 3, 107-120.

Edward, K., 1998. Air pollution. In: Peirce, J.J., Weiner, R.F., Vesilind, P.A. (Eds.) Environmental Pollution and Control, fourth ed. Butterworth-Heinemann, Woburn, pp. 245-269 (Chapter 18).

Errington, I., King, C.K., Wilkins, D., Spedding, T., Hose, G.C., 2018. Ecosystem effects and the management of petroleum-contaminated soils on subantarctic islands. Chemosphere 194, 200-210.

Fresco, L.F.M., 1973. A model for plant growth. Estimation of the parameters of the logistic function. Acta Bot. Neerl. 22, 486-489.

Gregorczyk, A., 1991. A logistic function-its application to the description and prognosis of plant growth. Acta Soc. Bot. Pol. 60, 67-76.

Hamdi, H., Benzarti, S., Aoyama, I., Jedidi, N., 2012. Rehabilitation of degraded soils containing aged PAHs based on phytoremediation with alfalfa (Medicago sativa L.). Int. Biodeterior. Biodegrad. 67, 40-47.

Hoffmann, W.A., Poorter, H., 2002. Avoiding bias in calculations of relative growth rate. Ann. Bot. 90, 37-42.

Hose, G.C., Symington, K., Lott, M.J., Lategan, M.J., 2016. The toxicity of arsenic(III), chromium(VI) and zinc to groundwater copepods. Environ. Sci. Pollut. Control Ser. 23, 18704-18713.

Hunt, R., 1990. Relative growth rates. In: Hunt, R. (Ed.), Basic Growth Analysis: Plant Growth Analysis for Beginners. Springer Netherlands, Dordrecht, pp. 25-34.

Joner, E.J., Corgié, S.C., Amellal, N., Leyval, C., 2002. Nutritional constraints to degradation of polycyclic aromatic hydrocarbons in a simulated rhizosphere. 
Soil Biol. Biochem. 34, 859-864.

Kirk, J.L., Klirnomos, J.N., Lee, H., Trevors, J.T., 2002. Phytotoxicity assay to assess plant species for phytoremediation of petroleum-contaminated soil. Ann. Finance 6, 57-63.

Kirkby, E.A., 2005. Essential elements. In: Hillel, D. (Ed.), Encyclopedia of Soils in the Environment. Elsevier, Oxford, pp. 478-485.

Kozlowski, T.T., Pallardy, S.G., 1997. Environmental regulation of vegetative growth. In: Kozlowski, T.T., Pallardy, S.G. (Eds.), Growth Control in Woody Plants. Academic Press, San Diego, pp. 195-322 (Chapter 5).

Liang, Y., Urano, D., Liao, K.-L., Hedrick, T.L., Gao, Y., Jones, A.M., 2017. A nondestructive method to estimate the chlorophyll content of Arabidopsis seedlings. Plant Methods 13, 26.

Lioussanne, L, Jolicoeur, M. St-Arnaud, M., 2008. Mycorrhizal colonization with Glomus intraradices and development stage of transformed tomato roots significantly modify the chemotactic response of zoospores of the pathogen Phytophthora nicotianae. Soil Biol. Biochem. 40, 2217-2224.

Marchand, C., Hogland, W., Kaczala, F., Jani, Y., Marchand, L., Augustsson, A., Hijri, M., 2016. Effect of Medicago sativa L. and compost on organic and inorganic pollutant removal from a mixed contaminated soil and risk assessment using ecotoxicological tests. Int. J. Phytoremediation 18, 1136-1147.

Marchand, C., Mench, M., Jani, Y., Kaczala, F., Notini, P., Hijri, M., Hogland, W., 2018. Pilot scale aided-phytoremediation of a co-contaminated soil. Sci. Total Environ. $618,753-764$.

Martin, B.C., George, S.J., Price, C.A., Ryan, M.H., Tibbett, M., 2014. The role of root exuded low molecular weight organic anions in facilitating petroleum hydrocarbon degradation: current knowledge and future directions. Sci. Total Environ. 472, 642-653.

McKee, R.H., White, R., 2013. The mammalian toxicological hazards of petroleumderived substances: an overview of the petroleum industry response to the high production volume challenge program. Int. J. Toxicol. 33, 4S-16S.

McLntyre, T., Lewis, G.M., 1997. The advancement of pytoremediation as an innovative environmental technology for stabilization, remediation, or restoration of contaminated sites in Canada: a discussion paper. J. Soil Contam. 6, 227-241.

Micallef, S.A., Shiaris, M.P., Colón-Carmona, A., 2009. Influence of Arabidopsis thaliana accessions on rhizobacterial communities and natural variation in root exudates. J. Exp. Bot. 60, 1729-1742.

Miethling, R., Wieland, G., Backhaus, H., Tebbe, C.C., 2000. Variation of microbial rhizosphere communities in response to crop species, soil origin, and inoculation with Sinorhizobium meliloti L33. Microb. Ecol. 40, 43-56.

Muszyńska, E., Labudda, M., 2019. Dual role of metallic trace elements in stress biology - from negative to beneficial impact on plants. Int. J. Mol. Sci. 20.

Pallardy, S.G., 2008. Photosynthesis. In: Pallardy, S.G. (Ed.), Physiology of Woody Plants, third ed. Academic Press, San Diego, pp. 107-167 (Chapter 5).

Panchenko, L., Muratova, A., Turkovskaya, O., 2017. Comparison of the phytoremediation potentials of Medicago falcata L. and Medicago sativa L. in aged oilsludge-contaminated soil. Environ. Sci. Pollut. Control Ser. 24, 3117-3130.

Pérez-Patricio, M., Camas-Anzueto, L.J., Sanchez-Alegría, A., Aguilar-González, A., Gutiérrez-Miceli, F., Escobar-Gómez, E., Voisin, Y., Rios-Rojas, C., GrajalesCoutiño, R., 2018. Optical method for estimating the chlorophyll contents in plant leaves. Sensors 18, 650.

Phillips, L.A., Greer, C.W., Farrell, R.E., Germida, J.J., 2012. Plant root exudates impact the hydrocarbon degradation potential of a weathered-hydrocarbon contaminated soil. Appl. Soil Ecol. 52, 56-64.

R Core Team, 2018. R: A Language and Environment for Statistical Computing. R
Foundation for Statistical Computing, Vienna, Austria.

Reilley, K.A., Banks, M.K., Schwab, A.P., 1996. Dissipation of polycyclic aromatic hydrocarbons in the rhizosphere. J. Environ. Qual. 25, 212-219.

Ritz, C., 2010. Toward a unified approach to dose-response modeling in ecotoxicology. Environ. Toxicol. Chem. 29, 220-229.

Ritz, C., Baty, F., Streibig, J.C., Gerhard, D., 2015. Dose-response analysis using R. PloS One 10, e0146021.

Rohrbacher, F., St-Arnaud, M., 2016. Root Exudation: the Ecological Driver of Hydrocarbon Rhizoremediation, vol. 6. Agronomy.

Sağlam, A., Yetişsin, F., Demiralay, M., Terzi, R., 2016. Copper stress and responses in plants. In: Ahmad, P. (Ed.), Plant Metal Interaction. Elsevier, pp. 21-40 (Chapter 2).

Sanderson, M.A., Stair, D.W., Hussey, M.A., 1997. Physiological and morphological responses of perennial forages to stress. In: Sparks, D.L. (Ed.), Advances in Agronomy. Academic Press, pp. 171-224.

Scherer, H.W., 2005. Fertilizers and fertilization. In: Hillel, D. (Ed.), Encyclopedia of Soils in the Environment. Elsevier, Oxford, pp. 20-26.

Shahid, M., Niazi, N.K., Rinklebe, J., Bundschuh, J., Dumat, C., Pinelli, E., 2020. Trace elements-induced phytohormesis: a critical review and mechanistic interpretation. Crit. Rev. Environ. Sci. Technol. 50, 1984-2015.

Siciliano, S.D., Germida, J.J., Banks, K., Greer, C.W., 2003. Changes in microbial community composition and function during a polyaromatic hydrocarbon phytoremediation field trial. Appl. Environ. Microbiol. 69, 483.

Sun, M., Fu, D., Teng, Y., Shen, Y., Luo, Y., Li, Z., Christie, P., 2011. In situ phytoremediation of PAH-contaminated soil by intercropping alfalfa (Medicago sativa L.) with tall fescue (Festuca arundinacea Schreb.) and associated soil microbial activity. J. Soils Sediments 11, 980-989.

Szparaga, A., Kocira, S., 2018. Generalized logistic functions in modelling emergence of Brassica napus L. PloS One 13, e0201980.

EPA/600/R-99/107 USEPA, 2000. Introduction to Phytoremediation. United States Environmental Protection Agency.

EPA 542-R-01-006 USEPA, 2001. Brownfields Technology Primer: Selecting and Using Phytoremediation for Site Cleanup. United States Environmental Protection Agency.

Van Waes, J.M., Debergh, P.C., 1986. Adaptation of the tetrazolium method for testing the seed viability, and scanning electron microscopy study of some Western European orchids. Physiol. Plantarum 66, 435-442.

Viebahn, M., Veenman, C., Wernars, K., van Loon, L.C., Smit, E., Bakker, P.A.H.M., 2005. Assessment of differences in ascomycete communities in the rhizosphere of field-grown wheat and potato. FEMS (Fed. Eur. Microbiol. Soc.) Microbiol Ecol. 53, 245-253.

Wickliff, J.L., Aronoff, S., 1962. Quantitative measurement of leaf chlorophylls by spectrophotometry of their pheophytins in aqueous alcoholic extracts. Plant Physiol. 37, 584.

Wiegant, F.A.C., de Poot, S.A.H., Boers-Trilles, V.E., Schreij, A.M.A., 2012. Hormesis and cellular quality control: a possible explanation for the molecular mechanisms that underlie the benefits of mild stress. Dose Response 11, 413-430.

Xue, K., Wu, L., Deng, Y., He, Z., Van Nostrand, J., Robertson, P.G., Schmidt, T.M., Zhou, J., 2013. Functional gene differences in soil microbial communities from conventional, low-Input, and organic farmlands. Appl. Environ. Microbiol. 79, 1284.

Yoshitomi, K.J., Shann, J.R., 2001. Corn (Zea mays L.) root exudates and their impact on ${ }^{14} \mathrm{C}$-pyrene mineralization. Soil Biol. Biochem. 33, 1769-1776. 


\title{
Chapter 4
}

\section{Assessing the effect of diesel fuel on the seed viability and germination of Medicago sativa using the event-time model}

\author{
Michael O. Eze ${ }^{1,2 *}$, Grant C. Hose ${ }^{3}$ and Simon C. George ${ }^{2}$ \\ ${ }^{1}$ Department of Genomic and Applied Microbiology and Goettingen Genomics Laboratory, \\ Georg-August University of Goettingen, 37077 Goettingen, Germany. \\ ${ }^{2}$ Department of Earth and Environmental Sciences and MQ Marine Research Centre, \\ Macquarie University, Sydney, NSW 2109, Australia. \\ ${ }^{3}$ Department of Biological Sciences, Macquarie University, Sydney, NSW 2109, Australia. \\ *Correspondence: meze@gwdg.de
}

Plants 9, 1062. https://doi.org/10.3390/plants9091062

\section{Relationship to the Overall Thesis}

This chapter complements the results of Chapter 3. While Chapter 3 identified Medicago sativa as the most hydrocarbon-tolerant species among the studied plants, this chapter further examined the effect of diesel fuel on seed viability and germination rate of $M$. sativa. The results from this study together with those presented in Chapter 3 indicate that $M$. sativa is a potentially effective plant species for the rhizoremediation of diesel fuel-contaminated sites.

\section{Author Contributions}

Conceived and designed the study: MOE, GCH and SCG

Performed the experiments: MOE

Analysed the data: MOE

Wrote the paper: MOE, GCH and SCG 


\title{
Assessing the Effect of Diesel Fuel on the Seed Viability and Germination of Medicago sativa Using the Event-Time Model
}

\author{
Michael O. Eze ${ }^{1,2, *(\mathbb{D})}$, Grant C. Hose ${ }^{3(\mathbb{C})}$ and Simon C. George ${ }^{2(B)}$ \\ 1 Department of Genomic and Applied Microbiology and Goettingen Genomic Laboratory, \\ Georg-August University of Goettingen, 37077 Goettingen, Germany \\ 2 Department of Earth and Environmental Sciences and MQ Marine Research Centre, Macquarie University, \\ Sydney, NSW 2109, Australia; simon.george@mq.edu.au \\ 3 Department of Biological Sciences, Macquarie University, Sydney, NSW 2109, Australia; \\ grant.hose@mq.edu.au \\ * Correspondence: meze@gwdg.de; Tel.: +49-152-1695-5801
}

Received: 14 July 2020; Accepted: 18 August 2020; Published: 19 August 2020

\begin{abstract}
The remediation of contaminated sites using plant-based techniques has gained increasing attention in recent decades. However, information on the effects of contaminant imbibition on seed viability and germination rates are often lacking in the literature. To this end, our research investigated, by means of an event-time model, the effect of diesel fuel imbibition on the seed viability and germination rate of Medicago sativa, a plant species with great potential for remediation of organic contaminants. The event-time model provided an accurate and biologically relevant method for analysing germination data. Our results reveal that the direct imbibition of diesel fuel by M. sativa seeds for $\leq 48 \mathrm{~h}$, or their exposure to soil diesel fuel concentrations of $0-10 \mathrm{~g} / \mathrm{kg}$ diesel fuel, affects their germination rates, as shown by increasing $t_{50}$ values from $90.6( \pm 2.78)$ to $114.2( \pm 2.67)$ hours, without significantly affecting seed viability. On the other hand, diesel fuel imbibition of longer duration, or the exposure of $M$. sativa seeds to $\geq 20 \mathrm{~g} / \mathrm{kg}$ diesel fuel-contaminated soils, leads to no further effect on time to seed emergence. Instead, these conditions compromise seed viability, resulting in a decrease in the proportion of germinated seeds from $0.91( \pm 0.03)$ in $10 \mathrm{~g} / \mathrm{kg}$ diesel fuel contaminated soil to $0.84( \pm 0.04)$ and $0.70( \pm 0.05)$ in 20 and $30 \mathrm{~g} / \mathrm{kg}$ diesel fuel-contaminated soils, respectively. The fact that low concentrations of diesel fuel and $0-48 \mathrm{~h}$ of direct imbibition delayed seed emergence without adversely affecting the percentage of viable seeds suggests that this inhibitory effect on germination at low diesel fuel exposure could be attributed more to physical constraints rather than biological damage on the seeds. The models used in this study provide an accurate and biologically relevant method for the analyses of germination data. This is vital since expensive germination experiments, be it in the field of toxicology or agriculture, deserve to be accurately analysed.
\end{abstract}

Keywords: phytoremediation; diesel fuel; Medicago sativa; germination; seed viability; event-time model

\section{Introduction}

There is a growing body of evidence that plant roots, in conjunction with their associated microbial communities, offer an effective treatment strategy for in situ remediation of contaminated soils $[1,2]$. Under a variety of environmental conditions, vegetation has been shown to enhance microbial degradation rates of organic chemical residues in soils [3]. Plant-based remediation (phytoremediation) is not a new concept. Constructed wetlands, reed beds and floating-plant systems have been widely 
used for the treatment of some types of wastewater. Current research now focuses on expanding phytoremediation to address contaminated soils and atmospheric pollutants [4]. These techniques provide environmentally friendly and cost-efficient advantages over excavation and off-site treatments of contaminated soils.

The focus of recent advances in bioremediation techniques has been to effectively restore polluted environments in an eco-friendly manner, and at a low cost [5]. To achieve this goal, various laboratory and greenhouse-based studies have been performed to assess the suitability of plant species for phytoremediation [6-8]. In many of these experiments, plants are first grown in uncontaminated soils for a week or two and then transplanted to contaminated soils. Hence, there is a dearth of literature on the effects of contaminant imbibition on seed viability and germination rates-something necessary to complement microcosm studies on phytoremediation of organic contaminants. The aim of the present study is to bridge this gap by examining the effect of exposure to diesel fuel on the seed viability and germination rate of Medicago sativa, a plant with great reclamation potential for soils contaminated with petroleum hydrocarbons [9-14].

Diesel fuel is hydrophobic [15], and in low permeability matrices such as soil will tend to not migrate into deeper sediments. Therefore, the majority of the hydrocarbon contaminants from diesel spills will be held within the surface and subsurface layers of soils, and within the rhizospheric zones of plants. As a result, seeds planted in such soils either for agricultural purposes or for the purpose of remediation and land reclamation will come into direct contact with diesel fuel and become coated by it. Thus, it is imperative that the effect of such hydrocarbon contaminants on seed viability and germination be properly understood.

Germination experiments can be divided into two groups: those in which new batches of seeds are used for each test, and those in which the same batch of seeds is followed over time. In the latter case, the same seeds are repeatedly observed over a pre-specified duration of the experiment until the event of interest occurs; the resulting data are often referred to as time-to-event data [16]. Time-to-event data have two inherent features. Firstly, the event of interest need not occur at all during the experiment. This phenomenon, known as right-censoring [17], is applicable to germination experiments since some seeds may not germinate for the entire duration of the experiment. Consequently, a plausible statistical model must allow for the event of interest (in this case, seed germination) occurring after termination of the experiment, or not occurring at all. Secondly, the event of interest may not be observed exactly at the time point when the event took place [17]. For instance, seeds in pots or petri dishes may only be inspected once a day and not on a continuous $24-h$ per day basis. These types of time-to-event data are often referred to as grouped data or interval-censored data $[16,18]$.

This study used the event-time model to analyse the effect of exposure to diesel fuel on the viability and germination rate of $M$. sativa seeds. The event-time model appropriately reflects the experimental design of right-censored germination experiments while allowing the meaningful biological interpretation of germination data.

\section{Results}

\subsection{Effect of Diesel Fuel on Germination}

The germination curves for M. sativa seeds sown in 0 (control), 5, 10, 20 and $30 \mathrm{~g} / \mathrm{kg}$ diesel fuel contaminated soils are shown in Figure 1. When compared to nonlinear regression models, the event-time model provided the best fit for the germination data. As expected, the proportions of germinated seeds varied with time, being largest at intermediate monitoring intervals ( $48-120 \mathrm{~h}$ for $0 \mathrm{~g} / \mathrm{kg} ; 72-144 \mathrm{~h}$ for both 5 and $10 \mathrm{~g} / \mathrm{kg}$; $96-168 \mathrm{~h}$ for both 20 and $30 \mathrm{~g} / \mathrm{kg}$ diesel fuel-contaminated soils) and smallest at the initial and final intervals when germination activity was low. 


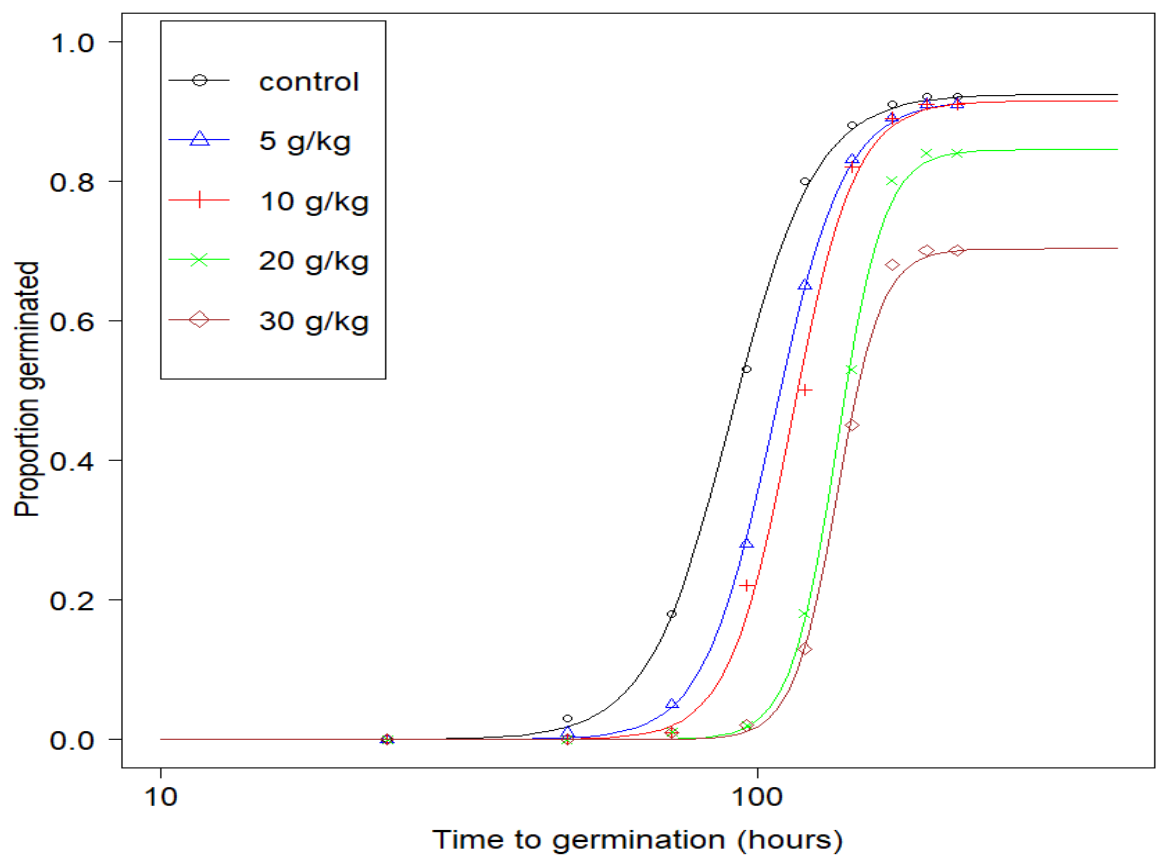

Figure 1. Germination curves for Medicago sativa seeds in 0 (control), 5, 10, 20 and $30 \mathrm{~g} / \mathrm{kg}$ diesel fuel contaminated soils.

Table 1 provides a summary of important germination parameters from Figure 1 . These parameters provide insight into the effect that diesel fuel imbibition had on the viability and germination rates of M. sativa seeds.

Table 1. Parameter estimates of the log-logistic model obtained by fitting the event-time model. (Values in parentheses indicate standard errors).

\begin{tabular}{cccc}
\hline Concentration of Diesel Fuel in Soils $\mathbf{( g / k g )}$ & $\boldsymbol{b}$ (Slope at $\boldsymbol{t}_{\mathbf{5 0}}$ ) & $\boldsymbol{d}$ (Upper Limit) & $\boldsymbol{t}_{\mathbf{5 0}}(\mathbf{h})$ \\
\hline 0 (control) & $-6.16(0.61)$ & $0.92(0.03)$ & $90.6(2.78)$ \\
5 & $-7.41(0.74)$ & $0.91(0.03)$ & $106.6(2.74)$ \\
10 & $-8.26(0.82)$ & $0.91(0.03)$ & $114.2(2.67)$ \\
20 & $-11.12(1.18)$ & $0.84(0.04)$ & $135.9(2.47)$ \\
30 & $-11.87(1.38)$ & $0.70(0.05)$ & $136.0(2.54)$ \\
\hline
\end{tabular}

The $t_{50}$ values for seeds planted in 0 (control), 5 and $10 \mathrm{~g} / \mathrm{kg}$ diesel fuel contaminated soils were $90.6 \pm 2.78,106.6 \pm 2.74$ and $114.2 \pm 2.67 \mathrm{~h}$, respectively (Table 1). As shown in Table 1, the proportions of seeds in 5 and $10 \mathrm{~g} / \mathrm{kg}$ diesel fuel-contaminated soils that germinated during the experimental period (indicated by the parameter $d$ ) were similar to that of the control samples. However, their germination slowed down, as indicated by the higher $t_{50}$ values. On the other hand, while the $t_{50}$ values for seeds in the $20 \mathrm{~g} / \mathrm{kg}$ diesel fuel-contaminated soil remained the same as those for the $30 \mathrm{~g} / \mathrm{kg}$ soil, the $d$ value of the $20 \mathrm{~g} / \mathrm{kg}$ diesel fuel-contaminated soil was greater than that of the $30 \mathrm{~g} / \mathrm{kg}$ diesel fuel-contaminated soil. This indicates a possible significant effect of diesel fuel on $M$. sativa seed viability when sown in soils with diesel fuel concentrations of $20 \mathrm{~g} / \mathrm{kg}$ or more. In addition, the value " $1-\mathrm{d}$ " indicates the proportion of the seeds that did not germinate during the experimental period owing to either non-viability or insufficient experimental duration. These seeds were considered to be right-censored.

\subsection{Effect of Diesel Fuel Exposure on Seed Viability Using Triphenyltetrazolium Chloride}

The effect of in vitro diesel fuel exposure on M. sativa seed viability can be seen in Figure 2. Diesel fuel imbibition reduced seeds viability, as shown by the number of seeds that were stained red or pink during the triphenyltetrazolium chloride test (Figure 2). These results are summarized 
in Figure 3. The graph indicates that the imbibition of diesel fuel for between 0 and about $48 \mathrm{~h}$ had little effect on seed viability. The percentage viability of seeds exposed to 0,24 and $48 \mathrm{~h}$ of diesel fuel imbibition were all greater than $90 \%$. However, exposure of $M$. sativa seeds to 72 and 96 h of diesel fuel imbibition resulted in a decline in percentage seed viability to approximately 84 and $70 \%$, respectively. This indicates that longer duration of direct exposure to diesel fuel affects the viability of M. sativa seeds.

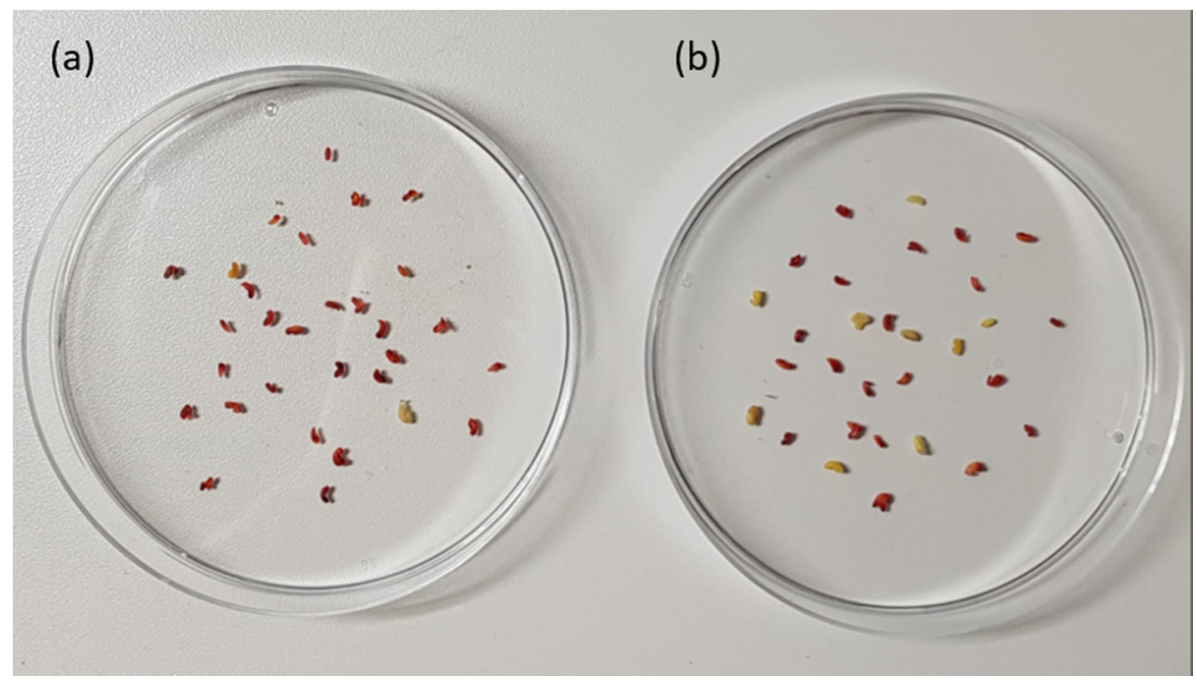

Figure 2. Number of viable Medicago sativa seeds, as shown by the red/pink colour of seeds following (a) 0 and (b) $96 \mathrm{~h}$ of diesel fuel imbibition.

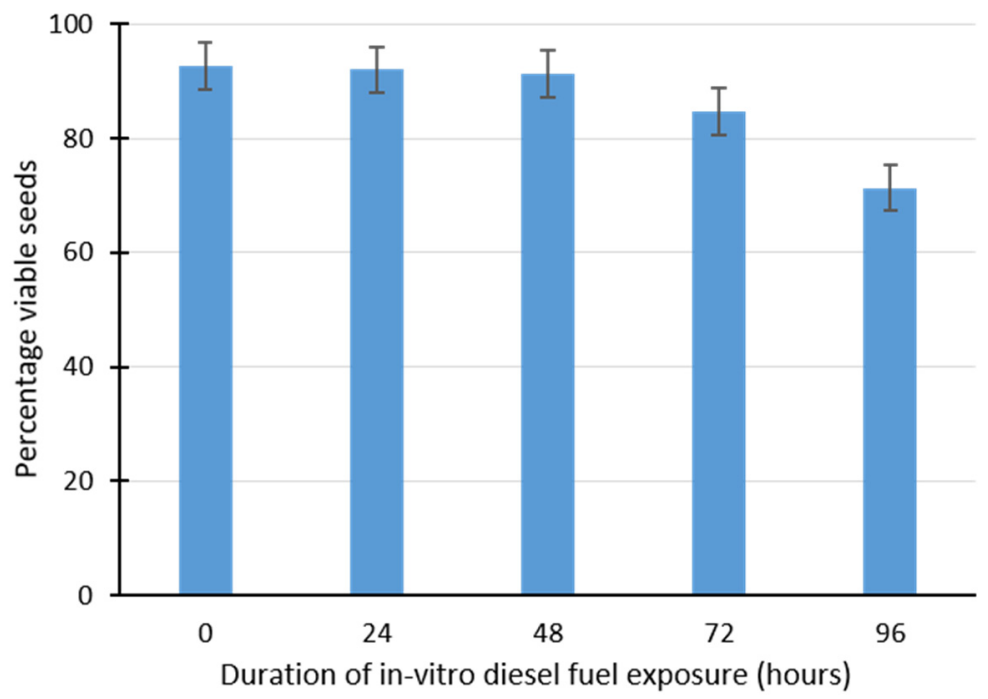

Figure 3. Percentage viability of Medicago sativa seeds following in vitro diesel fuel imbibition based on the triphenyltetrazolium chloride test. Error bars indicate standard errors.

\section{Discussion}

This study demonstrates that diesel fuel exposure impacts on the seed viability and germination rate of $M$. sativa, and that these effects are dependent on contaminant concentration and/or duration of exposure. The study also reveals interesting agreement between the grouped-data event-time model and triphenyltetrazolium chloride-dependent viability tests.

To assess the ability of $M$. sativa plants to resist high levels of diesel fuel toxicity, the diesel fuel concentrations used in the germination study were comparable to, or higher than, those used in previous studies involving organic contaminants [19-22]. Similarly, diesel fuel imbibition was also 
used to mimic extreme conditions of diesel fuel exposure [23], which enabled us to determine to what extent does extreme exposure to diesel fuel affect $M$. sativa seed viability.

Non-linear regression models are often used to model germination. However, in real life germination experiments, the underlying assumptions governing non-linear models (independence between proportions and variance homogeneity) are not satisfied. In contrast, the event-time model reflects the experimental design of germination experiments and allows meaningful biological interpretation of the germination data. Of course, the restriction F (0) $=0$ in the event-time model indicates that the experiment is right-skewed [24]. Thus, it permits log-logistic, log-normal as well as Weibull-type models, which are all models with logarithm transformation [25]. It does, however, rule out models such as the Gompertz, logistic and normal models.

The right-skewness of this model reflects real-life situations in which some seeds do not germinate owing to non-viability or insufficient experimental duration. In these experiments, the seeds viability test using triphenyltetrazolium chloride revealed that $M$. sativa seeds exposed to 24 and $48 \mathrm{~h}$ of diesel fuel imbibition have similar percentage viability $(92 \%$ and $91 \%$, respectively) to that of the control samples. This indicates that the viability of $M$. sativa seeds was unaffected by up to $48 \mathrm{~h}$ of diesel fuel absorption. The ability of $M$. sativa to withstand diesel fuel-related biological damage for $48 \mathrm{~h}$ is an indication of its potential for biotechnological application in the phytoremediation of diesel fuel contaminated sites. On the other hand, diesel fuel imbibition for $72 \mathrm{~h}$ or more impacted seed viability, leading to a decline in the percentage of viable seeds (Figure 3).

The relative resistance of $M$. sativa to diesel fuel toxicity shows its suitability for the rhizoremediation of diesel fuel contaminated sites. It is worth noting that in actual field remediation approaches, seeds are not soaked in diesel fuel. Therefore, we expect that field lethal values (in hours) would be higher than the experimental values from this study. Similarly, actual percentage viability in the field would be expected to be higher than our experimental values. The implication of this is that $M$. sativa is potentially able to survive in diesel fuel contaminated sites. This ability of a plant to withstand contaminant toxicity or similar abiotic stress in the environment is an important factor in designing and establishing successful remediation and reclamation approaches [19].

The results of the germination experiment (Figure 1 and Table 1) provide further biological details. Since the average germination time for $M$. sativa seeds is between two and four days at a temperature range of 18 to $30^{\circ} \mathrm{C}$, the experimental duration was set at nine days to enable the possible germination of all viable seeds. From the results, more than $90 \%$ of $M$. sativa seeds exposed to 0 to $10 \mathrm{~g} / \mathrm{kg}$ diesel fuel contaminated soils germinated during the experimental period, indicating that up to $10 \mathrm{~g} / \mathrm{kg}$ soil diesel fuel concentration did not affect viability. However, as revealed by the $t_{50}$ values, soil diesel fuel concentrations impacted significantly on time to germination (Table 1). This indicates increasing time to radicle emergence with increasing concentrations of diesel fuel.

Moreover, seeds exposed to 20 and $30 \mathrm{~g} / \mathrm{kg}$ of soil diesel fuel concentrations gave lower d values (Figure 1 and Table 1) than those in 0 to $10 \mathrm{~g} / \mathrm{kg}$ soils. While the proportion of seeds in $20 \mathrm{~g} / \mathrm{kg}$ and $30 \mathrm{~g} / \mathrm{kg}$ diesel fuel contaminated soils that germinated during the experimental period varied, their $t_{50}$ values remained the same (approximately $136 \mathrm{~h}$ ). This shows that higher concentrations of diesel fuel in soils affects seed viability rather than the time to germination. It can thus be concluded that up to $10 \mathrm{~g} / \mathrm{kg}$ diesel fuel concentration affects the time to germination of $M$. sativa seeds without significantly affecting their viability. On the other hand, higher concentrations of diesel fuel result in a significant reduction in the viability of these seeds, without further affecting the time required for the seeds to emerge.

The mechanisms by which diesel fuel impacts on seed viability and germination rate can be classified into two: biological damage (toxicity), and physical constraints (oxygen and water repellence). Diesel fuel contains both volatile and non-volatile components [23,26,27]. Previous studies have shown that it is the volatile fraction, rather than the non-volatile components, that is primarily responsible for the inhibition of seed germination and plant growth [23,27], and that at temperatures of $<20^{\circ} \mathrm{C}$, this effect is minimal, owing to reduced hydrocarbon volatility $[28,29]$. Medicago sativa seeds in diesel 
fuel tend to have a lag phase preceding germination (Figure 1), and this lag in germination increases with exposure to increasing diesel fuel concentrations. This can be attributed to the ability of the hydrophobic diesel fuel to create a water-repellent coating around the seeds. This consequently limits both oxygen and water absorption by M. sativa seeds, resulting in delayed germination. The fact that diesel fuel at low concentrations and 0-48 h of imbibition was delaying seed emergence without adversely affecting seed viability (as shown by the reduction of triphenyltetrazolium chloride to triphenylformazan) suggests that this inhibitory effect on germination could be attributed more to physical constraints rather than biological damage of the seeds. This is an important quality for biotechnological application since seeds used for phytoremediation purposes must be able to withstand biological damage.

\section{Materials and Methods}

\subsection{Soil Preparation}

The soil used for this experiment was a mixture of screened sand, soil, and composted organics, sold as "turf underlay" and obtained from Australian Native Landscapes Pty, Sydney, Australia. The soil was sieved using a $2 \mathrm{~mm}$ sieve to remove large particles. The soil textural class is dominantly sand $(86.2 \%$ sand, $5.1 \%$ silt and $8.7 \%$ clay), with $9.3 \%$ organic matter content by loss on ignition and $0.18 \%$ total nitrogen content. The soil was then air-dried until a constant weight was achieved. Different concentrations of diesel fuel contaminated soils $(0,5,10,20$ and $30 \mathrm{~g} / \mathrm{kg})$ were prepared by spiking the soil samples with appropriate amounts of diesel fuel. The diesel fuel used was petroleum diesel (also called petrodiesel), as opposed to synthetic diesel or biodiesel, and was obtained from a Shell service station along Epping Road, Macquarie Park, Sydney. The chemical composition is predominantly saturated hydrocarbons (C10 to C25 n-alkanes, iso- and cyclo-alkanes) and some aromatic hydrocarbons (e.g., alkylnaphthalenes and alkylbenzenes). The spiked soils were first mixed manually by hand, followed by a thorough mixing using a Sanfine portable electric $1800 \mathrm{~W}$ soil mixing machine (Model No. SF-HM1401/1401S, Taizhou, China). The mixing was performed for 15 min per pot ( $2 \mathrm{~kg}$ soil) with a break and manual shaking after every $5 \mathrm{~min}$ to achieve complete homogeneity.

\subsection{Germination as Grouped Time-to-Event Data}

One hundred seeds of $M$. sativa were placed in different $100 \mathrm{~mm}$ petri dishes containing $20 \mathrm{~g}$ of 0 (control), 5, 10, 20 and $30 \mathrm{~g} / \mathrm{kg}$ diesel fuel-contaminated soils. The petri dishes were incubated at $20{ }^{\circ} \mathrm{C}$ in the Organic Geochemistry laboratory and monitored at $24 \mathrm{~h}$ intervals for a period of nine days. The initial emergence of radicle from the seed testa was used as evidence of germination. The seeds that did not germinate during the nine days were considered to be right-censored [17].

\subsection{Seed Viability Test}

In addition to the germination experiment, a triphenyltetrazolium chloride (TTC) test was conducted in petri dishes to estimate seed viability [23,30]. Triphenyltetrazolium chloride is a clear, water soluble compound (a salt) which is reduced by respiring tissues to yield triphenylformazan, a water-insoluble red pigment. Thirty $M$. sativa seeds were pre-soaked in petri dishes containing diesel fuel for 24, 48, 72 and $96 \mathrm{~h}$ in order to imbibe seeds prior to the test. At the end of the four respective periods, the imbibed seeds and the control samples were subjected to the triphenyltetrazolium chloride test as follows. A 1\% triphenyltetrazolium chloride solution was prepared by dissolving triphenyltetrazolium chloride in distilled water. Each batch of seeds was placed in a beaker containing $50 \mathrm{~mL}$ of $1 \%$ triphenyltetrazolium chloride, and the beaker was covered. The beakers were placed in an incubator at $30^{\circ} \mathrm{C}$ for $1 \mathrm{~h}$. Following incubation, the liquid was decanted and the seeds were rinsed with distilled water until the wash water was clear. The seeds were blotted with a dry paper towel and the colour was observed. The seeds were classified into two categories according to their colour development, namely "red/pink" and "no colour", corresponding to "viable" and "not viable", respectively. This test was repeated to give five replicates per treatment concentration. 


\subsection{Statistical Analysis: Event-Time Model}

Statistical analyses were performed using R [31]. Non-linear regression models are often used to model germination [32,33]. However, these models are problematic as they ignore the fact that successive observations on the germination curve are highly correlated. In other words, the total number of seeds that have germinated at a particular time is highly dependent on the number of seeds that germinated previously [34]. Moreover, variation in the proportions of germinated seeds will vary with time, being largest at intermediate monitoring intervals and smallest at the initial and final intervals when germination activity is low. This means that the fundamental assumptions underlying nonlinear regression, namely independence between proportions and variance homogeneity, are not satisfied [17]. Consequently, this results in overly precise parameter estimates of, for example, time to reach $50 \%$ germination $\left(t_{50}\right)$, due to too small standard errors. Therefore, Ritz and Pipper [17] suggested a more appropriate approach where germination data were modelled as event times, that is, waiting times until germination no longer became possible due to termination of the experiment or non-viability of seeds. This approach provided a more adequate statistical description of the type of response that resulted from germination experiments [35] The present study used the drm package in library(drc) [31] to model the effect of diesel fuel exposure on seed viability as event-time data. This model is described using the following equation proposed by Ritz and Pipper [17]:

$$
F(t)=\frac{d}{1+\exp \left[b\left\{\log (t)-\log \left(t_{50}\right)\right\}\right]}=\frac{d}{1+\left(\frac{t}{t_{50}}\right)^{b}}
$$

The upper limit parameter $d$ denotes the proportion of seeds that germinated during the duration of the experiment out of the total number of seeds present at the beginning of the experiment. The parameter $b$ (excluding its sign) is proportional to the slope of $F$ at time $t$ equal to $t_{50}$, while $t_{50}$ has the same interpretation as effective or lethal doses $\mathrm{EC}_{50}$ or $\mathrm{LC}_{50}$ but relative to $d$ (the upper limit). Thus, $t_{50}$ refers to the time when $50 \%$ of the seeds that germinated during the experiment have germinated. This model reflects the experimental design of right-censored germination experiments while allowing meaningful biological interpretation of germination data. It also links the analysis of germination data with related dose-response analyses used in ecotoxicology where interest lies in obtaining a parametric model fit for an S-shaped curve.

\subsection{Statistical Analysis: Viability Data}

Viability data were analysed as binomial data using the 2-parameter log-logistic model in R [31]. As in the methods of Hose and Symington [36], a series of 2-parameter response curves including log-logistic, Weibull, log-normal and hormetic curves were fitted to the data, and the best fitting model based on Akaike information criterion was chosen. The e value from the model, also referred to as $\mathrm{LC}_{50}$, gives the duration of exposure (in hours) causing $50 \%$ reductions in viability of the test seed population. The 3-parameter log-logistic event-time model was fitted to the germination data. The event time considered is the time (hours) from sowing to germination, evidenced by the initial emergence of the radicle from the seed testa.

\section{Conclusions}

The examination of the effects of diesel fuel exposure on the viability and germination rate reveals that either the direct absorption of diesel fuel for up to two days or their exposure to soils contaminated with up to $10 \mathrm{~g} / \mathrm{kg}$ diesel fuel affect germination rate, leading to delayed emergence of $M$. sativa radicle. However, these short durations and low concentrations of exposure to diesel fuel does not affect the viability of $M$. sativa seeds. This is an important quality for biotechnological application since seeds used for phytoremediation purposes must be able to withstand biological damage. Longer duration of diesel fuel imbibition and/or exposure to higher concentrations of soil diesel fuel results in a significant reduction in viable seeds. The event-time model used here provided an accurate and biologically 
relevant method for analysing germination data. These models incorporate the experimental design of right-skewness and non-continuous observation of germination process. We are confident that the results of this study will prove helpful in the design of plant-based remediation techniques.

Author Contributions: Conceptualization: M.O.E., G.C.H. and S.C.G.; Methodology: M.O.E., G.C.H. and S.C.G.; Data curation: M.O.E.; Formal analysis: M.O.E., G.C.H. and S.C.G.; Funding acquisition: M.O.E.; Investigation: M.O.E., G.C.H. and S.C.G.; Project administration: M.O.E.; Resources: G.C.H. and S.C.G.; Validation: M.O.E., G.C.H. and S.C.G.; Visualization: M.O.E., G.C.H. and S.C.G.; Supervision: G.C.H. and S.C.G.; Writing-original draft: M.O.E.; Writing — review and editing: G.C.H. and S.C.G.; All authors have read and agreed to the published version of the manuscript.

Funding: This research was funded by the Commonwealth Government of Australia through an international Research Training Program (iRTP) scholarship awarded to M.O.E. (Grant number 2017561).

Acknowledgments: The authors would like to thank the Commonwealth Government of Australia for supporting this research project by providing M.O.E. with an international Research Training Program (iRTP) scholarship (Grant number 2017561). This publication was supported financially by the Open Access Grant Program of the German Research Foundation (DFG) and the Open Access Publication Fund of the University of Goettingen.

Conflicts of Interest: The authors declare no conflict of interest. The funders had no role in the design of the study; in the collection, analyses, or interpretation of data; in the writing of the manuscript, or in the decision to publish the results.

\section{References}

1. Anderson, T.A.; Guthrie, E.A.; Walton, B.T. Bioremediation in the rhizosphere. Environ. Sci. Technol. 1993, 27, 2630-2636. [CrossRef]

2. Corgié, S.C.; Joner, E.J.; Leyval, C. Rhizospheric degradation of phenanthrene is a function of proximity to roots. Plant Soil 2003, 257, 143-150. [CrossRef]

3. Cunningham, S.D.; Berti, W.R. Remediation of contaminated soils with green plants: An overview. In Vitro Cell. Dev. Biol. Plant 1993, 29, 207-212. [CrossRef]

4. Cunningham, S.D.; Berti, W.R.; Huang, J.W. Phytoremediation of contaminated soils. Trends Biotechnol. 1995, 13, 393-397. [CrossRef]

5. Azubuike, C.C.; Chikere, C.B.; Okpokwasili, G.C. Bioremediation techniques-classification based on site of application: Principles, advantages, limitations and prospects. World J. Microbiol. Biotechnol. 2016, 32, 180. [CrossRef]

6. Kirk, J.L.; Klirnomos, J.N.; Lee, H.; Trevors, J.T. Phytotoxicity assay to assess plant species for phytoremediation of petroleum-contaminated soil. Bioremediation J. 2002, 6, 57-63. [CrossRef]

7. Chouychai, W.; Thongkukiatkul, A.; Upatham, S.; Lee, H.; Pokethitiyook, P.; Kruatrachue, M. Phytotoxicity assay of crop plants to phenanthrene and pyrene contaminants in acidic soil. Environ. Toxicol. 2007, 22, 597-604. [CrossRef]

8. Kaimi, E.; Mukaidani, T.; Tamaki, M. Screening of Twelve Plant Species for Phytoremediation of Petroleum Hydrocarbon-Contaminated Soil. Plant Prod. Sci. 2007, 10, 211-218. [CrossRef]

9. USEPA. Introduction to Phytoremediation; United States Environmental Protection Agency: Washington, DC, USA, 2000.

10. Chekol, T.; Vough, L.R. A study of the use of Alfalfa (Medicago sativa L.) for the phytoremediation of organic contaminants in soil. Remediat. J. 2001, 11, 89-101. [CrossRef]

11. Sun, M.; Fu, D.; Teng, Y.; Shen, Y.; Luo, Y.; Li, Z.; Christie, P. In situ phytoremediation of PAH-contaminated soil by intercropping alfalfa (Medicago sativa L.) with tall fescue (Festuca arundinacea Schreb.) and associated soil microbial activity. J. Soils Sediments 2011, 11, 980-989. [CrossRef]

12. Hamdi, H.; Benzarti, S.; Aoyama, I.; Jedidi, N. Rehabilitation of degraded soils containing aged PAHs based on phytoremediation with alfalfa (Medicago sativa L.). Int. Biodeterior. Biodegrad. 2012, 67, 40-47. [CrossRef]

13. Panchenko, L.; Muratova, A.; Turkovskaya, O. Comparison of the phytoremediation potentials of Medicago falcata L. and Medicago sativa L. in aged oil-sludge-contaminated soil. Environ. Sci. Pollut. Res. 2017, 24, 3117-3130. [CrossRef] [PubMed]

14. Garrido-Sanz, D.; Redondo-Nieto, M.; Guirado, M.; Pindado Jiménez, O.; Millán, R.; Martin, M.; Rivilla, R. Metagenomic insights into the bacterial functions of a diesel-degrading consortium for the rhizoremediation of diesel-polluted soil. Genes 2019, 10, 456. [CrossRef] [PubMed] 
15. Eze, M.O.; George, S.C. Ethanol-blended petroleum fuels: Implications of co-solvency for phytotechnologies. RSC Adv. 2020, 10, 6473-6481. [CrossRef]

16. Fenlon, J.S. Chapter 7: Time to event analysis in the agricultural sciences. In Risk Assessment with Time to Event Models; Crane, M., Newman, M.C., Chapman, P.F., Fenlon, J., Eds.; Lewis Publishers: Boca Raton, FL, USA, 2002; pp. 103-119.

17. Ritz, C.; Pipper, C.B.; Streibig, J.C. Analysis of germination data from agricultural experiments. Eur. J. Agron. 2013, 45, 1-6. [CrossRef]

18. Ritz, C. Toward a unified approach to dose-response modeling in ecotoxicology. Environ. Toxicol. Chem. 2010, 29, 220-229. [CrossRef]

19. Adam, G.; Duncan, H. The effect of diesel fuel on common vetch (Vicia sativa L.) plants. Environ. Geochem. Health 2003, 25, 123-130. [CrossRef]

20. Wang, Y.; Oyaizu, H. Evaluation of the phytoremediation potential of four plant species for dibenzofurancontaminated soil. J. Hazard. Mater. 2009, 168, 760-764. [CrossRef]

21. Palmroth, M.R.T.; Pichtel, J.; Puhakka, J.A. Phytoremediation of subarctic soil contaminated with diesel fuel. Bioresour. Technol. 2002, 84, 221-228. [CrossRef]

22. Jagtap, S.S.; Woo, S.M.; Kim, T.-S.; Dhiman, S.S.; Kim, D.; Lee, J.-K. Phytoremediation of diesel-contaminated soil and saccharification of the resulting biomass. Fuel 2014, 116, 292-298. [CrossRef]

23. Adam, G.; Duncan, H. Influence of diesel fuel on seed germination. Environ. Pollut. 2002, 120, 363-370. [CrossRef]

24. O'Neill, M.E.; Thomson, P.C.; Jacobs, B.C.; Brain, P.; Butler, R.C.; Turner, H.; Mitakda, B. Fitting and comparing seed germination models with a focus on the inverse normal distribution. Aust. N. Z. J. Stat. 2004, 46, 349-366. [CrossRef]

25. Ritz, C.; Pipper, C.; Yndgaard, F.; Fredlund, K.; Steinrücken, G. Modelling flowering of plants using time-to-event methods. Eur. J. Agron. 2010, 32, 155-161. [CrossRef]

26. Ahmed, M.; George, S.C. Changes in the molecular composition of crude oils during their preparation for GC and GC-MS analyses. Org. Geochem. 2004, 35, 137-155. [CrossRef]

27. Adam, G.; Duncan, H.J. Effect of diesel fuel on growth of selected plant species. Environ. Geochem. Health 1999, 21, 353-357. [CrossRef]

28. Bossert, I.; Bartha, R. The fate of petroleum in soil ecosystems. In Petroleum Microbiology; Atlas, R.M., Ed.; Macmillan Publishing Company: New York, NY, USA, 1984; pp. 435-473.

29. Rogers, H.B.; Beyrouty, C.A.; Nichols, T.D.; Wolf, D.C.; Reynolds, C.M. Selection of cold-tolerant plants for growth in soils contaminated with organics. J. Soil Contam. 1996, 5, 171-186. [CrossRef]

30. Van Waes, J.M.; Debergh, P.C. Adaptation of the tetrazolium method for testing the seed viability, and scanning electron microscopy study of some Western European orchids. Physiol. Plant. 1986, 66, 435-442. [CrossRef]

31. R Core Team. R: A Language and Environment for Statistical Computing. R Foundation for Statistical Computing; R Core Team: Vienna, Austria, 2018.

32. Dantigny, P.; Tchobanov, I.; Bensoussan, M.; Zwietering, M.H. Modeling the Effect of Ethanol Vapor on the Germination Time of Penicillium chrysogenum. J. Food Prot. 2005, 68, 1203-1207. [CrossRef]

33. Keshtkar, E.; Kordbacheh, F.; Mesgaran, M.B.; Mashhadi, H.R.; Alizadeh, H.M. Effects of the sowing depth and temperature on the seedling emergence and early growth of wild barley (Hordeum spontaneum) and wheat. Weed Biol. Manag. 2009, 9, 10-19. [CrossRef]

34. Shafii, B.; Price, W.J. Estimation of cardinal temperatures in germination data analysis. J. Agric. Biol. Environ. Stat. 2001, 6, 356-366. [CrossRef]

35. Jensen, S.M.; Andreasen, C.; Streibig, J.C.; Keshtkar, E.; Ritz, C. A note on the analysis of germination data from complex experimental designs. Seed Sci. Res. 2017, 27, 321-327. [CrossRef]

36. Hose, G.C.; Symington, K.; Lott, M.J.; Lategan, M.J. The toxicity of arsenic (III), chromium (VI) and zinc to groundwater copepods. Environ. Sci. Pollut. Res. 2016, 23, 18704-18713. [CrossRef] [PubMed]

(C) 2020 by the authors. Licensee MDPI, Basel, Switzerland. This article is an open access article distributed under the terms and conditions of the Creative Commons Attribution (CC BY) license (http://creativecommons.org/licenses/by/4.0/). 


\section{Chapter 5}

\section{Metagenome assembly and metagenome-assembled genome sequences from a historical oil field located in Wietze, Germany}

Michael O. Eze ${ }^{\text {a,b,c }}$, Stephan A. Lütgert ${ }^{\mathrm{d}}$, Hannes Neubauer ${ }^{\mathrm{a}, \mathrm{b}}$, Angeliki Balouri ${ }^{\mathrm{a}, \mathrm{b}}$, Alina A. $\mathrm{Kraft}^{\mathrm{a}, \mathrm{b}}$, Anja Sieven ${ }^{\mathrm{a}, \mathrm{b}}$, Rolf Daniel ${ }^{\mathrm{a}, \mathrm{b}, *}$, Bernd Wemheuer ${ }^{\mathrm{a}, \mathrm{b}}$

${ }^{\mathrm{a} G e n o m i c ~ a n d ~ A p p l i e d ~ M i c r o b i o l o g y, ~ G e o r g-A u g u s t ~ U n i v e r s i t y ~ o f ~ G o ̈ t t i n g e n, ~ G o ̈ t t i n g e n, ~}$ Germany.

${ }^{\mathrm{b}}$ Göttingen Genomics Laboratory, Georg-August University of Göttingen, Göttingen, Germany.

cDepartment of Earth and Environmental Sciences, Macquarie University, Sydney, NSW, Australia.

${ }^{\mathrm{d}}$ German Oil Museum, Wietze, Germany.

*Correspondence: rdaniel@gwdg.de

Microbiology Resource Announcements 9, e00333-20. https://doi.org/10.1128/MRA.00333-20

\section{Relationship to the Overall Thesis}

Having identified a potential plant for rhizoremediation, it is vital to identify microorganisms with the metabolic capacity for hydrocarbon degradation. To this end, this chapter is an omics data set of metagenomes and metagenome-assembled genomes from a former crude oil borehole in Wietze, Germany, that provide preliminary understanding of petroleum-utilizing microbes.

\section{Author Contributions}

Conceived and designed the study: MOE, RD and BW

Performed the experiments: MOE, SAL, HN, AB, AAK, and AS

Analysed the data: MOE and BW

Wrote the paper: MOE, RD and BW 


\section{Metagenome Assembly and Metagenome-Assembled Genome Sequences from a Historical Oil Field Located in Wietze, Germany}

\author{
(D) Rolf Daniel,a,b Bernd Wemheuera,b \\ aGenomic and Applied Microbiology, Georg-August University of Göttingen, Göttingen, Germany \\ bGöttingen Genomics Laboratory, Georg-August University of Göttingen, Göttingen, Germany \\ cDepartment of Earth and Environmental Sciences, Macquarie University, Sydney, NSW, Australia \\ dGerman Oil Museum, Wietze, Germany
}

Michael O. Eze, a,b,c Stephan A. Lütgert, ${ }^{d}$ Hannes Neubauer,a,b Angeliki Balouri, a,b Alina A. Kraft, ${ }^{\text {a,b }}$ Anja Sieven, ${ }^{a, b}$

ABSTRACT Crude oil-polluted sites are a global threat, raising the demand for remediation worldwide. Here, we investigated a crude oil metagenome from a former borehole in Wietze, Germany, and reconstructed 42 metagenome-assembled genomes, many of which contained genes involved in crude oil degradation with a high potential for bioremediation purposes.

ioremediation of crude oil-contaminated sites is highly investigated due to severe pollution levels in various ecosystems worldwide. It can be enhanced by the application of microorganisms, and thus it is important to discover novel microbes capable of crude oil degradation (1).

Three crude oil-contaminated samples were taken on 11 October 2016 from a former borehole $(52.6592 \mathrm{~N}, 9.8323 \mathrm{E})$ located at a historical oil field in Wietze, Germany (https://www.erdoelmuseum.de). Approximately $5 \mathrm{~g}$ of contaminated soil was taken per sample, transported to the laboratory on ice, and stored at $-20^{\circ} \mathrm{C}$. Environmental DNA was extracted from $100 \mathrm{mg}$ of soil using the PowerSoil DNA extraction kit as recommended by the manufacturer (Qiagen, Hilden, Germany). Paired-end sequencing libraries were constructed using the Nextera DNA sample preparation kit (Illumina, San Diego, CA, USA) and the following Nextera DNA indices: N708/N508 (sample 1), N709/N508 (sample 2), and N710/N508 (sample 3). Paired-end sequencing was performed using a HiSeq 2500 instrument (rapid run mode, 500 cycles), as recommended by the manufacturer (Illumina), and resulted in 46,673,322 paired-end reads (sample 1, $16,094,584$ reads; sample 2, 17,883,658 reads; sample 3, 12,695,080 reads). Reads were processed with Trimmomatic version 0.36 (2). Processing included the removal of adapter sequences and low-quality regions. Default parameters were used for all software unless otherwise specified. The quality of the processing was confirmed using FastQC version 0.91. A total of 42,049,950 paired-end reads and 1,147,707 unpaired reads were retained and assembled using metaSPAdes version 3.13.2 (3). Assembly resulted in 1,544,944 scaffolds; of these, 22,257 were larger than 2,500 bp. Coverage information for each scaffold was determined using Bowtie 2 version 2.3.2 (4) and SAMtools version 1.7 (5). The average sequencing depth was approximately $7 \times$. Metagenome-assembled genomes (MAGs) were reconstructed with MetaBAT version 2.12.1 (6). MAG quality was determined using CheckM version 1.0.13 (7). Only MAGs with a completeness minus contamination of more than $50 \%$ and a contamination rate of less than 7\% were considered for further analysis. MAGs were classified taxonomically using GTDB-Tk version 1.0.2 and the Genome Taxonomy Database (GTDB) (release 86) $(8,9)$, resulting in 6 archaeal MAGs and 36 bacterial MAGs. Archaeal MAGs were
Citation Eze MO, Lütgert SA, Neubauer $\mathrm{H}$ Balouri A, Kraft AA, Sieven A, Daniel R, Wemheuer B. 2020. Metagenome assembly and metagenome-assembled genome sequences from a historical oil field located in Wietze, Germany. Microbiol Resour Announc 9:e00333-20. https://doi.org/10.1128/MRA .00333-20.

Editor Catherine Putonti, Loyola University Chicago

Copyright $\odot 2020$ Eze et al. This is an openaccess article distributed under the terms of the Creative Commons Attribution 4.0 International license.

Address correspondence to Rolf Daniel, rdaniel@gwdg.de.

Received 30 March 2020

Accepted 3 May 2020

Published 21 May 2020 
classified as members of the Euryarchaeota (1 MAG), Halobacterota (3 MAGs), and Thermoplasmatota (2 MAGs). Bacterial MAGs belonged to Actinobacteriota (4 MAGs), Bacteroidota (5 MAGs), Chloroflexota (5 MAGs), Desulfobacterota (4 MAGs), Firmicutes (2 MAGs), Omnitrophota (1 MAG), Patescibacteria (1 MAG), Proteobacteria (10 MAGs), Spirochaetota (1 MAG), Synergistota (1 MAG), and Thermotogota (1 MAG). One bacterial MAG was assigned to an unclassified taxon associated with Nitrospirae. After annotation with Prodigal version 2.6.3 (10), functional annotation was performed with DIAMOND version 0.9.29 (11) and the KEGG database (October 2018 release) (12). Functional analysis revealed that all MAGs obtained possess genes involved in xenobiotic degradation. One MAG assigned to Rugosibacter, a genus of known xenobiotic degraders (13), showed the highest abundance of pathways associated with xenobiotic degradation (11.8\%).

Data availability. Raw sequencing data are available at the NCBI Sequence Read Archive (SRA) under accession numbers SRR10568503, SRR10568510, and SRR10568511. The metagenome assembly and the MAGs are available at GenBank under accession numbers WOYI00000000 and WOYJ00000000 to WOZY00000000, respectively. Further genome characteristics and the functional annotation are publicly available at the Göttingen Research Online Database (https://doi.org/10.25625/VX8836).

\section{ACKNOWLEDGMENTS}

We thank Anja Poehlein and Melanie Heinemann for their assistance during sequencing. We are grateful to the staff of the oil museum in Wietze (https://www .erdoelmuseum.de) for help during sampling.

\section{REFERENCES}

1. Das N, Chandran P. 2011. Microbial degradation of petroleum hydrocarbon contaminants: an overview. Biotechnol Res Int 2011:941810. https:// doi.org/10.4061/2011/941810.

2. Bolger AM, Lohse M, Usadel B. 2014. Trimmomatic: a flexible trimmer for Illumina sequence data. Bioinformatics 30:2114-2120. https://doi.org/10 .1093/bioinformatics/btu170.

3. Bankevich A, Nurk S, Antipov D, Gurevich AA, Dvorkin M, Kulikov AS, Lesin VM, Nikolenko SI, Pham S, Prjibelski AD, Pyshkin AV, Sirotkin AV, Vyahhi N, Tesler G, Alekseyev MA, Pevzner PA. 2012. SPAdes: a new genome assembly algorithm and its applications to single-cell sequencing. J Comput Biol 19:455-477. https://doi.org/10.1089/cmb.2012.0021.

4. Langmead B, Salzberg SL. 2012. Fast gapped-read alignment with Bowtie 2. Nat Methods 9:357-359. https://doi.org/10.1038/nmeth.1923.

5. Li H, 1000 Genome Project Data Processing Subgroup, Handsaker B, Wysoker A, Fennell T, Ruan J, Homer N, Marth G, Abecasis G, Durbin R. 2009. The Sequence Alignment/Map format and SAMtools. Bioinformatics 25:2078-2079. https://doi.org/10.1093/bioinformatics/btp352.

6. Kang DD, Froula J, Egan R, Wang Z. 2015. MetaBAT, an efficient tool for accurately reconstructing single genomes from complex microbial communities. PeerJ 3:e1165. https://doi.org/10.7717/peerj.1165.

7. Parks DH, Imelfort M, Skennerton CT, Hugenholtz P, Tyson GW. 2015. CheckM: assessing the quality of microbial genomes recovered from isolates, single cells, and metagenomes. Genome Res 25:1043-1055. https://doi.org/10.1101/gr.186072.114.
8. Parks DH, Chuvochina M, Chaumeil P-A, Rinke C, Mussig AJ, Hugenholtz P. 2019. Selection of representative genomes for 24,706 bacterial and archaeal species clusters provide a complete genome-based taxonomy. bioRxiv https://doi.org/10.1101/771964.

9. Chaumeil P-A, Mussig AJ, Hugenholtz P, Parks DH. 2019. GTDB-Tk: a toolkit to classify genomes with the Genome Taxonomy Database. Bioinformatics 36:1925-1927. https://doi.org/10.1093/bioinformatics/ btz848.

10. Hyatt D, Chen GL, Locascio PF, Land ML, Larimer FW, Hauser LJ. 2010. Prodigal: prokaryotic gene recognition and translation initiation site identification. BMC Bioinformatics 11:119. https://doi.org/10.1186/1471 $-2105-11-119$

11. Buchfink B, Xie C, Huson DH. 2015. Fast and sensitive protein alignment using DIAMOND. Nat Methods 12:59-60. https://doi.org/10.1038/nmeth .3176 .

12. Kanehisa M, Goto S. 2000. KEGG: Kyoto Encyclopedia of Genes and Genomes. Nucleic Acids Res 28:27-30. https://doi.org/10.1093/nar/28.1 .27 .

13. Corteselli EM, Aitken MD, Singleton DR. 2017. Rugosibacter aromaticivorans gen. nov., sp. nov., a bacterium within the family Rhodocyclaceae, isolated from contaminated soil, capable of degrading aromatic compounds. Int J Syst Evol Microbiol 67:311-318. https://doi.org/10.1099/ ijsem.0.001622. 


\title{
Chapter 6
}

\section{Diversity and metagenome analysis of hydrocarbon-degrading bacterial consortium from asphalt lakes located in Wietze, Germany}

\author{
Michael O. Eze ${ }^{1,2 *}$, Grant C. Hose ${ }^{3}$, Simon C. George ${ }^{2}$ and Rolf Daniel ${ }^{1}$ \\ ${ }^{1}$ Department of Genomic and Applied Microbiology and Göttingen Genomics Laboratory, \\ Georg-August University of Göttingen, 37077 Göttingen, Germany. \\ ${ }^{2}$ Department of Earth and Environmental Sciences, Macquarie University, Sydney, NSW 2109, \\ Australia. \\ ${ }^{3}$ Department of Biological Sciences, Macquarie University, Sydney, NSW 2109, Australia. \\ *Correspondence: meze@gwdg.de
}

bioRxiv. https://doi.org/10.1101/2021.03.25.436929

\section{Relationship to the Overall Thesis}

This chapter is a detailed study of the diversity and metagenome analysis of hydrocarbondegrading consortia isolated from three different oil-contaminated sites in the historic oilfield in Wietze, Germany. This detailed analysis provided insight into the microbial species, genes and coding DNA sequences involved in the degradation of petroleum hydrocarbons.

\section{Author Contributions}

Conceived and designed the study: MOE, GCH, SCG and RD

Performed the experiments: MOE

Analysed the data: MOE

Wrote the paper: MOE, GCH, SCG and RD 


\title{
Diversity and metagenome analysis of a hydrocarbon-degrading bacterial consortium from asphalt lakes located in Wietze, Germany
}

\author{
Michael O. Eze ${ }^{1,2^{*}}$, Grant C. Hose $^{3}$, Simon C. George ${ }^{2}$ and Rolf Daniel ${ }^{1}$ \\ ${ }^{1}$ Department of Genomic and Applied Microbiology and Göttingen Genomics Laboratory, \\ Georg-August University of Göttingen, 37077 Göttingen, Germany. \\ ${ }^{2}$ Department of Earth and Environmental Sciences, Macquarie University, Sydney, NSW \\ 2109, Australia.
}

${ }^{3}$ Department of Biological Sciences, Macquarie University, Sydney, NSW 2109, Australia.

*Correspondence: meze@gwdg.de

\begin{abstract}
The pollution of terrestrial and aquatic environments by petroleum contaminants, especially diesel fuel, is a persistent environmental threat requiring cost-effective and environmentally sensitive remediation approaches. Bioremediation is one such approach, but is dependent on the availability of microorganisms with the necessary metabolic abilities and environmental adaptability. The aim of this study was to examine the microbial community in a petroleum contaminated site, and isolate organisms potentially able to degrade hydrocarbons. Through successive enrichment of soil microorganisms from samples of an historic petroleum contaminated site in Wietze, Germany, we isolated a bacterial consortium using diesel fuel hydrocarbons as sole carbon and energy source. The 16S rRNA gene analysis revealed the dominance of Alphaproteobacteria. We further reconstructed a total of 18 genomes from both the original soil sample and the isolated consortium. The analysis of both the metagenome of the consortium and the reconstructed metagenome-assembled genomes show that the most abundant bacterial genus in the consortium, Acidocella, possess many of the genes required for the degradation of diesel fuel aromatic hydrocarbons, which are often the most toxic component. This can explain why this genus proliferated in all the enrichment cultures. Therefore, this study reveals that the microbial consortium isolated in this study and its dominant genus, Acidocella, could potentially serve as an effective inoculum for the bioremediation of sites polluted with diesel fuel or other organic contaminants.
\end{abstract}

Keywords: Bacterial diversity, diesel fuel, consortium, metagenome, bioremediation. 


\section{INTRODUCTION}

Petroleum pollution is a recurring environmental threat resulting from oil and gas exploration, production, transport and storage (Eze and George 2020). Spills have occurred in terrestrial as well as aquatic environments, and they are often caused by human error, corrosion and equipment failure (Dalton and Jin 2010; Errington et al. 2018; Hassler 2016; Hong et al. 2010). This is a major threat to both the environment and human health, due to the phytotoxicity and carcinogenicity of petroleum hydrocarbons.

In view of the diversity of pollutants, a range of ex situ and in situ bioremediation techniques have been developed (Azubuike et al. 2016). Ex situ techniques involve the excavation and off-site treatment of contaminated soils or water, while in situ strategies involve on-site treatment of contaminants. As a result, ex situ techniques are often more expensive than in situ techniques owing to the additional costs associated with contaminant excavation and relocation (USEPA 2000). The United States Environmental Protection Agency indicated that implementing in situ degradation will result in cost savings of 50 to $80 \%$ over traditional methods such as excavation and landfill incineration (USEPA 2001). Moreover, ex situ methods are environmentally problematic as they alter the soil matrix and associated microbiomes.

The success of any oil spill remediation approach depends on environmental conditions such as temperature, $\mathrm{pH}$ and nutritional constraints in contaminated sites (Joner et al. 2002; Kleinsteuber et al. 2006; Leahy and Colwell 1990; Rohrbacher and St-Arnaud 2016). The hydrophobic nature of petroleum hydrocarbons limits their availability to biodegradation. Hence, the presence of microorganisms with the metabolic capability to degrade petroleum and the ability to adapt to a range of environmental conditions is a crucial factor (Das and Chandran 2011). Organisms capable of degrading diesel fuel and other organic contaminants are diverse and present in many natural habitats, including extreme ones (Gemmell and Knowles 2000; Hara and Uchiyama 2013; Lohi et al. 2008; Nie et al. 2014; Stapleton et al. 1998). Microorganisms from polluted environments hold the key to unlocking most of the challenges associated with bioremediation (Eze et al. 2020; Liang et al. 2019; Liang et al. 2016). One such environment is the heavily polluted oil field in Wietze, Germany.

Wietze is an important historical site of crude-oil production. In Germany, preindustrial oil production started in the $17^{\text {th }}$ century, followed by industrial oil extraction 
beginning in 1859 (Craig et al. 2018). Between 1900 and 1920, Wietze was the most productive oil field in Germany, with almost $80 \%$ of German oil produced there. Oil production in Wietze was discontinued in 1963, but the former oil field continues to witness considerable amounts of oil seepage, with several heavily polluted sites, contaminated ponds, and organic debris from surrounding plants (Figure 1). Therefore, it is an ideal site for obtaining microorganisms with the potential for bioremediation of petroleum hydrocarbons. Samples investigated in this study were taken from three sites around a small asphalt pond (Figure 1).

Due to the so-called uncultivability of many environmental microorganisms (Steen et al. 2019), several studies have concentrated on remediation by indigenous microorganisms (Kumar and Gopal 2015; Sarkar et al. 2016). More recent studies have shown that the inoculation of carefully cultivated hydrocarbon-degrading bacterial consortia or isolates enhances the effectiveness of various remediation techniques (Atashgahi et al. 2018; GarridoSanz et al. 2019). Therefore, it is important to discover novel microbes capable of degrading petroleum hydrocarbons either as single isolates, consortia, or synergistically with plants. The aim of this study was to investigate the diversity and genomic potential of bacterial consortia derived from a hydrocarbon contaminated asphalt lake in Wietze, Germany. We also aimed to reconstruct metagenome-assembled genomes, and to examine the potential of the reconstructed genomes for bioremediation of diesel fuel contaminated sites. 


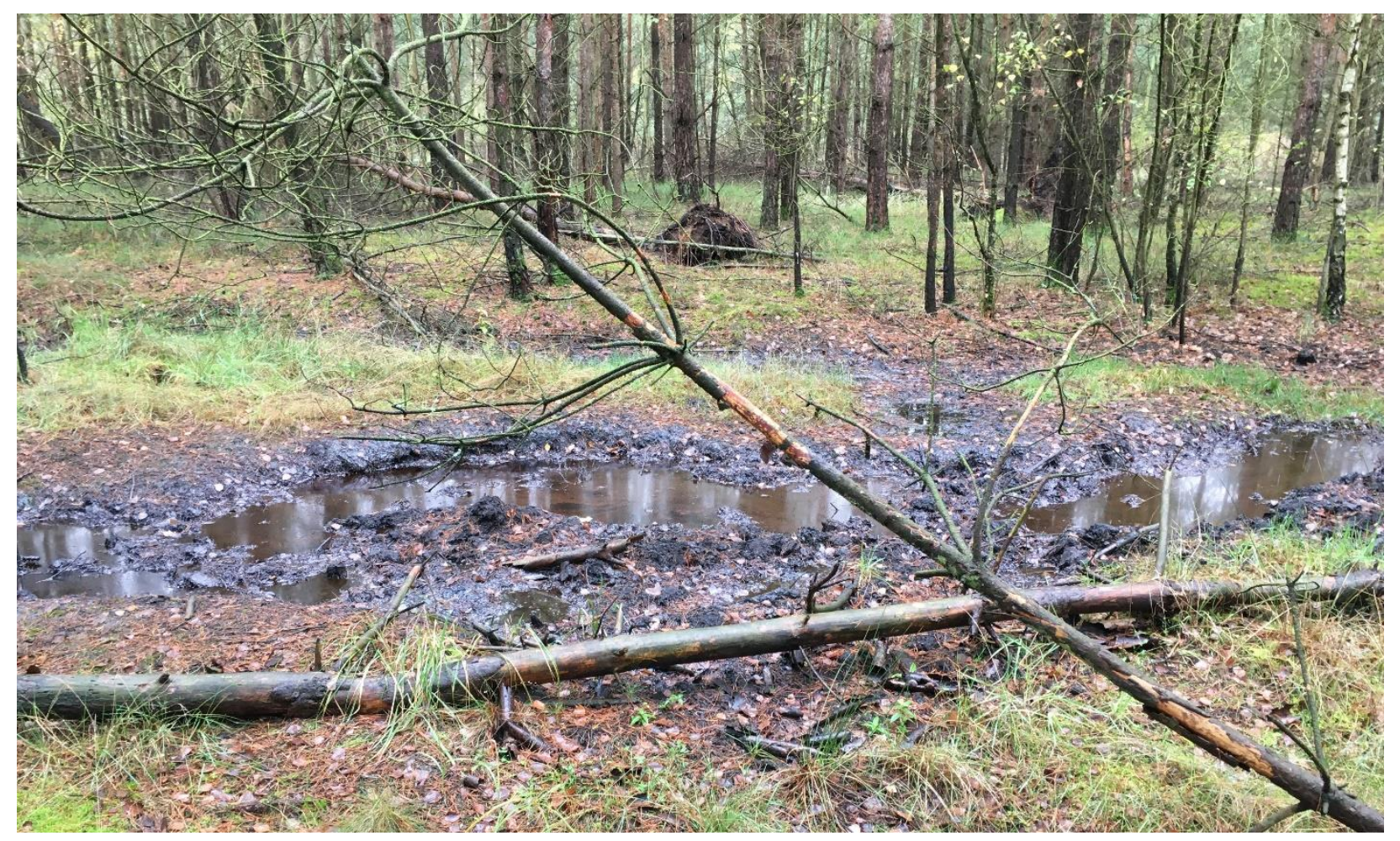

Figure 1. Sampling site in Wietze, Germany (52॰39'0’’N, 0950’0’’E).

\section{MATERIALS AND METHODS}

\section{Soil sampling}

Topsoil samples (10 g each) and water samples (approximately $50 \mathrm{~mL}$ each) were taken in November 2019 from three heavily polluted sites located at the historical oil field in Wietze (52³9'0'’ $\mathrm{N}, 09^{\circ} 50^{\prime} 0^{\prime}$ 'E), Germany. In addition, two reference samples were taken from nearby unpolluted soils. Samples were placed into $50 \mathrm{~mL}$ Eppendorf conical tubes. The samples were transported to the laboratory on ice.

\section{Enrichment cultures and growth conditions}

Approximately $1 \mathrm{~g}$ of each of the crude oil-polluted soil samples was added to Erlenmeyer flasks (300 mL) containing $100 \mathrm{~mL}$ of a liquid mineral medium (MM) composed of $\mathrm{KH}_{2} \mathrm{PO}_{4}$ $(0.5 \mathrm{~g} / \mathrm{L}), \mathrm{NaCl}(0.5 \mathrm{~g} / \mathrm{L})$, and $\mathrm{NH}_{4} \mathrm{Cl}(0.5 \mathrm{~g} / \mathrm{L})$. Sterile-filtered trace elements $(1 \mathrm{~mL} / \mathrm{L})$ (Atlas 2010), vitamin solution (1 mL/L) (Atlas 2010) and $\mathrm{MgSO}_{4} .7 \mathrm{H}_{2} \mathrm{O}(5 \mathrm{~mL} / \mathrm{L}$ of a $100 \mathrm{mg} / \mathrm{mL}$ solution) were added to the $\mathrm{MM}$, post MM-autoclaving. One $\mathrm{mL}$ of sterile-filtered diesel fuel $\left(\mathrm{C}_{10}-\mathrm{C}_{25}\right)$ was added to each flask as the sole carbon and energy source. The cultures were grown at $30^{\circ} \mathrm{C}$ with shaking at $110 \mathrm{rpm}$ (INFORS HT shaker, model $\mathrm{CH}-4103$, Infors AG, 
Bottmingen, Switzerland) and subcultured every five days. After three successive subculturing steps, $30 \mathrm{~mL}$ aliquots $\left(\mathrm{OD}_{600}, 0.635\right)$ were centrifuged for $10 \mathrm{~min}$ at $4,000 \times g$.

\section{DNA Extraction}

Microbial cells from approximately $30 \mathrm{~mL}$ of the enrichment cultures and water samples were harvested by centrifugation at $4,000 \times \mathrm{g}$ for $10 \mathrm{~min}$. The supernatant was subsequently discarded. DNA from the cell pellets and $100 \mathrm{mg}$ of each of the original samples were extracted using the PowerSoil@ DNA Extraction kit as recommended by the manufacturer (Qiagen, Hilden, Germany). DNA from one of the original soil samples and one of the three final enrichments (S3S and S3E3 respectively, Supplementary Figure S1) were used for metagenome studies.

\section{Sequencing of bacterial 16S rRNA genes}

Bacterial 16S rRNA genes were amplified using the forward primer S-D-Bact-0341-b-S-17 (5'CCT ACG GGN GGC WGC AG-3') and the reverse primer S-D-Bact-0785-a-A-21 (5'-GAC TAC HVG GGT ATC TAA TCC-3') (Klindworth et al. 2013) containing adapters for Illumina MiSeq sequencing. The PCR reaction ( $25 \mu \mathrm{L}$ final volume) contained $5 \mu \mathrm{L}$ of five-fold Phusion HF buffer, $200 \mu \mathrm{M}$ of each of the four deoxynucleoside triphosphates, $4 \mu \mathrm{M}$ of each primer, 1 U of Phusion high fidelity DNA polymerase (Thermo Scientific, Waltham, MA, USA), and approximately $50 \mathrm{ng}$ of the extracted DNA as the template. Negative controls were performed using the reaction mixture without a template. The following thermal cycling scheme was used: initial denaturation at $98{ }^{\circ} \mathrm{C}$ for $30 \mathrm{~s}, 30$ cycles of denaturation at $98{ }^{\circ} \mathrm{C}$ for $15 \mathrm{~s}$, annealing at $53{ }^{\circ} \mathrm{C}$ for $30 \mathrm{~s}$, followed by extension at $72{ }^{\circ} \mathrm{C}$ for $30 \mathrm{~s}$. The final extension was carried out at $72{ }^{\circ} \mathrm{C}$ for $2 \mathrm{~min}$. The PCR products that were obtained were controlled for appropriate size, and then purified using the MagSi-NGS Plus kit according to the manufacturer's protocol (Steinbrenner Laborsysteme GmbH, Germany). Quantification of the PCR products was performed using the Quant-iT dsDNA HS assay kit and a Qubit fluorometer, as recommended by the manufacturer (Thermo Scientific). The DNA samples were barcoded using the Nextera XT-Index kit (Illumina, San Diego, USA) and the Kapa HIFI Hot Start polymerase (Kapa Biosystems, USA). Sequencing was performed at the Göttingen Genomics Laboratory using an Illumina MiSeq Sequencing platform (paired-end $2 \times 300$ bp) and the MiSeq reagent kit v3, as recommended by the manufacturer (Illumina). 


\section{Processing of the 16S rRNA gene data}

Trimmomatic version 0.39 (Bolger et al. 2014) was initially used to truncate low-quality reads if quality dropped below 12 in a sliding window of $4 \mathrm{bp}$. Datasets were subsequently processed with Usearch version 11.0.667 (Edgar 2010) as described in Wemheuer et al. (2020). In brief, paired-end reads were merged and quality-filtered. Filtering included the removal of lowquality reads and reads shorter than $200 \mathrm{bp}$. Processed sequences of all samples were joined, dereplicated and clustered in zero-radius operational taxonomic units (zOTUs) using the UNOISE algorithm implemented in Usearch. A de novo chimera removal was included in the clustering step. Afterwards, zOTU sequences were taxonomically classified using the SINTAX algorithm against the SILVA database (SILVA SSURef 138 NR99). All non-bacterial zOTUs were removed based on taxonomic classification. Subsequently, processed sequences were mapped on final zOTU sequences to calculate the distribution and abundance of each OTU in every sample.

\section{Metagenome sequencing, assembly and analysis}

Sequencing libraries were generated from environmental DNA. These were barcoded using the Nextera XT-Index kit (Illumina, San Diego, USA) and the Kapa HIFI Hot Start polymerase (Kapa Biosystems, Wilmington, USA). Sequencing was performed by employing an Illumina HiSeq 2500 system and the HiSeq Rapid SBS kit V2 (2x250 bp) as recommended by the manufacturer (Illumina). Metagenomic reads were further processed as described previously (Eze et al. 2020). In brief, reads were processed with the Trimmomatic tool version 0.39 (Bolger et al. 2014) and assembled using metaSPAdes version 3.13.2 (Bankevich et al. 2012). Coverage information for each scaffold was determined using Bowtie2 version 2.3.2 (Langmead and Salzberg 2012) and SAMtools version 1.7 (Li et al. 2009). Metagenomeassembled genomes (MAGs) were reconstructed with MetaBAT version 2.12.1 (Kang et al. 2015). MAG quality was determined using CheckM version 1.0.13 (Parks et al. 2015). Only MAGs with a completeness minus contamination of more than $50 \%$ and a contamination rate of less than $7 \%$ were considered for further analysis. MAGs were classified taxonomically using GTDB-Tk version 1.0.2 and the Genome Taxonomy Database (release 86) (Chaumeil et al. 2019; Parks et al. 2019). Coding DNA sequences (CDSs) were identified with prodigal version 2.6.3 (Hyatt et al. 2010). Functional annotation was performed with diamond version v0.9.29 (Buchfink et al. 2015) and the KEGG database (October release 2018) (Kanehisa and Goto 2000). 


\section{Data analysis}

Data analysis was performed in R (RCoreTeam 2018). Richness, diversity, evenness, and coverage based on the Chao1 richness estimator were estimated in $\mathrm{R}$ using the vegan package (RCoreTeam 2018). In addition, richness was estimated using the Michaelis-Menten equation in R with the drc package (RCoreTeam 2018). Prior to alpha diversity analysis, the zOTU table was rarefied to 12,924 per sample. Beta-diversity was calculated in $\mathrm{R}$ using the vegan package. Non-metric multidimensional scaling plots were generated based on Bray-Curtis dissimilarities. Dissimilarities were calculated based on the raw zOTU table.

\section{RESULTS}

\section{Bacterial diversity of the sampling sites and the diesel-degrading cultures}

The 16S rRNA gene amplicon sequencing resulted in 242,025 16S rRNA gene sequences across all samples (36,441-10,309 reads per sample, average 22,002 per sample). Clustering resulted in a total of 6,453 zOTUs (average: 587) ranging from 225 to $813 \mathrm{zOTUs}$ per sample. The highest bacterial richness and diversity were observed in the reference samples, the lowest in the enrichment samples. Calculated coverage values indicate that the majority of the bacterial diversity (>80.9\%, see Supplementary Table S1) was recovered by the surveying effort.

Non-metric multidimensional scaling revealed clear differences between the microbial community composition of the polluted soil and water samples, enrichment cultures, and reference unpolluted soil samples (Figure 2). 


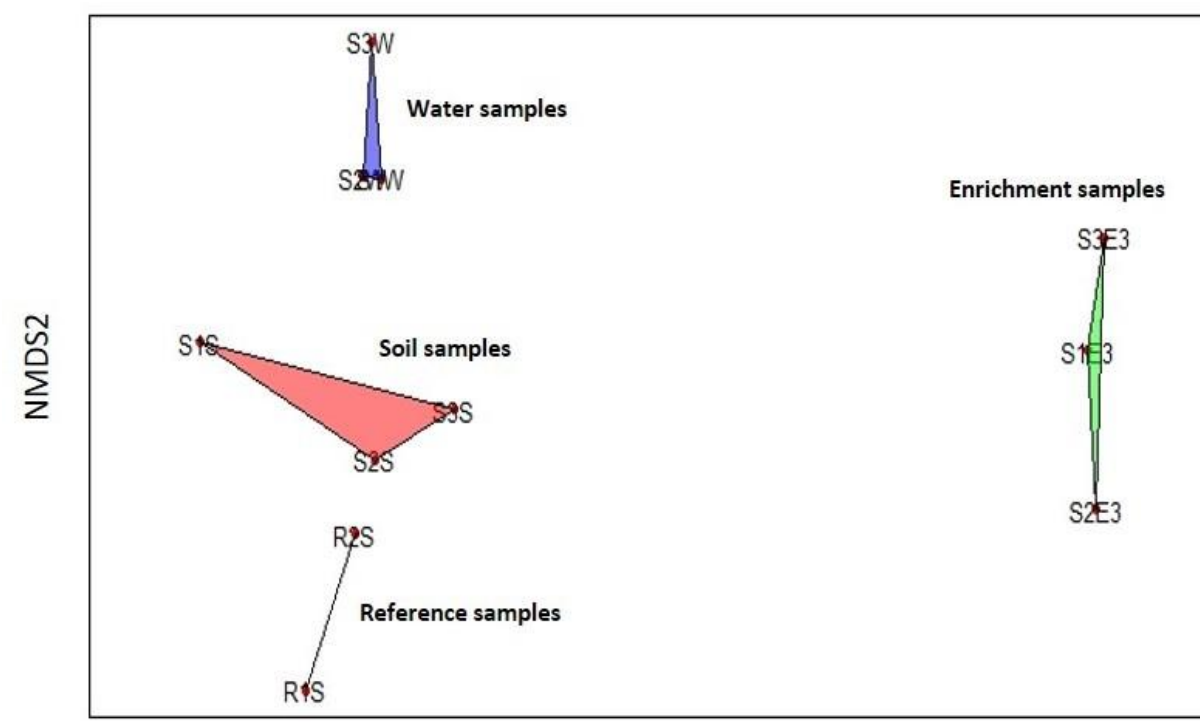

S1S: Soil sample from site 1 S2S: Soil sample from site 2

S3S: Soil sample from site 3 S1W: Water sample from site 1 S2W: Water sample from site 2 S3W: Water sample from site 3 R1S: Reference soil sample 1

R2S: Reference soil sample 2

S1E3: Final enrichment from site 1

S2E3: Final enrichment from site 2

S3E3: Final enrichment from site 3

NMDS1

Figure 2. Non-metric multidimensional scaling (NMDS) ordination plot showing differences in microbial community compositions of the water, soil, enrichment, and reference unpolluted soil samples based on community composition at the genus level.

The relative abundances at the bacterial class level (Figure 3a) showed the dominance of Gammaproteobacteria in the polluted water sample (90.6\%), followed by Alphaproteobacteria (3.2\%). The polluted soil samples contain similar relative abundances for Gammaproteobacteria, Alphaproteobacteria and Acidobacteriae (26.4\%, 21.4\% and 19.1\%, respectively). The enrichment cultures are dominated by members of the Alphaproteobacteria, with a relative abundance of $75.8 \%$. Other bacterial classes present in the enrichment culture include Gammaproteobacteria and Acidobacteriae (15.4\% and 8.6\%, respectively). A higher diversity and richness (Supplementary Table S1) was recorded in the unpolluted reference sample in which Actinobacteria (17.0\%), Alphaproteobacteria (14.6\%), Acidobacteriae (13.5\%), and Bacteroidia (10.1\%) are dominant. Other less abundant classes include Phycisphaerae and Verrucomicrobiae. At genus level, Acidocella are dominant in all the enrichment cultures from the three sites $(87.4 \%$ to $75.4 \%)$. Other genera present in the enrichment cultures include Acidobacterium and Paraburkholderia (Figure 3b). 
(a)

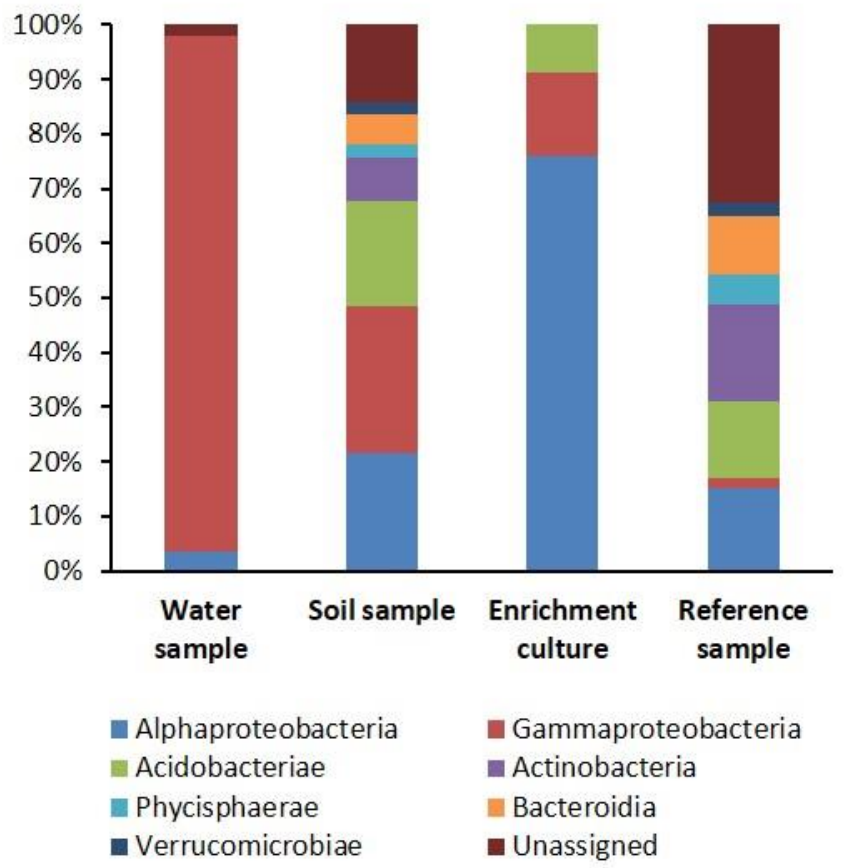

(b)

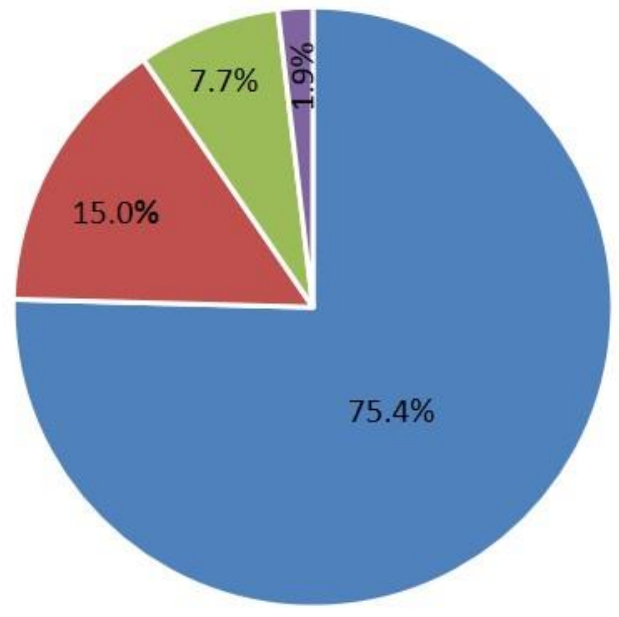

- Acidocella $\quad$ Paraburkholderia

- Acidobacterium - Other

Figure 3. (a) Bacterial community composition in selected water, soil, enrichment, and unpolluted reference samples. (b) relative abundance of the enrichment culture at the genus level. Only taxa with a relative abundance of $>1 \%$ across all samples are presented. For details on relative abundances and 16S rRNA gene amplicon data, see Supplementary Figure S1.

\section{Identification of aliphatic and aromatic hydrocarbon-degrading coding DNA sequences}

Functional analysis of the metagenome derived from the microbial diesel enrichment revealed the presence of 42 potential enzymatic classes represented by 186 coding DNA sequences (CDSs) involved in the degradation of aliphatic and aromatic hydrocarbons (Figure 4). 


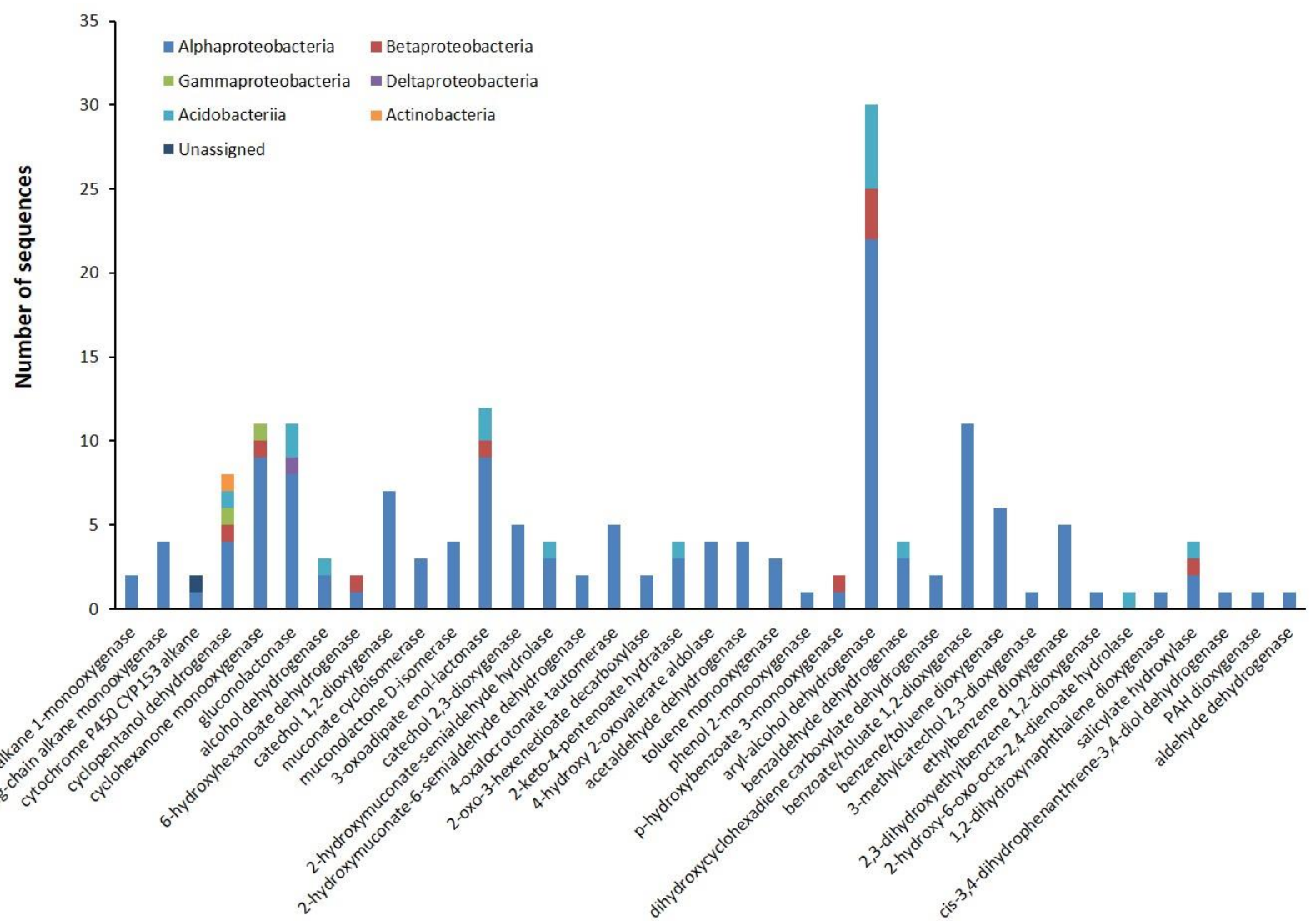

Figure 4. The number of sequences associated with specific hydrocarbon-degrading enzymes in each taxonomic group. The analysis was based on the metagenome of the S3E3 enrichment culture.

The enzymes considered as responsible for the degradation of aliphatic hydrocarbons included alkane 1-monooxygenase, long-chain alkane monooxygenase, cytochrome P450 CYP153 alkane hydroxylase, cyclopentanol dehydrogenase, cyclohexanone monooxygenase, gluconolactonase, alcohol dehydrogenase, and 6-hydroxyhexanoate dehydrogenase. Fortythree CDSs were detected that are considered to play a role in aliphatic hydrocarbon degradation. The majority of the genes that putatively code for aliphatic hydrocarbon degradation are involved in cycloalkane degradation. These include the $c p n A, \operatorname{chn} B, g n l, a d h$ and $\operatorname{chnD}$ genes, which are involved in the Baeyer-Villiger oxidation reactions (Figure 5). 
(a)

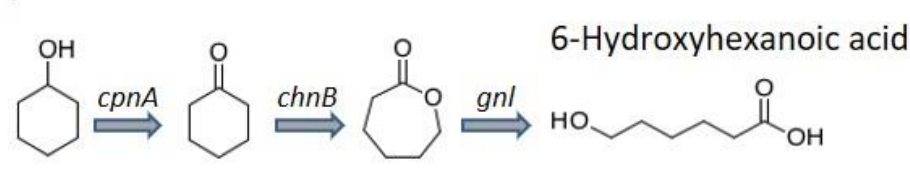

Cyclohexanol $\quad \varepsilon$-Caprolactone adh/chnD<smiles>C=CC(=O)OC(=O)CCCCC(=O)O</smiles>
Adipate semialdehyde Adipate

(b)

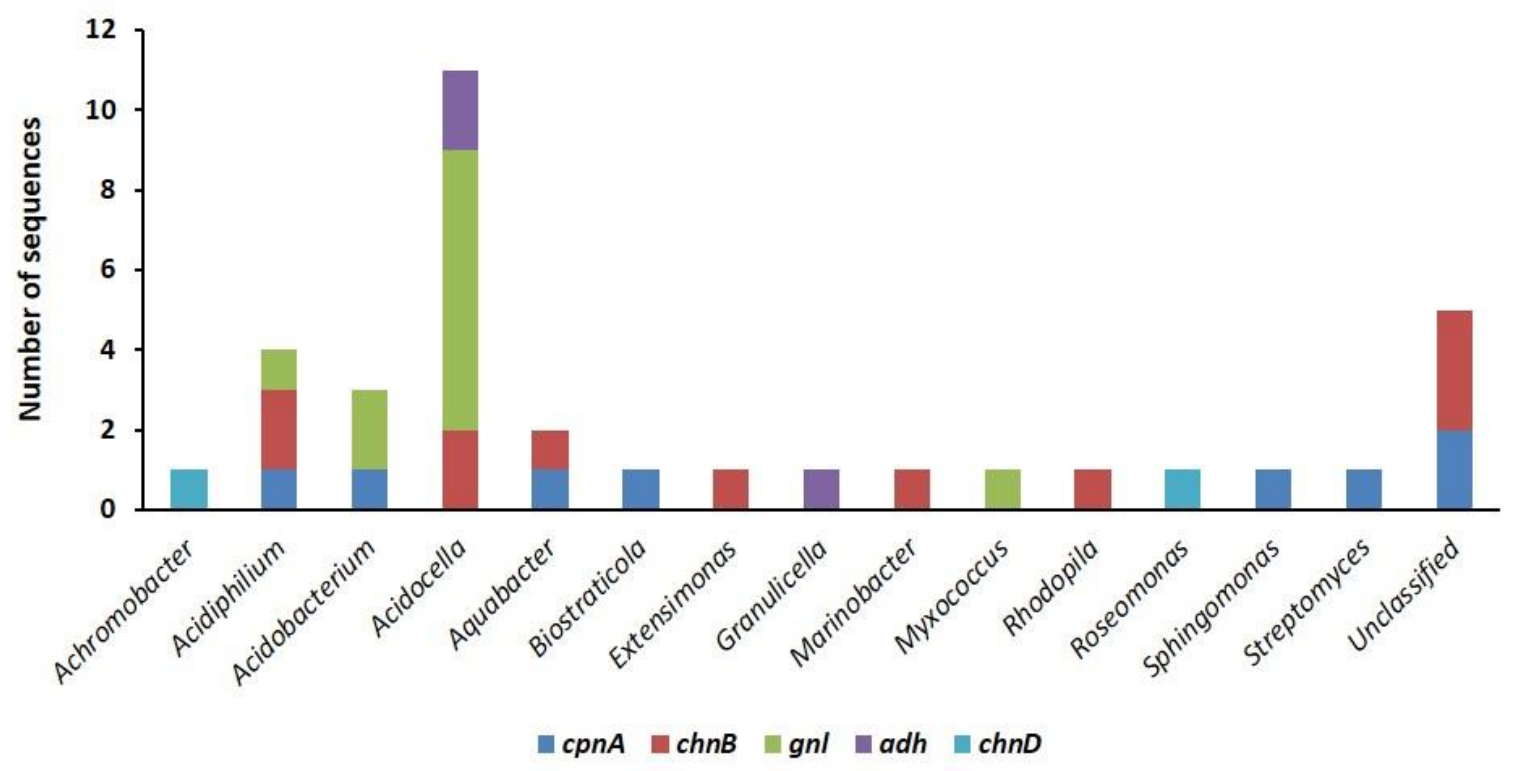

Figure 5. (a) Ring cleavage via the Baeyer-Villiger oxidation pathway for the degradation of cycloalkanes, and (b) genus assignment of the putative genes involved in the Baeyer-Villiger oxidation pathway identified in the diesel-degrading consortium.

The degradation of aromatic hydrocarbons occurs through a series of reactions involving oxidation, hydroxylation, dehydrogenation and ring cleavage. Out of the 186 CDSs putatively linked to diesel degradation, $143 \mathrm{CDSs}$ are potentially involved in aromatic hydrocarbon degradation. Among the $48 \mathrm{CDSs}$ belonging to the aromatic ring dioxygenases, eleven were annotated as benzoate/toluate 1,2-dioxygenase, six as biphenyl 2,3-dioxygenase, six as benzene/toluene/chlorobenzene dioxygenase, five as ethylbenzene dioxygenase, and three as naphthalene 1,2-dioxygenase (Table 1). 
Table 1. Key monooxygenases and dioxygenases involved in the activation and ring cleavage of aromatic hydrocarbons in the diesel-degrading consortium.

\begin{tabular}{l|l|l|c}
\hline Genes & Enzyme & Function & No. of CDSs \\
\hline$t m o C F$ & Toluene monooxygenase & Activation & 3 \\
$p o b A$ & p-Hydroxybenzoate 3-monooxygenase & Activation & 2 \\
$t o d A B C 1 C 2$ & Benzene/toluene/chlorobenzene dioxygenase & Activation & 6 \\
$e t b A a A b A c$ & Ethylbenzene dioxygenase & Activation & 5 \\
$b e n A B C$ & Benzoate/toluate 1,2-dioxygenase & Activation & 11 \\
$b p h A$ & Biphenyl 2,3-dioxygenase & Activation & 6 \\
$n a h A b$ & Naphthalene 1,2-dioxygenase & Activation (PAHs) & 3 \\
$n a h C$ & 1,2-Dihydroxynaphthalene dioxygenase & Activation (PAHs) & 1 \\
$n i d A$ & PAH dioxygenase & Activation (PAHs) & 1 \\
$c a t A$ & Catechol 1,2-dioxygenase & Ortho-cleavage & 7 \\
$d m p B$ & Catechol 2,3-dioxygenase & Meta-cleavage & 5 \\
$t o d E$ & 3-Methylcatechol 2,3-dioxygenase & Meta-cleavage & 1 \\
$e t b C$ & 2,3-Dihydroxyethylbenzene 1,2-dioxygenase & Meta-cleavage & 1 \\
$b p h C$ & Biphenyl-2,3-diol 1,2-dioxygenase & Meta-cleavage & 1 \\
\hline
\end{tabular}

\section{Reconstruction of metagenome-assembled genomes}

We were able to reconstruct fifteen nearly complete genomes from the whole-metagenome sequence of the original soil samples, and three nearly complete genomes from the enrichment culture (Supplementary Table S2). Quality analysis of the MAGs showed that the average completeness and contamination level for the MAGs were $85 \%$ and $2 \%$ respectively (Supplementary Table S3). The majority of the metagenome-assembled genomes (MAGs) were classified as belonging to the Gammaproteobacteria (8 MAGs), followed by Alphaproteobacteria (4 MAGs), Acidobacteriae (3 MAGs), Actinobacteria (2 MAGs) and Caldisericia (1 MAG). The three metagenome-assembled genomes from the enrichment culture were classified as Acidocella aminolytica, Acidobacterium capsulatum, and Acidocella sp., with a completeness of $72.4 \%, 99.8 \%$ and $100 \%$, respectively.

A comparison of the three nearly complete genomes reconstructed from the metagenome of the enrichment culture shows that the genes encoding enzymes involved in the activation and degradation of petroleum hydrocarbons are more abundant in Acidocella than in 
Acidobacterium (Supplementary Table S2). For example, while the two MAGs classified as Acidocella contain an average of $18 \mathrm{CDSs}$ involved in aromatic ring activation, Acidobacterium had only 7 CDSs encoding for the activation of aromatic hydrocarbons. Key enzymes that are encoded by the reconstructed MAGs belonging to Acidocella but are missing in those belonging to Acidobacterium include long-chain alkane monooxygenase, cyclohexanone monooxygenase, ethylbenzene dioxygenase, and benzoate/toluate 1,2dioxygenase.

Further comparisons performed between the MAGs assembled from the metagenome data of the enrichment culture and those obtained from a previous study of a crude oil bore hole (Eze et al. 2020) revealed that the Acidocella MAGs obtained from this study exhibit a higher abundance of genes that putatively encode the degradation of cycloalkanes. For example, in the 36 MAGs from Eze et al. (2020), genes that encode for cyclopentanol dehydrogenase $(c p n A)$ and cyclohexanone monooxygenase $(\operatorname{chn} B)$ were present in 16 and 11 MAGs, respectively. In this study, MAGs reconstructed from both the enrichment culture and the original soil samples were rich in genes that encode these enzymes with more than 6 CDSs per gene in some MAGs. The reconstructed MAGs were also found to be richer in CDSs that encode for aromatic degradation that those in the previous study. For example, aryl alcohol dehydrogenase, an enzyme vital for the degradation of aromatic hydrocarbons was missing in all of the 36 assembled MAGs from the crude oil bore hole study (Eze et al. 2020). Potential genes encoding the enzyme were present in two of the three MAGs from the enrichment culture of this study.

\section{DISCUSSION}

The successive enrichment of the different experimental samples using diesel fuel resulted in the dominance of Alphaproteobacteria. The dominance of Alphaproteobacteria in the bacterial communities, especially Acidocella and Paraburkholderia, indicates the tolerance of these genera to high concentrations of petroleum hydrocarbons and their potential degradative capacity for organic contaminants. The taxa that are abundant in the polluted water and soil, and in the enrichment cultures, were also associated with hydrocarbon pollution in other locations (Lee et al. 2019; Röling et al. 2006; Stapleton et al. 1998). The biodegradative ability of these taxa and their tolerance to heavy metals (Giovanella et al. 2020) indicate that they are 
potentially suitable for the remediation of multiple contaminants such as hydrocarbon-polluted acidic mine sites.

Diesel fuel contains aliphatic and aromatic hydrocarbons. The aliphatic hydrocarbon fraction is predominantly composed of normal-, iso- and cyclo-alkanes, while the aromatic hydrocarbon fraction is composed primarily of alkylbenzenes, naphthalene, alkylnaphthalenes, biphenyl and alkylbiphenyls (Woolfenden et al. 2011). The degradation of n-alkanes is primarily carried out by alkane 1-monooxygenase (alkB), cytochrome P450 CYP153 alkane hydroxylase (CYP153) and long-chain alkane monooxygenases (ladA) genes, and their roles in the degradation of $n$-alkanes and iso-alkanes have been extensively studied ( $\mathrm{Ji}$ et al. 2013; Li et al. 2008; van Beilen et al. 2006). The degradation of $n$-alkanes and iso-alkanes by the consortium is indicated by the presence of potential alkB, CYP153 and ladA genes. The low number of the corresponding gene sequences (eight) can be explained by the taxonomic composition of the consortium. Previous studies have shown that n-alkane degrading genes are often associated with Betaproteobacteria and Gammaproteobacteria especially the Pseudomonas genus (Garrido-Sanz et al. 2019; Liu et al. 2014; Shao and Wang 2013; van Beilen et al. 2001; van Beilen et al. 1994). In our study, the diesel-degrading consortium in the enrichment cultures was dominated by Alphaproteobacteria (Figures 2 and 3). Thus, the majority of CDSs in our metagenome consortium belong to the Alphaproteobacteria, especially the Acidocella genus and not to Pseudomonas.

Of the genes that putatively code for aliphatic hydrocarbon degradation, the majority are involved in cycloalkane degradation. These enzymes include cyclopentanol dehydrogenase $(\operatorname{cpnA})$, cyclohexanone monooxygenase $(\operatorname{chnB})$, gluconolactonase $(g n l)$, alcohol dehydrogenase $(a d h)$, and 6-hydroxyhexanoate dehydrogenase (chnD) (Bohren et al. 1989; Iwaki et al. 1999; Iwaki et al. 2002; Kanagasundaram and Scopes 1992). This is interesting since cycloalkanes are moderately resistant to biodegradation (Connan 1984). The degradation of cycloalkanes involves ring cleavage via Baeyer-Villiger oxidation (Perkel et al. 2018; Sheng et al. 2001), which requires an initial oxidation of cyclohexane to cyclohexanol by cyclohexane monooxygenase, and then a dehydrogenation reaction to cyclohexanone. This step is followed by another monooxygenase attack to form epsilon-caprolactone, followed by ring cleavage that is carried out by gluconolactonase (Figure 5a). All the genes involved in this degradation pathway are present in the metagenome of the enrichment culture, but a single taxon in the bacterial community that possess all the genes involved in this pathway was not detected 
(Figure 5b). This indicates a synergistic interaction of different bacterial genera in the degradation of recalcitrant hydrocarbons. The high number of $\operatorname{cpnA}, \operatorname{chnB}, g n l, a d h$ and $\operatorname{chn} D$ genes (35 CDSs) in the metagenome of the enrichment culture indicates the significant potential of the microbial community for the degradation of cycloalkanes present in diesel fuel.

The degradation of aromatic hydrocarbons requires initial activation by oxygenases resulting in the formation of oxygenated intermediates such as catechol (Atashgahi et al. 2018; Das and Chandran 2011; Peters et al. 2004). The bacterial consortium contains more genes that putatively encode dioxygenases than those that encode monooxygenases (Table 1). The genes that encode dioxygenases include the todABC1C2, etbAaAbAc and benABCD genes (Fong et al. 1996; Werlen et al. 1996; Zylstra and Gibson 1989). The higher abundance of genes encoding dioxygenases indicates that the activation of alkylbenzenes and phenolic compounds by the microbial consortium predominantly follows the dioxygenase pathway rather than the monooxygenase pathway.

The central metabolism of aromatic hydrocarbons that follows initial activation involves ortho- and meta-cleavage of catechol or methylcatechol (Benjamin et al. 1991; Ehrt et al. 1995; Hidalgo et al. 2020; Liang et al. 2019; Neidle et al. 1988; Peters et al. 2004; Rohrbacher and St-Arnaud 2016). Functional analysis reveals that genes encoding enzymes putatively involved in the central metabolism of aromatic hydrocarbons are present in the microbial community. The most abundant CDSs in our diesel-degrading community that are responsible for this reaction are catechol 1,2-dioxygenase and catechol 2,3-dioxygenase (7 and 5 CDSs, respectively) (Table 1). Other enzymes that are present include 3-oxoadipate enollactonase, muconolactone D-isomerase (a decarboxylating dehydrogenase), 4-oxalocrotonate tautomerase, and acetaldehyde dehydrogenase. Most of the corresponding genes are affiliated to Alphaproteobacteria.

Polycyclic aromatic hydrocarbons (PAHs) are more resistant to microbial attack than smaller aromatic hydrocarbons, and when biodegradation is possible, this often proceeds through oxidation and ring cleavage by dioxygenases (Sipilä et al. 2008). The metagenome contains genes that encode enzymes putatively involved in the degradation of PAHs and other recalcitrant hydrocarbons, such as biphenyl and alkylbiphenyls. These enzymes include naphthalene 1,2-dioxygenase (nahAb) and 1,2-dihydroxynaphthalene dioxygenase (nahC) for naphthalene and alkylnaphthalenes (Peng et al. 2008), biphenyl 2,3-dioxygenase ( $b p h A)$ for biphenyl and alkylbiphenyls, and PAH dioxygenase (nidA) for phenanthrene, 
alkylphenanthrenes, and other high molecular weight PAHs (Iwasaki et al. 2006; Robrock et al. 2011) (Table 1). Since crude oil and oil spills often contain significant amount of polycyclic aromatic hydrocarbons such as naphthalene, alkylnaphthalenes, phenanthrene and alkylphenanthrenes (Ahmed and George 2004; Eze and George 2020), the presence of putative genes encoding PAH dioxygenases in the metagenome of the consortium indicates the potential of the consortium for the remediation and reclamation of petroleum-contaminated soils.

Interestingly, the majority of previous studies on microbially-enhanced rhizoremediation of petroleum hydrocarbons have focused on Pseudomonas (de Lima-Morales et al. 2015; Di Martino et al. 2012), Burkholderia (Okoh et al. 2001), and Paraburkholderia (Dias et al. 2019; Lee and Jeon 2018), but these organisms often do not have the enzymes to run the complete metabolic pathways for the degradation of all hydrocarbons present in diesel fuel, especially the aromatic constituents. For example, in a study of rhizoremediation of dieselcontaminated soils, a scarcity of ring-hydroxylating and ring-cleavage dioxygenases among Gammaproteobacteria was reported by Garrido-Sanz et al. (2019). These researchers also noted that none of the nahA genes in the metagenome was affiliated to Pseudomonas or even to the Gammaproteobacteria class that dominated the PAH-degrading consortium. In contrast, the consortium reported here contains the CDSs required for the complete degradation of these aromatic components in diesel fuel.

The comparison made between the MAGs assembled from the metagenome data of the enrichment culture and those obtained from studies of similar sites (Eze et al. 2020) revealed the relatively higher abundance, in the consortium, of genes involved in hydrocarbon degradation. These include the $a d h P$ and yiaY genes encoding alcohol dehydrogenases (Drewke and Ciriacy 1988; Glasner et al. 1995; Williamson and Paquin 1987), and the cpnA and $\operatorname{chnB}$ involved in the degradation of cycloalkanes (Iwaki et al. 2002; Sheng et al. 2001). These genes are also involved in the degradation of other organic contaminants such as haloalkanes (Belkin 1992; Yokota et al. 1986). This difference in potential degradative capacity between the MAGs from the two studies can be explained by the taxonomic differences between the MAGs obtained in both cases. In the study of a crude oil bore hole (Eze et al. 2020), majority of the reconstructed MAGs were affiliated to Gammaproteobacteria. In contrast, Alphaproteobacteria, especially Acidocella was the dominant genus in both the enrichment culture and the MAGs from the enrichment culture. 
The potential of the enrichment culture to degrade recalcitrant hydrocarbons was also revealed by the presence of genes encoding enzymes involved in degradation of recalcitrant organic compounds. For example, one of the three MAGs from the enrichment culture contained genes encoding 2-halobenzoate 1,2-dioxygenase ( $c b d A)$, an enzyme that activates the oxidation of 2-chlorobenzoate to catechol. In contrast, none of the 36 MAGs from the previous study contains this gene. Since the enrichment culture is composed of predominantly Acidocella strains, the abundance of genes that putatively encode for the degradation of cycloalkanes and aromatic hydrocarbons in the MAGs classified as Acidocella is an indication for the potential of the consortium for petroleum hydrocarbon biodegradation.

\section{Conclusions}

The degradation of petroleum hydrocarbons requires several microorganisms with both the ability to withstand toxicity and to harbour the required metabolic pathways. Therefore, a foremost step in establishing a successful microbially-mediated bioremediation approach is the selective cultivation of a suitable microbial consortium with the required degradative capability for the target contaminants. Through successive enrichment using soil samples taken from an historical oil-contaminated site in Germany, we successfully generated a bacterial consortium capable of degrading diesel fuel. We further reconstructed a total of 18 genomes from both the original soil sample and the isolated consortium. The analysis of both the metagenome of the consortium and the reconstructed metagenome-assembled genomes shows that the most abundant bacterial genus in the consortium, Acidocella, possess many of the coding DNA sequences required for the degradation of diesel fuel aromatic hydrocarbons, which are often the most toxic components. This can explain why this genus proliferated in all the enrichment cultures. Therefore, this study revealed that the microbial consortium isolated in this study or its dominant genus, Acidocella, could potentially serve as an effective inoculum for biotechnological applications in the reclamation of soils contaminated with diesel fuel. 


\section{Conflict of Interest}

The authors declare that the research was conducted in the absence of any commercial or financial relationships that could be construed as a potential conflict of interest.

\section{Author Contributions}

Conceptualization and design: MOE, GCH, SCG and RD. Planning and implementation: MOE and RD. Experiments and bioinformatics analyses: MOE. Writing - original draft: MOE. Writing - review and editing: GCH, SCG and RD. Supervision: GCH, SCG and RD. All authors interpreted the results, and agreed to the final version of the manuscript.

\section{Acknowledgments}

The authors would like to thank Macquarie University and the Commonwealth Government of Australia for supporting this research project by providing M.O.E. with an international Research Training Program (iRTP) scholarship, and the German Academic Exchange Service (DAAD) for providing M.O.E. with a DAAD scholarship (Allocation Numbers: 2017561 and 91731339, respectively). This publication was supported financially by the Open Access Publication Fund of the University of Göttingen. The funders had no role in study design, data collection, and interpretation, or the decision to submit the work for publication. We also thank Dr. Anja Poehlein and Melanie Heinemann for assistance during the sequencing.

\section{Data Availability}

Raw sequencing data has been deposited in the sequence read archive of the National Center for Biotechnology Information under BioProject number PRJNA612814. 


\section{References}

Ahmed M, George SC (2004) Changes in the molecular composition of crude oils during their preparation for GC and GC-MS analyses. Org. Geochem. 35:137-155. doi:https://doi.org/10.1016/j.orggeochem.2003.10.002.

Atashgahi S, Hornung B, van der Waals MJ, da Rocha UN, Hugenholtz F, Nijsse B, Molenaar D, van Spanning R, Stams AJM, Gerritse J, Smidt H (2018) A benzenedegrading nitrate-reducing microbial consortium displays aerobic and anaerobic benzene degradation pathways. Sci. Rep. 8:4490. doi:10.1038/s41598-018-22617-x.

Atlas RM (2010) Handbook of microbiological media, Fourth edition edn. CRC Press, Boca Raton, Florida.

Azubuike CC, Chikere CB, Okpokwasili GC (2016) Bioremediation techniquesclassification based on site of application: principles, advantages, limitations and prospects. World J. Microbiol. Biotechnol. 32:180. doi:10.1007/s11274-016-2137-x.

Bankevich A, Nurk S, Antipov D, Gurevich AA, Dvorkin M, Kulikov AS, Lesin VM, Nikolenko SI, Pham S, Prjibelski AD, Pyshkin AV, Sirotkin AV, Vyahhi N, Tesler G, Alekseyev MA, Pevzner PA (2012) SPAdes: a new genome assembly algorithm and its applications to single-cell sequencing. J. Comput. Biol. 19:455-477. doi:10.1089/cmb.2012.0021.

Belkin S (1992) Biodegradation of haloalkanes. Biodegradation 3:299-313. doi:10.1007/BF00129090.

Benjamin RC, Voss JA, Kunz DA (1991) Nucleotide sequence of $x y l E$ from the TOL pDK1 plasmid and structural comparison with isofunctional catechol-2,3-dioxygenase genes from TOL, pWW0 and NAH7. J. Bacteriol. 173:2724. doi:10.1128/jb.173.8.27242728.1991.

Bohren KM, Bullock B, Wermuth B, Gabbay KH (1989) The aldo-keto reductase superfamily. cDNAs and deduced amino acid sequences of human aldehyde and aldose reductases. J. Biol. Chem. 264:9547-51.

Bolger AM, Lohse M, Usadel B (2014) Trimmomatic: a flexible trimmer for Illumina sequence data. Bioinformatics 30:2114-2120. doi:10.1093/bioinformatics/btu170.

Buchfink B, Xie C, Huson DH (2015) Fast and sensitive protein alignment using DIAMOND. Nat. Methods 12:59-60. doi:10.1038/nmeth.3176.

Chaumeil P-A, Mussig AJ, Hugenholtz P, Parks DH (2019) GTDB-Tk: a toolkit to classify genomes with the Genome Taxonomy Database. Bioinformatics 36:1925-1927. doi:10.1093/bioinformatics/btz848.

Connan J (1984) Biodegradation of crude oils in reservoirs. In: Advances in Petroleum Geochemistry, volume 1. Academic Press, London.

Craig J, Gerali F, MacAulay F, Sorkhabi R (2018) The history of the European oil and gas industry (1600s-2000s). Geological Society, London, Special Publications 465. doi:10.1144/SP465.23.

Dalton T, Jin D (2010) Extent and frequency of vessel oil spills in US marine protected areas. Mar. Pollut. Bull. 60:1939-1945. doi:https://doi.org/10.1016/j.marpolbul.2010.07.036.

Das N, Chandran P (2011) Microbial degradation of petroleum hydrocarbon contaminants: An overview. Biotechnol. Res. Int. 2011. doi:10.4061/2011/941810.

de Lima-Morales D, Chaves-Moreno D, Wos-Oxley ML, Jáuregui R, Vilchez-Vargas R, Pieper DH (2015) Degradation of benzene by Pseudomonas veronii 1YdBTEX2 and $1 Y B 2$ is catalyzed by enzymes encoded in distinct catabolism gene clusters. Appl. Environ. Microbiol. 82:167-173. doi:10.1128/AEM.03026-15.

Di Martino C, López NI, Raiger Iustman LJ (2012) Isolation and characterization of benzene, toluene and xylene degrading Pseudomonas sp. selected as candidates for 
bioremediation. Int. Biodeterior. Biodegradation 67:15-20

doi:https://doi.org/10.1016/j.ibiod.2011.11.004

Dias GM, de Sousa Pires A, Grilo VS, Castro MR, de Figueiredo Vilela L, Neves BC (2019)

Comparative genomics of Paraburkholderia kururiensis and its potential in bioremediation, biofertilization, and biocontrol of plant pathogens. MicrobiologyOpen 8:e00801. doi:10.1002/mbo3.801.

Drewke C, Ciriacy M (1988) Overexpression, purification and properties of alcohol dehydrogenase IV from Saccharomyces cerevisiae. Biochim. Biophys. Acta 950:5460. doi:https://doi.org/10.1016/0167-4781(88)90072-3.

Edgar RC (2010) Search and clustering orders of magnitude faster than BLAST. Bioinformatics 26:2460-2461. doi:10.1093/bioinformatics/btq461.

Ehrt S, Schirmer F, Hillen W (1995) Genetic organization, nucleotide sequence and regulation of expression of genes encoding phenol hydroxylase and catechol 1,2dioxygenase in Acinetobacter calcoaceticus NCIB8250. Mol. Microbiol. 18:13-20. doi:10.1111/j.1365-2958.1995.mmi_18010013.x.

Errington I, King CK, Wilkins D, Spedding T, Hose GC (2018) Ecosystem effects and the management of petroleum-contaminated soils on subantarctic islands. Chemosphere 194:200-210. doi:https://doi.org/10.1016/j.chemosphere.2017.11.157.

Eze MO, George SC (2020) Ethanol-blended petroleum fuels: implications of co-solvency for phytotechnologies. RSC Adv. 10:6473-6481. doi:10.1039/C9RA10919F.

Eze MO, Lütgert SA, Neubauer H, Balouri A, Kraft AA, Sieven A, Daniel R, Wemheuer B (2020) Metagenome assembly and metagenome-assembled genome sequences from a historical oil field located in Wietze, Germany. Microbiol. Resour. Announc. 9:e00333-20. doi:10.1128/MRA.00333-20.

Fong KP, Goh CB, Tan HM (1996) Characterization and expression of the plasmid-borne bedD gene from Pseudomonas putida ML2, which codes for a NAD+-dependent cisbenzene dihydrodiol dehydrogenase. J. Bacteriol. 178:5592. doi:10.1128/jb.178.19.5592-5601.1996.

Garrido-Sanz D, Redondo-Nieto M, Guirado M, Pindado Jiménez O, Millán R, Martin M, Rivilla R (2019) Metagenomic insights into the bacterial functions of a dieseldegrading consortium for the rhizoremediation of diesel-polluted soil. Genes 10. doi:10.3390/genes10060456.

Gemmell RT, Knowles CJ (2000) Utilisation of aliphatic compounds by acidophilic heterotrophic bacteria. The potential for bioremediation of acidic wastewaters contaminated with toxic organic compounds and heavy metals. FEMS Microbiol. Lett. 192:185-190. doi:10.1111/j.1574-6968.2000.tb09380.x.

Giovanella P, Vieira GAL, Ramos Otero IV, Pais Pellizzer E, de Jesus Fontes B, Sette LD (2020) Metal and organic pollutants bioremediation by extremophile microorganisms. J. Hazard. Mater. 382:121024. doi:https://doi.org/10.1016/j.jhazmat.2019.121024

Glasner JD, Kocher TD, Collins JJ (1995) Caenorhabditis elegans contains genes encoding two new members of the Zn-containing alcohol dehydrogenase family. J. Mol. Evol. 41:46-53 doi:10.1007/BF00174040.

Hara E, Uchiyama H (2013) Degradation of petroleum pollutant materials by fungi. In: Goltapeh EM, Danesh YR, Varma A (eds) Fungi as Bioremediators. Springer Berlin Heidelberg, Berlin, Heidelberg, pp 117-133.

Hassler B (2016) Oil Spills from Shipping: A Case Study of the Governance of Accidental Hazards and Intentional Pollution in the Baltic Sea. In: Gilek M, Karlsson M, Linke S, Smolarz K (eds) Environmental Governance of the Baltic Sea. Springer International Publishing, Cham, pp 125-146. 
Hidalgo KJ, Sierra-Garcia IN, Dellagnezze BM, de Oliveira VM (2020) Metagenomic insights into the mechanisms for biodegradation of polycyclic aromatic hydrocarbons in the oil supply chain. Front. Microbiol. 11. doi:10.3389/fmicb.2020.561506.

Hong X, Chen W, Zhang L (2010) A probabilistic risk forecast of accidental oil spills from vessels in Luoyuan Bay, Fujian Province, PRC. Procedia Environ. Sci. 2:49-56. doi:https://doi.org/10.1016/j.proenv.2010.10.008.

Hyatt D, Chen G-L, Locascio PF, Land ML, Larimer FW, Hauser LJ (2010) Prodigal: prokaryotic gene recognition and translation initiation site identification. BMC Bioinform. 11:119-119. doi:10.1186/1471-2105-11-119.

Iwaki H, Hasegawa Y, Teraoka M, Tokuyama T, Bergeron H, Lau PCK (1999) Identification of a transcriptional activator $(\mathrm{ChnR})$ and a 6-Oxohexanoate dehydrogenase (ChnE) in the cyclohexanol catabolic pathway in Acinetobacter sp. strain NCIMB 9871 and localization of the genes that encode them. Appl. Environ. Microbiol. 65:5158. doi:10.1128/AEM.65.11.5158-5162.1999.

Iwaki H, Hasegawa Y, Wang S, Kayser MM, Lau PCK (2002) Cloning and characterization of a gene cluster involved in cyclopentanol metabolism in Comamonas sp. strain NCIMB 9872 and biotransformations effected by Escherichia coli-expressed cyclopentanone 1,2-monooxygenase. Appl. Environ. Microbiol. 68:5671. doi:10.1128/AEM.68.11.5671-5684.2002.

Iwasaki T, Miyauchi K, Masai E, Fukuda M (2006) Multiple-subunit genes of the aromaticring-hydroxylating dioxygenase play an active role in biphenyl and polychlorinated biphenyl degradation in Rhodococcus sp. strain RHA1. Appl. Environ. Microbiol. 72:5396. doi:10.1128/AEM.00298-06.

Ji Y, Mao G, Wang Y, Bartlam M (2013) Structural insights into diversity and n-alkane biodegradation mechanisms of alkane hydroxylases. Front. Microbiol. 4:58

Joner EJ, Corgié SC, Amellal N, Leyval C (2002) Nutritional constraints to degradation of polycyclic aromatic hydrocarbons in a simulated rhizosphere. Soil Biol. Biochem. 34:859-864. doi:https://doi.org/10.1016/S0038-0717(02)00018-4.

Kanagasundaram V, Scopes R (1992) Isolation and characterization of the gene encoding gluconolactonase from Zymomonas mobilis. Biochim. Biophys. Acta 1171:198-200. doi:https://doi.org/10.1016/0167-4781(92)90120-O.

Kanehisa M, Goto S (2000) KEGG: kyoto encyclopedia of genes and genomes. Nucleic Acids Res. 28:27-30. doi:10.1093/nar/28.1.27.

Kang DD, Froula J, Egan R, Wang Z (2015) MetaBAT, an efficient tool for accurately reconstructing single genomes from complex microbial communities. PeerJ 3:e1165e1165. doi:10.7717/peerj.1165.

Kleinsteuber S, Riis V, Fetzer I, Harms H, Müller S (2006) Population dynamics within a microbial consortium during growth on diesel fuel in saline environments. Appl. Environ. Microbiol. 72:3531. doi:10.1128/AEM.72.5.3531-3542.2006.

Klindworth A, Pruesse E, Schweer T, Peplies J, Quast C, Horn M, Glöckner FO (2013) Evaluation of general $16 \mathrm{~S}$ ribosomal RNA gene PCR primers for classical and nextgeneration sequencing-based diversity studies. Nucleic Acids Res. 41:e1-e1. doi:10.1093/nar/gks808.

Kumar BL, Gopal DVRS (2015) Effective role of indigenous microorganisms for sustainable environment. 3 Biotech 5:867-876. doi:10.1007/s13205-015-0293-6.

Langmead B, Salzberg SL (2012) Fast gapped-read alignment with Bowtie 2. Nat. Methods 9:357-359. doi:10.1038/nmeth.1923.

Leahy JG, Colwell RR (1990) Microbial degradation of hydrocarbons in the environment. Microbiol. Rev. 54:305-315. 
Lee Y, Jeon CO (2018) Paraburkholderia aromaticivorans sp. nov., an aromatic hydrocarbon-degrading bacterium, isolated from gasoline-contaminated soil. Int. J. Syst. Evol. Microbiol. 68:1251-1257. doi:https://doi.org/10.1099/ijsem.0.002661.

Lee Y, Lee Y, Jeon CO (2019) Biodegradation of naphthalene, BTEX, and aliphatic hydrocarbons by Paraburkholderia aromaticivorans BN5 isolated from petroleumcontaminated soil. Sci. Rep. 9:860. doi:10.1038/s41598-018-36165-x.

Li H, Handsaker B, Wysoker A, Fennell T, Ruan J, Homer N, Marth G, Abecasis G, Durbin R, Genome Project Data Processing S (2009) The sequence alignment/map format and SAMtools. Bioinformatics 25:2078-2079. doi:10.1093/bioinformatics/btp352.

Li L, Liu X, Yang W, Xu F, Wang W, Feng L, Bartlam M, Wang L, Rao Z (2008) Crystal structure of long-chain alkane monooxygenase (LadA) in complex with coenzyme FMN: unveiling the long-chain alkane hydroxylase. J. Mol. Biol. 376:453-465. doi:https://doi.org/10.1016/j.jmb.2007.11.069.

Liang C, Huang Y, Wang H (2019) pahE, a functional marker gene for polycyclic aromatic hydrocarbon-degrading bacteria. Appl. Environ. Microbiol. 85:e02399-18. doi:10.1128/AEM.02399-18.

Liang J-L, JiangYang J-H, Nie Y, Wu X-L (2016) Regulation of the alkane hydroxylase CYP153 Gene in a gram-positive alkane-degrading bacterium, Dietzia sp. strain DQ12-45-1b. Appl. Environ. Microbiol. 82:608. doi:10.1128/AEM.02811-15.

Liu H, Xu J, Liang R, Liu J (2014) Characterization of the medium- and long-chain n-alkanes degrading Pseudomonas aeruginosa strain SJTD-1 and its alkane hydroxylase genes. PLOS ONE 9:e105506. doi:10.1371/journal.pone.0105506.

Lohi A, Alvarez Cuenca M, Anania G, Upreti SR, Wan L (2008) Biodegradation of diesel fuel-contaminated wastewater using a three-phase fluidized bed reactor. J. Hazard. Mater. 154:105-111. doi:https://doi.org/10.1016/j.jhazmat.2007.10.001.

Neidle EL, Hartnett C, Bonitz S, Ornston LN (1988) DNA sequence of the Acinetobacter calcoaceticus catechol 1,2-dioxygenase I structural gene catA: evidence for evolutionary divergence of intradiol dioxygenases by acquisition of DNA sequence repetitions. J. Bacteriol. 170:4874. doi:10.1128/jb.170.10.4874-4880.1988.

Nie Y, Chi C-Q, Fang H, Liang J-L, Lu S-L, Lai G-L, Tang Y-Q, Wu X-L (2014) Diverse alkane hydroxylase genes in microorganisms and environments. Sci. Rep. 4:4968. doi:10.1038/srep04968.

Okoh A, Ajisebutu S, Babalola G, Trejo-Hernandez M (2001) Potential of Burkholderia cepacia RQ1 in the biodegradation of heavy crude oil. Int. Microbiol. 4:83-87. doi:10.1007/s101230100018.

Parks DH, Chuvochina M, Chaumeil P-A, Rinke C, Mussig AJ, Hugenholtz P (2019) Selection of representative genomes for 24,706 bacterial and archaeal species clusters provide a complete genome-based taxonomy. bioRxiv:771964. doi:10.1101/771964.

Parks DH, Imelfort M, Skennerton CT, Hugenholtz P, Tyson GW (2015) CheckM: assessing the quality of microbial genomes recovered from isolates, single cells, and metagenomes. Genome Res. 25:1043-1055. doi:10.1101/gr.186072.114.

Peng R-H, Xiong A-S, Xue Y, Fu X-Y, Gao F, Zhao W, Tian Y-S, Yao Q-H (2008) Microbial biodegradation of polyaromatic hydrocarbons. FEMS Microbiol. Rev. 32:927-955. doi:10.1111/j.1574-6976.2008.00127.x.

Perkel AL, Voronina SG, Borkina GG (2018) The role of the Baeyer-Villiger reaction in the liquid-phase oxidation of organic compounds. Russ. Chem. Bull. 67:779-786. doi:10.1007/s11172-018-2137-0.

Peters KE, Walters CC, Moldowan JM (2004) The Biomarker Guide: Volume 2: Biomarkers and Isotopes in Petroleum Systems and Earth History. Cambridge University Press. 
R Core Team (2018) R: A language and environment for statistical computing. R Foundation for Statistical Computing, Vienna, Austria.

Robrock KR, Mohn WW, Eltis LD, Alvarez-Cohen L (2011) Biphenyl and ethylbenzene dioxygenases of Rhodococcus jostii RHA1 transform PBDEs. Biotechnol. Bioeng. 108:313-321. doi:10.1002/bit.22952.

Rohrbacher F, St-Arnaud M (2016) Root exudation: the ecological driver of hydrocarbon rhizoremediation. Agronomy 6. doi:10.3390/agronomy6010019.

Röling WFM, Ortega-Lucach S, Larter SR, Head IM (2006) Acidophilic microbial communities associated with a natural, biodegraded hydrocarbon seepage. J. Appl. Microbiol. 101:290-299. doi:10.1111/j.1365-2672.2006.02926.x.

Sarkar J, Kazy SK, Gupta A, Dutta A, Mohapatra B, Roy A, Bera P, Mitra A, Sar P (2016) Biostimulation of indigenous microbial community for bioremediation of petroleum refinery sludge. Front. Microbiol. 7:1407. doi:10.3389/fmicb.2016.01407.

Shao Z, Wang W (2013) Enzymes and genes involved in aerobic alkane degradation. Front. Microbiol. 4:116. doi:10.3389/fmicb.2013.00116.

Sheng D, Ballou DP, Massey V (2001) Mechanistic studies of cyclohexanone monooxygenase: chemical properties of intermediates involved in catalysis. Biochemistry 40:11156-11167. doi:10.1021/bi011153h.

Sipilä TP, Keskinen A-K, Åkerman M-L, Fortelius C, Haahtela K, Yrjälä K (2008) High aromatic ring-cleavage diversity in birch rhizosphere: $\mathrm{PAH}$ treatment-specific changes of I.E.3 group extradiol dioxygenases and 16S rRNA bacterial communities in soil. ISME J. 2:968-981. doi:10.1038/ismej.2008.50.

Stapleton RD, Savage DC, Sayler GS, Stacey G (1998) Biodegradation of aromatic hydrocarbons in an extremely acidic environment. Appl. Environ. Microbiol. 64:41804184.

Steen AD, Crits-Christoph A, Carini P, DeAngelis KM, Fierer N, Lloyd KG, Cameron Thrash J (2019) High proportions of bacteria and archaea across most biomes remain uncultured. ISME J. 13:3126-3130. doi:10.1038/s41396-019-0484-y.

USEPA (2000) EPA/600/R-99/107: Introduction to Phytoremediation. United States Environmental Protection Agency.

USEPA (2001) EPA 542-R-01-006: Brownfields Technology Primer: Selecting and Using Phytoremediation for Site Cleanup. United States Environmental Protection Agency.

van Beilen JB, Funhoff EG, van Loon A, Just A, Kaysser L, Bouza M, Holtackers R, Röthlisberger M, Li Z, Witholt B (2006) Cytochrome P450 Alkane Hydroxylases of the CYP153 Family Are Common in Alkane-Degrading Eubacteria Lacking Integral Membrane Alkane Hydroxylases. Appl. Environ. Microbiol. 72:59. doi:10.1128/AEM.72.1.59-65.2006.

van Beilen JB, Panke S, Lucchini S, Franchini AG, Röthlisberger M, Witholt B (2001) Analysis of Pseudomonas putida alkane-degradation gene clusters and flanking insertion sequences: evolution and regulation of the alk genes. Microbiology 147:1621-1630. doi:10.1099/00221287-147-6-1621.

van Beilen JB, Wubbolts MG, Witholt B (1994) Genetics of alkane oxidation by Pseudomonas oleovorans. Biodegradation 5:161-174. doi:10.1007/BF00696457.

Wemheuer F, Berkelmann D, Wemheuer B, Daniel R, Vidal S, Bisseleua Daghela HB (2020) Agroforestry management systems drive the composition, diversity, and function of fungal and bacterial endophyte communities in Theobroma cacao leaves. Microorganisms 8:405. doi:10.3390/microorganisms8030405.

Werlen C, Kohler HP, van der Meer JR (1996) The broad substrate chlorobenzene dioxygenase and cis-chlorobenzene dihydrodiol dehydrogenase of Pseudomonas sp. 
strain P51 are linked evolutionarily to the enzymes for benzene and toluene degradation. J. Biol. Chem. 271:4009-16. doi:10.1074/jbc.271.8.4009.

Williamson VM, Paquin CE (1987) Homology of Saccharomyces cerevisiae ADH4 to an iron-activated alcohol dehydrogenase from Zymomonas mobilis. Mol. Gen. Genet. 209:374-381. doi:10.1007/BF00329668.

Woolfenden ENM, Hince G, Powell SM, Stark SC, Snape I, Stark JS, George SC (2011) The rate of removal and the compositional changes of diesel in Antarctic marine sediment. Sci. Total Environ. 410-411:205-216.

doi:https://doi.org/10.1016/j.scitotenv.2011.09.013.

Yokota T, Fuse H, Omori T, Minoda Y (1986) Microbial dehalogenation of haloalkanes mediated by oxygenase or halidohydrolase. Agric. Biol. Chem. 50:453-460. doi:10.1080/00021369.1986.10867402.

Zylstra GJ, Gibson DT (1989) Toluene degradation by Pseudomonas putida F1. Nucleotide sequence of the todC1C2BADE genes and their expression in Escherichia coli. J. Biol. Chem. 264:14940-6. 
Diversity and metagenome analysis of a hydrocarbon-degrading bacterial consortium from asphalt lakes located in Wietze, Germany

Michael O. Eze $\mathrm{e}^{1,2^{*}}$, Grant C. Hose ${ }^{3}$, Simon C. George ${ }^{2}$ and Rolf Daniel ${ }^{1}$

${ }^{1}$ Department of Genomic and Applied Microbiology and Göttingen Genomics Laboratory, GeorgAugust University of Göttingen, 37077 Göttingen, Germany.

${ }^{2}$ Department of Earth and Environmental Sciences, Macquarie University, Sydney, NSW 2109, Australia.

${ }^{3}$ Department of Biological Sciences, Macquarie University, Sydney, NSW 2109, Australia.

*Correspondence: meze@gwdg.de

\section{$\underline{\text { Supplementary Materials }}$}

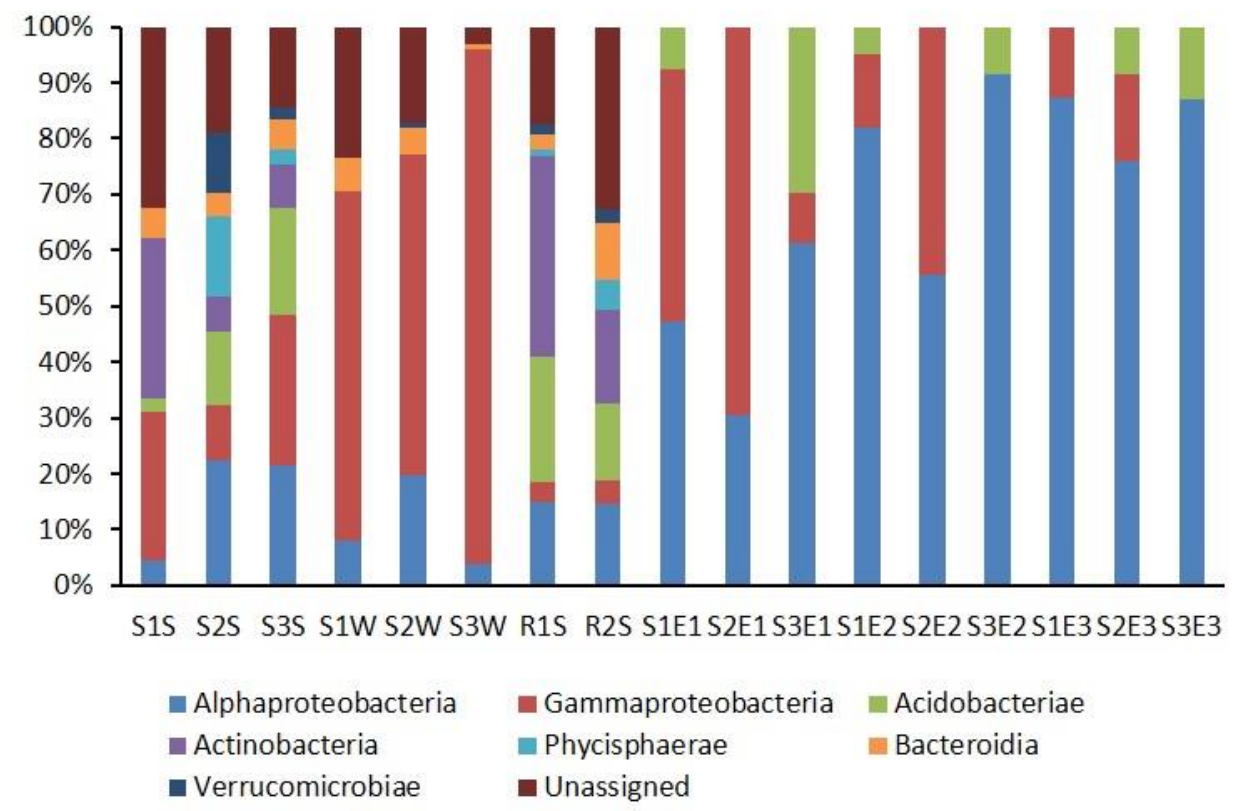

Supplementary Figure S1. Bacterial taxonomic distribution of all samples based on 16S rRNA gene amplicon data. 
Supplementary Table S1. Richness, diversity and evenness obtained from the 16S rRNA sequencing of sampling sites and enrichment cultures

\begin{tabular}{|l|l|r|r|r|r|r|}
\hline Sample ID & & & & $\begin{array}{l}\text { Shannon } \\
\text { Diversity }\end{array}$ & \multicolumn{1}{l|}{$\begin{array}{l}\text { Pielou's } \\
\text { Evenness }\end{array}$} \\
\hline X20200114.BEWE.a.2136_S261 & S1S & 381.99 & 475.51 & 80.33 & 4.140482857 & 0.696418531 \\
\hline X20200114.BEWE.a.2137_S262 & S2S & 958.43 & 1166.75 & 82.15 & 5.927652696 & 0.863422675 \\
\hline X20200114.BEWE.a.2138_S263 & S3S & 885.54 & 1076.78 & 82.24 & 5.625668073 & 0.828986773 \\
\hline X20200114.BEWE.a.2139_S264 & S1W & 731.44 & 971.95 & 75.25 & 4.491982504 & 0.68111784 \\
\hline X20200114.BEWE.a.2140_S265 & S2W & 666.94 & 848.21 & 78.63 & 3.840835511 & 0.590652415 \\
\hline X20200114.BEWE.a.2141_S266 & S3W & 389 & 581.5 & 66.9 & 2.409478261 & 0.40403223 \\
\hline X20200114.BEWE.a.2142_S267 & R1S & 629.32 & 806.44 & 78.04 & 4.89315041 & 0.759258936 \\
\hline X20200114.BEWE.a.2143_S268 & R2S & 1168.08 & 1274.35 & 91.66 & 6.322569919 & 0.89515298 \\
\hline X20200114.BEWE.a.2144_S269 & S1E1 & 62.34 & 67.76 & 92 & 2.684138231 & 0.649503002 \\
\hline X20200114.BEWE.a.2145_S270 & S2E1 & 44.91 & 50.35 & 89.2 & 2.228003222 & 0.585598434 \\
\hline X20200114.BEWE.a.2146_S271 & S3E1 & 38.41 & 40.95 & 93.8 & 1.755745383 & 0.481247923 \\
\hline X20200114.BEWE.a.2147_S272 & S1E2 & 45.09 & 56.52 & 79.78 & 1.896011697 & 0.497815886 \\
\hline X20200114.BEWE.a.2148_S273 & S2E2 & 31.88 & 35.16 & 90.68 & 1.921605494 & 0.555059859 \\
\hline X20200114.BEWE.a.2149_S274 & S3E2 & 14.05 & 14.66 & 95.82 & 0.829529079 & 0.313903749 \\
\hline X20200114.BEWE.a.2150_S275 & S1E3 & 23.26 & 30.09 & 77.3 & 1.761694985 & 0.55984851 \\
\hline X20200114.BEWE.a.2151_S276 & S2E3 & 27.44 & 40.95 & 67 & 1.257543211 & 0.379692792 \\
\hline X20200114.BEWE.a.2152_S277 & S3E3 & 15.28 & 19.03 & 80.3 & 0.962736927 & 0.353097786 \\
\hline
\end{tabular}


Supplementary Table S2. Metagenome-assembled genomes (MAGs) from both the soil and the enrichment metagenomes.

\begin{tabular}{|c|c|c|c|c|c|}
\hline User_genome & $\begin{array}{l}\text { Source } \\
\text { metagenome }\end{array}$ & classification & closest_placement_taxonomy & closest_placement_ani & aa_percent \\
\hline BEWE_m_45_metabat2.1 & Soil sample & f__Acidobacteriaceae;g__Terracidiphilus;s & s__Terracidiphilus sp002314435 & 80.06 & 73.89 \\
\hline BEWE_m_45_metabat2.11 & Soil sample & f__Mycobacteriaceae;g__Williamsia_A;s_ & S_Williamsia_A herbipolensis & 80.27 & 89.46 \\
\hline BEWE_m_45_metabat2.15 & Soil sample & f__Acetobacteraceae;g_Acidocella;s__ & N/A & N/A & 74.21 \\
\hline BEWE_m_45_metabat2.18 & Soil sample & f__Steroidobacteraceae;g_;s__ & N/A & N/A & 71.59 \\
\hline BEWE_m_45_metabat2.19 & Soil sample & f__Koribacteraceae;g__Koribacter;s & s__Koribacter sp003151155 & 89.00 & 70.85 \\
\hline BEWE_m_45_metabat2.21 & Soil sample & f__Rhodanobacteraceae;g__Rudaea;s__ & S__Rudaea cellulosilytica & 78.03 & 68.95 \\
\hline BEWE_m_45_metabat2.25 & Soil sample & f__UBA5335;g__;s__ & N/A & N/A & 94.40 \\
\hline BEWE_m_45_metabat2.26 & Soil sample & f__Nevskiaceae;g__Solimonas;s_ & N/A & N/A & 65.24 \\
\hline BEWE_m_45_metabat2.27 & Soil sample & f__Burkholderiaceae;g__BOG-994;s_ & N/A & N/A & 86.96 \\
\hline BEWE_m_45_metabat2.28 & Soil sample & f__UBA4822;g_UBA4822;s & N/A & N/A & 73.71 \\
\hline BEWE_m_45_metabat2.33 & Soil sample & f__Actinomycetaceae;g__Pauljensenia;s__ & N/A & N/A & 81.75 \\
\hline BEWE_m_45_metabat2.35 & Soil sample & f__UBA5335;g__; _ _ & N/A & N/A & 87.62 \\
\hline BEWE_m_45_metabat2.41 & Soil sample & f__Acetobacteraceae;g__; __ & N/A & N/A & 66.59 \\
\hline BEWE_m_46_metabat2.2 & Enrichment culture & f__Acetobacteraceae;g_Acidocella;s__ & s__Acidocella aminolytica & 82.29 & 82.02 \\
\hline BEWE_m_46_metabat2.4 & Enrichment culture & f__Acidobacteriaceae;g_Acidobacterium;s & s__Acidobacterium capsulatum & 85.13 & 97.02 \\
\hline BEWE_m_46_metabat2.5 & Enrichment culture & f__Acetobacteraceae;g__Acidocella;s__ & N/A & N/A & 96.83 \\
\hline
\end{tabular}


Supplementary Table S3. Quality check for the MAGs

\begin{tabular}{|c|c|c|c|c|c|c|c|c|c|c|c|c|c|}
\hline Bin.ld & Marker.lineage & X..genomes & X..markers & X..marker.sets & $\mathrm{XO}$ & $\mathrm{X} 1$ & $\mathrm{x} 2$ & X3 & $\mathrm{X} 4$ & $\times 5$. & Completeness & Contamination & $\begin{array}{l}\text { Strain. } \\
\text { Hetero- } \\
\text { geneity }\end{array}$ \\
\hline BEWE_m_45_metabat2.1 & k_Bacteria (UID3187) & 2258 & 187 & 116 & 54 & 125 & 8 & 0 & 0 & 0 & 82.75 & 6.47 & 12.5 \\
\hline BEWE_m_45_metabat2.11 & $\begin{array}{l}\text { o Actinomycetales } \\
\text { (UID1814) }\end{array}$ & 148 & 572 & 276 & 25 & 547 & 0 & 0 & 0 & 0 & 97.53 & 0 & 0 \\
\hline BEWE_m_45_metabat2.15 & $\begin{array}{l}\text { O Rhodospirillales } \\
\text { (UID3754) }\end{array}$ & 63 & 336 & 201 & 48 & 284 & 4 & 0 & 0 & 0 & 93.75 & 1.49 & 25 \\
\hline BEWE_m_45_metabat2.18 & $\begin{array}{l}\text { c Gammaproteobacteria } \\
\text { (UID4202) }\end{array}$ & 67 & 481 & 276 & 110 & 329 & 41 & 0 & 1 & 0 & 77.26 & 8.06 & 0 \\
\hline BEWE_m_45_metabat2.19 & k_ Bacteria (UID3187) & 2258 & 188 & 117 & 55 & 132 & 1 & 0 & 0 & 0 & 87.39 & 0.85 & 0 \\
\hline BEWE_m_45_metabat2.21 & $\begin{array}{l}\text { f Xanthomonadaceae } \\
\text { (UID4214) }\end{array}$ & 55 & 659 & 290 & 103 & 536 & 20 & 0 & 0 & 0 & 91.72 & 3.88 & 30 \\
\hline BEWE_m_45_metabat2.22 & $\begin{array}{l}\text { c_Gammaproteobacteria } \\
\text { (UID4201) }\end{array}$ & 1164 & 275 & 174 & 93 & 179 & 3 & 0 & 0 & 0 & 64.27 & 1.72 & 66.67 \\
\hline BEWE_m_45_metabat2.25 & $\begin{array}{l}\text { c Gammaproteobacteria } \\
\text { (UID4267) }\end{array}$ & 119 & 544 & 284 & 28 & 513 & 3 & 0 & 0 & 0 & 94.55 & 0.82 & 0 \\
\hline BEWE_m_45_metabat2.26 & k_Bacteria (UID203) & 5449 & 104 & 58 & 48 & 52 & 4 & 0 & 0 & 0 & 66.07 & 6.03 & 50 \\
\hline BEWE_m_45_metabat2.27 & $\begin{array}{l}\text { C Betaproteobacteria } \\
\text { (UID3888) }\end{array}$ & 323 & 387 & 234 & 41 & 340 & 5 & 1 & 0 & 0 & 89.01 & 0.88 & 25 \\
\hline BEWE_m_45_metabat2.28 & k_Bacteria (UID203) & 5449 & 102 & 56 & 13 & 89 & 0 & 0 & 0 & 0 & 80.36 & 0 & 0 \\
\hline BEWE_m_45_metabat2.33 & $\begin{array}{l}\text { f_Actinomycetaceae } \\
\text { (UID1531) }\end{array}$ & 42 & 420 & 211 & 58 & 358 & 2 & 2 & 0 & 0 & 87.1 & 2.37 & 25 \\
\hline BEWE_m_45_metabat2.35 & $\begin{array}{l}\text { c Gammaproteobacteria } \\
\text { (UID4267) }\end{array}$ & 119 & 544 & 284 & 44 & 493 & 7 & 0 & 0 & 0 & 90.77 & 1.88 & 14.29 \\
\hline BEWE_m_45_metabat2.41 & $\begin{array}{l}\text { O_Rhodospirillales } \\
\text { (UID3754) }\end{array}$ & 63 & 336 & 201 & 114 & 219 & 3 & 0 & 0 & 0 & 65.49 & 0.76 & 66.67 \\
\hline BEWE_m_45_metabat2.6 & $\begin{array}{l}\text { g_Burkholderia } \\
\text { (UID4006) }\end{array}$ & 64 & 769 & 248 & 51 & 692 & 26 & 0 & 0 & 0 & 94.03 & 1.51 & 38.46 \\
\hline BEWE_m_46_metabat2.2 & $\begin{array}{l}\text { O Rhodospirillales } \\
\text { (UID3754) }\end{array}$ & 63 & 336 & 201 & 80 & 256 & 0 & 0 & 0 & 0 & 72.39 & 0 & 0 \\
\hline BEWE_m_46_metabat2.4 & k_Bacteria (UID3187) & 2258 & 188 & 117 & 1 & 186 & 1 & 0 & 0 & 0 & 99.79 & 0.85 & 0 \\
\hline BEWE_m_46_metabat2.5 & $\begin{array}{l}\text { O_Rhodospirillales } \\
\text { (UID3754) }\end{array}$ & 63 & 336 & 201 & 0 & 335 & 1 & 0 & 0 & 0 & 100 & 0.08 & 0 \\
\hline
\end{tabular}




\title{
Chapter 7
}

\section{Metagenomic insight into the plant growth-promoting potential of a diesel- degrading bacterial consortium for enhanced rhizoremediation application}

\author{
Michael O. Eze ${ }^{1,2 *}$, Volker Thiel ${ }^{3}$, Grant C. Hose ${ }^{4}$, Simon C. George ${ }^{2 \dagger}$ and Rolf Daniel ${ }^{1 \dagger}$ \\ ${ }^{1}$ Department of Genomic and Applied Microbiology and Göttingen Genomics Laboratory, \\ Georg-August University of Göttingen, 37077 Göttingen, Germany. \\ ${ }^{2}$ Department of Earth and Environmental Sciences, Macquarie University, Sydney, NSW 2109, \\ Australia. \\ ${ }^{3}$ Geobiology, Geoscience Centre, Georg-August University of Göttingen, 37077 Göttingen, \\ Germany. \\ ${ }^{4}$ Department of Biological Sciences, Macquarie University, Sydney, NSW 2109, Australia. \\ †These authors contributed equally to this work. \\ *Correspondence: meze@gwdg.de
}

bioRxiv. https://doi.org/10.1101/2021.03.26.437261

\section{Relationship to the Overall Thesis}

This chapter perfectly complements the preceding chapter by examining, through metagenome and greenhouse studies, the plant growth-promoting capacity of the isolated hydrocarbondegrading bacterial consortium. This is an important step since the goal was to identify microorganisms potentially involved in both hydrocarbon degradation (Chapter 6) and plant growth promotion (Chapter 7).

\section{Author Contributions}

Conceived and designed the study: MOE, GCH, SCG and RD

Performed the experiments: MOE and VT

Analysed the data: MOE and VT

Wrote the paper: MOE, VT, GCH, SCG and RD 


\title{
Metagenomic insight into the plant growth-promoting potential of a diesel-degrading bacterial consortium for enhanced rhizoremediation application
}

\author{
Michael O. Eze ${ }^{1,2 *}$, Volker Thiel ${ }^{3}$, Grant C. Hose ${ }^{4}$, Simon C. George ${ }^{2 \dagger}$ and Rolf Daniel ${ }^{1 \dagger}$ \\ ${ }^{1}$ Department of Genomic and Applied Microbiology and Göttingen Genomics Laboratory, \\ Georg-August University of Göttingen, 37077 Göttingen, Germany. \\ ${ }^{2}$ Department of Earth and Environmental Sciences, Macquarie University, Sydney, NSW 2109, \\ Australia. \\ ${ }^{3}$ Geobiology, Geoscience Centre, Georg-August University of Göttingen, 37077 Göttingen, \\ Germany. \\ ${ }^{4}$ Department of Biological Sciences, Macquarie University, Sydney, NSW 2109, Australia. \\ †These authors contributed equally to this work. \\ *Correspondence: meze@gwdg.de
}

\begin{abstract}
The slow rate of natural attenuation of organic pollutants, together with unwanted environmental impacts of traditional remediation strategies, has necessitated the exploration of plant-microbe systems for enhanced bioremediation applications. The identification of microorganisms capable of promoting both plant growth and hydrocarbon degradation is crucial to the success of plant-based remediation techniques. Through successive enrichments of a soil sample from a historic oil-contaminated site in Wietze, Germany, we isolated a plant growth-promoting and hydrocarbon-degrading bacterial consortium. Metagenome analysis of the consortium led to the identification of genes and taxa putatively associated with these processes. The majority of the coding DNA sequences involved in these reactions were affiliated to Acidocella aminolytica and Acidobacterium capsulatum. In microcosm experiments performed in association with Medicago sativa L., the consortium achieved $91 \%$ rhizodegradation of diesel fuel hydrocarbons within 60 days, indicating its potential for biotechnological applications in the remediation of sites contaminated by organic pollutants.
\end{abstract}

Keywords: Plant growth promotion, plant-microbe synergy, rhizoremediation, diesel fuel, Acidocella aminolytica, Acidobacterium capsulatum. 


\section{INTRODUCTION}

Phytoremediation is the remediation of contaminants by plant-based techniques. This approach offers an environmentally friendly and cost-effective in-situ method for the remediation of contaminated soils ${ }^{1}$, and has been applied to both organic and inorganic contaminants. Closely related to phytoremediation is rhizoremediation, which is the degradation of contaminants by root-associated microorganisms. To enhance the effectiveness of phytoremediation and rhizoremediation, plant growth-promoting rhizobacteria (PGPR) have been the focus of research in recent decades ${ }^{2,3}$.

PGPR inhabit the rhizospheric zones of plants and can directly or indirectly influence plant growth. PGPR provide nutrients to host plants, produce phytohormones that regulate plant growth and metabolic activities, and protect host plants from pathogens and abiotic stress 4,5. The plant growth-promoting activities of PGPR include nitrogen fixation, phosphate and potassium solubilization, indoleacetic acid and pyrroloquinoline quinone biosynthesis, siderophore transport, induction of systemic resistance, and interference with pathogen toxin production ${ }^{6-8}$.

PGPR readily establish in soils due to their high growth rate and adaptability to a wide variety of environments, and in some cases, due to their ability to metabolize a wide range of natural and xenobiotic compounds ${ }^{6}$. Consequently, there is an increasing interest in enhancing rhizoremediation through the inoculation of microbial consortia with the required metabolic pathways ${ }^{9,10}$. Unfortunately, research to date has focused just on hydrocarbon-degrading microbes ${ }^{11,12}$, with few studies targeting organisms capable of both plant growth promotion and hydrocarbon degradation ${ }^{13}$.

Rhizospheric soils derived from petroleum contaminated sites are often a rich source of microorganisms that have the metabolic ability to degrade organic contaminants while enhancing plant growth ${ }^{14-16}$. Since microorganisms present in oil-polluted sites often possess adaptability and resistance to toxic organic compounds, an examination of their plant growthpromoting ability will help bridge the knowledge gap required to develop effective plant growth-promoting inocula for plants in contaminated soils. The application of such inocula will enhance the tolerance of plants to hydrocarbon toxicity, promote biomass production, and enhance rhizoremediation. Thus, the aims of this study were to isolate a bacterial consortium capable of enhancing plant growth and hydrocarbon degradation. In microcosm experiments performed in association with Medicago sativa L., the consortium significantly enhanced the 
growth of $M$. sativa, and achieved $91 \%$ rhizodegradation of diesel fuel hydrocarbons within 60 days. The choice of $M$. sativa was based on our previous study that revealed the plant's tolerance to hydrocarbons ${ }^{17}$. The results of this study will expand the range of available PGPR for use in rhizoremediation of environmental contaminants.

\section{RESULTS}

\section{Bacterial diversity in the consortium}

The consortium used in this study was isolated by Eze, et al. ${ }^{18}$ from a crude-oil polluted site in Wietze, Germany. The bacterial diversity in both the original soil sample and the enrichment culture was discussed in Eze, et al. ${ }^{18}$.

The relative abundance of classifiable bacterial sequences based on metagenome analysis showed the dominance of Alphaproteobacteria in the original soil sample, with relative abundance of $22 \%$ (Figure 1). This was followed by Acidobacteriia (9\%), Betaproteobacteria (8\%), Gammaproteobacteria (6\%), Actinobacteria (5\%), Deltaproteobacteria (2\%), Sphingobacteria (1\%) and Planctomycetia (1\%). Viruses and Archaea accounted for $0.09 \%$ and $0.3 \%$ of the total sequences, while Eukaryota accounted for 3\% (of which $2 \%$ are Fungi). At genus level, Bradyrhizobium (3\%) dominated in the original soil followed by Pseudomonas (2\%). Other genera present included Sphingomonas, Mycobacterium, Mucilaginibacter, Acidocella, Acidobacterium and Aquabacter. The successive enrichments resulted in a consortium with approximately $60 \%$ relative abundance of Alphaproteobacteria (predominantly Acidocella), followed by Acidobacteriia (Figures 1b and 1c). Other bacterial classes with representative abundance (at least 1\%) in the consortium include Betaproteobacteria, Gammaproteobacteria and Actinobacteria. At the genus level, Acidocella, Acidobacterium and Acidiphilium dominated (Figure 1b). 
(a)

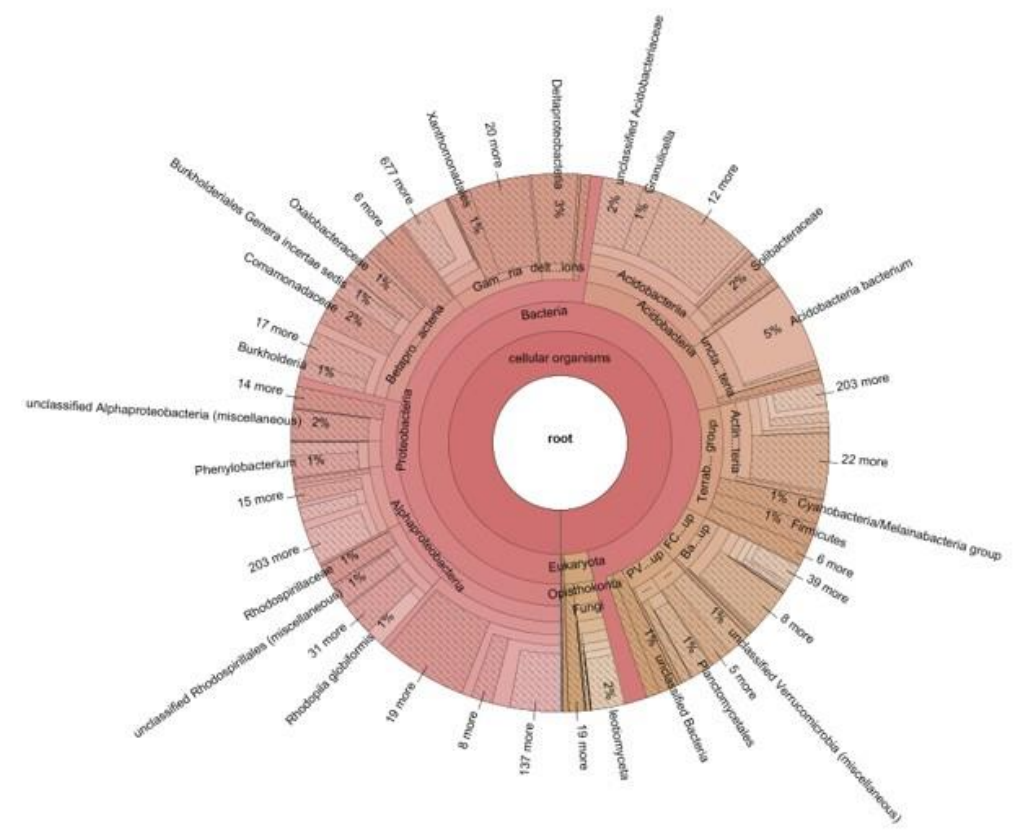

(c)

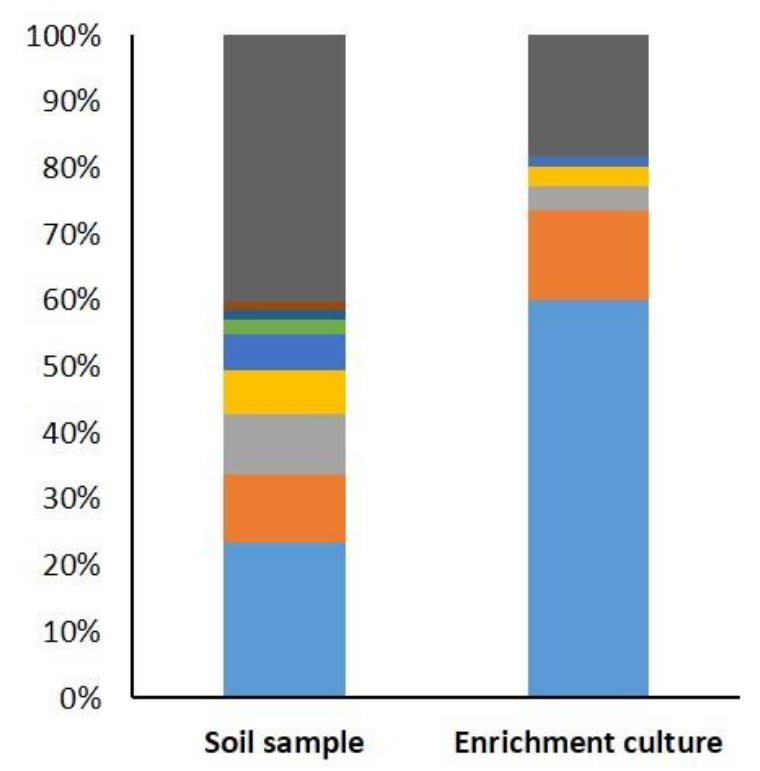

(b)

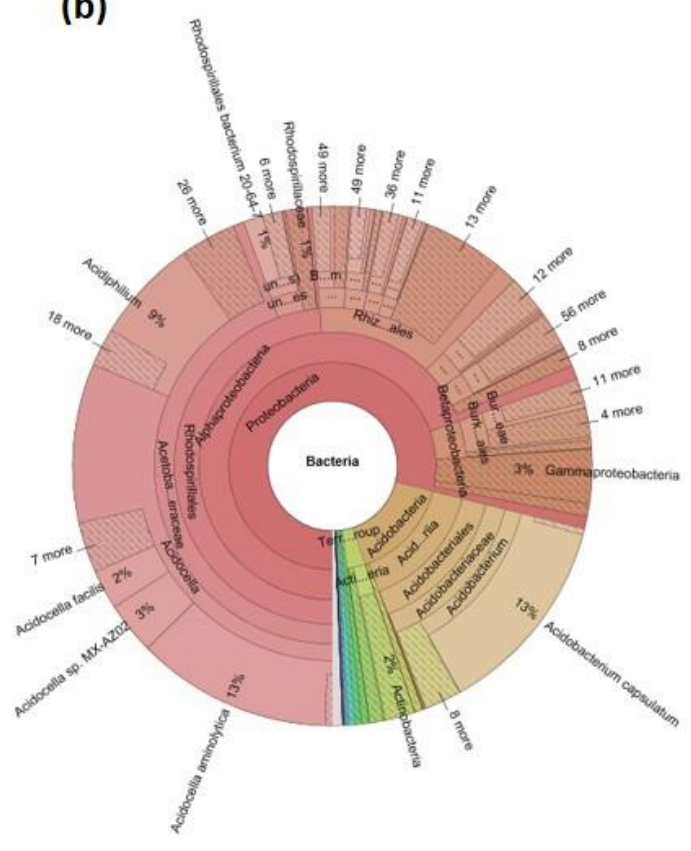

alphaproteobacteria

acidobacteriia

n Betaproteobacteria

- Gammaproteobacteria

- Actinobacteria

- Deltaproteobacteria

- Sphingobacteriia

- Planctomycetia

- Unclassified

Figure 1. Taxonomic classification of (a) the original soil sample and (b) the enrichment culture based on metagenome data, with (c) a summary column chart of the key differences in the bacterial community composition.

\section{Identification of plant growth-promoting enzymes}

Functional analysis of the bacterial consortium revealed the presence of 26 enzymatic classes involved in plant growth-promoting activities putatively (Figure 2). The majority of the 177 coding DNA sequences (CDSs) potentially involved in these reactions were associated with 
phosphate solubilization and nitrogen fixation (99 and $55 \mathrm{CDSs}$, respectively). These were followed by pyrroloquinoline quinone synthesis (13 CDSs), zinc solubilization (5 CDSs), siderophore transport (3 CDSs), and indoleacetic acid synthesis (2 CDSs).

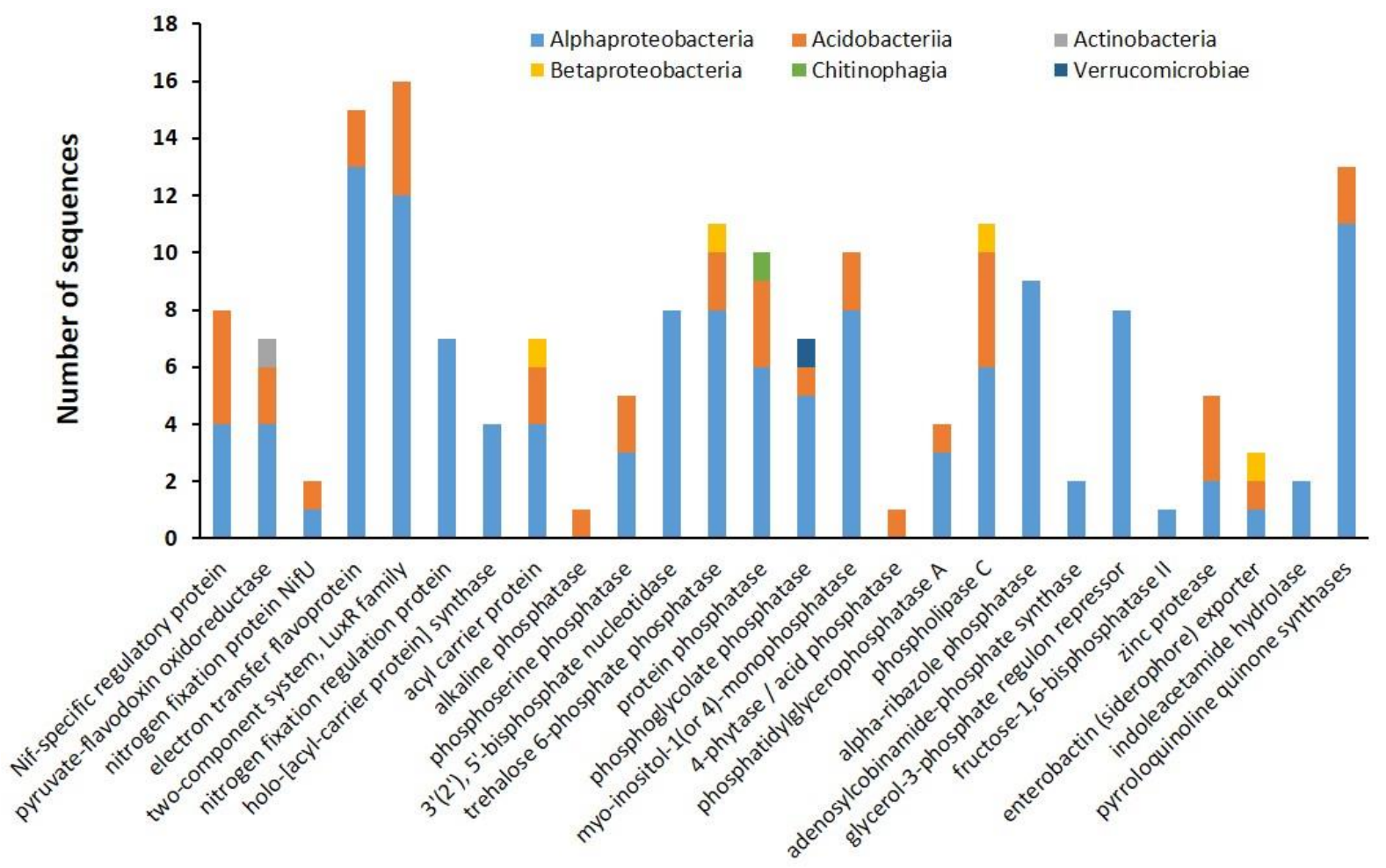

Figure 2. Key enzymes involved in plant growth-promoting activities and their taxonomic assignation at the class level. For detailed information, see Supplementary Table S1.

\section{Taxonomic assignation of CDSs associated with nitrogen uptake}

Functional analysis of the metagenome data revealed the presence of 55 CDSs potentially involved in nitrogen uptake by plants. These include the nifAJU and fixABJKL genes ${ }^{19-21}$. Taxonomic assignment revealed that $56 \%$ of the CDSs involved in nitrogen uptake (31 CDSs) belonged to the Acidocella and Acidobacterium genera (Figure 3). Other represented genera include Acidiphilium, Rhodopseudomonas, Acetobacter, Asaia and Bradyrhizobium. At the species level, Acidocella aminolytica accounted for the majority of the CDSs assigned to Acidocella (Supplementary Table S1). 


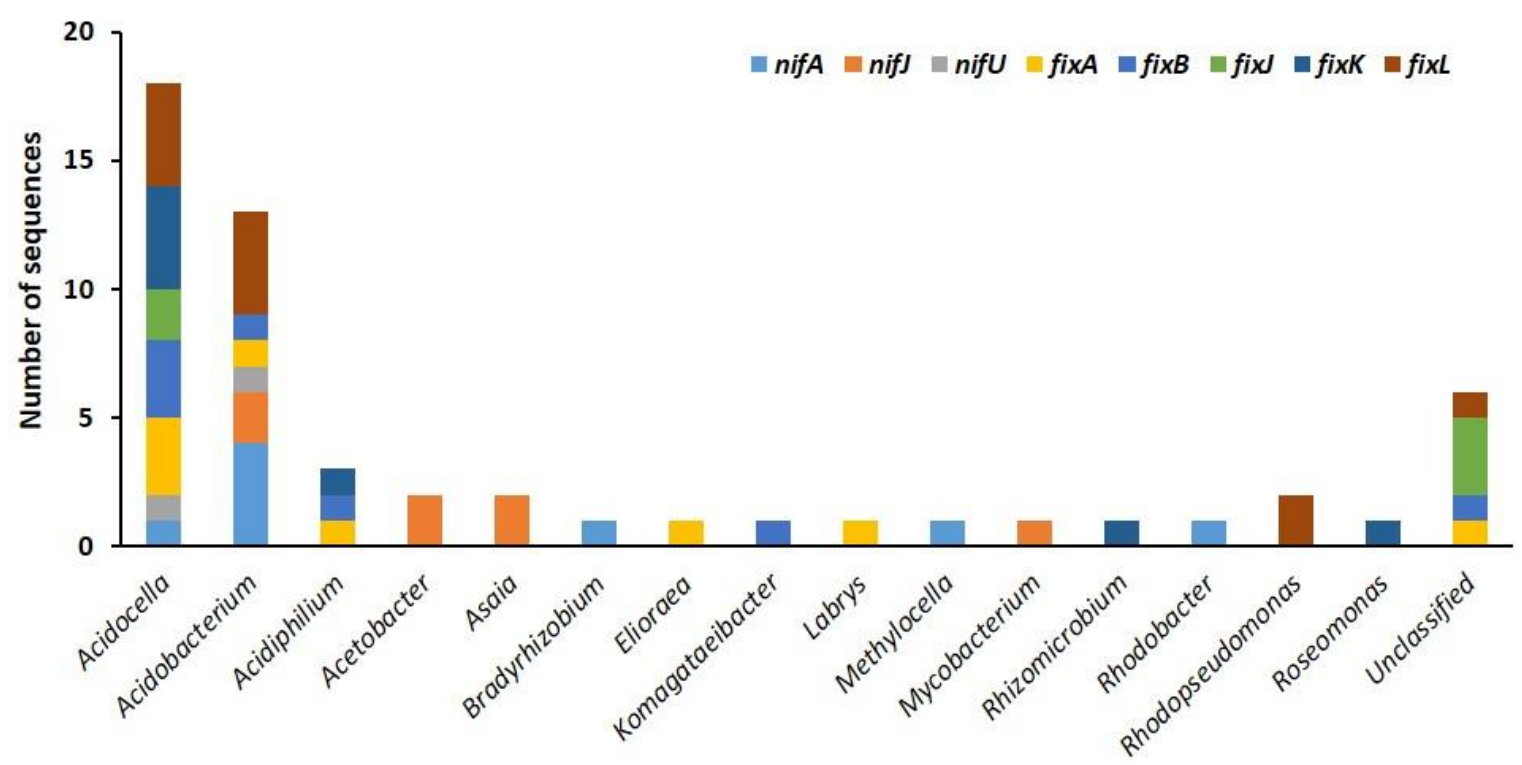

Figure 3. Genus assignment of the genes involved in biological nitrogen fixation. nifA: Nif-specific regulatory protein; nifJ: pyruvate-flavodoxin oxidoreductase; nifU: nitrogen fixation protein NifU; fixA: electron transfer flavoprotein beta subunit; fixB: electron transfer flavoprotein alpha subunit; fixJ: two-component system, LuxR family, response regulator; fixK: nitrogen fixation regulation protein; fixL: two-component system, LuxR family, sensor kinase.

\section{Taxonomic assignation of CDSs associated with phosphate solubilization}

Bacterial taxa involved in phosphate solubilization include Alphaproteobacteria such as Acidocella, Acidiphilium, Methylovirgula, Roseovarius, Skermanella and Sphingomonas; Betaproteobacteria such as Paraburkholderia and Hydrogenophaga; Acidobacteriia such as Acidobacterium capsulatum; Chitinophagia such as Niastella; and Verrucomicrobiae such as Pedosphaera (Supplementary Table S1). The majority of the CDSs belonged to the Acidocella (68\%) and Acidobacterium (19\%). At the species level, the majority of the CDSs belonged to Acidocella aminolytica (44 CDSs) and Acidobacterium capsulatum (19 CDSs) (Supplementary Table S1).

Zinc solubilization, siderophore, indoleacetic acid and pyrroloquinoline quinone syntheses

The results of the metagenome analysis showed that 5 CDSs were putatively involved in zinc solubilization, 3 CDSs in siderophore transport, 2 CDSs in indoleacetic acid synthesis, and 13 CDSs in pyrroloquinoline quinone synthesis (Figure 4). Of the five zinc-solubilizing CDSs, three were assigned to Acidobacterium capsulatum, one to Acidocella aminolytica and one to 
Acidocella facilis (Supplementary Table S1). The three CDSs involved in siderophore production were assigned to Acidobacterium, Acidocella and an unclassified Burkholderiales (1 CDS each) (Figure 4a). The two CDSs responsible for indoleacetic acid synthesis were assigned to Hyphomicrobium and Mesorhizobium genera (Figure 4b). The majority of the pyrroloquinoline quinone synthases belong to Acidocella (9 CDSs), followed by Acidobacterium (2 CDSs), Acidiphilium (1 CDS) and Bosea (1 CDS).

(a)

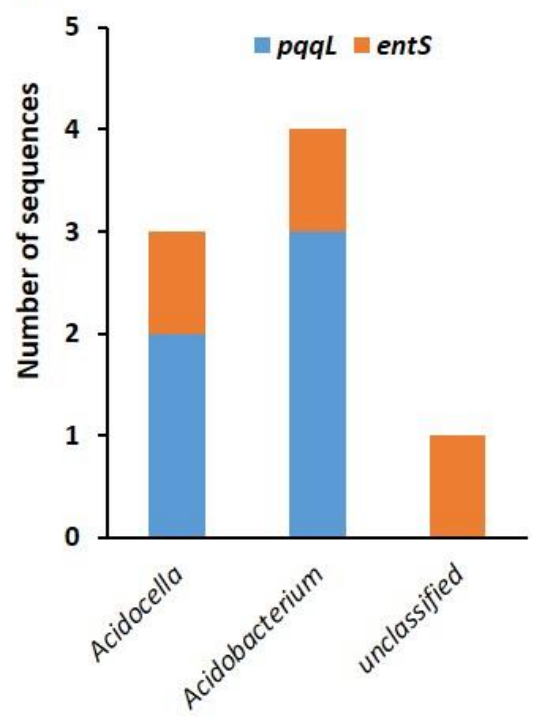

(b)

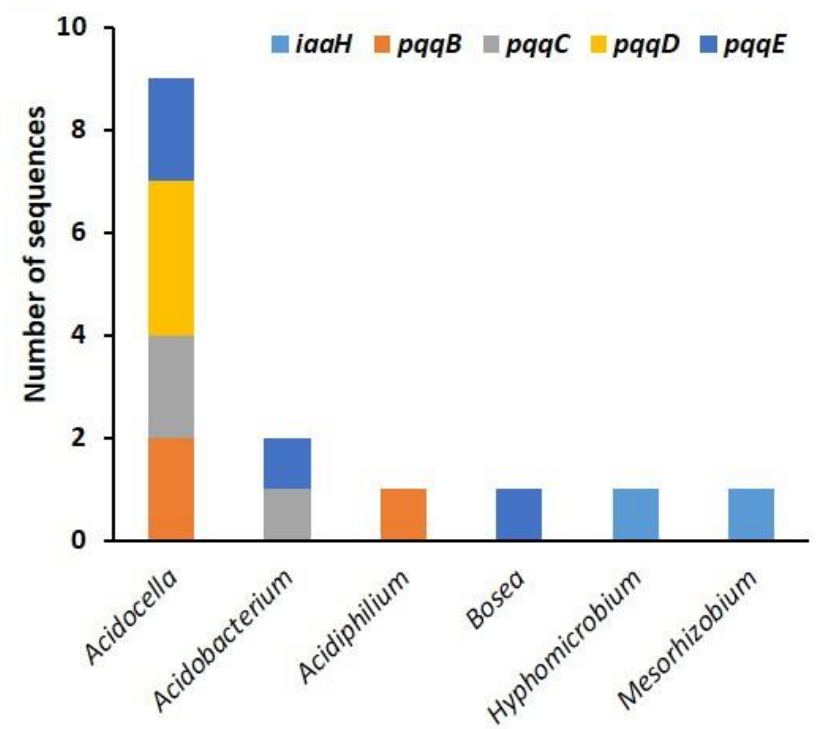

Figure 4. Genus assignment of the genes involved in (a) zinc solubilization and siderophore transport; and (b) indoleacetic acid and pyrroloquinoline quinone biosynthesis. $p q q L$ : zinc protease; entS: Enterobactin (siderophore) exporter; $\mathrm{ia} a \mathrm{H}$ : indoleacetamide hydrolase; $p q q \mathrm{~B}$ : pyrroloquinoline quinone biosynthesis protein $\mathrm{B}$; $p q q C$ : pyrroloquinoline-quinone synthase; $p q q D$ : pyrroloquinoline quinone biosynthesis protein $\mathrm{D} ; p q q E$ : PqqA peptide cyclase.

\section{Effect of bacterial inoculation on plant growth and biomass production}

The inoculation of Medicago sativa with the isolated consortium resulted in increased growth and biomass production of the inoculated plants (Figure 5). The mean dry biomass ( \pm standard error) of $M$. sativa plants inoculated with the consortium was $5.48 \pm 0.07 \mathrm{~g}$, significantly greater $(p<0.001)$ than the dry biomass of plants in the uninoculated control $(3.30 \pm 0.07 \mathrm{~g})$. 


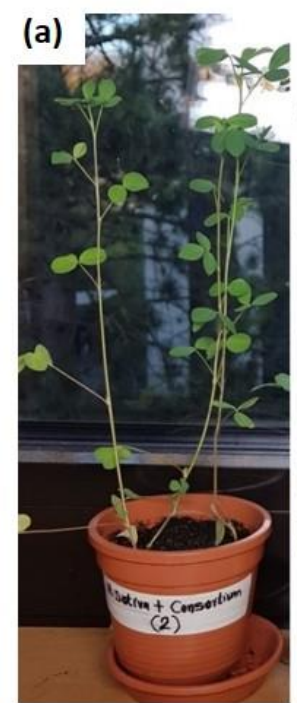

M. sativa + Consortium (b)

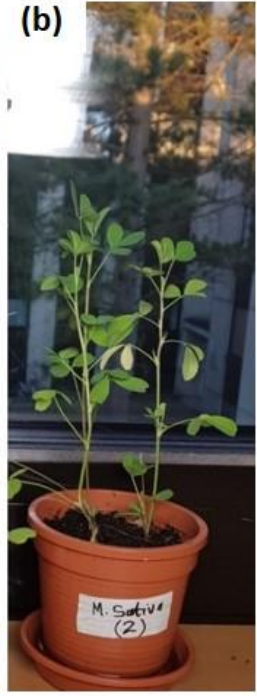

M. sativa (c)

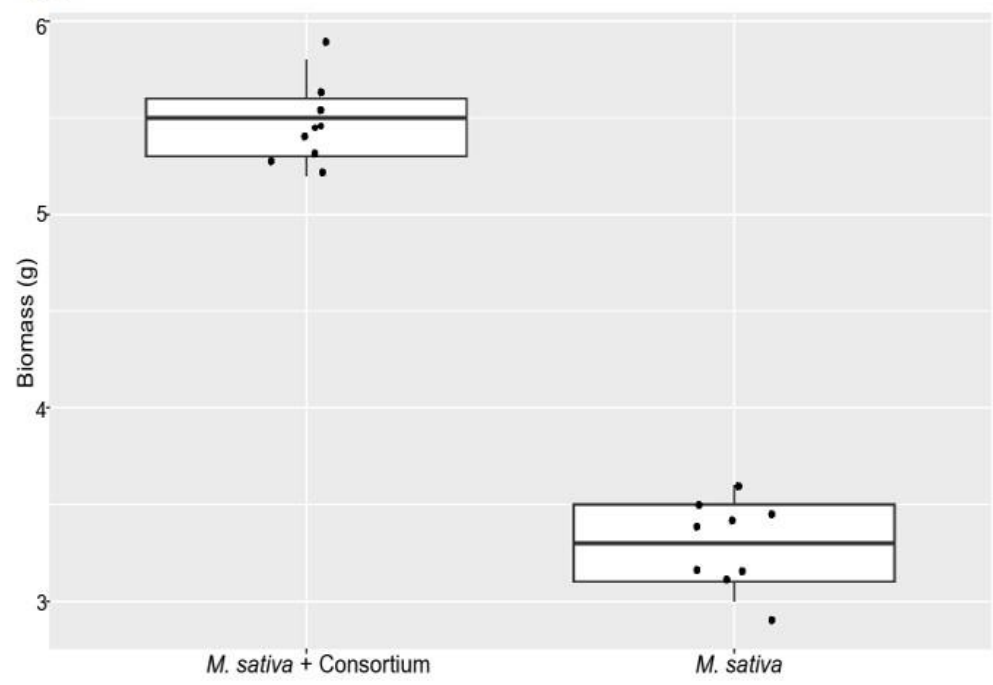

Figure 5. Changes in growth and biomass production of (a) Medicago sativa plants inoculated with the isolated microbial consortium, in comparison with (b) uninoculated Medicago sativa plants. (c) Boxplot showing significant differences in biomass production of inoculated and uninoculated plants.

\section{Effect of inoculation on biodegradation of petroleum hydrocarbons}

Microbial inoculation of $M$. sativa enhanced the biodegradation of petroleum hydrocarbons. The mean residual total petroleum hydrocarbon concentrations ( \pm standard error) for the "Control" (representing natural attenuation) was $2.77 \pm 0.03 \mathrm{~g} / \mathrm{Kg}$, for " $M$. sativa" was $1.36 \pm$ $0.04 \mathrm{~g} / \mathrm{Kg}$, for the "Consortium" was $1.15 \pm 0.05 \mathrm{~g} / \mathrm{Kg}$, and for " $M$. sativa + Consortium" was $0.40 \pm 0.03 \mathrm{~g} / \mathrm{Kg}$ (Figure 6a). These concentrations represent 40\%, 70\%, 75\% and 91\% degradation, respectively. Statistical analysis showed that the effects of the different treatment options were significantly different $(p<0.05)$ from each other. Gas chromatography-mass spectrometry (GC-MS) of solvent extracts prepared from the experimental soils revealed a near complete degradation of both the aliphatic and aromatic hydrocarbons in diesel fuel in the " $M$. sativa + Consortium" treatment (Figure $6 \mathrm{~b}$ and $6 \mathrm{c}$ ). Thus, while natural attenuation resulted in the lowest degradation efficiency, synergistic interactions of $M$. sativa and the consortium led to a significantly higher degradation efficiency. 


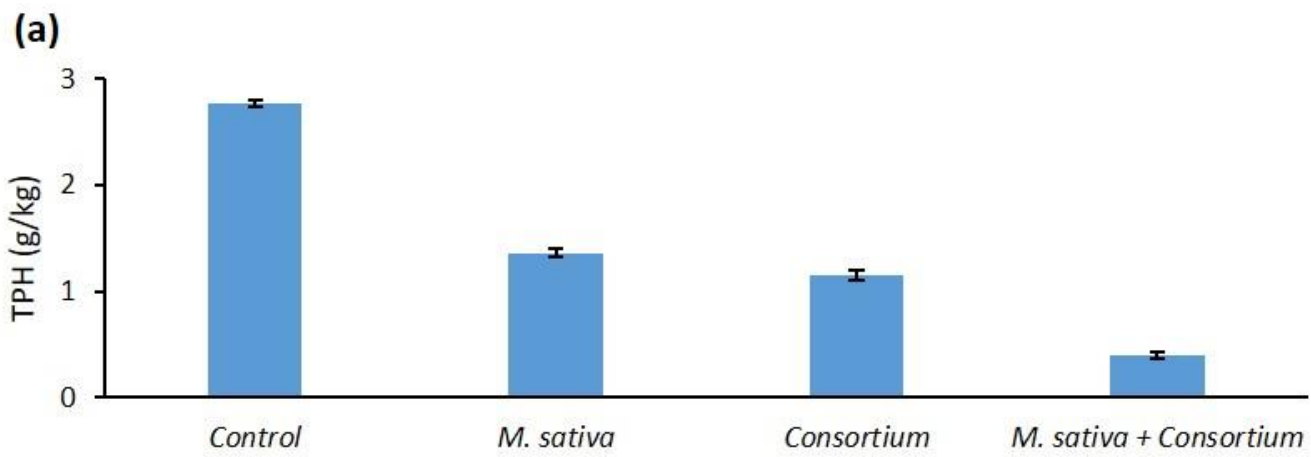

(b)

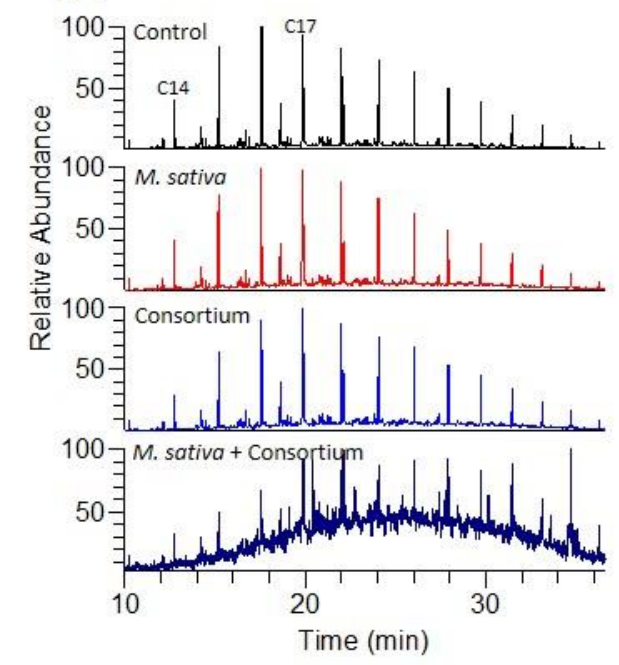

(c)

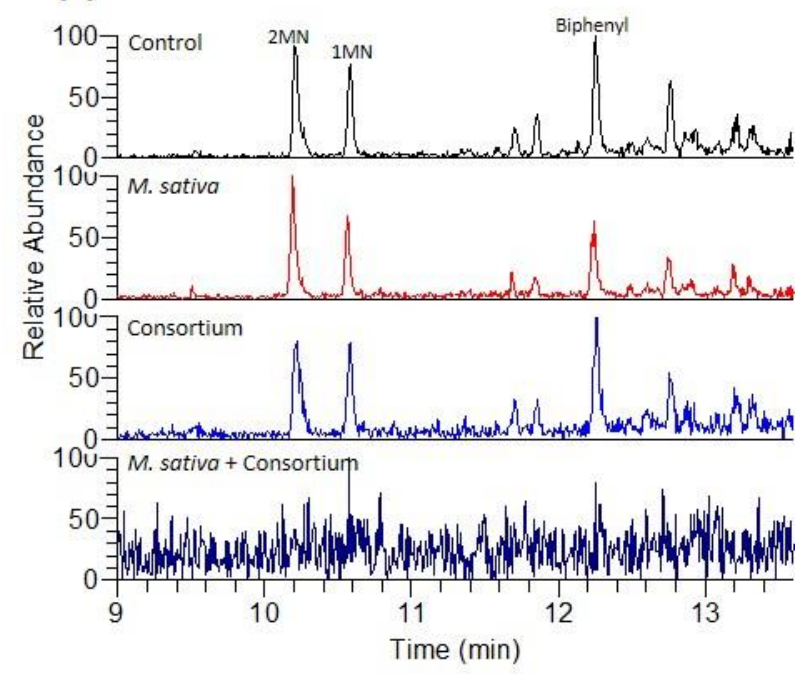

Figure 6. (a) Bar chart showing the mean values of residual total petroleum hydrocarbons (TPH, g/Kg) for the different treatments after 60 days $(\mathrm{n}=3)$. (b) Partial $\mathrm{m} / \mathrm{z} 57$ mass chromatograms showing a homologous series of residual $n$-alkanes in the contaminated soils under different treatments (carbon numbers annotated for $n$ tetradecane and $n$-heptadecane). (c) Partial $\mathrm{m} / z, 142+154$ mass chromatograms of residual soils at the end of the experiment showing differential degradation of methylnaphthalene isomers (MN) and biphenyl under different treatments.

\section{DISCUSSION}

The use of plants to clean up contaminated sites is an eco-friendly and cost-effective technology. However, petroleum hydrocarbons are phytotoxic to most plant species, and consequently impact negatively on plant growth and biomass production ${ }^{17}$. Most plants are unable to prosper in contaminated soils due to hydrocarbon-induced toxicity. Therefore, the isolation of microbial consortia capable of stimulating plant growth and enhancing contaminant degradation in the rhizosphere is crucial to the success of plant-based remediation techniques. The bacterial consortium cultured in this study enabled both enhanced growth of M. sativa and the degradation of hydrocarbons added to the soil. 
The successive enrichment of microorganisms in the contaminated soil resulted in a shift in microbial community composition and diversity. Although Alphaproteobacteria were dominant in both the original soil sample and the enrichment culture, successive enrichment using diesel fuel resulted in an increase in the percentage of Alphaproteobacteria from $22 \%$ in the soil sample to approximately $60 \%$ in the enrichment culture, with Acidocella being the dominant genus. Similarly, previous studies have shown that with increasing duration of hydrocarbon contamination in the environment, there is usually a preferential increase in Alphaproteobacteria over Gammaproteobacteria ${ }^{22}$.

The consortium isolated from this study contains enzymes involved in nitrogen uptake by plants. These include the nif and fix genes. Studies of nitrogenases have revealed that they require electrons to reduce $\mathrm{N}_{2}$, and either a flavodoxin or a ferredoxin is required to transfer electrons from a donor to a nitrogenase, and that nifF and nifJ are responsible for such electron transport ${ }^{19,23}$. In addition, nifA encode a number of regulatory proteins involved in nitrogen fixation ${ }^{24}$. Besides the nif genes, regulation of nitrogen fixation is dependent on the fix genes 21. The majority of CDSs putatively encoding for nitrogen uptake in the metagenome data were assigned to Acidobacterium and Acidocella. This is not surprising considering the dominance of these genera in the consortium (Figure 1). A recent study of various strains of Acidobacteria revealed that they harboured homologous genes for nitrogen uptake ${ }^{25}$. The presence of similar genes in the consortium indicate its potential to enhance nitrogen uptake. Nitrogen is an important limiting element for plant growth and production. It is required for the synthesis of macromolecules such as amino acids, nucleic acids, and chlorophyll. Significantly, efforts toward maximizing plant's nitrogen uptake, translocation and assimilation by rhizobacteria inoculation have attracted much attention in recent decades ${ }^{26-30}$.

Metagenome analysis revealed the presence of genes putatively responsible for phosphate solubilization in our microbial consortium (99 CDSs, Supplementary Table S1). These include acpPS (acyl carrier proteins), phoAB (alkaline phosphatase), otsB (trehalose 6phosphate phosphatase), gph (phosphoglycolate phosphatase), and plc (phospholipase). Previous studies have shown that acyl carrier proteins play a crucial role in the synthesis of fatty acids, which are necessary for cellular membranes' integrity, fluidity and permeability 31,32. Fatty acids also confer structural barriers to the environmental stresses that plants face ${ }^{33}$. Five of the seven CDSs putatively encoding phosphoglycolate phosphatase were assigned to Acidocella (Supplementary Table S1). This enzyme plays a major role in photorespiratory 2phosphoglycolate metabolism, an essential pathway for photosynthesis in plants ${ }^{34-36}$. 
Similarly, seven of the eleven CDSs encoding trehalose 6-phosphate phosphatase, an enzyme that catalyses the biosynthesis of trehalose, were assigned to Acidocella. Trehalose has been found to enhance the tolerance of plants to stress ${ }^{37}$. Consequently, the abundance of such phosphatases in our consortium may account for not only the growth promotion of $M$. sativa plants but also their tolerance to diesel fuel toxicity.

Functional analysis of the metagenome of the consortium from the enrichment revealed the presence of other potential genes important for plant growth promotion. These genes include $p q q L$ (for zinc solubilisation), entS (for siderophore transport), iaaH (for indoleacetic acid synthesis) and $p q q B C D E$ (for pyrroloquinoline quinone synthesis) (Supplementary Table S1). The enzymes that they encode are vital for plant growth and tolerance to contaminant toxicity. For example, the defence strategies of plants against pathogens has been linked to their ability to solubilize zinc ${ }^{38}$. Rhizobacteria that are able to release iron-chelating molecules serve to attract iron towards the rhizosphere, where it can be absorbed by the plants ${ }^{39}$. In addition, siderophore-producing PGPR can hinder the growth of pathogens by limiting the iron available for the pathogen, mostly fungi, which are unable to absorb the iron-siderophore complex ${ }^{40,41}$. Previous studies on siderophore and pyrroloquinoline quinone biosynthesis have focused on Pseudomonas ${ }^{42}$. Similarly, studies on indoleacetic acid production by PGPR have generally been limited to a few microorganisms such as Azospirillum, Pseudomonas, Rhizobium and Burkholderia ${ }^{7,43-46}$. Hence, the identification of Acidocella and Acidobacterium as being potentially involved in these processes, coupled with their hydrocarbon-degrading potentials ${ }^{18}$, significantly expands the range of PGPR applicable for microbially-enhanced phytoremediation of organic pollutants.

During the pot experiment, the consortium significantly enhanced plant growth and hydrocarbon degradation. The inoculation of $M$. sativa with the consortium significantly enhanced plant growth and biomass production (66\%, Figure 5), indicating that the consortium was effective in promoting the growth of $M$. sativa in contaminated soils. Similarly, geochemical analyses revealed not only a reduction in the total petroleum hydrocarbons but also the degradation of both aliphatic and aromatic hydrocarbons (Figure 6). In terms of unitary application, $M$. sativa and the consortium resulted in $70 \%$ and $75 \%$ degradation respectively, indicating that the consortium was marginally more effective for hydrocarbon degradation than M. sativa alone. These results differed from that of a previous study by Garrido-Sanz, et al. ${ }^{10}$, in which the isolated consortium was less effective than $M$. sativa for hydrocarbon remediation. The difference in remediation effectiveness between the two consortia may be attributed to 
differences in their bacterial community composition. The consortium isolated by GarridoSanz, et al. ${ }^{10}$ was dominated by Gammaproteobacteria, especially Pseudomonas. In contrast, Alphaproteobacteria dominated in the consortium isolated in this study (Figure 1). The hydrocarbon-degrading ability of the consortium is evidently associated with the presence of CDSs putatively encoding for monooxygenase and dioxygenases. Previous metagenome analysis of the consortium revealed the presence of key monooxygenases and dioxygenases including, but not limited to, long-chain alkane monooxygenase (ladA), toluene monooxygenase $(\operatorname{tmoCF})$, benzene/toluene/chlorobenzene dioxygenase (todABC1C2) and ethylbenzene dioxygenase $(e t b A a A b A c)^{18}$. Central metabolism of aromatic hydrocarbons that follows initial activation involves ortho- and meta-cleavage of catechol or methylcatechol, and these reactions are orchestrated by enzymes such as catechol 1,2-dioxygenase and catechol 2,3dioxygenase ${ }^{47-53}$. These genes are also present in the metagenome data of the consortium ${ }^{18}$.

Our experiments using the isolated consortium highlighted the role of plant-microbe synergy in the remediation of environmental pollutants. Although bioremediation by either $M$. sativa or the consortium significantly enhanced biodegradation of petroleum hydrocarbons, the greatest effectiveness was achieved in the $M$. sativa + Consortium treatment (91\% degradation within 60 days). These results are of interest not only for biotechnological applications aimed at phytoremediation of toxic compounds, but also for improving crop yield in agriculture ${ }^{54,55}$. The affiliation of most of the plant growth-promoting and hydrocarbon-degrading activities to the two dominant species, namely, Acidocella aminolytica and Acidobacterium capsulatum, is an indication that these species are promising candidates for biotechnological applications in the remediation of organic contaminants.

\section{MATERIALS AND METHODS}

\section{Study site description}

Wietze is an important historical site in terms of crude-oil production. Industrial extraction of petroleum in Germany began in 1859 56. Between 1900 and 1920, Wietze was the most productive oil field in Germany, and almost $80 \%$ of German crude oil was produced here. Although oil production ceased at Wietze several decades ago, there are still a significant number of oil seeps, contaminating soils, and water bodies. These sites harbour several plant species. Therefore, Wietze is an ideal place to mine for plant growth-promoting and hydrocarbon-degrading microorganisms. 


\section{Soil sampling, enrichment and growth conditions}

Approximately $10 \mathrm{~g}$ of topsoil $(0-10 \mathrm{~cm})$ was taken from a heavily polluted site located at the

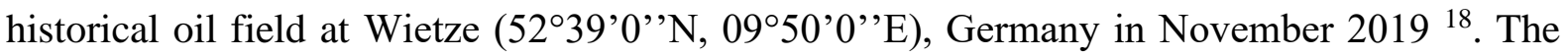
sample was transported to the laboratory on ice.

A $1 \mathrm{~g}$ subsample of the field sample was added to an Erlenmeyer flask (300 mL) containing $100 \mathrm{~mL}$ of liquid mineral medium. Mineral medium was $\mathrm{KH}_{2} \mathrm{PO}_{4}(0.5 \mathrm{~g} / \mathrm{L}), \mathrm{NaCl}(0.5 \mathrm{~g} / \mathrm{L})$, $\mathrm{NH}_{4} \mathrm{Cl}(0.5 \mathrm{~g} / \mathrm{L})$. Sterile-filtered trace elements $(1 \mathrm{~mL} / \mathrm{L}){ }^{57}$, vitamin solution $(1 \mathrm{~mL} / \mathrm{L}){ }^{57}$ and $\mathrm{MgSO}_{4} \cdot 7 \mathrm{H}_{2} \mathrm{O}(5 \mathrm{~mL}$ of a $100 \mathrm{mg} / \mathrm{mL}$ ) were added post-autoclaving. Sterile-filtered diesel fuel $(1 \mathrm{~mL})$ was added to the flask as the sole carbon and energy source. The culture was grown at $30^{\circ} \mathrm{C}$ with constant shaking at $110 \mathrm{rpm}$ (INFORS HT shaker, model $\mathrm{CH}-4103$, Infors AG, Bottmingen, Switzerland) and subcultured every five days. After three successive enrichments, microbial cells were harvested for both metagenome studies and a greenhouse experiment.

\section{DNA extraction}

Microbial cells $\left(\mathrm{OD}_{600}=0.635\right)$ from $30 \mathrm{~mL}$ of the enrichment culture were harvested by centrifugation at $4000 \mathrm{x} g$ for $10 \mathrm{~min}$. The supernatant was subsequently discarded. DNA from the cell pellets was extracted using the PowerSoil ${ }^{\circ}$ DNA Extraction kit (Qiagen, Hilden, Germany).

\section{DNA extraction, metagenome sequencing, assembly and analysis}

The extraction of the DNA was described in Eze, et al. ${ }^{18}$. In brief, microbial cells $\left(\mathrm{OD}_{600}=\right.$ 0.635 ) from $30 \mathrm{~mL}$ of the enrichment culture were harvested by centrifugation at $4000 \mathrm{x} \mathrm{g}$ for 10 min. DNA from the cell pellets was extracted using the PowerSoil@ DNA Extraction kit (Qiagen, Hilden, Germany). Sequencing libraries were generated from environmental DNA. These were barcoded using the Nextera XT-Index kit (Illumina, San Diego, USA) and the Kapa HIFI Hot Start polymerase (Kapa Biosystems, Wilmington, USA). The Göttingen Genomics Laboratory determined the sequences employing an Illumina HiSeq 2500 system using the HiSeq Rapid SBS kit V2 (2x250 bp). Metagenomic reads were further processed as described in Eze, et al. ${ }^{16}$. In brief, reads were processed with the Trimmomatic tool version $0.39{ }^{58}$ and assembled using metaSPAdes version 3.13.2 ${ }^{59}$. Coverage information for each scaffold was determined using Bowtie2 version 2.3.2 ${ }^{60}$ and SAMtools version $1.7^{61}$. Functional annotation of coding DNA sequences putatively encoding for the various plant growth-promoting 
enzymes was as described previously ${ }^{18}$, and taxonomic assignment was performed using kaiju version $1.7 .3^{62}$.

\section{Potential plant growth-promoting enzymes}

The enzymes of interest include nif-specific regulatory protein, pyruvate-flavodoxin oxidoreductase, nitrogen fixation protein, electron transfer flavoprotein, nitrogen fixation regulation protein, phosphatases, acyl carrier protein, phospholipases, zinc protease, enterobactin (siderophore) exporter, indoleacetamide hydrolase and pyrroloquinoline quinone synthases.

\section{Plant growth and bacterial inoculation}

Plant growth and bacterial inoculation involved the inoculation of diesel fuel-spiked soils with the isolated consortium in order to determine effects on plant growth and hydrocarbon change. The soil used for this experiment was "Primaster turf". Primaster turf is made from a mixture of screened sand, soil, and composted organics. It is blended with a nitrogen-phosphorouspotassium fertiliser to promote root growth throughout the year. The soil texture was sand ( $88.6 \%$ sand, $6.1 \%$ silt and $5.3 \%$ clay), with $12.5 \%$ organic matter content measured by loss on ignition. The soil had a total nitrogen content of $0.15 \%$ and a $\mathrm{pH}$ of 7.1. The soil was sieved using a 2-mm sieve to remove large particles. Diesel fuel $\left(\mathrm{C}_{10}-\mathrm{C}_{25}\right)$ from a Shell service station in Göttingen (Germany) was added to the soil and homogenized following the methods of Eze, et al. ${ }^{17}$ with some modifications. In brief, the soil was manually homogenized for an hour. This was followed by automatic homogenization using a portable soil mixing machine (Güde Model GRW 1400) for 30 minutes. Gas chromatography-mass spectrometry analysis revealed that the resulting total petroleum hydrocarbons concentration in the diesel fuel-contaminated soil was $4.59 \mathrm{~g} / \mathrm{kg}$. Viable seeds of Medicago sativa $\mathrm{L}$. were placed in pots (3 seeds per pot) containing $150 \mathrm{~g}$ of diesel fuel contaminated soils.

The contaminated soil was treated with the following: (1) M. sativa; (2) Consortium; (3) M. sativa + consortium. An unplanted and uninoculated soil served as the control. Since the goal of the study was to assess the effectiveness of each treatment for hydrocarbon degradation, the soil used for the entire experiment was the diesel fuel-contaminated soil $(4.59 \mathrm{~g} / \mathrm{kg})$ as described above. The microbial consortium used was harvested from the culture by centrifugation at $4000 \mathrm{x} \mathrm{g}$ for $10 \mathrm{~min}$, washed twice in mineral medium and concentrated to $\mathrm{OD}_{600}=1.800$. For the $M$. sativa + consortium treatment, the cells $\left(\right.$ at $\left.\mathrm{OD}_{600}=1.800\right)$ were inoculated to the base of one-week-old Medicago sativa L. seedlings at the depth of $1.5 \mathrm{~cm}$ 
below-ground level. The whole experiment was performed in triplicate, and pots were watered with $90 \mathrm{~mL}$ sterile water every three days for the first two weeks. After that, the planted pots were watered with $90 \mathrm{~mL}$ sterile water every two days to compensate for the water needs of $M$. sativa plants. After 60 days, the plants were harvested, washed under tap water, oven-dried at $70{ }^{\circ} \mathrm{C}$ until constant weights were achieved, and then their dry biomass weights were obtained.

\section{Organic geochemical analysis of biodegradation}

At the end of the experimental period, soils in each pot were homogenized as described earlier. Soils were freeze dried and $1 \mathrm{~g}$ of the ground freeze-dried soil was further homogenized with a small amount of sodium sulfate $\left(\mathrm{Na}_{2} \mathrm{SO}_{4}\right)$ and transferred into a Teflon microwave digestion vessel for hydrocarbon analysis. The samples were solvent extracted twice with fresh $2.5 \mathrm{~mL}$ n-hexane each in a microwave device (Mars Xpress, CEM; 1600W, $100{ }^{\circ} \mathrm{C}, 20 \mathrm{~min}$ ). For reference, $2.5 \mu \mathrm{L}$ diesel fuel (density $=0.82 \mathrm{~g} / \mathrm{mL}$ ) was dissolved in $5 \mathrm{~mL} n$-hexane instead of $1 \mathrm{~g}$ soil sample. The extracts for each sample were combined into a $7 \mathrm{~mL}$ vial and topped to 5 $\mathrm{mL}$ with $n$-hexane. A $1 \mathrm{~mL}$ aliquot (20\%) of each extract was pipetted into a $2 \mathrm{~mL}$ autosampler vial, and $20 \mu \mathrm{L} \mathrm{n}$-icosane D42 [200 mg/L] was added as an internal quantification standard.

Gas chromatography-mass spectrometry (GC-MS) analyses of the samples were performed using a Thermo Scientific Trace 1300 Series GC coupled to a Thermo Scientific Quantum XLS Ultra MS. The GC capillary column used was a Phenomenex Zebron ZB-5MS (30 m, $0.1 \mu \mathrm{m}$ film thickness, inner diameter $0.25 \mathrm{~mm}$ ). Compounds were transferred splitless to the GC column at an injector temperature of $300{ }^{\circ} \mathrm{C}$. Helium was used as the carrier gas at a flow rate of $1.5 \mathrm{~mL} / \mathrm{min}$. The GC temperature program was as follows: $80{ }^{\circ} \mathrm{C}$ (hold $1 \mathrm{~min}$ ), $80{ }^{\circ} \mathrm{C}$ to 310 ${ }^{\circ} \mathrm{C}$ at $5{ }^{\circ} \mathrm{C} / \mathrm{min}$ (hold $20 \mathrm{~min}$ ). Electron ionization mass spectra were recorded at $70 \mathrm{eV}$ electron energy in full scan mode (mass range m/z 50-600, scan time $0.42 \mathrm{~s}$ ). Peak areas were integrated using Thermo Xcalibur software version 2.2 (Thermo Fisher Scientific Inc., USA).

\section{Statistical analysis}

All statistical analysis were performed using $\mathrm{R}^{63}$. One-way analysis of variance (ANOVA) was used to compare the mean dry biomass of " $M$. sativa" and " $M$. sativa + consortium" treatments. Similarly, comparisons of soil residual hydrocarbon concentrations between treatments were made using one-way ANOVA, followed by Tukey's all-pairwise comparisons. In all cases, the normality of variances was tested by the Shapiro-Wilk's method ${ }^{64}$, while homogeneity of variances was tested using Levene's test ${ }^{65}$. Differences were considered significant at $p<0.05$. The $p$ values were adjusted using the Holm method, as this approach 
offers a simple, yet uniformly powerful method to control family-wise error rate in multiple comparisons ${ }^{66,67}$.

\section{Acknowledgements}

The authors would like to thank the Commonwealth Government of Australia and the German Academic Exchange Service (DAAD) for supporting this research project by providing M.O.E. with an international Research Training Program (iRTP) Scholarship and DAAD Scholarship (Allocation Numbers: 2017561 and 91731339 respectively). This publication was supported financially by the Open Access Grant Program of the German Research Foundation (DFG) and the Open Access Publication Fund of the University of Goettingen. We also thank Dr. Anja Poehlein and Melanie Heinemann for the assistance during sequencing.

\section{Author contributions}

Conceptualization and design: MOE, GCH, SCG and RD. Planning and implementation: MOE, SCG and RD. Experiments and bioinformatics analyses: MOE. Geochemical analysis: MOE and VT. Writing - original draft: MOE. Writing - review and editing: VT, GCH, SCG and RD. Supervision: GCH, SCG and RD.

\section{Competing interests}

The authors declare no competing interests.

\section{Data Availability}

Raw sequencing data has been deposited in the sequence read archive of the National Center for Biotechnology Information under BioProject number PRJNA612814. The accession numbers used in this study are SRR11310428 and SRR11310429. 


\section{References}

1 USEPA EPA/600/R-99/107. Introduction to Phytoremediation. United States Environmental Protection Agency (2000).

2 Glick, B. R. Phytoremediation: synergistic use of plants and bacteria to clean up the environment. Biotechnol. Adv. 21, 383-393, doi:https://doi.org/10.1016/S07349750(03)00055-7 (2003).

3 Dzantor, E. K. Phytoremediation: the state of rhizosphere 'engineering' for accelerated rhizodegradation of xenobiotic contaminants. J. Chem. Technol. Biotechnol. 82, 228-232, doi:10.1002/jctb.1662 (2007).

4 Sun, S.-L. et al. The plant growth-promoting rhizobacterium Variovorax boronicumulans CGMCC 4969 regulates the level of indole-3-acetic acid synthesized from indole-3-acetonitrile. Appl. Environ. Microbiol. 84, e00298-00218, doi:10.1128/AEM.00298-18 (2018).

5 Goswami, D., Thakker, J. N. \& Dhandhukia, P. C. Portraying mechanics of plant growth promoting rhizobacteria (PGPR): A review. Cogent Food Agric. 2, doi:10.1080/23311932.2015.1127500 (2016).

6 Bhattacharyya, P. N. \& Jha, D. K. Plant growth-promoting rhizobacteria (PGPR): emergence in agriculture. World J. Microbiol. Biotechnol. 28, 1327-1350, doi:10.1007/s11274-011-0979-9 (2012).

7 Saharan, B. S. \& Nehra, V. Plant growth promoting rhizobacteria: a critical review. Life Sci. Med. Res. 2011 (2011).

8 Bashan, Y. \& de-Bashan, L. How the plant growth-promoting bacterium Azospirillum promotes plant growth - a critical assessment. Adv. Agron. 108, 77-136, doi:10.1016/S0065-2113(10)08002-8 (2010).

9 Garrido-Sanz, D., Manzano, J., Martín, M., Redondo-Nieto, M. \& Rivilla, R. Metagenomic analysis of a biphenyl-degrading soil bacterial consortium reveals the metabolic roles of specific populations. Front. Microbiol. 9, doi:10.3389/fmicb.2018.00232 (2018).

10 Garrido-Sanz, D. et al. Metagenomic insights into the bacterial functions of a dieseldegrading consortium for the rhizoremediation of diesel-polluted soil. Genes $\mathbf{1 0}$, doi:10.3390/genes10060456 (2019).

11 Di Martino, C., López, N. I. \& Raiger Iustman, L. J. Isolation and characterization of benzene, toluene and xylene degrading Pseudomonas sp. selected as candidates for bioremediation. Int. Biodeterior. Biodegradation 67, 15-20, doi:https://doi.org/10.1016/j.ibiod.2011.11.004 (2012).

12 de Lima-Morales, D. et al. Degradation of benzene by Pseudomonas veronii 1 YdBTEX2 and 1YB2 is catalyzed by enzymes encoded in distinct catabolism gene clusters. Appl. Environ. Microbiol. 82, 167-173, doi:10.1128/AEM.03026-15 (2015). 
13 Dias, G. M. et al. Comparative genomics of Paraburkholderia kururiensis and its potential in bioremediation, biofertilization, and biocontrol of plant pathogens. MicrobiologyOpen 8, e00801, doi:10.1002/mbo3.801 (2019).

14 Lee, Y. \& Jeon, C. O. Paraburkholderia aromaticivorans sp. nov., an aromatic hydrocarbon-degrading bacterium, isolated from gasoline-contaminated soil. Int. J. Syst. Evol. Microbiol. 68, 1251-1257, doi:https://doi.org/10.1099/ijsem.0.002661 (2018).

15 Lee, Y., Lee, Y. \& Jeon, C. O. Biodegradation of naphthalene, BTEX, and aliphatic hydrocarbons by Paraburkholderia aromaticivorans BN5 isolated from petroleumcontaminated soil. Sci. Rep. 9, 860, doi:10.1038/s41598-018-36165-x (2019).

16 Eze, M. O. et al. Metagenome assembly and metagenome-assembled genome sequences from a historical oil field located in Wietze, Germany. Microbiol. Resour. Announc. 9, e00333-00320, doi:10.1128/MRA.00333-20 (2020).

17 Eze, M. O., George, S. C. \& Hose, G. C. Dose-response analysis of diesel fuel phytotoxicity on selected plant species. Chemosphere 263, 128382, doi:https://doi.org/10.1016/j.chemosphere.2020.128382 (2021).

18 Eze, M. O., Hose, G. C., George, S. C. \& Daniel, R. Diversity and metagenome analysis of a hydrocarbon-degrading bacterial consortium from asphalt lakes located in Wietze, Germany. bioRxiv, 2021.2003.2025.436929,

doi:10.1101/2021.03.25.436929 (2021).

19 Hill, S. \& Kavanagh, E. P. Roles of nifF and nifJ gene products in electron transport to nitrogenase in Klebsiella pneumoniae. J. Bacteriol. 141, 470-475 (1980).

20 Noel, K. D. Rhizobia, in: Encyclopedia of Microbiology (Third Edition) ed. Moselio Schaechter. Oxford Academic Press, 261-277 (2009).

21 Lindström, K. \& Mousavi, S. A. Effectiveness of nitrogen fixation in rhizobia. Microb. Biotechnol. 13, 1314-1335, doi:10.1111/1751-7915.13517 (2020).

22 Bordenave, S., Goñi-Urriza, M. S., Caumette, P. \& Duran, R. Effects of heavy fuel oil on the bacterial community structure of a pristine microbial mat. Appl. Environ. Microbiol. 73, 6089, doi:10.1128/AEM.01352-07 (2007).

23 Nieva-Gómez, D., Roberts, G. P., Klevickis, S. \& Brill, W. J. Electron transport to nitrogenase in Klebsiella pneumoniae. Proc. Natl. Acad. Sci. U.S.A. 77, 2555-2558, doi:10.1073/pnas.77.5.2555 (1980).

24 Ludden, P. W. in New Horizons in Nitrogen Fixation: Proceedings of the 9th International Congress on Nitrogen Fixation, Cancún, Mexico, December 6-12, 1992 (eds Rafael Palacios, Jaime Mora, \& William E. Newton), 101-104, Springer Netherlands (1993).

25 Eichorst, S. A. et al. Genomic insights into the Acidobacteria reveal strategies for their success in terrestrial environments. Environ. Microbiol. 20, 1041-1063, doi:10.1111/1462-2920.14043 (2018). 
26 Xu, G., Fan, X. \& Miller, A. J. Plant nitrogen assimilation and use efficiency. Annu. Rev. Plant Biol. 63, 153-182, doi:10.1146/annurev-arplant-042811-105532 (2012).

27 Koskey, G. et al. Potential of native rhizobia in enhancing nitrogen fixation and yields of climbing beans (Phaseolus vulgaris L.) in contrasting environments of eastern Kenya. Front. Plant Sci. 8, doi:10.3389/fpls.2017.00443 (2017).

28 Zahran, H. H. Rhizobium-legume symbiosis and nitrogen fixation under severe conditions and in an arid climate. Microbiol. Mol. Biol. Rev. 63, 968-989 (1999).

29 Mus, F. et al. Symbiotic nitrogen fixation and the challenges to its extension to nonlegumes. Appl. Environ. Microbiol. 82, 3698, doi:10.1128/AEM.01055-16 (2016).

30 Mahmud, K., Makaju, S., Ibrahim, R. \& Missaoui, A. Current progress in nitrogen fixing plants and microbiome research. Plants 9, 97, doi:10.3390/plants9010097 (2020).

31 Rodríguez-Vargas, S., Sánchez-García, A., Martínez-Rivas, J. M., Prieto, J. A. \& Randez-Gil, F. Fluidization of membrane lipids enhances the tolerance of Saccharomyces cerevisiae to freezing and salt stress. Appl. Environ. Microbiol. 73, 110-116, doi:10.1128/AEM.01360-06 (2007).

32 Maejima, E. \& Watanabe, T. Proportion of phospholipids in the plasma membrane is an important factor in Al tolerance. Plant Signal. Behav. 9, e29277-e29277, doi:10.4161/psb.29277 (2014).

33 Huang, J. et al. Genes of acyl carrier protein family show different expression profiles and overexpression of acyl carrier protein 5 modulates fatty acid composition and enhances salt stress tolerance in Arabidopsis. Front. Plant Sci. 8, 987, doi:10.3389/fpls.2017.00987 (2017).

34 Flügel, F. et al. The photorespiratory metabolite 2-phosphoglycolate regulates photosynthesis and starch accumulation in Arabidopsis. Plant Cell 29, 2537-2551, doi:10.1105/tpc.17.00256 (2017).

35 Norman, E. G. \& Colman, B. Purification and characterization of phosphoglycolate phosphatase from the Cyanobacterium Coccochloris peniocystis. Plant Physiol. 95, 693-698, doi:10.1104/pp.95.3.693 (1991).

36 Duff, S. M. G., Sarath, G. \& Plaxton, W. C. The role of acid phosphatases in plant phosphorus metabolism. Physiol. Plant. 90, 791-800, doi:10.1111/j.13993054.1994.tb02539.x (1994).

37 Paul, M. J., Gonzalez-Uriarte, A., Griffiths, C. A. \& Hassani-Pak, K. The role of trehalose 6-phosphate in crop yield and resilience. Plant Physiol. 177, 12-23, doi:10.1104/pp.17.01634 (2018).

38 Cabot, C. et al. A role for zinc in plant defense against pathogens and herbivores. Front. Plant Sci. 10, 1171, doi:10.3389/fpls.2019.01171 (2019).

39 Payne, S. M. Detection, isolation and characterization of siderophores, in: Methods in Enzymology Vol. 235, 329-344, Academic Press (1994). 
40 Shen, X., Hu, H., Peng, H., Wang, W. \& Zhang, X. Comparative genomic analysis of four representative plant growth-promoting rhizobacteria in Pseudomonas. BMC Genom. 14, 271, doi:10.1186/1471-2164-14-271 (2013).

41 Glick, B. R. The enhancement of plant growth by free-living bacteria. Can. J. Microbiol. 41, 109-117, doi:10.1139/m95-015 (1995).

42 Haas, D. \& Défago, G. Biological control of soil-borne pathogens by fluorescent pseudomonads. Nat. Rev. Microbiol. 3, 307-319, doi:10.1038/nrmicro1129 (2005).

43 Theunis, M., Kobayashi, H., Broughton, W. J. \& Prinsen, E. Flavonoids, nodD1, nodD2, and nod-Box NB15 modulate expression of the $\mathrm{y} 4 \mathrm{wEFG}$ locus that is required for indole-3-acetic acid synthesis in Rhizobium sp. strain NGR234. Mol. Plant Microbe Interact. 17, 1153-1161, doi:10.1094/MPMI.2004.17.10.1153 (2004).

44 Malhotra, M. \& Srivastava, S. An ipdC gene knock-out of Azospirillum brasilense strain SM and its implications on indole-3-acetic acid biosynthesis and plant growth promotion. Antonie van Leeuwenhoek 93, 425-433, doi:10.1007/s10482-007-9207-x (2008).

45 Patten, C. L. \& Glick, B. R. Role of Pseudomonas putida indoleacetic acid in development of the host plant root system. Appl. Environ. Microbiol. 68, 3795, doi:10.1128/AEM.68.8.3795-3801.2002 (2002).

46 Liu, W.-H. et al. Indole-3-acetic acid in Burkholderia pyrrocinia JK-SH007: Enzymatic identification of the indole-3-acetamide synthesis pathway. Front. Microbiol. 10, 2559, doi:10.3389/fmicb.2019.02559 (2019).

47 Neidle, E. L., Hartnett, C., Bonitz, S. \& Ornston, L. N. DNA sequence of the Acinetobacter calcoaceticus catechol 1,2-dioxygenase I structural gene catA: evidence for evolutionary divergence of intradiol dioxygenases by acquisition of DNA sequence repetitions. J. Bacteriol. 170, 4874, doi:10.1128/jb.170.10.48744880.1988 (1988).

48 Benjamin, R. C., Voss, J. A. \& Kunz, D. A. Nucleotide sequence of $x y l E$ from the TOL pDK1 plasmid and structural comparison with isofunctional catechol-2,3dioxygenase genes from TOL, pWW0 and NAH7. J. Bacteriol. 173, 2724, doi:10.1128/jb.173.8.2724-2728.1991 (1991).

49 Ehrt, S., Schirmer, F. \& Hillen, W. Genetic organization, nucleotide sequence and regulation of expression of genes encoding phenol hydroxylase and catechol 1,2dioxygenase in Acinetobacter calcoaceticus NCIB8250. Mol. Microbiol. 18, 13-20, doi:10.1111/j.1365-2958.1995.mmi_18010013.x (1995).

50 Peters, K. E., Walters, C. C. \& Moldowan, J. M. The Biomarker Guide: Volume 2: Biomarkers and Isotopes in Petroleum Systems and Earth History. Cambridge University Press. (2004).

51 Liang, C., Huang, Y. \& Wang, H. pahE, a functional marker gene for polycyclic aromatic hydrocarbon-degrading bacteria. Appl. Environ. Microbiol. 85, e0239902318, doi:10.1128/AEM.02399-18 (2019). 
52 Hidalgo, K. J., Sierra-Garcia, I. N., Dellagnezze, B. M. \& de Oliveira, V. M. Metagenomic insights into the mechanisms for biodegradation of polycyclic aromatic hydrocarbons in the oil supply chain. Front. Microbiol. 11, 2250, doi:10.3389/fmicb.2020.561506 (2020).

53 Rohrbacher, F. \& St-Arnaud, M. Root exudation: the ecological driver of hydrocarbon rhizoremediation. Agronomy 6, doi:10.3390/agronomy6010019 (2016).

54 Olanrewaju, O. S., Glick, B. R. \& Babalola, O. O. Mechanisms of action of plant growth promoting bacteria. World J. Microbiol. Biotechnol. 33, 197-197, doi:10.1007/s11274-017-2364-9 (2017).

55 Tsavkelova, E. A., Cherdyntseva, T. A., Botina, S. G. \& Netrusov, A. I. Bacteria associated with orchid roots and microbial production of auxin. Microbiol. Res. 162, 69-76, doi:https://doi.org/10.1016/j.micres.2006.07.014 (2007).

56 Craig, J., Gerali, F., MacAulay, F. \& Sorkhabi, R. The history of the European oil and gas industry (1600s-2000s). Geological Society, London, Special Publications 465, 1, doi:10.1144/SP465.23 (2018).

57 Atlas, R. M. Handbook of microbiological media. Fourth edition edn. CRC Press, Boca Raton, Florida (2010).

58 Bolger, A. M., Lohse, M. \& Usadel, B. Trimmomatic: a flexible trimmer for Illumina sequence data. Bioinformatics 30, 2114-2120, doi:10.1093/bioinformatics/btu170 (2014).

59 Bankevich, A. et al. SPAdes: a new genome assembly algorithm and its applications to single-cell sequencing. J. Comput. Biol. 19, 455-477, doi:10.1089/cmb.2012.0021 (2012).

60 Langmead, B. \& Salzberg, S. L. Fast gapped-read alignment with Bowtie 2. Nat. Methods 9, 357-359, doi:10.1038/nmeth.1923 (2012).

$61 \mathrm{Li}, \mathrm{H}$. et al. The sequence alignment/map format and SAMtools. Bioinformatics $\mathbf{2 5}$, 2078-2079, doi:10.1093/bioinformatics/btp352 (2009).

62 Menzel, P., Ng, K. L. \& Krogh, A. Fast and sensitive taxonomic classification for metagenomics with Kaiju. Nat. Commun. 7, 11257, doi:10.1038/ncomms11257 (2016).

63 R Core Team. R: A language and environment for statistical computing. R Foundation for Statistical Computing, Vienna, Austria (2018).

64 Ghasemi, A. \& Zahediasl, S. Normality tests for statistical analysis: a guide for nonstatisticians. Int. J. Endocrinol. Metab. 10, 486-489, doi:10.5812/ijem.3505 (2012).

65 Levene, H. Robust tests for equality of variances, in: Contributions to Probability and Statistics; Essays in Honor of Harold Hotelling, eds Olkin Ingram \& Hotelling Harold, 278-292, Stanford University Press (1960). 
66 Lee, S. \& Lee, D. K. What is the proper way to apply the multiple comparison test? Korean J. Anesthesiol. 71, 353-360, doi:10.4097/kja.d.18.00242 (2018).

67 Holm, S. A simple sequentially rejective multiple test procedure. Scand. J. Stat. 6, 6570 (1979). 
Metagenomic insight into the plant growth-promoting potential of a diesel-degrading bacterial consortium for enhanced rhizoremediation application

Michael O. Eze ${ }^{1,2 *}$, Volker Thiel $^{3}$, Grant C. Hose ${ }^{4}$, Simon C. George ${ }^{2 \dagger}$ and Rolf Daniel ${ }^{1 \dagger}$

${ }^{1}$ Department of Genomic and Applied Microbiology and Göttingen Genomics Laboratory, Georg-August University of Göttingen, 37077 Göttingen, Germany.

${ }^{2}$ Department of Earth and Environmental Sciences, Macquarie University, Sydney, NSW 2109, Australia.

${ }^{3}$ Geobiology, Geoscience Centre, Georg-August University of Göttingen, 37077 Göttingen, Germany.

${ }^{4}$ Department of Biological Sciences, Macquarie University, Sydney, NSW 2109, Australia.

†These authors contributed equally to this work.

*Correspondence: meze@gwdg.de

\section{$\underline{\text { Supplementary Materials }}$}


Supplementary Table S1. Genes involved in plant growth promotion, number of coding DNA sequences (CDSs), and their taxonomic classification.

\begin{tabular}{|c|c|c|c|c|c|}
\hline Group & Genes & $\begin{array}{c}\text { KEGG } \\
\text { Orthology }\end{array}$ & $\begin{array}{c}\text { No. of } \\
\text { CDSs }\end{array}$ & Taxa (Class) & Taxa (Genus) \\
\hline \multicolumn{6}{|c|}{ Nitrogen fixation } \\
\hline \multirow[t]{5}{*}{ Nitrogen uptake } & nifA & K02584 & 1 & Alphaproteobacteria & Acidocella aminolytica \\
\hline & & K02584 & 4 & Acidobacteriia & $\begin{array}{l}\text { Acidobacterium } \\
\text { capsulatum }\end{array}$ \\
\hline & & K02584 & 1 & Alphaproteobacteria & Bradyrhizobium mercantei \\
\hline & & K02584 & 1 & Alphaproteobacteria & Rhodobacter \\
\hline & & K02584 & 1 & Alphaproteobacteria & Methylocella silvestris \\
\hline \multirow[t]{5}{*}{ Nitrogen uptake } & por, nifJ & K03737 & 2 & Acidobacteriia & $\begin{array}{l}\text { Acidobacterium } \\
\text { capsulatum }\end{array}$ \\
\hline & & K03737 & 1 & Actinobacteria & $\begin{array}{l}\text { Mycobacterium } \\
\text { malmoense }\end{array}$ \\
\hline & & K03737 & 2 & Alphaproteobacteria & Asaia sp. W19 \\
\hline & & K03737 & 1 & Alphaproteobacteria & Acetobacter senegalensis \\
\hline & & K03737 & 1 & Alphaproteobacteria & Acetobacter cibinongensis \\
\hline \multirow[t]{2}{*}{ Nitrogen uptake } & iscU, nifU & K04488 & 1 & Acidobacteriia & $\begin{array}{l}\text { Acidobacterium } \\
\text { capsulatum }\end{array}$ \\
\hline & & K04488 & 1 & Alphaproteobacteria & Acidocella aminolytica \\
\hline \multirow[t]{6}{*}{ Nitrogen uptake } & fix $A$, etfB & K03521 & 1 & Alphaproteobacteria & Elioraea sp. YIM 72297 \\
\hline & & K03521 & 1 & Alphaproteobacteria & unclassified Rhizobiales \\
\hline & & K03521 & 1 & Acidobacteriia & $\begin{array}{l}\text { Acidobacterium } \\
\text { capsulatum }\end{array}$ \\
\hline & & K03521 & 1 & Alphaproteobacteria & Labrys okinawensis \\
\hline & & K03521 & 3 & Alphaproteobacteria & $\begin{array}{l}\text { Acidocella aminolytica (2) } \\
\text { and Acidocella (1) }\end{array}$ \\
\hline & & K03521 & 1 & Alphaproteobacteria & $\begin{array}{l}\text { Acidiphilium multivorum } \\
\text { AlU301 }\end{array}$ \\
\hline \multirow[t]{5}{*}{ Nitrogen uptake } & fix $B$, etfA & K03522 & 1 & Alphaproteobacteria & Komagataeibacter \\
\hline & & K03522 & 1 & Alphaproteobacteria & unclassified Rhizobiales \\
\hline & & K03522 & 1 & Acidobacteriia & $\begin{array}{l}\text { Acidobacterium } \\
\text { capsulatum }\end{array}$ \\
\hline & & K03522 & 3 & Alphaproteobacteria & $\begin{array}{l}\text { Acidocella aminolytica (2) } \\
\text { and Acidocella (1) }\end{array}$ \\
\hline & & K03522 & 1 & Alphaproteobacteria & $\begin{array}{l}\text { Acidiphilium multivorum } \\
\text { AlU301 }\end{array}$ \\
\hline \multirow[t]{4}{*}{ Nitrogen uptake } & fixL & K14986 & 4 & Acidobacteriia & $\begin{array}{l}\text { Acidobacterium } \\
\text { capsulatum }\end{array}$ \\
\hline & & K14986 & 2 & Alphaproteobacteria & $\begin{array}{l}\text { Rhodopseudomonas } \\
\text { palustris }\end{array}$ \\
\hline & & K14986 & 4 & Alphaproteobacteria & $\begin{array}{l}\text { Acidocella aminolytica (2) } \\
\text { and Acidocella (2) }\end{array}$ \\
\hline & & K14986 & 1 & Alphaproteobacteria & unclassified Rhizobiales \\
\hline \multirow[t]{3}{*}{ Nitrogen uptake } & fixJ & K14987 & 1 & Alphaproteobacteria & $\begin{array}{l}\text { unclassified } \\
\text { Alphaproteobacteria }\end{array}$ \\
\hline & & K14987 & 2 & Alphaproteobacteria & $\begin{array}{l}\text { Acidocella aminolytica (1) } \\
\text { and Acidocella (1) }\end{array}$ \\
\hline & & K14987 & 2 & Alphaproteobacteria & unclassified Rhizobiales \\
\hline Nitrogen uptake & fixk & K15861 & 4 & Alphaproteobacteria & $\begin{array}{l}\text { Acidocella aminolytica (1) } \\
\text { and Acidocella (3) }\end{array}$ \\
\hline
\end{tabular}




\begin{tabular}{|c|c|c|c|c|c|}
\hline & & K15861 & 1 & Alphaproteobacteria & $\begin{array}{l}\text { Rhizomicrobium sp. SCGC } \\
\text { AG-212-E05 }\end{array}$ \\
\hline & & K15861 & 1 & Alphaproteobacteria & Roseomonas rosea \\
\hline & & K15861 & 1 & Alphaproteobacteria & Acidiphilium \\
\hline & & Subtotal: & 55 & & \\
\hline \multicolumn{6}{|c|}{ Phosphate solubilization } \\
\hline Phosphate solubilization & acps & K00997 & 4 & Alphaproteobacteria & $\begin{array}{l}\text { Acidocella aminolytica (2) } \\
\text { and Acidocella (2) }\end{array}$ \\
\hline \multirow[t]{4}{*}{ Phosphate solubilization } & $a c p P$ & K02078 & 1 & Alphaproteobacteria & Skermanella stibiiresistens \\
\hline & & K02078 & 2 & Acidobacteriia & $\begin{array}{l}\text { Acidobacterium } \\
\text { capsulatum }\end{array}$ \\
\hline & & K02078 & 3 & Alphaproteobacteria & $\begin{array}{l}\text { Acidocella aminolytica (2) } \\
\text { and Acidocella (1) }\end{array}$ \\
\hline & & K02078 & 1 & Betaproteobacteria & Hydrogenophaga \\
\hline Phosphate solubilization & phoA, phoB & K01077 & 1 & Acidobacteriia & $\begin{array}{l}\text { Acidobacterium } \\
\text { capsulatum }\end{array}$ \\
\hline \multirow[t]{2}{*}{ Phosphate solubilization } & serB, PSPH & K01079 & 2 & Acidobacteriia & $\begin{array}{l}\text { Acidobacterium } \\
\text { capsulatum }\end{array}$ \\
\hline & & K01079 & 3 & Alphaproteobacteria & $\begin{array}{l}\text { Acidocella aminolytica (2) } \\
\text { and Acidocella (1) }\end{array}$ \\
\hline \multirow[t]{3}{*}{ Phosphate solubilization } & cysQ & K01082 & 6 & Alphaproteobacteria & $\begin{array}{l}\text { Acidocella aminolytica (3) } \\
\text { and Acidocella (3) }\end{array}$ \\
\hline & & K01082 & 1 & Alphaproteobacteria & Acidiphilium \\
\hline & & K01082 & 1 & Alphaproteobacteria & Sphingomonas sp. YR710 \\
\hline \multirow[t]{4}{*}{ Phosphate solubilization } & ots $B$ & K01087 & 1 & Alphaproteobacteria & unclassified Rhizobiales \\
\hline & & K01087 & 7 & Alphaproteobacteria & $\begin{array}{l}\text { Acidocella aminolytica (4) } \\
\text { and Acidocella (3) }\end{array}$ \\
\hline & & K01087 & 2 & Acidobacteriia & $\begin{array}{l}\text { Acidobacterium } \\
\text { capsulatum }\end{array}$ \\
\hline & & K01087 & 1 & Betaproteobacteria & $\begin{array}{l}\text { Paraburkholderia sp. } \\
\text { BL23I1N1 }\end{array}$ \\
\hline \multirow[t]{3}{*}{ Phosphate solubilization } & E3.1.3.16 & K01090 & 3 & Acidobacteriia & $\begin{array}{l}\text { Acidobacterium } \\
\text { capsulatum }\end{array}$ \\
\hline & & K01090 & 6 & Alphaproteobacteria & $\begin{array}{l}\text { Acidocella aminolytica (4) } \\
\text { and Acidocella (2) }\end{array}$ \\
\hline & & K01090 & 1 & Chitinophagia & Niastella \\
\hline \multirow[t]{3}{*}{ Phosphate solubilization } & gph & K01091 & 1 & Acidobacteriia & $\begin{array}{l}\text { Acidobacterium } \\
\text { capsulatum }\end{array}$ \\
\hline & & K01091 & 1 & Verrucomicrobiae & Pedosphaera parvula \\
\hline & & K01091 & 5 & Alphaproteobacteria & $\begin{array}{l}\text { Acidocella aminolytica (4) } \\
\text { and Acidocella (1) }\end{array}$ \\
\hline \multirow[t]{2}{*}{ Phosphate solubilization } & $\operatorname{suh} B$ & K01092 & 2 & Acidobacteriia & $\begin{array}{l}\text { Acidobacterium } \\
\text { capsulatum }\end{array}$ \\
\hline & & K01092 & 8 & Alphaproteobacteria & $\begin{array}{l}\text { Acidocella aminolytica (4) } \\
\text { and Acidocella (4) }\end{array}$ \\
\hline Phosphate solubilization & appA & K01093 & 1 & Acidobacteriia & $\begin{array}{l}\text { Acidobacterium } \\
\text { capsulatum }\end{array}$ \\
\hline \multirow[t]{2}{*}{ Phosphate solubilization } & pgpA & K01095 & 1 & Acidobacteriia & $\begin{array}{l}\text { Acidobacterium } \\
\text { capsulatum }\end{array}$ \\
\hline & & K01095 & 3 & Alphaproteobacteria & $\begin{array}{l}\text { Acidocella aminolytica (2) } \\
\text { and Acidocella (1) }\end{array}$ \\
\hline
\end{tabular}




\begin{tabular}{|c|c|c|c|c|c|}
\hline Phosphate solubilization & plc & K01114 & 4 & Acidobacteriia & $\begin{array}{l}\text { Acidobacterium } \\
\text { capsulatum }\end{array}$ \\
\hline & & K01114 & 5 & Alphaproteobacteria & Acidocella aminolytica \\
\hline & & K01114 & 1 & Betaproteobacteria & $\begin{array}{l}\text { Paraburkholderia sp. } \\
\text { PDC91 }\end{array}$ \\
\hline & & K01114 & 1 & Alphaproteobacteria & unclassified Rhizobiales \\
\hline Phosphate solubilization & $c o b C, p h p B$ & K02226 & 9 & Alphaproteobacteria & $\begin{array}{l}\text { Acidocella aminolytica (6); } \\
\text { Acidocella facilis (1) and } \\
\text { Acidocella (2) }\end{array}$ \\
\hline \multirow[t]{2}{*}{ Phosphate solubilization } & $c b i B, c o b D$ & K02227 & 1 & Alphaproteobacteria & Roseovarius sp. A-2 \\
\hline & & K02227 & 1 & Alphaproteobacteria & Acidocella aminolytica \\
\hline \multirow[t]{2}{*}{ Phosphate solubilization } & $g / p R$ & K02444 & 7 & Alphaproteobacteria & $\begin{array}{l}\text { Acidocella aminolytica (5) } \\
\text { and Acidocella (2) }\end{array}$ \\
\hline & & K02444 & 1 & Alphaproteobacteria & Methylovirgula sp. 4M-Z18 \\
\hline \multirow[t]{2}{*}{ Phosphate solubilization } & $g \operatorname{lp} X$ & K02446 & 1 & Alphaproteobacteria & Acidiphilium \\
\hline & & Subtotal: & 99 & & \\
\hline \multicolumn{6}{|c|}{ Zinc solubilization } \\
\hline \multirow[t]{3}{*}{ Zinc solubilization } & $p q q L$ & K07263 & 3 & Acidobacteriia & $\begin{array}{l}\text { Acidobacterium } \\
\text { capsulatum }\end{array}$ \\
\hline & & K07263 & 2 & Alphaproteobacteria & $\begin{array}{l}\text { Acidocella aminolytica (1) } \\
\text { and Acidocella facilis (1) }\end{array}$ \\
\hline & & Subtotal: & 5 & & \\
\hline \multicolumn{6}{|c|}{ Siderophore transport } \\
\hline \multirow[t]{4}{*}{ Siderophore transport } & ents & K08225 & 1 & Acidobacteriia & $\begin{array}{l}\text { Acidobacterium } \\
\text { capsulatum }\end{array}$ \\
\hline & & K08225 & 1 & Betaproteobacteria & $\begin{array}{l}\text { unclassified } \\
\text { Burkholderiales }\end{array}$ \\
\hline & & K08225 & 1 & Alphaproteobacteria & Acidocella \\
\hline & & Subtotal: & 3 & & \\
\hline \multicolumn{6}{|c|}{ Indoleacetic acid (IAA) synthesis } \\
\hline \multirow[t]{3}{*}{ IAA synthesis } & iaaH & K21801 & 1 & Alphaproteobacteria & Hyphomicrobium sp. 99 \\
\hline & & K21801 & 1 & Alphaproteobacteria & Mesorhizobium \\
\hline & & Subtotal: & 2 & & \\
\hline \multicolumn{6}{|c|}{ Pyrroloquinoline quinone synthesis } \\
\hline \multirow[t]{2}{*}{ PQQ synthesis } & $p q q B$ & K06136 & 1 & Alphaproteobacteria & Acidiphilium \\
\hline & & K06136 & 2 & Alphaproteobacteria & $\begin{array}{l}\text { Acidocella aminolytica (1) } \\
\text { and Acidocella (1) }\end{array}$ \\
\hline \multirow[t]{2}{*}{ PQQ synthesis } & $p q q C$ & K06137 & 1 & Acidobacteriia & $\begin{array}{l}\text { Acidobacterium } \\
\text { capsulatum }\end{array}$ \\
\hline & & K06137 & 2 & Alphaproteobacteria & $\begin{array}{l}\text { Acidocella aminolytica (1) } \\
\text { and Acidocella (1) }\end{array}$ \\
\hline PQQ synthesis & $p q q D$ & K06138 & 3 & Alphaproteobacteria & $\begin{array}{l}\text { Acidocella aminolytica (2) } \\
\text { and Acidocella (1) }\end{array}$ \\
\hline \multirow[t]{5}{*}{ PQQ synthesis } & $p q q E$ & K06139 & 1 & Alphaproteobacteria & Bosea sp. 117 \\
\hline & & K06139 & 1 & Acidobacteriia & $\begin{array}{l}\text { Acidobacterium } \\
\text { capsulatum }\end{array}$ \\
\hline & & K06139 & 2 & Alphaproteobacteria & $\begin{array}{l}\text { Acidocella aminolytica (1) } \\
\text { and Acidocella facilis (1) }\end{array}$ \\
\hline & & Subtotal: & 13 & & \\
\hline & & TOTAL: & 177 & & \\
\hline
\end{tabular}




\section{Chapter 8}

\section{Exploiting synergistic interactions of Medicago sativa $\mathbf{L}$. and Paraburkholderia tropica for enhanced biodegradation of diesel fuel hydrocarbons}

Michael O. Eze ${ }^{1,2 *}$, Volker Thiel ${ }^{3}$, Grant C. Hose ${ }^{4}$, Simon C. George ${ }^{2 \dagger}$ and Rolf Daniel ${ }^{1 \dagger *}$

${ }^{1}$ Department of Genomic and Applied Microbiology and Göttingen Genomics Laboratory, Georg-August University of Göttingen, 37077 Göttingen, Germany.

${ }^{2}$ Department of Earth and Environmental Sciences, Macquarie University, Sydney, NSW 2109, Australia.

${ }^{3}$ Geobiology, Geoscience Centre, Georg-August University of Göttingen, 37077 Göttingen, Germany.

${ }^{4}$ Department of Biological Sciences, Macquarie University, Sydney, NSW 2109, Australia.

†These authors contributed equally to this work.

*Correspondence: meze@gwdg.de; rdaniel@gwdg.de

bioRxiv. doi: https://doi.org/10.1101/2021.03.30.437699

\section{Relationship to the Overall Thesis}

The biotechnological applicability of consortia is limited since they are often difficult to reproduce. Therefore, the identification of specific single bacterial isolates capable of enhancing both plant growth promotion and hydrocarbon degradation will expand the range of bacteria available for biotechnological applications. Additionally, this paper examined the synergistic efficacy of Medicago sativa and Paraburkholderia tropica for enhanced rhizoremediation of diesel fuel hydrocarbons, with potential in situ applications.

\section{Author Contributions}

Conceived and designed the study: MOE, GCH, SCG and RD

Performed the experiments: MOE and VT

Analysed the data: MOE and VT

Wrote the paper: MOE, VT, GCH, SCG and RD 


\title{
Exploiting synergistic interactions of Medicago sativa L. and Paraburkholderia tropica for enhanced biodegradation of diesel fuel hydrocarbons
}

Michael O. Eze ${ }^{1,2 *}$, Volker Thiel ${ }^{3}$, Grant C. Hose ${ }^{4}$, Simon C. George ${ }^{2 \dagger}$ and Rolf Daniel ${ }^{1 \uparrow *}$

${ }^{1}$ Department of Genomic and Applied Microbiology and Göttingen Genomics Laboratory, Georg-August University of Göttingen, 37077 Göttingen, Germany.

${ }^{2}$ Department of Earth and Environmental Sciences, Macquarie University, Sydney, NSW 2109, Australia.

${ }^{3}$ Geobiology, Geoscience Centre, Georg-August University of Göttingen, 37077 Göttingen, Germany.

${ }^{4}$ Department of Biological Sciences, Macquarie University, Sydney, NSW 2109, Australia.

${ }^{\dagger}$ These authors contributed equally to this work.

*Correspondence: meze@gwdg.de; rdaniel@gwdg.de

\begin{abstract}
The biotechnological application of microorganisms for rhizoremediation of contaminated sites requires the development of plant-microbe symbionts capable of plant growth promotion and hydrocarbon degradation. Studies focusing on microbial consortia are often difficult to reproduce, thereby necessitating the need for culturable single bacterial species for biotechnological applications. Through genomic analyses and plant growth experiments, we examined the synergistic interactions of Medicago sativa L. and Paraburkholderia tropica for enhanced remediation of diesel fuel-contaminated soils. Comparative genomics revealed strong potential of $P$. tropica for plant growth-promotion, chemotaxis and motility, root nodulation and colonization, and diesel fuel degradation. Plant growth experiments confirmed that $P$. tropica thrived in the contaminated soils and effectively enhanced $M$. sativa growth. Geochemical analysis showed that the $M$. sativa $+P$. tropica treatment resulted in an efficient degradation of diesel fuel hydrocarbons within two months, offering great prospects for enhanced biodegradation of organic pollutants.
\end{abstract}

Keywords: Biodegradation, rhizoremediation, diesel fuel hydrocarbons, Medicago sativa L., Paraburkholderia tropica. 


\section{INTRODUCTION}

The quest for energy to meet the growing global demand has depended largely on petroleum and other fossil fuels. Consequently, petroleum spillage, either through human error or equipment failure has plagued the environment for decades ${ }^{1}$. For example, in 2010, the Deepwater Horizon oil spill discharged more than 700 million litres of South Louisiana crude oil into the Gulf of Mexico, resulting in the largest marine oil spill in U.S. history and the second largest in the world ${ }^{2,3}$. While large-scale marine spills often make headlines, the majority of petroleum spills occur on land, with significant human health and ecological impacts ${ }^{4}$.

Remediation of petroleum contaminated sites is essential to mitigating the human and ecological risks. Remediation strategies are classified as either ex situ or in situ ${ }^{5}$. Ex situ techniques involve the excavation and relocation of contaminants for off-site treatments and, as a result, are expensive and environmentally unfriendly. In contrast, in situ remediation involves the on-site treatment of contaminants, which is typically more eco-friendly and 50 to $80 \%$ cheaper than traditional methods such as excavation and landfill incineration ${ }^{6}$.

Phytoremediation, that is, the use of plants to remediate contaminated sites, is a costeffective method for in situ remediation. This technique relies on the use of plant interactions (physical, biochemical, biological, chemical, and microbiological) to remediate the toxic effects of pollutants ${ }^{7,8}$. This technique is based on carefully selected plants with fibrous roots that serve as a natural host for hydrocarbon-degrading microorganisms. The extensive rooting systems allow air to enter the rhizosphere, thus serving as a natural bioventing system, leading to increased biodegradation of pollutants. Notwithstanding the merits of this technique, the slow metabolic activity of the hydrocarbon-degrading microorganisms leads to longer remediation times, limiting the application of the technique. To address this shortfall, there is growing interest in the isolation of microbial consortia usable as inocula for contaminant degradation.

In addition to their hydrocarbon-degrading capacities, some of the inoculated microbes can potentially enhance the growth of host plants through processes such as nitrogen fixation, and phosphate and potassium solubilization ${ }^{9}$. In turn, the root exudates released by the host plants provide nutrition to the associated bacteria, enabling continuous biodegradation of contaminants. This synergistic relationship has been described as the ecological driver of 
rhizoremediation ${ }^{10}$. Therefore, when carefully applied, bioaugmentation offers great potential for effective reclamation of hydrocarbon contaminated sites.

While a number of studies have been carried out on the use of microbial consortia for rhizoremediation ${ }^{11,12}$, few studies have been performed with single bacterial isolates. This is a major challenge to the adoption of microbially-enhanced rhizoremediation since the replication of consortia is always difficult. Hence, there is an urgent need to isolate single culturable bacterial species for biotechnological applications. Therefore, the aims of this study were to isolate potential plant growth-promoting and hydrocarbon-degrading single bacterial species, and examine their capacity to enhance the rhizodegradation of diesel fuel hydrocarbons. Specifically, this study is the first attempt to examine the synergistic interactions of Medicago sativa L. and Paraburkholderia tropica for enhanced rhizoremediation of diesel fuel-contaminated soils. This is highly relevant considering recent studies have shown that Paraburkholderia strains can potentially promote plant growth and/or degrade contaminants 13, 14 . Additionally, our earlier studies revealed that $M$. sativa has high tolerance to petroleum hydrocarbons, relative to other plant species ${ }^{15}$, thereby making it an ideal plant to investigate plant-microbe synergy for biodegradation. By combining genome studies of $P$. tropica with a pot-based rhizodegradation experiment, we demonstrate that synergistic interactions between $M$. sativa and $P$. tropica promotes rhizodegradation of petroleum hydrocarbons.

\section{RESULTS}

\section{Genome Sequencing}

The sequencing of the three genomes resulted in a total of 4,228,774 gene sequences. After processing, a total of 3,450,275 paired-end reads and 356,023 unpaired reads were retained and assembled. Assembly resulted in 575 scaffolds (Supplementary Table S1). The average sequencing depth was approximately 30x. The three genomes were taxonomically classified as Acidocella facilis, Burkholderia sp. and Paraburkholderia tropica.

\section{Functional Analysis of the Genomes}

\section{Plant growth-promotion, chemotaxis, motility and root colonization}

Functional analysis of the three genomes revealed that $P$. tropica has the greatest potential for plant growth promotion, with 36, 31, 4, 2 and 2 coding DNA sequences (CDSs) putatively 
involved in nitrogen fixation, phosphate solubilization, pyrroloquinoline quinone synthesis, siderophore transport and indoleacetic acid synthesis respectively (Supplementary Table S2). Key genes involved in these processes include the nifAUQ, fixABJL, acpP, otsB, gph, plc, $p q q B C D E$, ent $S$ and $i a a H$ genes (Table 1). In comparison, the genomes of the other bacterial isolates had far fewer (24-44) CDSs putatively involved in plant growth promotion, with nifAQ, phoD, entS and iaaH genes missing in the genome of A. facilis (Supplementary Table S2).

Table 1. Key genes in Paraburkholderia tropica genome that are potentially involved in plant growth promotion, bacterial chemotaxis, motility, root nodulation and colonization (See Supplementary Table S2 for more details).

\begin{tabular}{l|c|l|l}
\hline Genes & CDSs & Enzyme & Function \\
\hline \multicolumn{1}{l|}{ Plant growth promotion } & \multicolumn{2}{l}{} \\
\hline nifA & 2 & Nif-specific regulatory protein & Nitrogen fixation \\
nifUQ & 2 & Nitrogen fixation proteins NifU, NifQ & Nitrogen fixation \\
fixAB & 10 & Electron transfer flavoprotein & Nitrogen fixation \\
fixJL & 22 & Two-component system, LuxR family & Nitrogen fixation \\
acpP & 4 & Acyl carrier protein & Phosphate solubilization \\
otsB & 3 & Trehalose 6-phosphate phosphatase & Phosphate solubilization \\
gph & 6 & Phosphoglycolate phosphatase & Phosphate solubilization \\
plc & 9 & Phospholipase C & Phosphate solubilization \\
pqqBDE & 3 & Pyrroloquinoline quinone biosynthesis & PQQ synthesis \\
pqqC & 1 & Pyroteins B, D, E & PQQ synthesis \\
entS & 2 & MFS transporter, ENTS family, & Siderophore transport \\
iaaH & 2 & Indoleacetamide hydrolase & IAA synthesis \\
\hline
\end{tabular}

Bacterial chemotaxis, motility, and root colonization

\begin{tabular}{|c|c|c|c|}
\hline cheABCDVWXYZ & 20 & Two-component chemotaxis protein & Bacterial chemotaxis \\
\hline$w s p B D E F$ & 4 & Two-component chemotaxis protein & Bacterial chemotaxis \\
\hline $\begin{array}{l}\text { mcp, tsr, tar, trg, } \\
\text { tap, wspA }\end{array}$ & 47 & Methyl-accepting chemotaxis protein & Bacterial chemotaxis \\
\hline$f l g, f l h, f l i$ & 52 & Flagellar proteins & Bacterial motility \\
\hline $\operatorname{nod} D$ & 2 & $\begin{array}{l}\text { Nod-box dependent transcriptional } \\
\text { activator }\end{array}$ & Root nodulation \\
\hline $\operatorname{tad} B$ & 2 & Tight adherence protein B & Plant colonization \\
\hline $\operatorname{tad} C$ & 2 & Tight adherence protein $\mathrm{C}$ & Plant colonization \\
\hline
\end{tabular}

PQQ: Pyrroloquinoline quinone; IAA: Indole-3-acetic acid. 


\section{Hydrocarbon-degrading potential}

Functional analysis revealed that $P$. tropica contains genes putatively involved in hydrocarbon degradation (Table 2). While the three isolates are potentially able to degrade petroleum hydrocarbons, there were some specific differences in their metabolic capabilities. For example, the genomes of P. tropica and Burkholderia sp. encode for greater numbers of enzymes putatively involved in the degradation of $n$-alkanes (especially long-chain $n$-alkanes) and cycloalkanes than the Acidocella genome (Supplementary Table S3). This is crucial for diesel fuel degradation since the chemical composition of diesel fuel is $75 \%$ saturated hydrocarbons (predominantly long-chain $n$-alkanes and cycloalkanes) ${ }^{16,17}$.

Table 2. Key genes in the Paraburkholderia tropica genome that putatively encode for hydrocarbon-degrading enzymes.

\begin{tabular}{l|l|l|l}
\hline Genes & CDSs & Enzyme & Function \\
\hline \multicolumn{1}{l}{ Hydrocarbon degradation } & n-Alkane degradation \\
\hline$l a d A$ & 6 & Long-chain alkane monooxygenase & Activates AlkM expression \\
alkR & 2 & Alkane utilization regulator & n-Alkane degradation \\
adhP & 4 & Alcohol dehydrogenase (propanol-preferring) & Cycloalkane activation \\
$c p n A$ & 2 & Cyclopentanol dehydrogenase & Cycloalkane activation \\
$c h n B$ & 2 & Cyclohexanone monooxygenase & Ring cleavage of \\
cycloalkanes \\
gnl
\end{tabular}

CDSs $=$ coding DNA sequences. 
The degradation of aromatic hydrocarbons proceeds through initial activation by monooxygenases, followed by ring cleavage of catechols. While genes putatively encoding for monooxygenases and dehydrogenases were more abundant in the genome of $P$. tropica, genes encoding for ring-activating dioxygenases (such as benzoate/toluate 1,2-dioxygenase) were more abundant in the A. facilis genome (Supplementary Table S3). In addition, putative DNA sequences encoding for ortho-cleavage of catechol (catABC and $p c a D L$ genes) were more abundant in the P. tropica and Burkholderia sp. genomes than in the genomes of A. facilis (Supplementary Table S3).

\section{Effect of Bacterial Inoculation on Plant Growth and Biomass Production}

The inoculation of $M$. sativa with $P$. tropica resulted in increased growth rate and biomass production (Figure 1). The analysis of variance (ANOVA) revealed that the mean dry biomass ( \pm standard error, SE) produced by plants inoculated with $P$. tropica $(6.74 \pm 0.06 \mathrm{~g})$ was significantly higher than, and significantly different $(p<0.001)$ from that of the uninoculated plants $(3.38 \pm 0.07 \mathrm{~g})$ (Figure $1 \mathrm{~b})$. Statistical analysis of growth (in terms of mean shoot height per time) revealed that the inoculated $M$. sativa plants exhibited greater relative growth rate $(0.109 \pm 0.002 \mathrm{~cm} /$ day at the point of inflection) than the uninoculated plants $(0.092 \pm 0.004$ $\mathrm{cm} /$ day) (Figure 1c). 
(a)

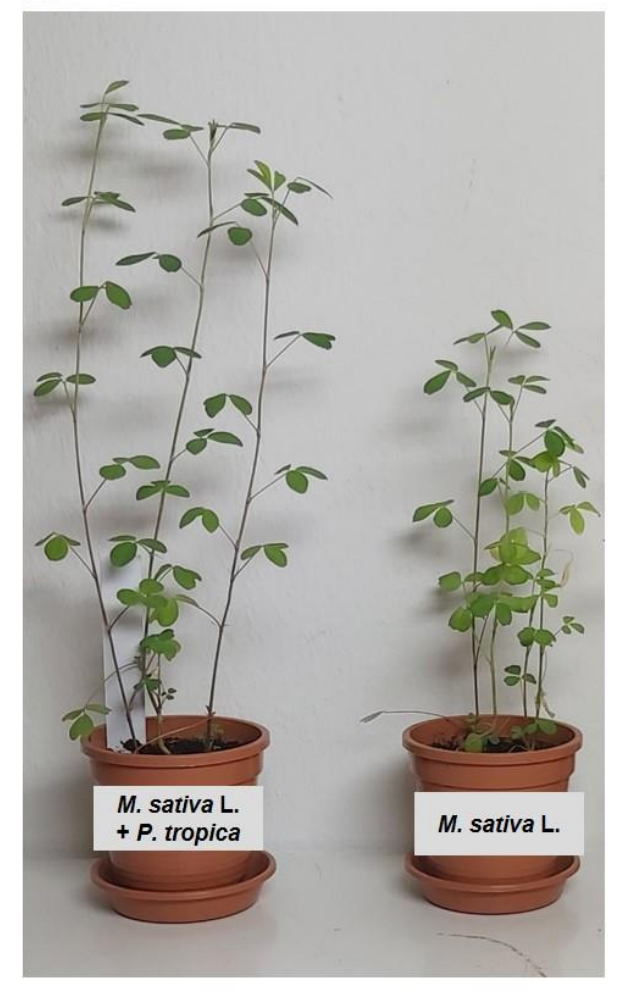

(b)

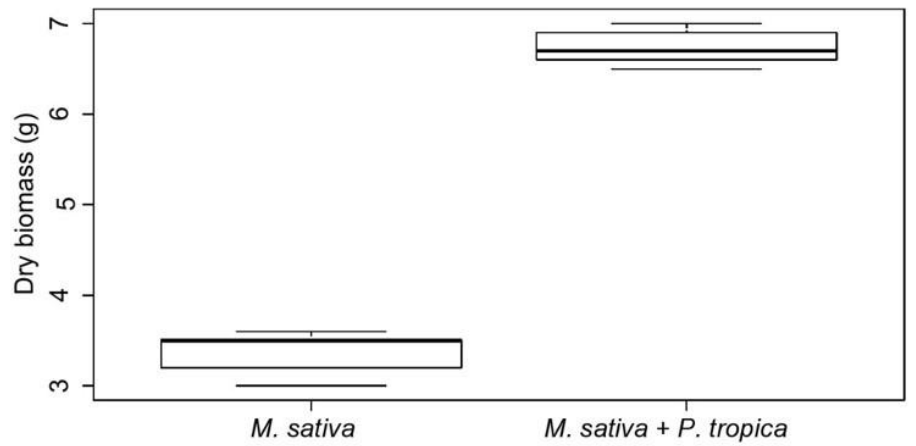

(c)

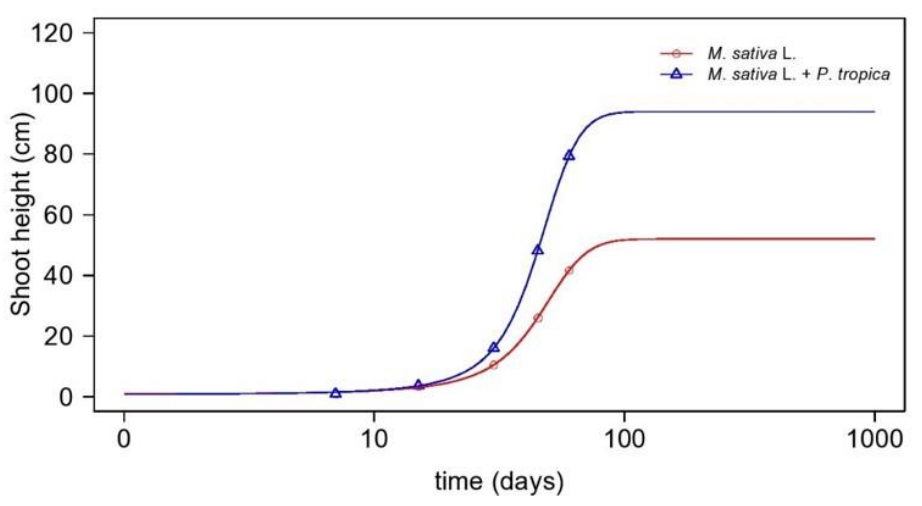

Figure 1. (a) Enhancement of growth and biomass production of $M$. sativa plant by $P$. tropica inoculation. (b) Boxplot showing significant differences in dry biomass of inoculated and uninoculated plants. (c) 3-parameter logistic model showing differential growth rates (cm/day) of $M$. sativa inoculated with $P$. tropica vs. uninoculated control.

\section{Organic Geochemical Analysis of Biodegradation}

\section{Total petroleum hydrocarbons}

Geochemical analysis of residual hydrocarbons revealed that the inoculation of contaminated soils with the $P$. tropica isolate significantly enhanced hydrocarbon degradation and reclamation of the diesel fuel-contaminated soils (Figure 2). As shown in the gas chromatograph-mass spectrometry (GC-MS) chromatograms, nearly all the distinctive diesel fuel hydrocarbons, including $\mathrm{C}_{10}-\mathrm{C}_{25} n$-alkanes, branched alkanes, cyclic alkanes and aromatic hydrocarbons (approximately 96\%) were degraded in the planted and inoculated soils (Figure 2a). Similar results were obtained with the replicates (Supplementary Figure S1). The mean total petroleum hydrocarbons $( \pm \mathrm{SE})$ at the beginning of the experiment (T0) was $4.13 \pm 0.04$ $\mathrm{g} / \mathrm{kg}$. At the end of the experimental period, the greatest decrease in residual total petroleum hydrocarbons was observed in the "planted and inoculated soils" (Soil+M.sativa+P.tropica), while the least decrease occurred in the "unplanted and uninoculated soils" (Soil at T60) 
(Figure 2b). This is an indication of greatest biodegradation in the "Soil + M.sativa + P.tropica" treatment, a claim further supported by the huge UCM observed under this treatment (Figure 2c). Preparation blanks ruled out possible cross contamination of hydrocarbons among the samples (Supplementary Figure S2).

(a)

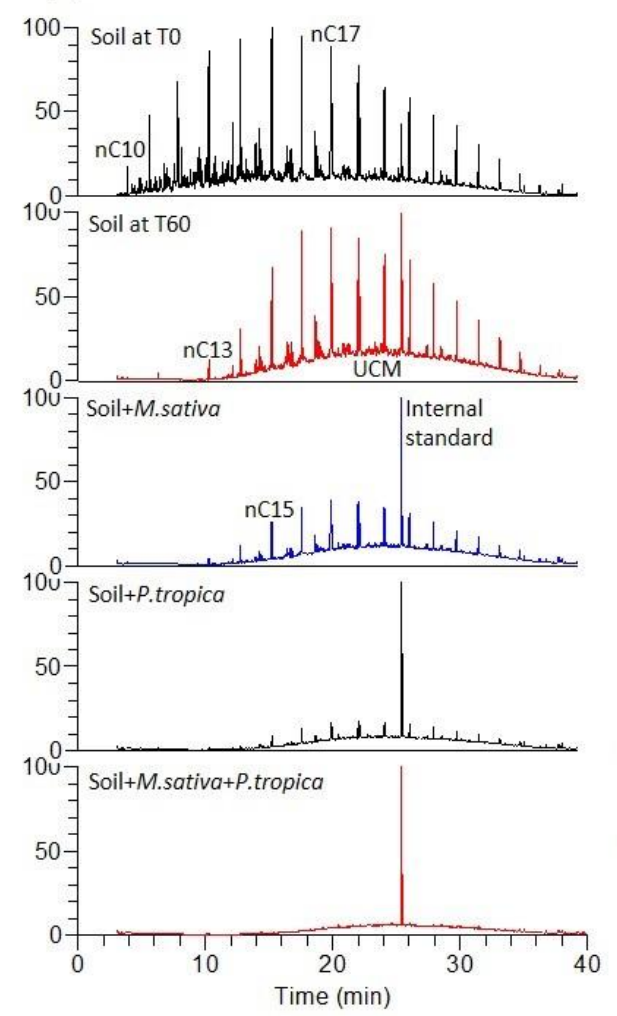

(b)

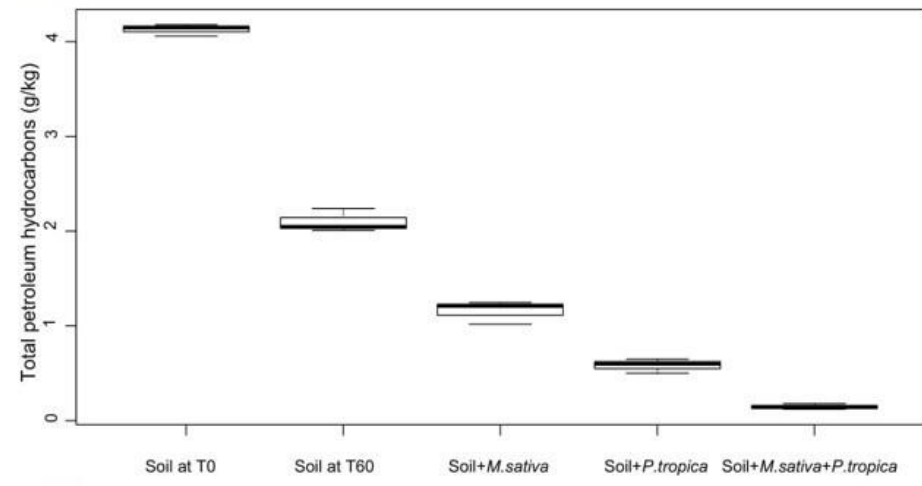

(c)

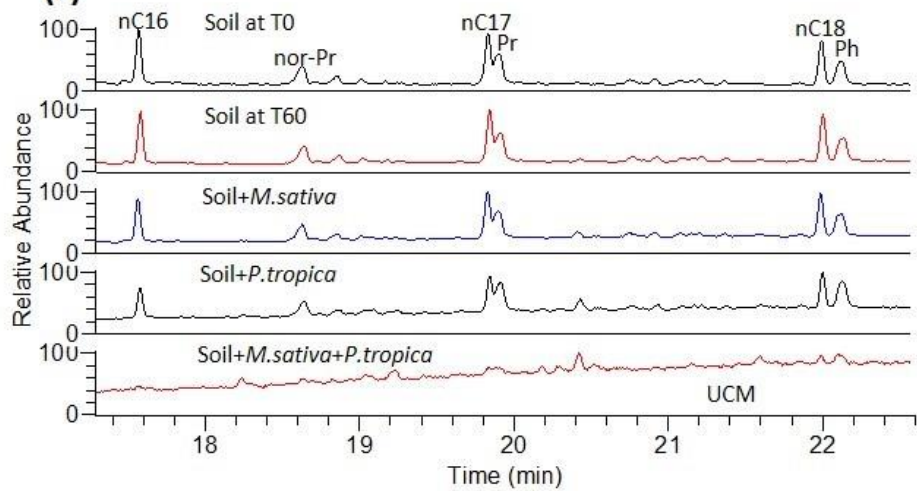

Figure 2. (a) Partial total ion chromatograms showing the initial total hydrocarbons in the contaminated soils and the residual hydrocarbons after 60 days under different treatments. The chromatograms can be directly compared with reference to the internal standard peak (the same amount was added to all samples). (b) Boxplot showing the mean values of residual total petroleum hydrocarbons for the different treatments. (c) Partial total ion chromatograms showing preferential biodegradation of $\mathrm{nC} 16, \mathrm{nC} 17$ and $\mathrm{nC} 18$ relative to nor-pristane (nor-Pr), pristane $(\mathrm{Pr})$, and phytane $(\mathrm{Ph})$ with increasing biodegradation among the different treatments. "Soil at T0": contaminated soils at the beginning of experiment; "Soil at T60": unplanted and uninoculated soils after 60 days; "Soil+M.sativa": soils planted with M. sativa L.; "Soil+P.tropica": soils inoculated with P. tropica; "Soil+M.sativa+P.tropica": soils planted with $M$. sativa L. and inoculated with P. tropica; UCM: unresolved complex mixture.

\section{Biodegradation parameters}

The highest values of $\mathrm{nC} 17 / \mathrm{Pr}, \mathrm{nC} 18 / \mathrm{Ph}, \mathrm{nC} \mathrm{n} / \mathrm{nor}-\mathrm{Pr}$ and total petroleum hydrocarbons/unresolved complex mixture (TPH/UCM) (1.34, 1.39, 2.65 and 1.82 respectively) were observed in the aged initial contaminated soil (Soil at T0) (Table 3), followed by the unplanted and uninoculated contaminated soil at the end of the experimental period (Soil at T60). The lowest values of these ratios, indicating most intense biodegradation, 
were found in the planted and inoculated soils (Soil+M.sativa+P.tropica). The nC17/Pr, $\mathrm{nC} 18 / \mathrm{Ph}, \mathrm{nC} 16 /$ nor-Pr and TPH/UCM ratios for the treatment "Soil+P.tropica" were smaller than that of "Soil+M.sativa" treatment (Table 3). This is an indication that the inoculation of diesel fuel-contaminated soils with $P$. tropica alone resulted in greater hydrocarbon degradation than simple phytoremediation using $M$. sativa. This is also in agreement with the results of total residual hydrocarbon measurements (Figure 2b).

Table 3. Biodegradation parameters (ratios) for the different treatments.

\begin{tabular}{l|c|c|c|c}
\hline \multicolumn{5}{c}{ Biodegradation Parameters } \\
\hline Treatment & $\mathbf{n C 1 7 / P r}$ & $\mathbf{n C 1 8 / P h}$ & $\mathbf{n C 1 6 / n o r - P r}$ & TPH/UCM \\
\hline Soil at T0 & 1.34 & 1.39 & 2.65 & 1.82 \\
Soil at T60 & 1.33 & 1.37 & 2.58 & 1.45 \\
Soil+M.sativa & 1.29 & 1.34 & 2.10 & 1.39 \\
Soil+P.tropica & 0.82 & 0.92 & 1.42 & 1.33 \\
Soil+M.sativa+P.tropica & 0.57 & 0.60 & 0.55 & 1.18 \\
\hline
\end{tabular}

Tukey's pairwise comparisons showed that the mean total petroleum hydrocarbons $(\mathrm{g} / \mathrm{kg})$ in the soils at the end of the experiment (Soil at T60) were significantly different from the initial mean concentration (Soil at T0), indicating that biodegradation occurred in the treatments (Supplementary Table S4). It also revealed that the residual hydrocarbon concentrations differed significantly between each treatment (Figure 2b; Supplementary Table S4). The greatest percentage of biodegradation (96\%) observed in the planted and inoculated samples (Soil+M.sativa+P.tropica) were the result of the synergistic actions of M. sativa and P. tropica.

\section{Biodegradation of polycyclic aromatic hydrocarbons}

Molecular analysis of residual polycyclic aromatic hydrocarbons such as alkylnaphthalenes and alkylphenanthrenes revealed that the combined application of M. sativa and P. tropica resulted in complete biodegradation of these otherwise recalcitrant hydrocarbons (Figure 3). When compared to other treatments, "M. sativa $+P$. tropica" treatment appeared to be the mosteffective approach for biodegradation of these organic pollutants (Supplementary Figure S3). 

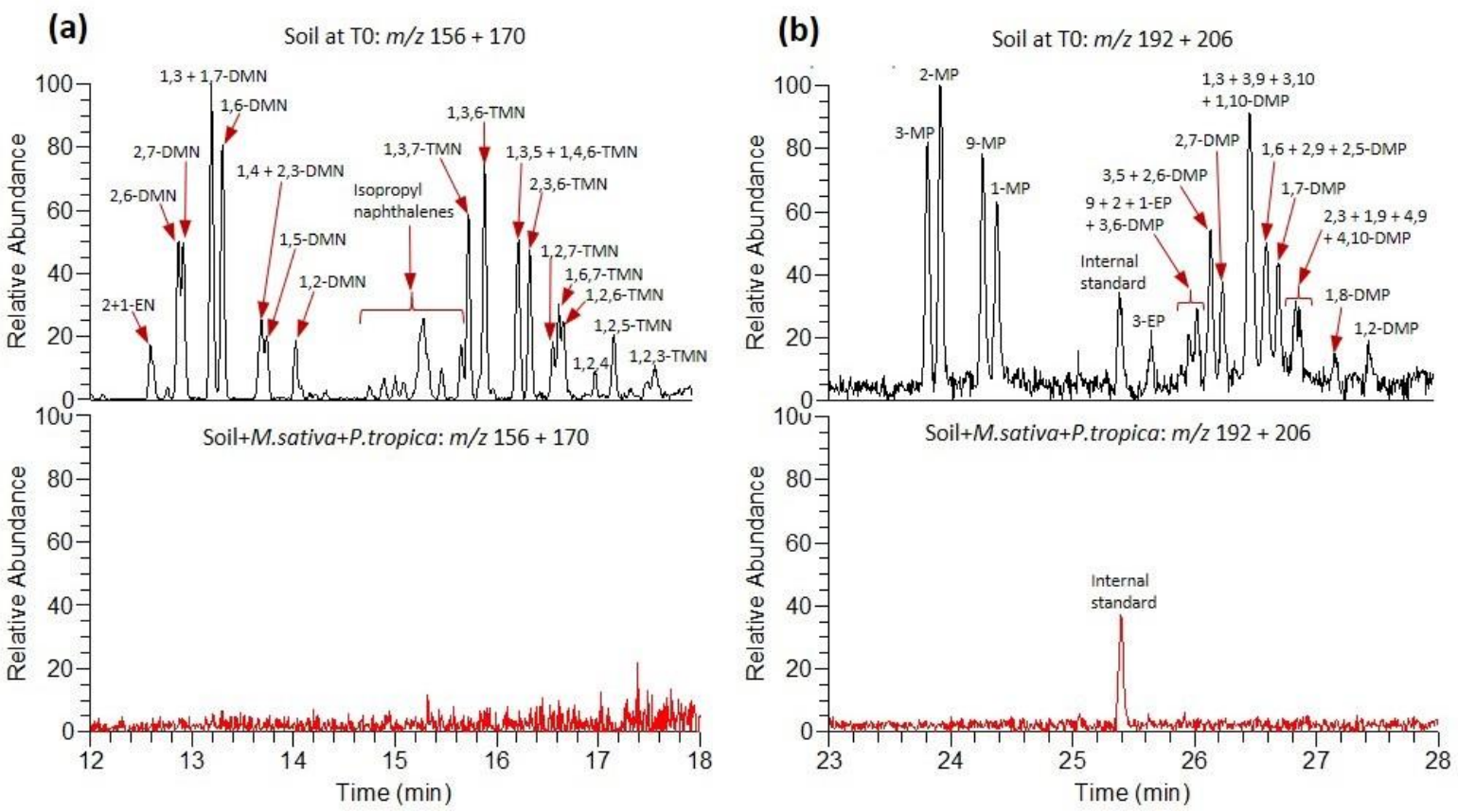

Figure 3. Partial (a) $\mathrm{m} / \mathrm{z}, 156+170$ and (b) $\mathrm{m} / \mathrm{z}, 192+206$ mass chromatograms of contaminated "soil at T0" and "planted and inoculated soil" at the end of the experiment, showing effective biodegradation of alkylnaphthalenes and alkylphenanthrenes by the combined actions of $M$. sativa and $P$. tropica. EN: ethylnaphthalene; DMN: dimethylnaphthalene; MP: methylphenanthrene; EP: ethylphenanthrene; DMP: dimethylphenanthrene. Numbers denote positions of alkylation.

\section{S rRNA Analysis of the Residual Soils}

The relative abundances of Paraburkholderia in the uninoculated soils (both planted and unplanted) were less than $1 \%$. In contrast, the relative abundance of Paraburkholderia in the inoculated soil was approximately $5 \%$, making it the fourth most-abundant bacterial genera in the inoculated soils (Supplementary Figure S4). This indicates that the inoculated microbes prospered in the rhizosphere.

\section{DISCUSSION}

The results of whole genome analysis revealed that $P$. tropica is a potential plant growthpromoting bacterium (Table 1). Functional analysis of the genomes of the three isolates revealed that $P$. tropica has the highest potential for plant growth promotion. For example, while $A$. facilis has 11 coding DNA sequences (CDSs) potentially involved in nitrogen uptake processes, $P$. tropica has 36 CDSs potentially involved in nitrogen metabolism (Supplementary Table S2). Similarly, P. tropica isolates possess the highest number of genes encoding 
phosphatases, siderophore exporter and indoleacetic acid synthase. The potential of P. tropica to enhance plant growth through these processes have also been documented in few recent studies ${ }^{14,18}$.

The genome of $P$. tropica revealed other important genes involved in chemotaxis, motility, and root colonization. These processes are highly important if the inoculated isolate is to prosper in the rhizosphere. Chemotaxis proteins identified in the genome include 24 genes encoding two-component systems (cheABCDVWXYZ and wspBDEF genes) and 47 methylaccepting chemotaxis proteins. This is about 2-4 times the number present in the genomes of the other bacteria (Supplementary Table S2). We also identified 52 flagellar biosynthesis proteins belonging to the $f l g$, flh and $f l i$ genes. These genes are crucial for bacterial motility. For example, Böhm, Hurek and Reinhold-Hurek ${ }^{19}$ found that the deletion of genes involved in motility in the endophyte Azoarcus sp. prevented their twitching, motility and colonization of rice plants. The nod and tad genes are vital for root nodulation and plant colonization. The nodD gene has previously been associated with root nodulation in Rhizobium ${ }^{20}$. Similarly, previous in silico and experimental studies of other plant growth promoting bacteria have linked the tight adherence ( $\mathrm{tad}$ ) systems to plant attachment and colonization ${ }^{21-23}$. The presence of more genes encoding for plant growth-promoting processes, and for chemotaxis, motility, and root colonization in P. tropica than in the other bacteria, strongly suggests a possible advantage in rhizoremediation.

Diesel fuel is phytotoxic to most plant species, and therefore often has negative effects on plant growth and biomass production ${ }^{15}$. The inoculation of $M$. sativa with $P$. tropica in this study resulted in increased growth rate and biomass production of $M$. sativa. The mean dry biomass of inoculated plants was more than twice that of the uninoculated plants (Figure 1). Additionally, during the 60-day experimental period, the inoculated plants attained an average height of $80 \mathrm{~cm}$, in contrast to approximately $42 \mathrm{~cm}$ for the uninoculated plants. These results are not surprising in view of the strong plant growth-promoting potential of $P$. tropica as shown by the genome analysis.

Rhizoremediation of petroleum-contaminated soils also depends on the ability of the inoculated bacteria to degrade hydrocarbons. The examination of the three genomes revealed that all of them are potentially able to utilize aliphatic and aromatic hydrocarbons as carbon and energy sources. Key hydrocarbon-degrading enzymes present in the genome of $P$. tropica include long-chain alkane monooxygenase, cyclohexanone monooxygenase, benzoate/toluate 
1,2-dioxygenase, protocatechuate 3,4-dioxygenase, catechol 1,2-dioxygenase and catechol 2,3dioxygenase (Table 2). Among the three genomes, $P$. tropica genome possesses more genes potentially involved in long-chain alkane (ladA and alkR genes) and cycloalkane (cpnA, chnB and $g n l$ genes) degradation. Since diesel fuels and similar low-volatile petroleum distillates are composed predominantly of aliphatic hydrocarbons (approximately 75\%) ${ }^{16,17}$, the presence of more high-molecular weight aliphatic hydrocarbon-degrading genes in $P$. tropica than in other species suggests stronger potential for the biodegradation of diesel spills. The presence of ringcleavage dioxygenase such as catechol 1,2-dioxygenase and catechol 2,3-dioxygenase in the genome of $P$. tropica also indicates its potential to metabolise intermediate products of aromatic hydrocarbon degradation. In a recent study, a particular strain of Paraburkholderia aromaticivorans isolated from a petroleum-contaminated soil was found capable of degrading naphthalene and BTEX (benzene, toluene, ethylbenzene and xylene) ${ }^{24}$. In addition, Paraburkholderia isolate exhibited higher growth rate in neutral $\mathrm{pH}$ (as determined by $\mathrm{OD}_{600}$ values) than either the Acidocella or the Burkholderia isolate, indicating potential wider application of $P$. tropica for rhizoremediation than the other species. Conversely, the adaptability of Acidocella to acidic conditions can be exploited for the remediation of sites contaminated with metals and organic pollutants such as mining sites ${ }^{25-27}$.

Geochemical analysis of biodegradation revealed that $M$. sativa $+P$. tropica treatment significantly enhanced the biodegradation of diesel fuel hydrocarbons, resulting in $96 \%$ rhizodegradation of the total petroleum hydrocarbons (Figure 2). Natural attenuation led to only $49 \%$ degradation. In comparison, $M$. sativa alone, $P$. tropica alone, and $M$. sativa $+P$. tropica treatments resulted in $72 \%, 86 \%$ and $96 \%$ biodegradation respectively. Biodegradation parameters revealed that the removal of petroleum hydrocarbons in the different treatments came from biodegradation. These parameters (nC17/Pr, $\mathrm{nC} 18 / \mathrm{Ph}, \mathrm{nC} 16 /$ nor-Pr and TPH/UCM) followed the expected trends, with $n$-alkanes more biodegradable than branched alkanes, and the UCM more recalcitrant than TPH. The parameters indicate that the highest degree of biodegradation among the different treatments occurred in "planted and inoculated" soils (Table 3). Tukey's pairwise comparisons confirmed these results and also indicated that the results of biodegradation were significantly different among the different treatments.

Although the chemical composition of diesel fuel is predominantly $n$-alkanes, branched alkanes and cycloalkanes, it also contains approximately $25 \%$ aromatic hydrocarbons such as alkylbenzenes, naphthalene, alkylnaphthalenes, phenanthrene, and alkylphenanthrenes ${ }^{17}$. Molecular analysis of residual polycyclic aromatic hydrocarbons revealed that $M$. sativa $+P$. 
tropica treatment led to an almost complete degradation of these contaminants (Figure 3). These results are of great relevance considering the toxicity of these compounds. Among the United States Environmental Protection Agency's 16 priority polycyclic aromatic hydrocarbons are naphthalene and phenanthrene ${ }^{28}$. Naphthalene is also classified as a group 2b carcinogen. In 2019, the European Chemical Agency added phenanthrene to the candidate list of substances of very high concern due to its very persistent, very bioaccumulative (vPvB) nature 29,30 .

Finally, the relative abundances of Paraburkholderia in the residual uninoculated and inoculated soils were $<1 \%$ and $5 \%$ respectively. This indicated that the inoculated bacteria thrived in the soils and were evidently responsible for the observed growth promotion of $M$. sativa and associated diesel fuel degradation. While many plant growth-promoting rhizobacteria have been experimented as inoculants for agricultural purposes, a major setback has always been the failure of inoculated microorganisms to effectively thrive against indigenous microbes ${ }^{31}$. Therefore, the results of this study will prove beneficial not only for environmental remediation but also for biotechnological applications in agriculture.

\section{MATERIALS AND METHODS}

\section{Soil Sampling}

A topsoil sample $(10 \mathrm{~g})$ was taken from a heavily polluted site in Wietze $\left(52^{\circ} 39^{\prime} 0^{\prime}\right.$ ' $\mathrm{N}$, 09 50'0' 'E), Germany in November 2019 and transported to the laboratory on ice. Wietze is a site of historical petroleum production beginning in $1859^{32}$. Between 1900 and 1920, about $80 \%$ of German crude oil was produced in Wietze. The former oil field still contains petroleum seepages (Supplementary Figure S5) amidst a forested environment.

\section{Enrichment Cultures, Isolation of Single Bacterial Isolates and Growth Conditions}

Approximately $1 \mathrm{~g}$ of the crude-oil-polluted soil was added to an Erlenmeyer flask $(300 \mathrm{~mL})$ containing $100 \mathrm{~mL}$ of liquid mineral medium (MM) composed of $\mathrm{KH}_{2} \mathrm{PO}_{4}(0.5 \mathrm{~g} / \mathrm{L}), \mathrm{NaCl}(0.5$ $\mathrm{g} / \mathrm{L}), \mathrm{NH}_{4} \mathrm{Cl}(0.5 \mathrm{~g} / \mathrm{L})$. Sterile-filtered trace elements $(1 \mathrm{~mL} / \mathrm{L})^{33}$, vitamin solution $(1 \mathrm{~mL} / \mathrm{L})^{33}$ and $\mathrm{MgSO}_{4} .7 \mathrm{H}_{2} \mathrm{O}(5 \mathrm{~mL}$ of a $100 \mathrm{mg} / \mathrm{mL}$ solution) were added to the $\mathrm{MM}$, post $\mathrm{MM}$ autoclaving. The $\mathrm{pH}$ was adjusted to 7.0. One $\mathrm{mL}$ of sterile-filtered diesel fuel was added to the flask as the sole carbon and energy source. The culture was grown at $30^{\circ} \mathrm{C}$ with shaking at $110 \mathrm{rpm}$ (INFORS HT shaker, model CH-4103, Infors AG, Bottmingen, Switzerland) and 
subcultured after every five days. After three successive subculturing, the cells were plated on agar plates, after which diesel fuel was added to the plates using an airbrush. The plates were incubated at $30^{\circ} \mathrm{C}$. After 48 hours, single colonies were transferred into separate flasks containing $100 \mathrm{~mL}$ liquid MM and $1 \mathrm{~mL}$ diesel fuel, and grown for five days. During the fiveday period, bacterial growth in terms of optical density $\left(\mathrm{OD}_{600}\right)$ was monitored every 12 hours using the UV/Visible spectrophotometer (Ultrospec 3000, Model 80-2106-20, Pharmacia Biotech, Cambridge England). Based on the $\mathrm{OD}_{600}$ values, three representative isolates were selected for whole genome studies.

\section{DNA Extraction}

Microbial cells from approximately $30 \mathrm{~mL}$ of the cultures containing single isolates were harvested by centrifugation at $4000 \mathrm{x}$ g for $10 \mathrm{~min}$. DNA from the cell pellets were extracted using a MasterPure ${ }^{\mathrm{TM}}$ DNA Extraction kit (Epicentre ${ }^{\circledR}$, Madison, USA) according to the manufacturer's protocol. The DNA was used for Illumina-based whole genome sequencing. In addition, microbial cells from $30 \mathrm{~mL}$ of the cultures were harvested for Nanopore-based whole genome sequencing. Similarly, at the end of the experimental period, DNA from $100 \mathrm{mg}$ of the inoculated and uninoculated residual soil samples were extracted using the PowerSoil@ DNA Extraction kit (Qiagen, Hilden, Germany).

\section{High-Throughput Sequencing}

\section{Genome sequencing and assembly}

Genomes were sequenced at the Göttingen Genomics Laboratory, Germany. Short-reads were generated using a MiSeq sequencer and v3 chemistry (Illumina, San Diego, CA, USA), while long-reads were sequenced using a MinIon (Oxford Nanopore Technologies; Oxford, England). Reads were quality filtered with fastp version $0.20 .1^{34}$. The leading $15 \mathrm{cp}$ were truncated from forward and reverse reads. Read shorter than $30 \mathrm{bp}$ were removed. Adaptor sequences were trimmed. Nanopore data were processed with porechop version 0.2.4 ${ }^{35}$. Default parameters were used for all software unless otherwise specified. The quality of the processing was confirmed using FastQC version 0.91. Reads were assembled using Unicycler version $0.4 .8^{36}$. Contigs shorter than $500 \mathrm{bp}$ were removed. Coverage information for each scaffold was determined using Bowtie 2 version 2.4.2 ${ }^{37}$ and SAMtools version $1.11^{38}$. Genomes were classified taxonomically using GTDB-Tk version 1.0.2 and the Genome Taxonomy Database (release 86$)^{39,40}$. 


\section{Sequencing of bacterial 16S rRNA genes from residual soils}

Bacterial 16S rRNA genes were amplified using the forward primer S-D-Bact-0341-b-S-17 (5'CCT ACG GGN GGC WGC AG-3') ${ }^{41}$ and the reverse primer S-D-Bact-0785-a-A-21 (5'-GAC TAC HVG GGT ATC TAA TCC-3') ${ }^{41}$ containing Illumina Nextera adapters for sequencing. The PCR reaction $(25 \mu \mathrm{L})$ contained $5 \mu \mathrm{L}$ of five-fold Phusion HF buffer, $200 \mu \mathrm{M}$ of each of the four deoxynucleoside triphosphates, $4 \mu \mathrm{M}$ of each primer, $1 \mathrm{U}$ of Phusion high fidelity DNA polymerase (Thermo Scientific, Waltham, MA, USA), and approximately $50 \mathrm{ng}$ of the extracted DNA as a template. The negative controls were performed by using the reaction mixture without a template. The following thermal cycling scheme was used: initial denaturation at $98{ }^{\circ} \mathrm{C}$ for $30 \mathrm{~s}, 30$ cycles of denaturation at $98{ }^{\circ} \mathrm{C}$ for $15 \mathrm{~s}$, annealing at $53{ }^{\circ} \mathrm{C}$ for $30 \mathrm{~s}$, followed by extension at $72{ }^{\circ} \mathrm{C}$ for $30 \mathrm{~s}$. The final extension was carried out at $72{ }^{\circ} \mathrm{C}$ for 2 min. Obtained PCR products per sample were controlled for appropriate size and purified using the MagSi-NGS Plus kit according to the manufacturer's protocol (Steinbrenner Laborsysteme GmbH, Germany). The quantification of the PCR products was performed using the Quant-iT dsDNA HS assay kit and a Qubit fluorometer, as recommended by the manufacturer (Thermo Scientific). The DNA samples were barcoded using the Nextera XTIndex kit (Illumina, San Diego, USA) and the Kapa HIFI Hot Start polymerase (Kapa Biosystems, USA). Sequencing was performed at the Göttingen Genomics Laboratory on an Illumina MiSeq Sequencing platform (paired end $2 \times 300$ bp) using the MiSeq Reagent kit v3, as recommended by the manufacturer (Illumina). All bacterial samples were sequenced on the same MiSeq run.

\section{Processing of the 16S rRNA gene data}

Trimmomatic version $0.39^{42}$ was initially used to truncate low quality reads if quality dropped below 12 in a sliding window of $4 \mathrm{bp}$. Datasets were subsequently processed with Usearch version 11.0.667 ${ }^{43}$ as described in Wemheuer, Berkelmann, Wemheuer, Daniel, Vidal and Bisseleua Daghela ${ }^{44}$. In brief, paired end reads were merged and quality-filtered. Filtering included the removal of low-quality reads (maximum number of expected errors $>2$ and more than 1 ambitious base, respectively) and those shorter than $200 \mathrm{bp}$. Processed sequences of all samples were joined, dereplicated and clustered in zero-radius operational taxonomic units (zOTUs) using the UNOISE algorithm implemented in Usearch. A de novo chimera removal was included in the clustering step. Afterwards, zOTU sequences were taxonomically classified using the SINTAX algorithm against the SILVA database (SILVA SSURef 138 NR99). All non-bacterial zOTUs were removed based on their taxonomic classification. Subsequently, 
processed sequences were mapped on final zOTU sequences to calculate the distribution and abundance of each OTU in every sample. Richness and coverage based on the Chaol richness estimator were estimated in $\mathrm{R}$ using the vegan package.

\section{Functional Analysis of the Genomes}

\section{Identification of CDSs involved in plant growth promoting and hydrocarbon-degrading processes}

Coding DNA sequences of putative enzymes involved in both plant growth-promoting activities and hydrocarbon degradation were identified in the bacterial genomes by means of annotations with prodigal version 2.6.3 ${ }^{45}$. Functional annotation was performed with diamond version v0.9.29 ${ }^{46}$ and the KEGG database (October release 2018) ${ }^{47}$. The plant growthpromoting enzymes of interest include nif-specific regulatory protein, nitrogen fixation protein, electron transfer flavoprotein, acyl carrier protein, trehalose 6-phosphate phosphatase, phosphoglycolate phosphatase, phospholipase $\mathrm{C}$, pyrroloquinoline quinone biosynthesis proteins B, D and E, pyrroloquinoline quinone-synthase, enterobactin (siderophore) exporter, and indoleacetamide hydrolase. Additionally, the genes responsible for bacterial chemotaxis, motility and root colonization were examined. These include the che, wsp, flg, flh, fli and tad genes. Similarly, the hydrocarbon-degrading enzymes of interest include long-chain alkane monooxygenase, cyclopentanol dehydrogenase, cyclohexanone monooxygenase, benzoate/toluate 1,2-dioxygenase, benzaldehyde dehydrogenase, dihydroxycyclohexadiene carboxylate dehydrogenase, catechol 1,2-dioxygenase, catechol 2,3-dioxygenase, muconate cycloisomerase, muconolactone D-isomerase, 3-oxoadipate enol-lactonase. On the basis of the following factors, $P$. tropica was selected for greenhouse-based rhizoremediation study: (1) the differences in the plant growth-promoting potentials of the different species as revealed by functional genomics, and (2) the differences in species' tolerance to and utilization of diesel fuel hydrocarbons as shown by their growth rates $\left(\mathrm{OD}_{600}\right)$ in the diesel-containing mineral medium.

\section{Plant Growth and Bacterial Inoculation}

The soil used for this experiment was "Primaster turf", which is a mixture of screened sand, soil, and composted organics blended with an NPK fertiliser. The soil textural class was determined as sand (88.6\% sand, $6.1 \%$ silt and $5.3 \%$ clay) with $12.5 \%$ organic matter content by loss on ignition, total nitrogen content of $0.15 \%$, and a $\mathrm{pH}$ of 7.1 . The soil was initially homogenized by sieving using a $2-\mathrm{mm}$ mesh sieve to remove large particles. Diesel fuel- 
contaminated soil was prepared following the detailed procedure described in Eze, Thiel, Hose, George and Daniel ${ }^{48}$. Preliminary gas chromatography-mass spectrometry (GC-MS) analysis of the diesel fuel revealed the presence of fatty acid methyl esters (FAMEs) evidently from biodiesel (Supplementary Figure S6). Therefore, the soil was allowed to age for 7 days, so as to enable the removal of the FAMEs through natural attenuation by indigenous organisms. The resulting total petroleum hydrocarbons in the soil after ageing (designated as time T0) was determined using GC-MS. Viable seeds of Medicago sativa L. were placed in pots (3 seeds per pot) containing $150 \mathrm{~g}$ of the aged diesel fuel-contaminated soils.

The contaminated soil was treated with the following: (1) M. sativa; (2) P. tropica; (3) M. sativa + P. tropica. An unplanted and uninoculated soil served as the control. Since the goal of the study was to assess the effectiveness of each treatment for hydrocarbon degradation, the soil used for the entire experiment was the diesel fuel-contaminated soil described above. The microbial consortium used was harvested from the culture by centrifugation at $4000 \mathrm{x} g$ for 10 min, washed twice in mineral medium and concentrated to $\mathrm{OD}_{600}=1.650$. The same amount of cells were applied to both the "P. tropica" and the "M. sativa $+P$. tropica" treatments. For the $M$. sativa + P. tropica treatment, the cells (at $\mathrm{OD}_{600}=1.650$ ) were inoculated to the base of one-week-old $M$. sativa seedlings at the depth of $1.5 \mathrm{~cm}$ below-ground level. The whole experiment was performed in triplicate, and pots were watered with $90 \mathrm{~mL}$ sterile water every three days for the first two weeks. After that, the planted pots were watered with $90 \mathrm{~mL}$ sterile water every two days to compensate for the water needs of $M$. sativa plants. To assess the effect of bacterial inoculation on growth rate, shoot heights (in mean values of plants per pot) attained with time were taken every two weeks. Plant height was measured from the shoot tip to the base of stem ${ }^{15,49}$. After 60 days, each plant was harvested, washed under tap water, oven-dried at $70^{\circ} \mathrm{C}$ until constant weights were achieved, and then their dry biomass weights were recorded.

\section{Geochemical Assessment of Microbial-Enhanced Bioremediation}

\section{Extraction of residual hydrocarbons}

After 60 days, $M$. sativa plants were harvested from the pots. The soil samples from each pot were first manually homogenized. For hydrocarbon analyses, $1 \mathrm{~g}$ of the ground freeze-dried soils were further homogenized with a small amount of sodium sulfate $\left(\mathrm{Na}_{2} \mathrm{SO}_{4}\right)$ and transferred into a Teflon microwave digestion vessel. The samples were solvent extracted twice with fresh $2.5 \mathrm{~mL}$ n-hexane in a microwave device (Mars Xpress, CEM; $1600 \mathrm{~W}, 100^{\circ} \mathrm{C}, 20$ 
$\min$ ). For reference, $2.5 \mu \mathrm{L}$ diesel fuel (density $=0.82 \mathrm{~g} / \mathrm{mL}$ ) were dissolved in $5 \mathrm{~mL} n$-hexane instead of $1 \mathrm{~g}$ soil sample. The extracts were combined into $7 \mathrm{~mL}$ vials and topped to $5 \mathrm{~mL}$ with $n$-hexane. A $1 \mathrm{~mL}$ aliquot (20\%) of each extract was pipetted into a $2 \mathrm{~mL}$ autosampler vial, and $20 \mu \mathrm{L} n$-icosane D42 [200 mg/L] was added as an internal quantification standard.

\section{Molecular analysis of biodegradation}

GC-MS analyses of the samples were performed using a Thermo Scientific Trace 1300 Series GC coupled to a Thermo Scientific Quantum XLS Ultra MS. The GC capillary column was a Phenomenex Zebron ZB-5MS (30 m, $0.1 \mu \mathrm{m}$ film thickness, inner diameter $0.25 \mathrm{~mm}$ ). Compounds were transferred splitless to the GC column at an injector temperature of $300^{\circ} \mathrm{C}$. Helium was used as the carrier gas at a flow rate of $1.5 \mathrm{~mL} / \mathrm{min}$. The GC temperature program was as follows: $80^{\circ} \mathrm{C}$ (hold $1 \mathrm{~min}$ ), $80^{\circ} \mathrm{C}$ to $310^{\circ} \mathrm{C}$ at $5^{\circ} \mathrm{C} / \mathrm{min}$ (hold $20 \mathrm{~min}$ ). Electron ionization mass spectra were recorded at $70 \mathrm{eV}$ electron energy in full scan mode (mass range $\mathrm{m} / \mathrm{z}$ 50-600, scan time $0.42 \mathrm{~s}$ ). Peak areas were integrated using Thermo Xcalibur software version 2.2 (Thermo Fisher Scientific Inc., USA).

\section{Biodegradation parameters}

To assess the nature and extent of biodegradation in the different treatments, the ratios of $n$ hexadecane (nC16), $n$-heptadecane (nC17) and $n$-octadecane (nC18) versus the more refractory isoprenoid hydrocarbons nor-pristane (2,6,10-trimethylpentadecane, nor-Pr), pristane (2,6,10,14-tetramethylpentadecane, $\mathrm{Pr})$ and phytane (2,6,10,14-tetramethylhexadecane, $\mathrm{Ph})$ were calculated. As an additional parameter, the relative abundance of total petroleum hydrocarbons (TPH) versus the unresolved complex mixture (UCM, often referred to as the "hump", a typical indicator of biodegradation ${ }^{50}$ ) was determined.

\section{Statistical Analyses}

All statistical analysis were performed using $\mathrm{R}^{51}$. One-way analysis of variance (ANOVA) was used to compare the mean dry biomass of $M$. sativa and $M$. sativa $+P$. tropica treatments. The normality and homogeneity of variances were tested by the Shapiro-Wilk's test ${ }^{52}$ and the Levene's test ${ }^{53}$ respectively. Relative growth rates of plants under different treatments were determined following the method of Eze, George and Hose ${ }^{15}$. This method involved the assessment of growth rate in terms of mean shoot height per pot attained with time. This approach eliminates the biases associated with destructive harvesting methods ${ }^{54}$. The logistic 
model was used for the statistical analysis of relative growth rate ${ }^{55,56}$. The lower asymptote $c$ was fixed at 0 since height at time $t_{0}$ is 0 , resulting in a 3-parameter logistic model.

Similarly, comparisons of soil hydrocarbon concentrations before (T0) and after (T60), and between treatments were made using one-way ANOVA, followed by Tukey's all-pairwise comparisons. In all cases, the normality of variances was tested by the Shapiro-Wilk's method ${ }^{52}$, and homogeneity of variances was tested using the Levene's test ${ }^{53}$. The significance level (nominally 0.05) was adjusted for multiple comparisons using the Holm method ${ }^{57,58 .}$

\section{Author contributions}

Conceptualization and design: MOE, GCH, SCG and RD. Planning and implementation: MOE and RD. Experiments and bioinformatics analyses: MOE. Geochemical analysis: MOE and VT. Writing - original draft: MOE. Writing - review and editing: VT, GCH, SCG and RD. Supervision: GCH, SCG and RD.

\section{Competing interests}

The authors hereby declare no competing interests.

\section{Acknowledgements}

The authors would like to thank the Commonwealth Government of Australia and the German Academic Exchange Service (DAAD) for supporting this research project by providing M.O.E. with an international Research Training Program (iRTP) Scholarship and DAAD Scholarship (Allocation Numbers: 2017561 and 91731339 respectively). This publication was supported financially by the Open Access Grant Program of the German Research Foundation (DFG) and the Open Access Publication Fund of the University of Goettingen. We also thank Dr. Anja Poehlein and Melanie Heinemann for the assistance during sequencing.

\section{Data Availability}

The whole genome shotgun project has been deposited at DDBJ/ENA/GenBank under the accession numbers JAGIXD000000000, JAGIXE000000000 and JAGIXF000000000. The versions described in this paper are JAGIXD010000000, JAGIXE010000000 and JAGIXF010000000. 


\section{References}

1. Bragg, J.R., Prince, R.C., Harner, E.J. \& Atlas, R.M. Effectiveness of bioremediation for the Exxon Valdez oil spill. Nature 368, 413-418 (1994).

2. Abbriano, R. et al. Deepwater Horizon oil spill: a review of the planktonic response. Oceanography 24, 294-301 (2011).

3. Hemmer, M.J., Barron, M.G. \& Greene, R.M. Comparative toxicity of eight oil dispersants, Louisiana sweet crude oil (LSC), and chemically dispersed LSC to two aquatic test species. Environ. Toxicol. Chem. 30, 2244-2252 (2011).

4. Duffy, J.J., Peake, E. \& Mohtadi, M.F. Oil spills on land as potential sources of groundwater contamination. Environ. Int. 3, 107-120 (1980).

5. Azubuike, C.C., Chikere, C.B. \& Okpokwasili, G.C. Bioremediation techniquesclassification based on site of application: principles, advantages, limitations and prospects. World J. Microbiol. Biotechnol. 32, 180 (2016).

6. USEPA, EPA/600/R-99/107. Introduction to phytoremediation. United States Environmental Protection Agency (2000).

7. USEPA, EPA 542-R-01-006. Brownfields technology primer: selecting and using phytoremediation for site cleanup. United States Environmental Protection Agency (2001).

8. Meagher, R.B. Phytoremediation of toxic elemental and organic pollutants. Current Opin. Plant Biol. 3, 153-162 (2000).

9. Bevivino, A., Dalmastri, C., Tabacchioni, S. \& Chiarini, L. Efficacy of Burkholderia cepacia MCI 7 in disease suppression and growth promotion of maize. Biology and Fertility of Soils 31, 225-231 (2000).

10. Rohrbacher, F. \& St-Arnaud, M. Root exudation: the ecological driver of hydrocarbon rhizoremediation. Agronomy 6, 19 (2016).

11. Garrido-Sanz, D. et al. Metagenomic insights into the bacterial functions of a dieseldegrading consortium for the rhizoremediation of diesel-polluted soil. Genes $\mathbf{1 0}, 456$ (2019).

12. Glick, B.R. Phytoremediation: synergistic use of plants and bacteria to clean up the environment. Biotechnol. Adv. 21, 383-393 (2003).

13. Dias, G.M. et al. Comparative genomics of Paraburkholderia kururiensis and its potential in bioremediation, biofertilization, and biocontrol of plant pathogens. MicrobiologyOpen 8, e00801 (2019).

14. García, S.S. et al. Paraburkholderia tropica as a plant-growth-promoting bacterium in barley: characterization of tissues colonization by culture-dependent and independent techniques for use as an agronomic bioinput. Plant Soil (2019). 
15. Eze, M.O., George, S.C. \& Hose, G.C. Dose-response analysis of diesel fuel phytotoxicity on selected plant species. Chemosphere 263, 128382 (2021).

16. Eze, M.O. \& George, S.C. Ethanol-blended petroleum fuels: implications of cosolvency for phytotechnologies. RSC Adv. 10, 6473-6481 (2020).

17. ATSDR. Toxicological profile for fuel oil. Agency for Toxic Substances and Disease Registry, United States (1995).

18. Esmaeel, Q. et al. Paraburkholderia phytofirmans PsJN-plants interaction: from perception to the induced mechanisms. Front. Microbiol. 9, 2093 (2018).

19. Böhm, M., Hurek, T. \& Reinhold-Hurek, B. Twitching motility is essential for endophytic rice colonization by the $\mathrm{N}_{2}$-fixing endophyte Azoarcus sp. strain BH72. Mol. Plant Microbe Interact. 20, 526-533 (2007).

20. Brencic, A. \& Winans, S.C. Detection of and response to signals involved in hostmicrobe interactions by plant-associated bacteria. Microbiol. Mol. Biol. Rev. 69, 155194 (2005).

21. Chen, Y. et al. Comparative genomic analysis and phenazine production of Pseudomonas chlororaphis, a plant growth-promoting rhizobacterium. Genom. Data 4, 33-42 (2015).

22. Haq, I.U., Graupner, K., Nazir, R. \& van Elsas, J.D. The genome of the fungalinteractive soil bacterium Burkholderia terrae BS001 - a plethora of outstanding interactive capabilities unveiled. Genome Biol. Evol. 6, 1652-1668 (2014).

23. Shen, X., Hu, H., Peng, H., Wang, W. \& Zhang, X. Comparative genomic analysis of four representative plant growth-promoting rhizobacteria in Pseudomonas. BMC Genom. 14, 271 (2013).

24. Lee, Y., Lee, Y. \& Jeon, C.O. Biodegradation of naphthalene, BTEX, and aliphatic hydrocarbons by Paraburkholderia aromaticivorans BN5 isolated from petroleumcontaminated soil. Sci. Rep. 9, 860 (2019).

25. Gemmell, R.T. \& Knowles, C.J. Utilisation of aliphatic compounds by acidophilic heterotrophic bacteria. The potential for bioremediation of acidic wastewaters contaminated with toxic organic compounds and heavy metals. FEMS Microbiol. Lett. 192, 185-190 (2000).

26. Röling, W.F.M., Ortega-Lucach, S., Larter, S.R. \& Head, I.M. Acidophilic microbial communities associated with a natural, biodegraded hydrocarbon seepage. J. Appl. Microbiol. 101, 290-299 (2006).

27. Giovanella, P. et al. Metal and organic pollutants bioremediation by extremophile microorganisms. J. Hazard. Mater. 382, 121024 (2020).

28. Bojes, H.K. \& Pope, P.G. Characterization of EPA's 16 priority pollutant polycyclic aromatic hydrocarbons (PAHs) in tank bottom solids and associated contaminated soils at oil exploration and production sites in Texas. Regul. Toxicol. Pharmacol. 47, 288-295 (2007). 
29. ECHA, ECHA/PR/19/01 The candidate list of substances of very high concern (SVHCs). European Chemical Agency (2019).

30. Loibner, A.P., Szolar, O.H.J., Braun, R. \& Hirmann, D. Toxicity testing of 16 priority polycyclic aromatic hydrocarbons using Lumistox ${ }^{\circledR}$. Environ. Toxicol. Chem. 23, 557-564 (2004).

31. Bashan, Y., de-Bashan, L.E., Prabhu, S.R. \& Hernandez, J.-P. Advances in plant growth-promoting bacterial inoculant technology: formulations and practical perspectives (1998-2013). Plant Soil 378, 1-33 (2014).

32. Craig, J., Gerali, F., MacAulay, F. \& Sorkhabi, R. The history of the European oil and gas industry (1600s-2000s). Geol. Soc. Spec. Publ. 465, 1 (2018).

33. Atlas, R.M. Handbook of microbiological media, 4th edition. CRC Press, Boca Raton, Florida (2010).

34. Chen, S., Zhou, Y., Chen, Y. \& Gu, J. fastp: an ultra-fast all-in-one FASTQ preprocessor. Bioinformatics 34, i884-i890 (2018).

35. Wick, R. Porechop, Github (https://github.com/rrwick/Porechop) (2017).

36. Wick, R.R., Judd, L.M., Gorrie, C.L. \& Holt, K.E. Unicycler: Resolving bacterial genome assemblies from short and long sequencing reads. PLOS Comput. Biol. 13, e1005595 (2017).

37. Langmead, B. \& Salzberg, S.L. Fast gapped-read alignment with Bowtie 2. Nat. Methods 9, 357-359 (2012).

38. Li, H. et al. The sequence alignment/map format and SAMtools. Bioinformatics $\mathbf{2 5}$, 2078-2079 (2009).

39. Chaumeil, P.-A., Mussig, A.J., Hugenholtz, P. \& Parks, D.H. GTDB-Tk: a toolkit to classify genomes with the Genome Taxonomy Database. Bioinformatics 36, 19251927 (2019).

40. Parks, D.H. et al. Selection of representative genomes for 24,706 bacterial and archaeal species clusters provide a complete genome-based taxonomy. bioRxiv, 771964 (2019).

41. Klindworth, A. et al. Evaluation of general 16S ribosomal RNA gene PCR primers for classical and next-generation sequencing-based diversity studies. Nucleic Acids Res. 41, e1-e1 (2013).

42. Bolger, A.M., Lohse, M. \& Usadel, B. Trimmomatic: a flexible trimmer for Illumina sequence data. Bioinformatics 30, 2114-2120 (2014).

43. Edgar, R.C. Search and clustering orders of magnitude faster than BLAST. Bioinformatics 26, 2460-2461 (2010). 
44. Wemheuer, F. et al. Agroforestry management systems drive the composition, diversity, and function of fungal and bacterial endophyte communities in Theobroma cacao leaves. Microorganisms 8 (2020).

45. Hyatt, D. et al. Prodigal: prokaryotic gene recognition and translation initiation site identification. BMC Bioinform. 11, 119-119 (2010).

46. Buchfink, B., Xie, C. \& Huson, D.H. Fast and sensitive protein alignment using DIAMOND. Nat. Methods 12, 59-60 (2015).

47. Kanehisa, M. \& Goto, S. KEGG: kyoto encyclopedia of genes and genomes. Nucleic Acids Res. 28, 27-30 (2000).

48. Eze, M.O., Thiel, V., Hose, G.C., George, S.C. \& Daniel, R. Metagenomic insight into the plant growth-promoting potential of a diesel-degrading bacterial consortium for enhanced rhizoremediation application. bioRxiv, 2021.2003.2026.437261 (2021).

49. Chen, S., Li, J., Fritz, E., Wang, S. \& Hüttermann, A. Sodium and chloride distribution in roots and transport in three poplar genotypes under increasing $\mathrm{NaCl}$ stress. For. Ecol. Manag. 168, 217-230 (2002).

50. Peters, K.E., Walters, C.C. \& Moldowan, J.M. The Biomarker Guide: Volume 2: Biomarkers and Isotopes in Petroleum Systems and Earth History. Cambridge University Press (2004).

51. R Core Team. R: a languange and environment for statistical computing. $\mathrm{R}$ Foundation for Statistical Computing, Vienna, Austria (2018).

52. Ghasemi, A. \& Zahediasl, S. Normality tests for statistical analysis: a guide for nonstatisticians. Int. J. Endocrinol. Metab. 10, 486-489 (2012).

53. Levene, H. Robust tests for equality of variances, in: Contributions to Probability and Statistics; Essays in Honor of Harold Hotelling (eds. O. Ingram \& H. Harold) 278292. Stanford University Press, Stanford, California (1960).

54. Hoffmann, W.A. \& Poorter, H. Avoiding bias in calculations of relative growth rate. Ann. Bot. 90, 37-42 (2002).

55. Gregorczyk, A. A logistic function - its application to the description and prognosis of plant growth. Acta Soc. Bot. Pol. 60, 67-76 (1991).

56. Szparaga, A. \& Kocira, S. Generalized logistic functions in modelling emergence of Brassica napus L. PLOS ONE 13, e0201980 (2018).

57. Lee, S. \& Lee, D.K. What is the proper way to apply the multiple comparison test? Korean J. Anesthesiol. 71, 353-360 (2018).

58. Holm, S. A simple sequentially rejective multiple test procedure. Scand. J. Stat. 6, 6570 (1979). 
Exploiting synergistic interactions of Medicago sativa L. and Paraburkholderia tropica for enhanced biodegradation of diesel fuel hydrocarbons

Michael O. Eze ${ }^{1,2 *}$, Volker Thiel ${ }^{3}$, Grant C. Hose ${ }^{4}$, Simon C. George ${ }^{2 \dagger}$ and Rolf Daniel ${ }^{1 \dagger *}$

${ }^{1}$ Department of Genomic and Applied Microbiology and Göttingen Genomics Laboratory, Georg-August University of Göttingen, 37077 Göttingen, Germany.

${ }^{2}$ Department of Earth and Environmental Sciences, Macquarie University, Sydney, NSW 2109, Australia.

${ }^{3}$ Geobiology, Geoscience Centre, Georg-August University of Göttingen, 37077 Göttingen, Germany.

${ }^{4}$ Department of Biological Sciences, Macquarie University, Sydney, NSW 2109, Australia.

${ }^{\dagger}$ These authors contributed equally to this work.

*Correspondence: meze@gwdg.de; rdaniel@gwdg.de

\section{Supplementary Materials}

Supplementary Table S1. Sequencing results for the three genomes

\begin{tabular}{|c|c|c|c|c|c|c|c|}
\hline \multirow[t]{2}{*}{ Genomes } & \multirow[t]{2}{*}{ Size (bp) } & \multirow[t]{2}{*}{ Raw reads } & \multicolumn{2}{|c|}{ Fastp } & \multirow[t]{2}{*}{ Scaffolds } & \multirow{2}{*}{$\begin{array}{l}\text { Scaffolds } \\
\text { (>500 bp) }\end{array}$} & \multirow[t]{2}{*}{ Coverage } \\
\hline & & & Paired reads & Unpaired reads & & & \\
\hline Acidocella facilis & $4,079,951$ & $1,234,060$ & $1,119,120$ & 52,554 & 216 & 181 & 44.4 \\
\hline Burkholderia sp. & $7,741,599$ & 813,998 & 636,137 & 79,504 & 263 & 235 & 13.1 \\
\hline $\begin{array}{l}\text { Paraburkholderia } \\
\text { tropica }\end{array}$ & $8,454,837$ & $2,180,716$ & $1,695,018$ & 223,965 & 96 & 81 & 31.8 \\
\hline Total & & $4,228,774$ & $3,450,275$ & 356,023 & 575 & 497 & Avg: $30 x$ \\
\hline
\end{tabular}


Supplementary Table S2. Plant growth promoting genes and number of CDSs for the three genomes

\begin{tabular}{llrrl}
\hline Gene & \multicolumn{2}{c}{ Genomes } & \multicolumn{2}{l}{ Enzyme name } \\
\hline \multicolumn{5}{l}{ Plant growth promotion } \\
\multicolumn{2}{l}{ Nitrogen metabolism } \\
nifA & $\mathbf{3}$ & & \\
nifU & 0 & 5 & 2 & Nif-specific regulatory protein \\
nifQ & 1 & 1 & 1 & Nitrogen fixation protein NifU and related proteins \\
fixA & 0 & 1 & 1 & Nitrogen fixation protein NifQ \\
fixB & 2 & 5 & 5 & Electron transfer flavoprotein beta subunit \\
fixL & 2 & 4 & 5 & Electron transfer flavoprotein alpha subunit \\
fixJ & 3 & 1 & 11 & Two-component system, sensor kinase FixL \\
\hline PhOSp & 3 & 2 & 11 & Two-component system, response regulator FixJ \\
\hline
\end{tabular}

\section{Phosphate solubilization}

\begin{tabular}{llrll}
$\operatorname{acpS}$ & 1 & 1 & 1 & Holo-[acyl-carrier protein] synthase [EC:2.7.8.7] \\
$\operatorname{acp} P$ & 1 & 2 & 4 & Acyl carrier protein \\
$\operatorname{ser} B$ & 1 & 1 & 1 & Phosphoserine phosphatase [EC:3.1.3.3] \\
otsB & 4 & 2 & 3 & Trehalose 6-phosphate phosphatase [EC:3.1.3.12] \\
gph & 3 & 6 & 6 & Phosphoglycolate phosphatase [EC:3.1.3.18] \\
phoD & 0 & 1 & 1 & Alkaline phosphatase D [EC:3.1.3.1] \\
plc & 1 & 10 & 9 & Phospholipase C [EC:3.1.4.3] \\
glpR & 4 & 4 & 6 & Glycerol-3-phosphate regulon repressor \\
\hline
\end{tabular}

Pyrroloquinoline quinone synthesis

\begin{tabular}{lllll}
$p q q B$ & 1 & 1 & 1 & Pyrroloquinoline quinone biosynthesis protein B \\
$p q q C$ & 1 & 1 & 1 & Pyrroloquinoline-quinone synthase [EC:1.3.3.11] \\
$p q q D$ & 2 & 1 & 1 & Pyrroloquinoline quinone biosynthesis protein D \\
$p q q E$ & 1 & 1 & 1 & Pyrroloquinoline quinone biosynthesis protein E \\
\hline
\end{tabular}

Siderophore transport

\begin{tabular}{lrrrl} 
entS & 0 & 1 & 2 & Enterobactin (siderophore) exporter \\
\hline $\begin{array}{l}\text { Indoleacetic acid synthesis } \\
\text { iaaH }\end{array}$ & 0 & 0 & 2 & Indoleacetamide hydrolase [EC:3.5.1.-] \\
\hline Total & $\mathbf{3 1}$ & $\mathbf{5 1}$ & $\mathbf{7 5}$ & \\
\hline Bacterial chemotaxis, & motility, & root nodulation and colonization \\
\hline cheABCDVWXYZ & 12 & 13 & 20 & Two-component chemotaxis protein \\
wspBDEF & 0 & 4 & 4 & Two-component chemotaxis protein \\
mcp, tsr, tar, trg, & 7 & 11 & 47 & Methyl-accepting chemotaxis protein \\
tap, wspA & & & & \\
flg, flh, fli & 43 & 48 & 52 & Flagellar proteins \\
nodD & 1 & 3 & 2 & Nod-box dependent transcriptional activator \\
tadB & 1 & 2 & 2 & Tight adherence protein B \\
tadC & 1 & 2 & 2 & Tight adherence protein C \\
\hline Total & 65 & 83 & $\mathbf{1 2 9}$ & \\
\hline
\end{tabular}

Genome 1: Acidocella facilis; Genome 2: Burkholderia sp.; Genome 3: Paraburkholderia tropica. 
Supplementary Table S3. Selected genes putatively involved in hydrocarbon degradation and number of CDSs

\begin{tabular}{|c|c|c|c|c|}
\hline \multirow[t]{2}{*}{ Gene } & \multicolumn{3}{|c|}{ Genomes } & \multirow[t]{2}{*}{ Enzyme name } \\
\hline & 1 & 2 & 3 & \\
\hline \multicolumn{5}{|c|}{ Aliphatic hydrocarbon degradation } \\
\hline \multicolumn{5}{|c|}{ n-Alkanes } \\
\hline alkM & 2 & 1 & 0 & Alkane 1-monooxygenase \\
\hline alkR & 1 & 2 & 2 & Alkane utilization regulator \\
\hline $\operatorname{lad} A$ & 3 & 6 & 6 & Long-chain alkane monooxygenase \\
\hline prmB & 1 & 0 & 1 & Propane monooxygenase reductase component \\
\hline \multicolumn{5}{|c|}{ Cycloalkanes } \\
\hline cpnA & 0 & 4 & 2 & Cyclopentanol dehydrogenase \\
\hline $\operatorname{chn} B$ & 0 & 2 & 2 & Cyclohexanone monooxygenase \\
\hline$g n l$ & 3 & 1 & 5 & Gluconolactonase \\
\hline$c h n D$ & 0 & 0 & 1 & 6-Hydroxyhexanoate dehydrogenase \\
\hline \multicolumn{5}{|c|}{ Aromatic hydrocarbon degradation } \\
\hline tmoF & 0 & 0 & 2 & Toluene monooxygenase \\
\hline pobA & 1 & 1 & 1 & p-Hydroxybenzoate 3-monooxygenase \\
\hline adhPE & 7 & 12 & 13 & Alcohol dehydrogenase \\
\hline benABC & 0 & 6 & 6 & Benzoate/toluate 1,2-dioxygenase \\
\hline benD & 1 & 1 & 1 & Dihydroxycyclohexadiene carboxylate dehydrogenase \\
\hline pcaGH & 4 & 2 & 2 & Protocatechuate 3,4-dioxygenase \\
\hline$e t b D$ & 0 & 1 & 1 & 2-Hydroxy-6-oxo-octa-2,4-dienoate hydrolase \\
\hline $\operatorname{cat} A$ & 0 & 3 & 2 & Catechol 1,2-dioxygenase \\
\hline catB & 0 & 2 & 2 & Muconate cycloisomerase \\
\hline catC & 0 & 2 & 2 & Muconolactone D-isomerase \\
\hline$p c a D L$ & 6 & 8 & 8 & 3-Oxoadipate enol-lactonase \\
\hline$d m p B$ & 2 & 2 & 1 & Catechol 2,3-dioxygenase \\
\hline praC & 1 & 4 & 4 & 4-Oxalocrotonate tautomerase \\
\hline$m h p D$ & 0 & 2 & 2 & 2-Keto-4-pentenoate hydratase \\
\hline$m h p E$ & 0 & 1 & 1 & 4-Hydroxy 2-oxovalerate aldolase \\
\hline
\end{tabular}

Genome 1: Acidocella facilis; Genome 2: Burkholderia sp.; Genome 3: Paraburkholderia tropica. 
(a)

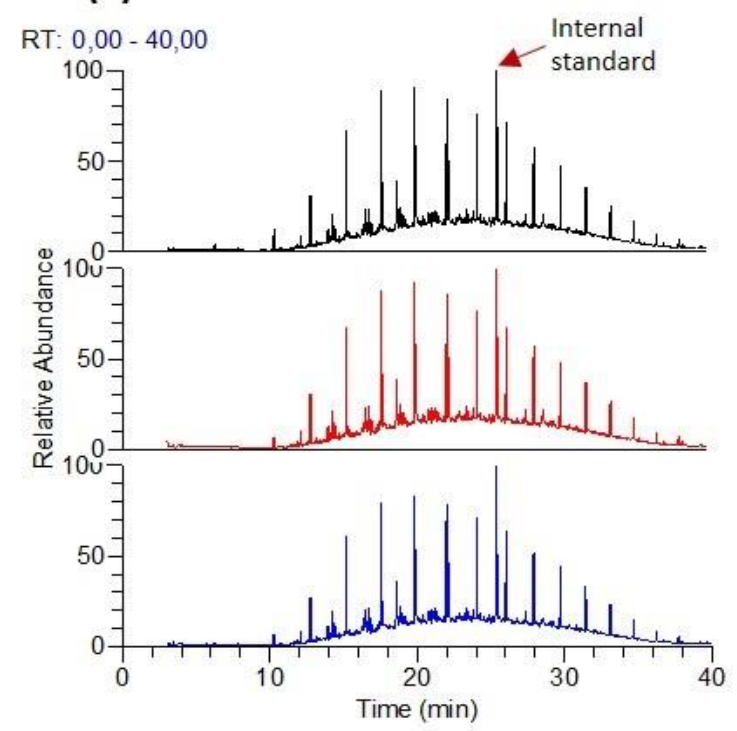

(c)

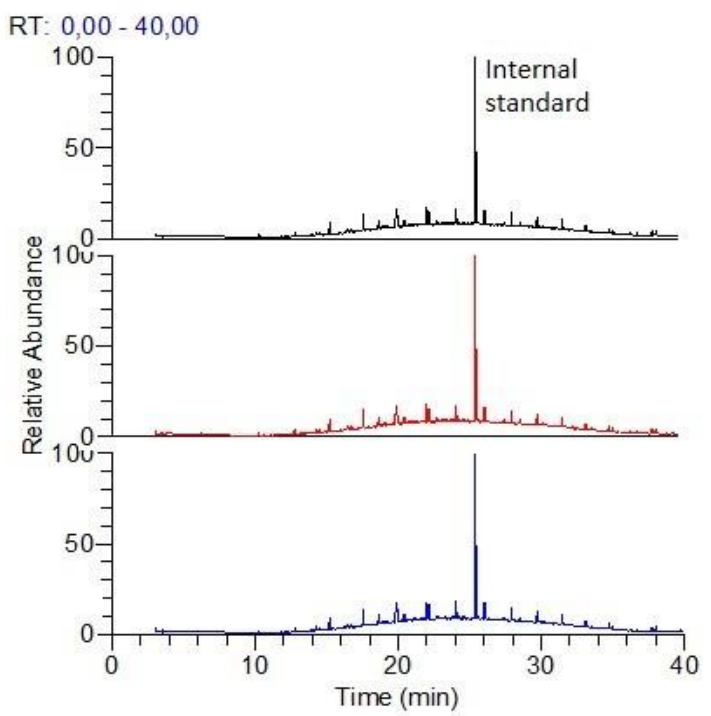

(b)

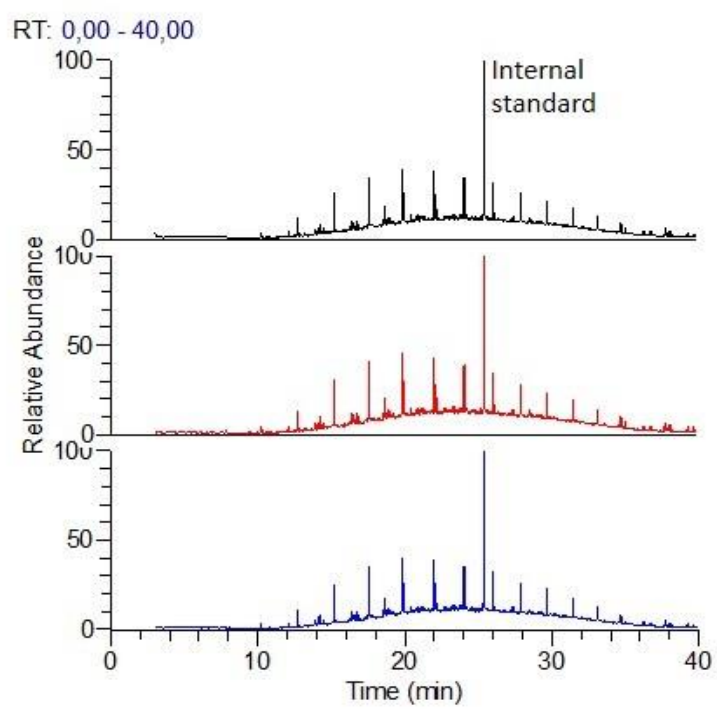

(d)

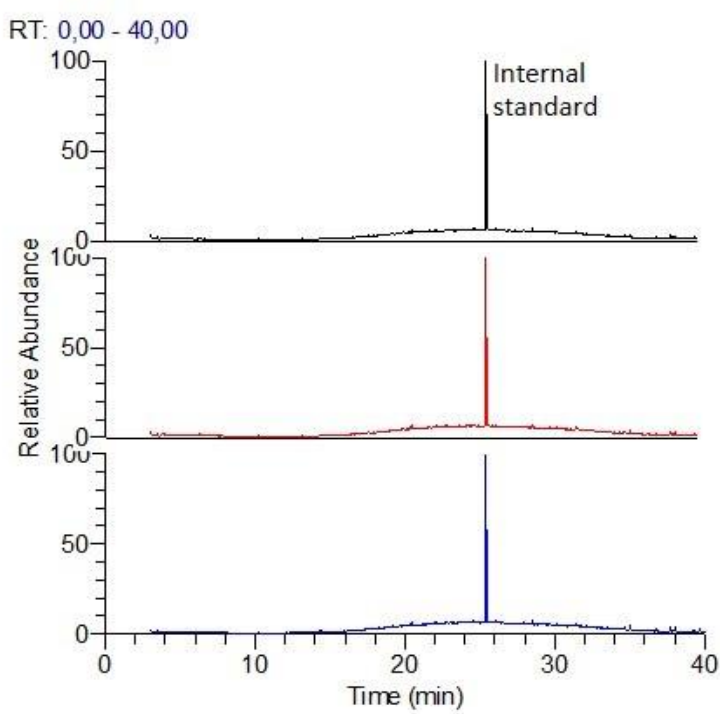

Supplementary Figure S1. Partial total ion chromatograms showing replicates of (a) Soil at Tf, (b) Soil+M.sativa, (c) Soil+P.tropica, and (d) Soil+M.sativa+P.tropica. Refer to Figure 2 in the main text for sample descriptions.

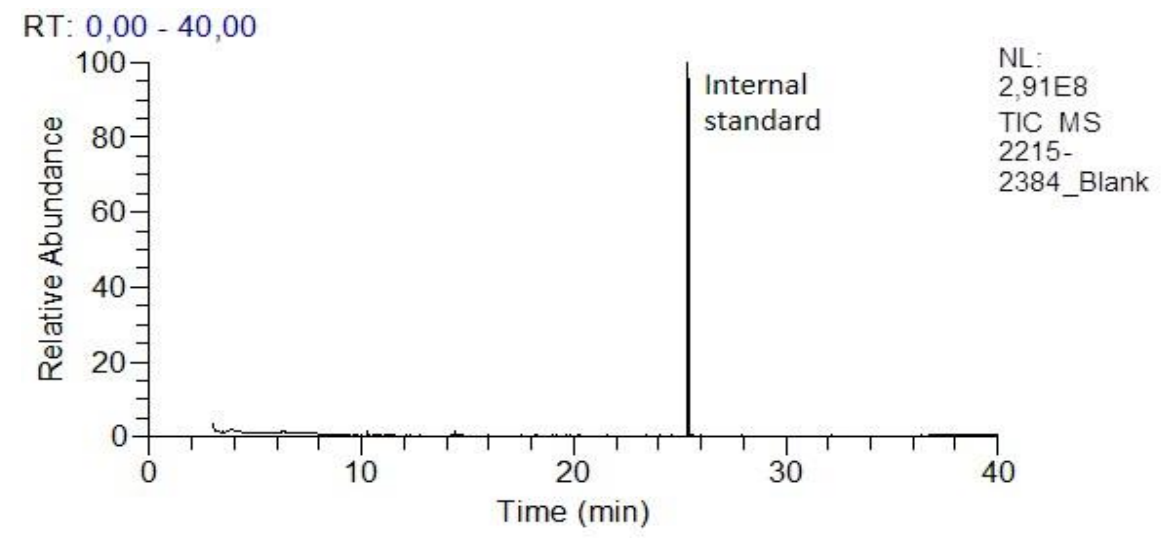

Supplementary Figure S2. Partial total ion chromatogram of preparation blank used to control cross contamination. 
Supplementary Table S4. Statistical parameters for Tukey's test showing significant differences in the mean values of residual hydrocarbons between treatments.

\begin{tabular}{|c|c|c|c|c|}
\hline Linear hypothesis (Tukey contrasts) & Estimate & Std. Error & $t$ value & $\operatorname{Pr}(>|t|)$ \\
\hline Soil at T60 - Soil at T0 $==0$ & -2.0300 & 0.0738 & -27.50 & 9.37e-10*** \\
\hline Soil+M.sativa - Soil at T0 $==0$ & -2.9700 & 0.0738 & -40.23 & $2.15 \mathrm{e}-11 * * *$ \\
\hline Soil+P.tropica - Soil at T0 $==0$ & -3.5467 & 0.0738 & -48.05 & $3.68 \mathrm{e}-12 * * *$ \\
\hline Soil+M.sativa + P.tropica - Soil at T0 $==0$ & -3.9833 & 0.0738 & -53.96 & $1.16 \mathrm{e}-12 * * *$ \\
\hline Soil+M.sativa - Soil at T60 $==0$ & -0.9400 & 0.0738 & -12.73 & $1.67 \mathrm{e}-06 * * *$ \\
\hline Soil+P.tropica - Soil at T60 $==0$ & -1.5167 & 0.0738 & -20.55 & $1.65 \mathrm{e}-08 * * *$ \\
\hline Soil+M.sativa + P.tropica - Soil at $\mathrm{T} 60==0$ & -1.9533 & 0.0738 & -26.46 & $1.37 \mathrm{e}-09 * * *$ \\
\hline Soil+P.tropica - Soil + M.sativa $==0$ & -0.5767 & 0.0738 & -7.81 & $1.45 \mathrm{e}-04 * * *$ \\
\hline Soil + M.sativa $+P$.tropica - Soil + M. sativa $==0$ & -1.0133 & 0.0738 & -13.73 & $8.17 \mathrm{e}-07 * * *$ \\
\hline Soil + M.sativa $+P$.tropica - Soil $+P$.tropica $=0$ & -0.4367 & 0.0738 & -5.92 & $0.0015 * *$ \\
\hline
\end{tabular}

Significant codes: $0^{\prime * * * \prime} 0.001^{* * \prime} 0.01^{* * \prime} 0.05$ '? $0.1^{\prime \prime \prime} 1$. (Adjusted $p$ values reported -- Holm method).

(a)

RT: $12,00-18,00$

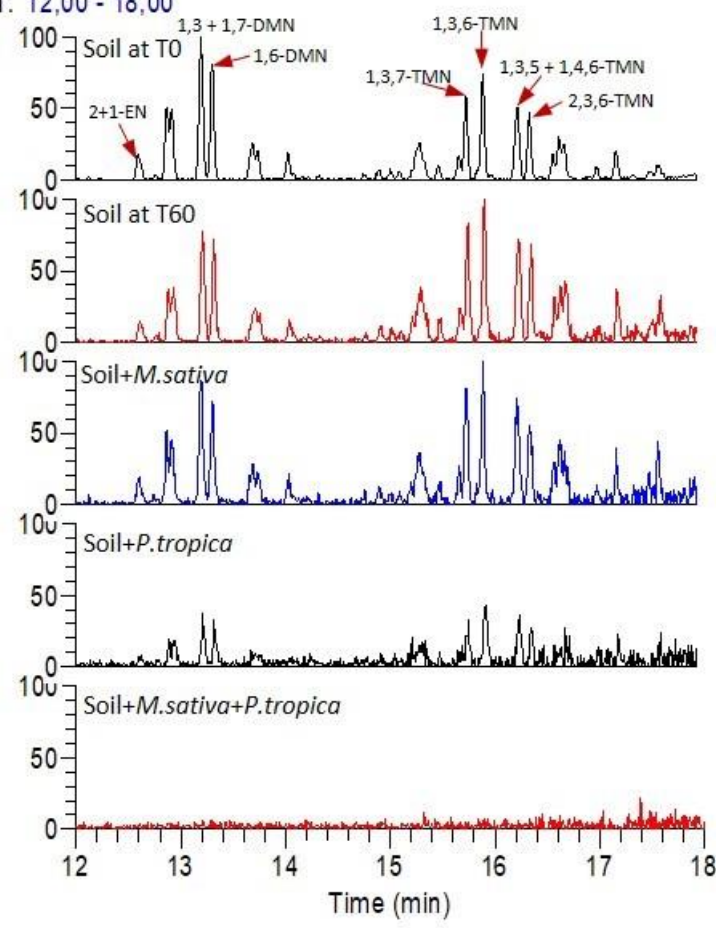

(b)

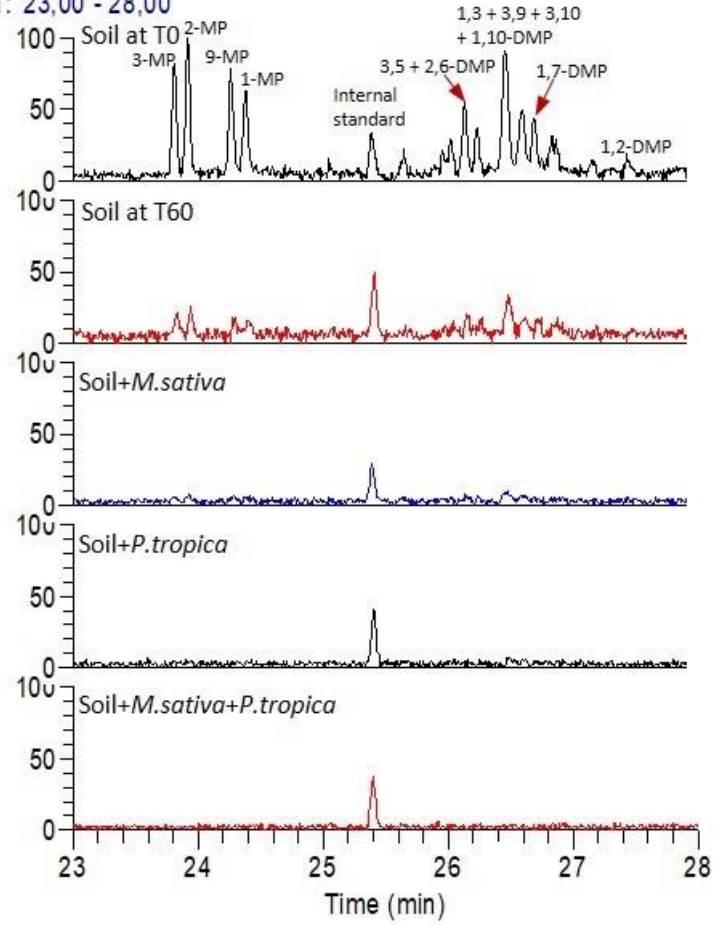

Supplementary Figure S3. Partial (a) $\mathrm{m} / \mathrm{z} 156+170$ and (b) $\mathrm{m} / \mathrm{z} 192+206$ GC-MS chromatograms of the different treatments showing differential biodegradation of naphthalenes and phenanthrenes. EN: ethylnaphthalene; DMN: dimethylnaphthalene; MP: methylphenanthrene; DMP: dimethylphenanthrene. Numbers denote positions of alkylation. 


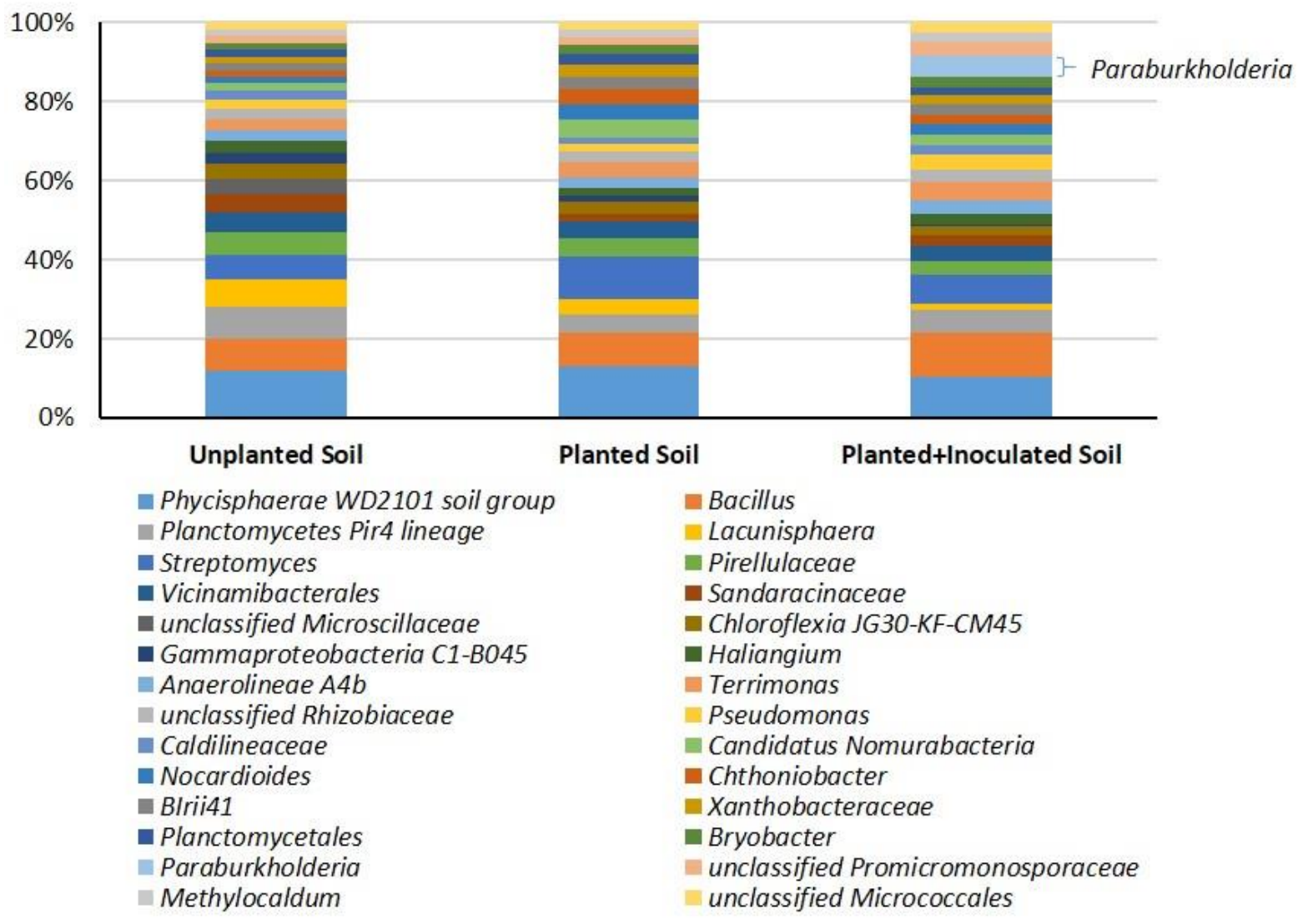

Supplementary Figure S4. Relative abundances of bacterial populations in the residual soils based on 16S rRNA gene amplicon data. Only taxa with relative abundance of $\geq 1 \%$ are presented.

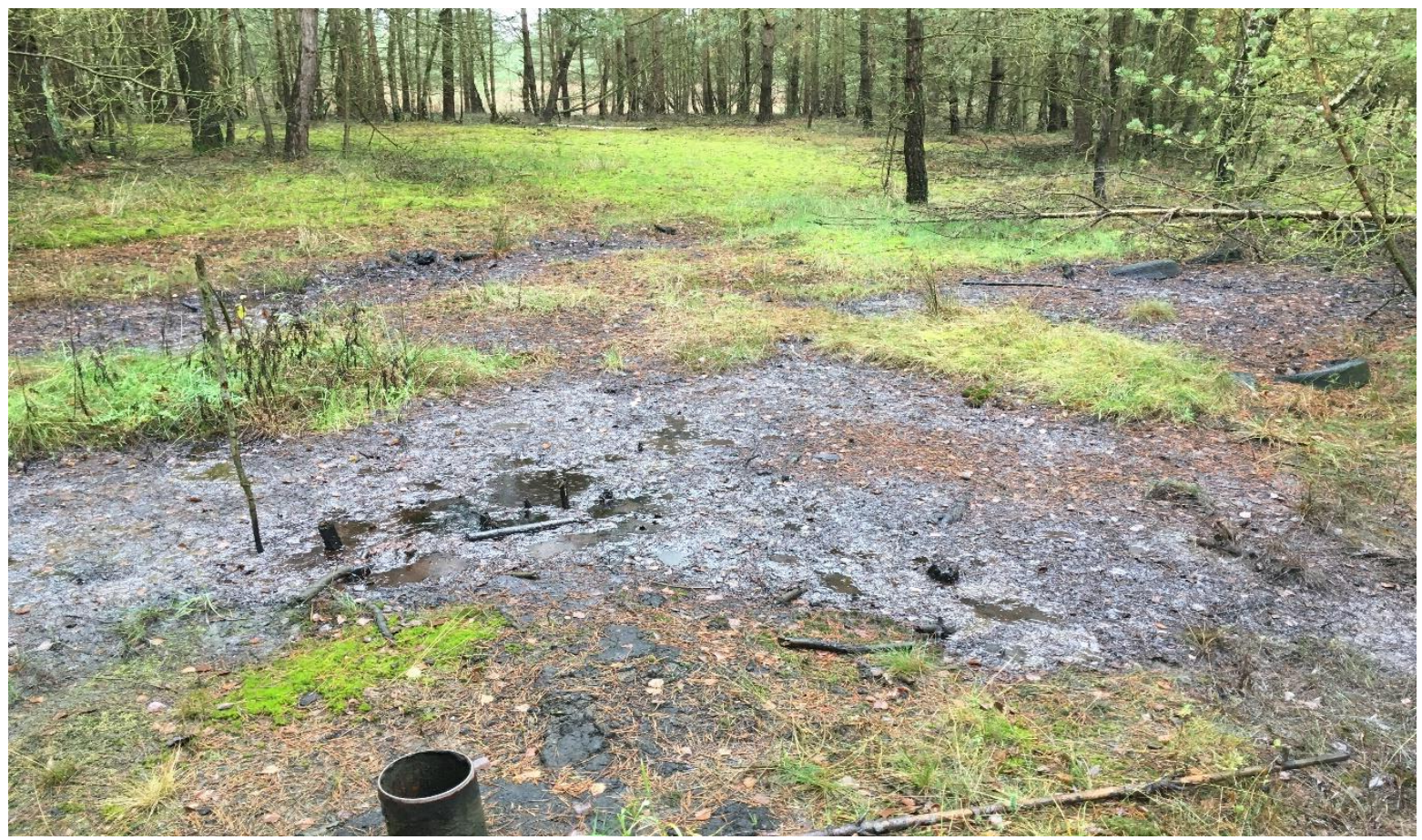

Supplementary Figure S5. Picture of the sampling site in Wietze, Germany. 

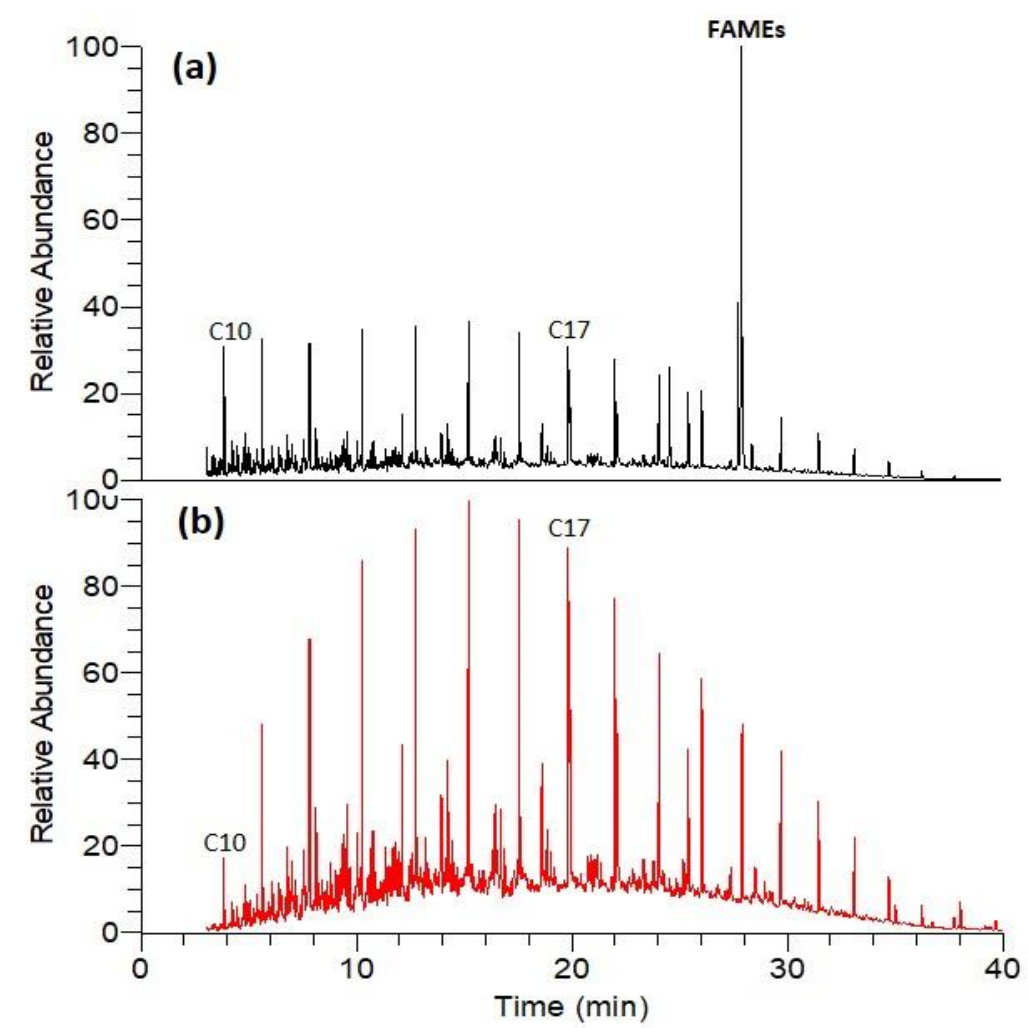

Supplementary Figure S6. Partial total ion chromatograms of (a) pure diesel fuel prior to soil spiking and ageing showing the presence of fatty acid methyl esters (FAMEs) from a biodiesel component, and (b) extracted diesel fuel after ageing showing the absence of FAMEs. 


\section{Chapter 9}

\section{Synthesis and Conclusions}

\section{$9.1 \quad$ Summary}

The $20^{\text {th }}$ Century novelist, Agatha Christie, DBE, once said: "everything must be taken into account. If the fact will not fit the theory - let the theory go" (Christie, 1920) This statement underpins the approach adopted in this study.

The purpose of this $\mathrm{PhD}$ thesis was to examine the potentials of plant growth-promoting bacteria to enhance the rhizoremediation of diesel fuel hydrocarbons. Employing the tools of (meta)genomics and organic geochemistry, this innovative research evaluated any hypothesized agreement between bacterial potentials as revealed by functional genomics ("theory") and actual biodegradation of contaminants ("fact").

Rhizoremediation of hydrocarbons relies heavily on biodegradation of contaminants by rootassociated bacteria (Rohrbacher and St-Arnaud, 2016). This therefore requires that the contaminants of interest must be within the rooting zones of plants, for rhizoremediation to be effective. The results of the leaching experiment in this study revealed that oxygenates such as ethanol, though beneficial in reducing the carbon footprint, enhance the leaching potentials of petroleum hydrocarbons by serving as co-solvents (Chapter 2). Consequently, appropriate care was taken when selecting plant species for phytotoxicity experiments, with many of the selected plants having rooting depths of about 1 metre.

Fifteen plant species were examined for their ability to withstand diesel fuel toxicity (Chapters 3 and 4). The results of this greenhouse experiment revealed an important truth: plant response to diesel fuel toxicity is species-specific. With the exception of the perennial legume Medicago sativa L. (common names are lucerne and alfalfa), diesel fuel impacted negatively on most of the studied plants, even at low concentrations (Chapter 3). This was expected considering the cytotoxic nature of hydrocarbons (Adam and Duncan, 2003; Chouychai et al., 2007). On the other hand, diesel fuel up to $10 \mathrm{~g} / \mathrm{kg}$ soil concentration had a stimulatory effect on the growth of $M$. sativa plants. Although previous studies have shown that $M$. sativa is tolerant to hydrocarbons (Chekol and Vough, 2001; Marchand et al., 2018), this study is the first attempt to describe diesel fuel-induced hormesis using the Cedergreen-Ritz-Streibig model (Cedergreen et al., 2005). Interestingly, the concept of hormesis is gaining growing attention in recent decades, with some researchers claiming that hormesis is the norm rather than the exception 
(Calabrese and Baldwin, 2003; Agathokleous et al., 2019; 2020). The suitability of $M$. sativa for diesel fuel rhizoremediation was further tested by examining the effect of diesel fuel on seed viability and the germination rate of $M$. sativa (Chapter 4). Significantly, the results revealed that neither the direct imbibition of diesel fuel by $M$. sativa seeds for $\leq 48$ hours nor their exposure to soil diesel fuel concentrations of 0-10 g/kg compromised seed viability. Instead, these conditions only delayed seed emergence or germination, owing to the diesel fuel creating a physical barrier to air and water absorption by the seeds. These results suggest that the inhibitory effect of diesel fuel on $M$. sativa germination at $\leq 10 \mathrm{~g} / \mathrm{kg}$ concentration could be attributed to physical constraints, rather than to biological damage to the seeds. Therefore, the results from Chapters 3 and 4 indicate that $M$. sativa is the most-promising plant species for rhizoremediation of diesel fuel. On this basis, M. sativa was chosen for further studies on microbially-enhanced rhizoremediation.

The metagenome study provided insight into the diversity and potentials of hydrocarbondegrading consortia isolated from different petroleum-contaminated sites. The omics dataset of metagenomes and metagenome-assembled genomes (MAGs) from a former crude oil borehole in Wietze, Germany (Chapter 5) revealed that most of the bacterial MAGs belonged to Proteobacteria (10 MAGs). Other represented phyla include Actinobacteriota (4 MAGs), Bacteroidota (5 MAGs), Chloroflexota (5 MAGs), Desulfobacterota (4 MAGs), Firmicutes (2 MAGs), Omnitrophota (1 MAG), Patescibacteria (1 MAG), Spirochaetota (1 MAG), Synergistota (1 MAG), and Thermotogota (1 MAG), with one bacterial MAG assigned to an unclassified taxon associated with Nitrospirae. Functional analysis revealed that all MAGs possess genes associated with xenobiotic degradation. The enrichment of soil samples from three contaminated sites in the oil field resulted in consortia that are dominated by Alphaproteobacteria in all cases (Chapter 6). The dominance of Alphaproteobacteria in the bacterial communities, especially Acidocella and Paraburkholderia, indicates that these genera are tolerant to high concentrations of diesel fuel. It is also an indication of their potential degradative capacity for organic contaminants (Lee et al., 2019). The dominance of Acidocella in the enrichment cultures may also be related to the slightly acidic conditions in the cultures. Previous studies by Röling et al. (2006) and Obieze et al. (2020) associated a number of Alphaproteobacteria, predominantly Acidiphilium and Acidocella, with natural oil seepages and acidic conditions. The biodegradative ability of these taxa and their tolerance to heavy metals (Giovanella et al., 2020) indicate that they are potentially suitable for the remediation of multiple contaminants such as hydrocarbon-polluted acidic mine sites. Metagenome analysis of one of the isolated consortia revealed the presence of genes putatively encoding for plant growth-promoting and hydrocarbon-degrading enzymes (Chapter 7). 
The growth of single bacterial isolates in mineral medium composed of $\mathrm{KH}_{2} \mathrm{PO}_{4}(0.5 \mathrm{~g} / \mathrm{L}), \mathrm{NaCl}$ $(0.5 \mathrm{~g} / \mathrm{L})$, and $\mathrm{NH}_{4} \mathrm{Cl}(0.5 \mathrm{~g} / \mathrm{L})$ and supplemented with sterile-filtered trace elements $(1 \mathrm{~mL} / \mathrm{L})$ (Atlas, 2010), vitamin solution (1 mL/L) (Atlas, 2010) and $\mathrm{MgSO}_{4} .7 \mathrm{H}_{2} \mathrm{O}(5 \mathrm{~mL} / \mathrm{L}$ of a 100 $\mathrm{mg} / \mathrm{mL}$ solution) revealed that Paraburkholderia proliferated more under neutral $\mathrm{pH}$, as shown by optical density $\left(\mathrm{OD}_{600}\right)$ values. Genome analysis revealed that while both Acidocella and Paraburkholderia genera possess genes putatively involved in the biodegradation of petroleum hydrocarbons, Paraburkholderia was found to be potentially more effective for plant growth promotion (Chapter 8) than Acidocella. In view of Paraburkholderia tropica's potential for greater plant growth stimulation, coupled with its stable growth under neutral $\mathrm{pH}$ conditions, P. tropica was selected for a series of rhizoremediation pot experiments.

Finally, the results of the greenhouse-based experiments revealed that either the consortium (dominated by Acidocella) or the P. tropica single isolate, when used as a bacterial inoculum, significantly enhanced the growth of $M$. sativa and the rhizodegradation of diesel fuel hydrocarbons. However, the greatest remediation effect was seen with $P$. tropica inoculation, with " $P$. tropica $+M$. sativa" treatment achieving a $96 \%$ biodegradation of the total petroleum hydrocarbons.

\subsection{Outlook and Suggestions for Future Research}

The application of phytotechnology to clean up contaminated sites will continue to be an expanding field of research, owing to the low cost and eco-friendliness of this technology (Ali et al., 2013; Rohrbacher and St-Arnaud, 2016). Currently, the innovative use of single bacteria species in association with suitable plants is attracting increasing attention (dos Santos and Maranho, 2018; Fei et al., 2020). I expect that research in this emerging area of green science will be on the increase in the coming years, resulting in the possible development of more commercially-viable inocula for enhanced rhizoremediation.

Notwithstanding the novelty of microbially-enhanced rhizoremediation, a major drawback is the inability of most bacterial species to proliferate in the soil following inoculation (Bashan et al., 2014). Consequently, this is an area requiring future research. Although this $\mathrm{PhD}$ thesis has shown that $P$. tropica thrived in soil following inoculation, more research is needed to confirm its viability in the field (in situ), thereby justifying commercial development. In addition, considering the wide range of contaminated sites, and the enormous diversity in the pollutants involved, there is a need to identify more bacterial species that will expand the range of microbes that are applicable for enhanced rhizoremediation under different environmental conditions, including those considered extreme. 


\subsection{Conclusions}

The use of plants to clean up contaminated sites is a cost-effective, environmentally-friendly and green approach for the reclamation of polluted sites. In this study, I carefully examined the suitability of $M$. sativa for hydrocarbon rhizoremediation. Utilizing the tools of (meta)genomics, I presented a synopsis of the ability of certain microbial species to enhance plant growth promotion and rhizodegradation of diesel fuel, with potential application in the remediation of petroleum-contaminated sites. Geochemical analysis of biodegradation revealed that the synergistic interactions between suitable microbial species and $M$. sativa plants resulted in enhanced rhizoremediation of diesel fuel contaminated soils. Most importantly, this study revealed that " $M$. sativa-P. tropica" are effective symbionts capable of effecting a nearcomplete degradation of diesel fuel hydrocarbons. Thus, the results from this study will no doubt expand the range of culturable microbes for biotechnological applications in the remediation of sites contaminated with petroleum hydrocarbons or other organic contaminants. I am confident that the future is greener with green science! 


\subsection{References}

Adam, G., \& Duncan, H. (2003). The effect of diesel fuel on common vetch (Vicia sativa L.) plants. Environ. Geochem. Health 25, 123-130. doi:10.1023/A:1021228327540

Agathokleous, E., Kitao, M., \& Calabrese, E. J. (2019). Hormesis: a compelling platform for sophisticated plant science. Trends Plant Sci. 24, 318-327.

doi:https://doi.org/10.1016/j.tplants.2019.01.004

Agathokleous, E., Kitao, M., \& Calabrese, E. J. (2020). Hormesis: highly generalizable and beyond laboratory. Trends Plant Sci. 25, 1076-1086.

doi:https://doi.org/10.1016/j.tplants.2020.05.006

Ali, H., Khan, E., \& Sajad, M. A. (2013). Phytoremediation of heavy metals-Concepts and applications. Chemosphere 91, 869-881.

doi:https://doi.org/10.1016/j.chemosphere.2013.01.075

Atlas, R. M. (2010). Handbook of microbiological media (Fourth ed.). CRC Press, Boca Raton, Florida.

Bashan, Y., de-Bashan, L. E., Prabhu, S. R., \& Hernandez, J.-P. (2014). Advances in plant growth-promoting bacterial inoculant technology: formulations and practical perspectives (1998-2013). Plant Soil 378, 1-33. doi:10.1007/s11104-013-1956-x

Calabrese, E. J., \& Baldwin, L. A. (2003). Toxicology rethinks its central belief. Nature 421, 691-692. doi:10.1038/421691a

Cedergreen, N., Ritz, C., \& Streibig, J. C. (2005). Improved empirical models describing hormesis. Environ. Toxicol. Chem. 24, 3166-3172. doi:10.1897/05-014R.1

Chekol, T., \& Vough, L. R. (2001). A study of the use of alfalfa (Medicago sativa L.) for the phytoremediation of organic contaminants in soil. Remediation 11, 89-101. doi:10.1002/rem.1017

Chouychai, W., Thongkukiatkul, A., Upatham, S., Lee, H., Pokethitiyook, P., \& Kruatrachue, M. (2007). Phytotoxicity assay of crop plants to phenanthrene and pyrene contaminants in acidic soil. Environ. Toxicol. 22, 597-604. doi:10.1002/tox.20285

Christie, A. (1920). The mysterious affair at Styles: a detective story. Grosset \& Dunlap, New York.

dos Santos, J. J., \& Maranho, L. T. (2018). Rhizospheric microorganisms as a solution for the recovery of soils contaminated by petroleum: a review. J. Environ. Manage. 210, 104113. doi:https://doi.org/10.1016/j.jenvman.2018.01.015

Fei, J. J., Wan, Y. Y., He, X. Y., Zhang, Z. H., \& Ying, Y. X. (2020). Unitary and binary remediations by plant and microorganism on refining oil-contaminated soil. Environ. Sci. Pollut. Res. 27, 41253-41264. doi:10.1007/s11356-020-10025-6

Giovanella, P., Vieira, G. A. L., Ramos Otero, I. V., Pais Pellizzer, E., de Jesus Fontes, B., \& Sette, L. D. (2020). Metal and organic pollutants bioremediation by extremophile microorganisms. J. Hazard. Mater. 382, 121024. doi:https://doi.org/10.1016/j.jhazmat.2019.121024 
Lee, Y., Lee, Y., \& Jeon, C. O. (2019). Biodegradation of naphthalene, BTEX, and aliphatic hydrocarbons by Paraburkholderia aromaticivorans BN5 isolated from petroleumcontaminated soil. Sci. Rep. 9, 860. doi:10.1038/s41598-018-36165-x

Marchand, C., Mench, M., Jani, Y., Kaczala, F., Notini, P., Hijri, M., \& Hogland, W. (2018). Pilot scale aided-phytoremediation of a co-contaminated soil. Sci. Total Environ. 618, 753-764. doi:https://doi.org/10.1016/j.scitotenv.2017.08.143

Obieze, C. C., Chikere, C. B., Selvarajan, R., Adeleke, R., Ntushelo, K., \& Akaranta, O. (2020). Functional attributes and response of bacterial communities to nature-based fertilization during hydrocarbon remediation. Int. Biodeterior. Biodegradation 154, 105084. doi:https://doi.org/10.1016/j.ibiod.2020.105084

Rohrbacher, F., \& St-Arnaud, M. (2016). Root exudation: the ecological driver of hydrocarbon rhizoremediation. Agronomy 6, 19. doi:10.3390/agronomy6010019

Röling, W. F. M., Ortega-Lucach, S., Larter, S. R., \& Head, I. M. (2006). Acidophilic microbial communities associated with a natural, biodegraded hydrocarbon seepage. $J$. Appl. Microbiol. 101, 290-299. doi:10.1111/j.1365-2672.2006.02926.x 
Appendix A

Ethanol-blended petroleum fuels: implications of co-solvency for phytotechnologies

\author{
Michael O. Eze and Simon C. George
}

RSC Adv., 2020, 10, 6473-6481

DOI: 10.1039/C9RA10919F

Selected for and featured in:

2020 RSC Advances

HOT Articles

Visit the collection

rsc.li/rsc-advances

ROYAL SOCIETY OF CHEMISTRY

\section{RSC Advances}

Appendix B

Australian Government

Geoscience Australia

Record 2018/44 | eCat 124056

\section{Organic Geochemistry Conference: Origins of Oil, Old Organics and Organisms}

Program and Abstracts: 3-7 December, 2018 


\subsubsection{Session 1: Microorganisms and genetics}

\section{PLENARY}

$09: 25-10: 15$

\section{Paula Welander}

Membrane lipid biosynthesis in the archaeon Sulfolobus acidocaldarius

$10: 15-10: 40$

Bronwyn Teece, Simon C. George, Tara Djokic, Kathleen A. Campbell, Steven W. Ruff and Martin J. van Kranendonk

Hydrocarbons and hot springs; looking at analogues in the quest for life on Mars

10:40 - 11:00

\section{COFFEE BREAK}

$11.00-11.25$

Bronwyn C. Campbell, Se Gong, Simon C. George and David J. Midgley

Geochemical characteristics of coal seam biodegradation

$11: 25-11: 50$

Michael O. Eze and Simon C. George

Effect of ethanol on the vertical migration of diesel fuel: implications for phytoremediation

$11: 50-12.15$

Matthew Campbell, Marco Coolen, Pieter Visscher, Brendan Burns and Kliti Grice

Diversity and function of microorganisms in microbial mat communities from Shark Bay, Western Australia

\subsubsection{Session 2: Origins of oil and gas}

$12: 15-12.40$

Emmanuelle Grosjean, Dianne Edwards, Ziqing Hong, Jacob Sohn, Neel Jinadasa and Junhong Chen

Does the Phoenix South 1 oil represent an extension of the Lower Triassic petroleum system of the Perth Basin? 
(Condensed Program)

\section{Monday, December 3}

$17.00-20.00 \quad$ Icebreaker and registration

\section{Tuesday, December 4}
$08.45-09.10$
Registration
$09.10-09.25$
Opening

Session 1: Microorganisms and Genetics
$09.25-10.15$
Paula Welander (Plenary)
$10.15-10.40$
Bronwyn Teece
$11.00-11.25$
Bronwyn C. Campbell
$11.25-11.50$
Michael O. Eze
$11.50-12.15$
Matthew Campbell

Session 2: Origin of Oil and Gas
$12.15-12.40$
Emmanuelle Grosjean
$14.00-14.40$
Christopher J. Boreham (Keynote)
$14.40-15.05$
Jamie Burgess
$15.05-15.30$
Fausto Mosca
$15.30-15.55$
Lukman Johnson

\section{Poster Session}

$16.00-17.30 \quad$ Coffee $\&$ posters

\section{Wednesday, December 5}

Session 3: Methods
09:00 - 09:50
Ellle Chimiak (Plenary)
09:50 - 10:15
Zhongsheng $\mathrm{Li}$
$10: 15-10: 40$
Huitong Wang

Session 4: Old Organic Rocks and Organisms

$\begin{array}{ll}\text { 11:00-11:25 } & \text { John K. Volkman } \\ \text { 11:25-11:50 } & \text { Nannan He } \\ \text { 11:50-12:15 } & \text { Sebastian Naeher } \\ \text { 12:15-12:40 } & \text { Amber Jarrett }\end{array}$

Session 5: Early Life 
Appendix C

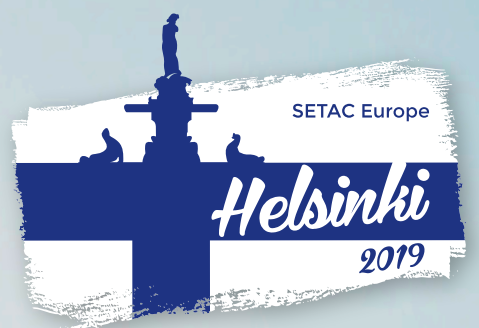

\section{SETAC Europe} $29^{\text {th }}$ Annual Meeting 26-30 May 2019 | Helsinki, Finland

Abstract Book

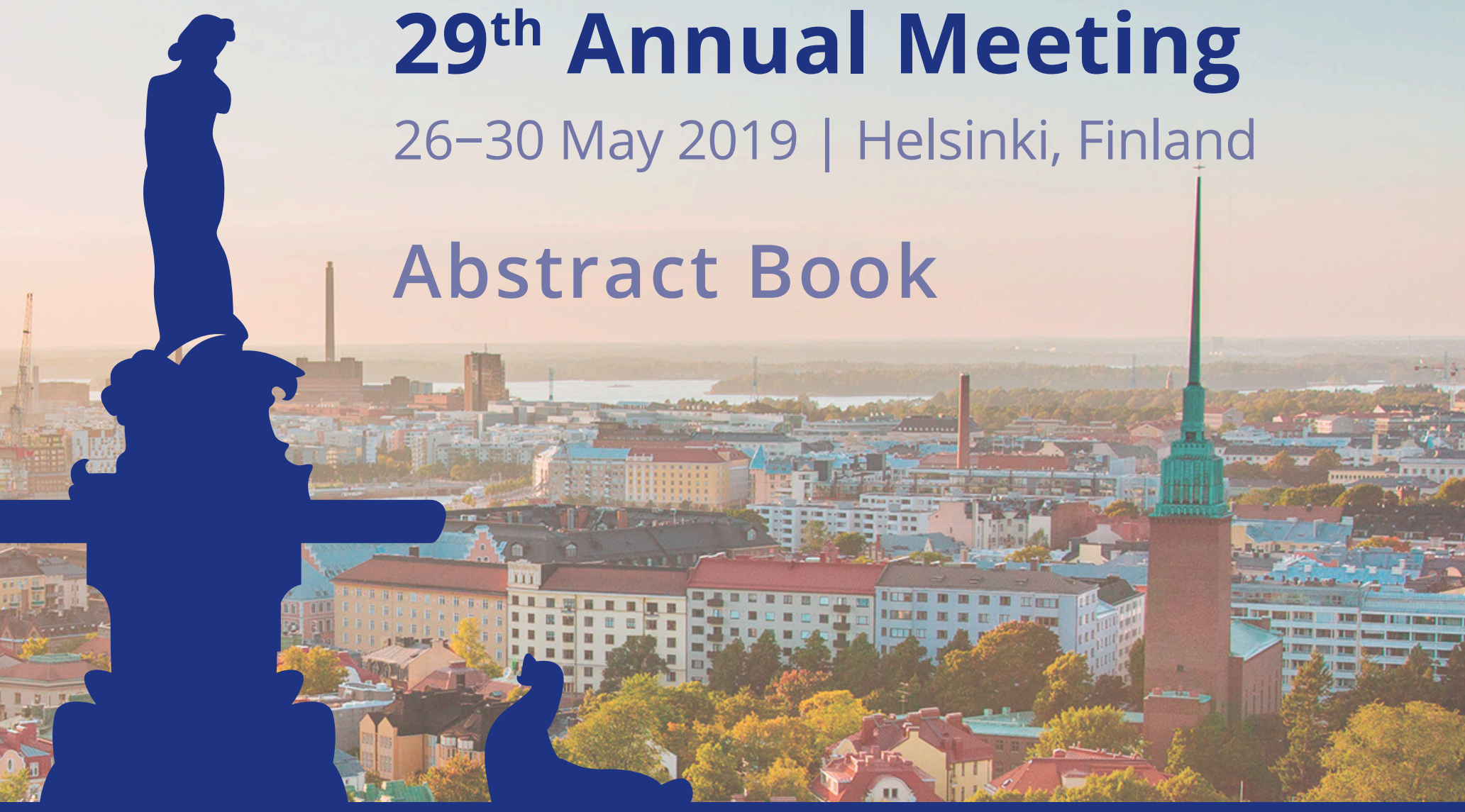

One Environment. One Health. Sustainable Societies.

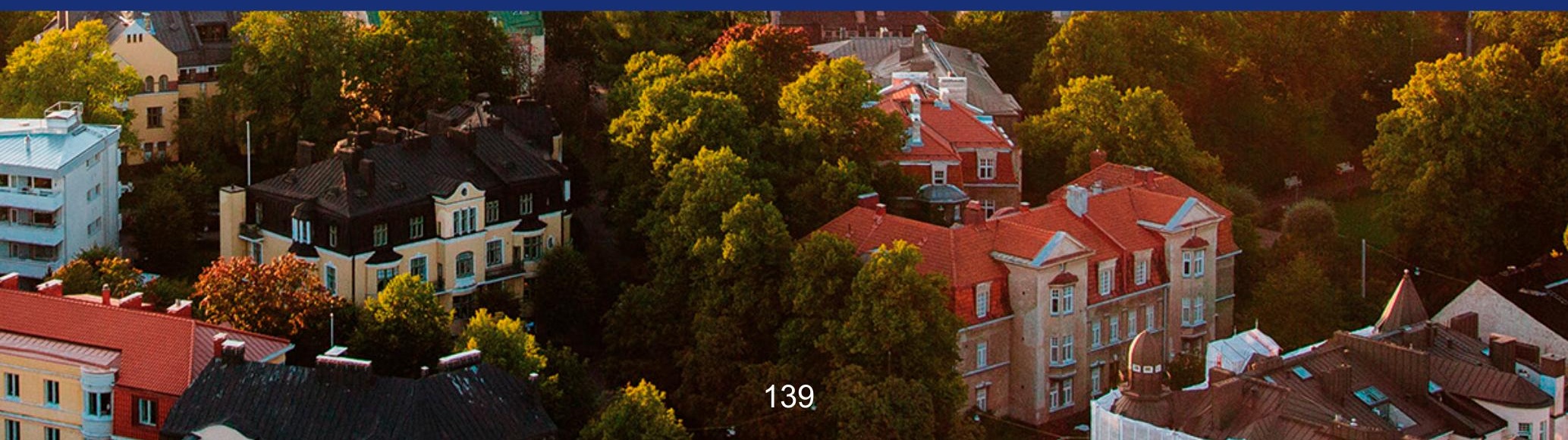


Esguerra, John Laurence. 443 Esimbekova, Elena. MO197, TU185

Esko, Tõnu. 551

Espejo, Winfred. 205, TU064

Espin, Silvia. TU242, TU247,

TU248, TU249

Espín, Silvia. TU250

Espindola, Evaldo. TU124,

\section{TU295}

Espinosa, Carmen. 326

Espuis, Maria Teresa. 598

Esteban, Marta. TU259, WE009

Esteves, Ivânia. WEPC11

Estrany, Francesc. WE273

Etcheverria, Bruno. TU276

Etxebarria, Nestor. 461, MO099,

TU161, TU167, WE233

Eulaers, Igor. 525, MO291,

MO298, TU237, TU239

Evangelista Correia, Jorge.

MO215, MO216, TU077

Evariste, Lauris. TH191, TU108

Evensen, Øystein. 23

Evenset, Anita. MO296

Evon, Philippe. 47

Exposito, Nora. MO191,

MOPC02

Eyckmans, Johan. MO117

Eyer, Michael. TU307

Eytcheson, Stephanie. 22

Eze, Michael Onyedika. MO110

Ezeji, Ethelbert. TU188

Ezendam, Janine. 136

\section{$\mathbf{F}$}

Fabbri, Elena. 496

Fabbri, Federica. TU225

Faber, Daniel. 544, TH004,

TH005

Faber, Jack. TH196

Fabisiak, Jacek. 398

Fadini, Pedro. MO011

Faetsch, Sonja. MO053, TH015

Fahlman, Johan. MO020

Faist-Emmenegger, Mireille.

TH121

Fait, Gabriella. 344

Fajardo, Carmen. TH086, WE172

Falås, Per. WE068

Falciani, Francesco. 21, TH162

Falini, Giuseppe. 496

Falkenhain, Anna-Maria. TH166

Faltin, E. 590

Fältström, Emma. MO249

Fang, Chengwei. TU015

Fantke, Peter. 333, 336, 615

Farkas, Julia. MO225, TU095,

WE235

Farley, Kevin. 262

Farmer, TJ. 271

Farre, Marinella. 267, 268, 269,

620

Fassbender, Christopher. MO068, MO206

Fastner, Jutta. 104

Fatoki, Olalekan. 391

Faupel, Michael. TH197, WE166

Faure, Olivier. 305

Fauser, Aline. TU305

Faust, Michael. 470

Fay, Kellie. 374

Febbo, Eric. TH142

Feckler, Alexander. 430, 499,

WE033

Fedoseeva, Elena. 107, MO014,

WE159

Fedrizzi, Davide. 492

Fedyunin, Vladimir. 638

Feerick, Anna. 510
Feibicke, Michael. 472, TU131

Feidt, Cyril. TU286

Feifarek, David. 374

Feigis, Michelle. TH120

Feiler, Ute. TH018

Fel, Jean-Pierre. 511

Feller, James. TH171

Fellner, Johann. MO276

Feng, Yong-Lai. 34

Fenner, Kathrin. 41, 43, 45,

TH060, TH124

Fenske, Martina. TU094

Fer, Miroslav. TH104

Ferdinand, Paschaline. TU188

Fernandes, Jose. TU139

Fernandes, Leticia. 548

Fernandes, Saul Simão. TU199

Fernandes, Teresa. 512, 577, 580,

TH192, WE092

Fernandez, Alberto. WEPC04

Fernández, Grisel. WE158

Fernandez, Marcos. WE043

Fernández González, Antonio. 50

Fernández González, Laura

Emilia. TH089

Fernandez-Cruz, Maria Luisa. 71

Fernández-González, Verónica.

MO255, MO280

Fernandez-Piñas, Francisca.

\section{TU098}

Fernández-Rosas, Elisabet.

MO201

Fernie, Kim. 281

Ferrara, Allyse. WE226

Ferrari, Benoît. 36, TH017,

TH018

Ferrario, Claudia. TH067

Ferreira, Abel. WEPC10

Ferreira, Carla. WE128

Ferreira, Inês. 592

Ferreira da Silva, Eduardo.

MO268

Ferrer Amata, Carmen. TU318

Ferret, Pierre-Jacques. 290

Ferriol, Jessica. TU108

Fettweis, Andreas. TUPC13

Fialova, Pavla. 587

Fick, Jerker. 487, WE255,

WE261, WE262

Fidalgo, Fernanda. WE183

Fidanza, Maria Rosaria. WE019

Fiebig, Silke. MO131, TH135

Fiedler, Heidelore. TU153

Figueira, Etelvina. 361, 546

Figueiredo, Joana. WE105

Figueiredo, Livia. TU124

Figueiredo, Neusa. WE031

Filazi, Ayhan. MO072, MO073

Filella, Montserrat. WE082

Filipovic, Marko. TU142

Filipsson, Helena. WE277

Fillmann, Gilberto. MO211

Finizio, Antonio. TU006, TU190

Finkbeiner, Matthias. 202, 448

Finkelstein, Sarah. MO254

Finnegan, Colin. MO075, MO085

Fischer, Benedikt. TU140

Fischer, Fabian. 75

Fischer, Stellan. 32

Fisk, Peter. TU200

Fitzgerald, Jennifer. 352, 372,

490, 495, WE282

Fitzpatrick, Karen. MO084

Flahaut, Emmanuel. TH191

flamant, Frederic. 378

Fletcher, Tim. WE025

Fletcher, Tony. TH079

Fliedner, Annette. 208, TH109

Flippin, Jennifer. 526

Floeter, Carolin. MO235, MO237
Florberger, Maria. WE181

Floreani, Federico. TU057

Flyckt-Nielsen, Matias. 644

Fochi, Igor. MO089

Focks, Andreas. 10, 412, 64, 66,

9, MO159, MO160, MO182,

MOPC14

Foekema, Edwin. TU068

Foerster, Bernhard. WE178

Foit, Kaarina. MOPC21

Fojtová, Dana. 296, WE086

Fokina, Natalia. WE243

Folch, Jaume. MOPC02

Fomunyam, Timothy. WE180

Fontanetti, Carmem. MO138,

MO215, MO216, TU077

Fontas, Claudia. TU258

Fontenot, Quenton. WE226

Fontes, Mayana. TU050

Fontes, Mayana Karoline. TH037

Forbes, Valery. 287

Ford, Alex. 24, 483, MO046,

MO102, MO202, TH035, TH036,

WE266, WE267, WE281

Forné, Raphael. WE142

Forner-Piquer, Isabel. TU075

Forquet, Nicolas. TH053

Forsberg, Kristin. WE181

Forsberg, Norman. TH051

Fort, Douglas. WE190

Fortin, Claude. 184

Fossi, Maria Cristina. MO257,

TU061

Foster, Karen. 493, 77, WE219,

WE224

Foudoulakis, Manousos. 345, 347

TU244, TU252, TU254, TUPC22

Fouque, Chantal. 183, TU273

Fouz, Belen. TU088

Fox, David. 404, 405, 409

Fox, Michelle. TH010, TH184

Fra-Vázquez, Andrea. TU221

Fragouli, Despina. 593

Frances-Tudel, Gemma. MO150

Francis, Robert. MO274

Franco, Javier. 241, TU046

Frankenbach, Silja. 303

Frankowska-Łukawska, Justyna.

TH193, WE100

Fransson, Kristin. TU213,

WE114, WE119

Franz, Mathias. 67

Franzellitti, Silvia. 496

Fraser, Christopher. WE160

Fraser, Thomas. TU084

Frattini, Stefano 529

Fredricks, Timothy. 345, TU252,

TUPC22

Frehland, Stefan. 116

Freire, Fausto. MO116

Freisleben, Jindrich. TU174

Freitas, Juliane Silberschmidt

TU295

Freitas, Rosa. 361

Frenkel, Johannes. WEPC08

Frese, Lukas. WE260

Frey, Manfred. WEPC14

Fricke, Julian. TU306

Friesl, Judith. 580

Frijns, Evelien. MO201

Frische, Tobias. 427, 472, TU202

Fritz, Ken. 604

Frolova, Natalia. 637

Frost, Tone. WE241

Fryer, Michael. 349, MO207

$\mathrm{Fu}$, Hualing. MO070

$\mathrm{Fu}$, Qiuguo. 492

Fuad, Nafis. TU277

Fuchte, Hanna. TH090, TH097,

TH103

Fuelling, Olaf. 348, TU233,

TUPC24

Fulgoni III, Victor. 259

Fullana, Pere. MO122, MOPC09

Furberg, Anna. WE114

Furmanski, Nicola. WE005

Fursdon, Jack. 485

Fuß, Bastian. MO305

Füser, Hendrik. TU101

Futter, Martyn. MO281

Færøvig, Per. 624

Förlin, Lars. TUPC08

\section{G}

Gabbert, Silke. 446, TH065

Gabriel, Aikaterini. 550

Gabrielsen, Geir. TU326, TU330

Gabrielsen, Geir Wing. 282,

TU321

Gaetschenberger, Heike. TU305

Gaga, Eftade. 646

Gagliardi, Gabriele Guglielmo.

MO002

Gago-Ferrero, Pablo. MO095,

TH039

Gaillard, Juliette. TU286

Gajda-Meissner, Zuzanna.

TH192, WE092

Galbán, Cristobal. MO039

Galbán-Malagón, Cristobal. 205,

MO038, MO297

Galban-Malagon, Cristobal.

MO037

Galceran, Josep. TU176, TU194,

TU257, TU258, WE082, WE107

Galert, Wiebke. WE003

Galetti, Adele. WE019

galgani, francois. 2

Galic, Nika. 286, 287, 379, 63

MO179, TU315, TU316

Galimberti, Francesco. MO148,

MO149, MO183, MO184, WE209

Gallampois, Christine. 229,

WEPC15

Galland, Victor. 616

Galle, Tom. MO191

Gallego, Juan. TU224

Gallet, Alison. 368, WE141

Galli, Emanuela. TU190 


\section{We certify that}

\section{Michael Onyedika EZE}

(Macquarie University, Sydney, Australia)

attended the

SETAC Europe 29th Annual Meeting in

Helsinki, Finland on 26-30 May 2019

\section{And presented a Poster presentation}

Entitled:

"Ethanol-blended fossil fuels: is reduction of atmospheric pollution the only concern?"

In Session: Target and NonTarget Mass Spectrometry for Human and Environmental Exposure Assessment $(P)$

authors:

Michael O. Eze, Simon C. George

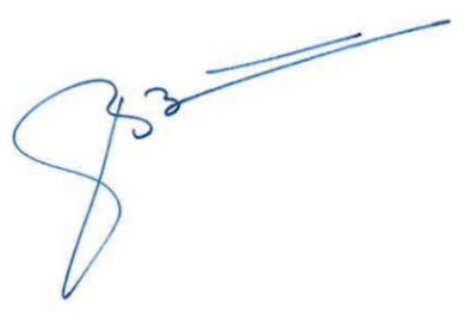

Bart Bosveld

SETAC Europe Executive Director 
Appendix D

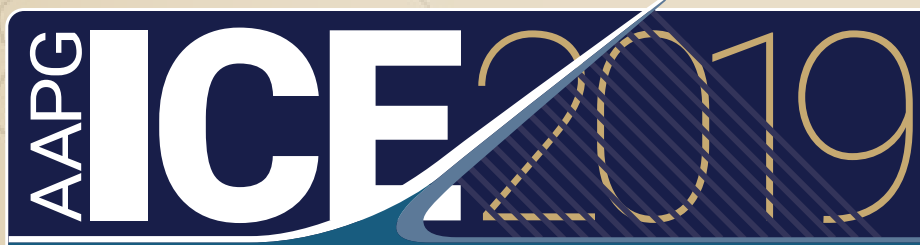

International Conference \& Exhibition

AAPG

27-30 August

Buenos Aires,

Argentina

(1)

EXPANDIIIG FRONTIERS AND UNLOCKNIIG RESOURCES FOR FUTURE GENERATIONS

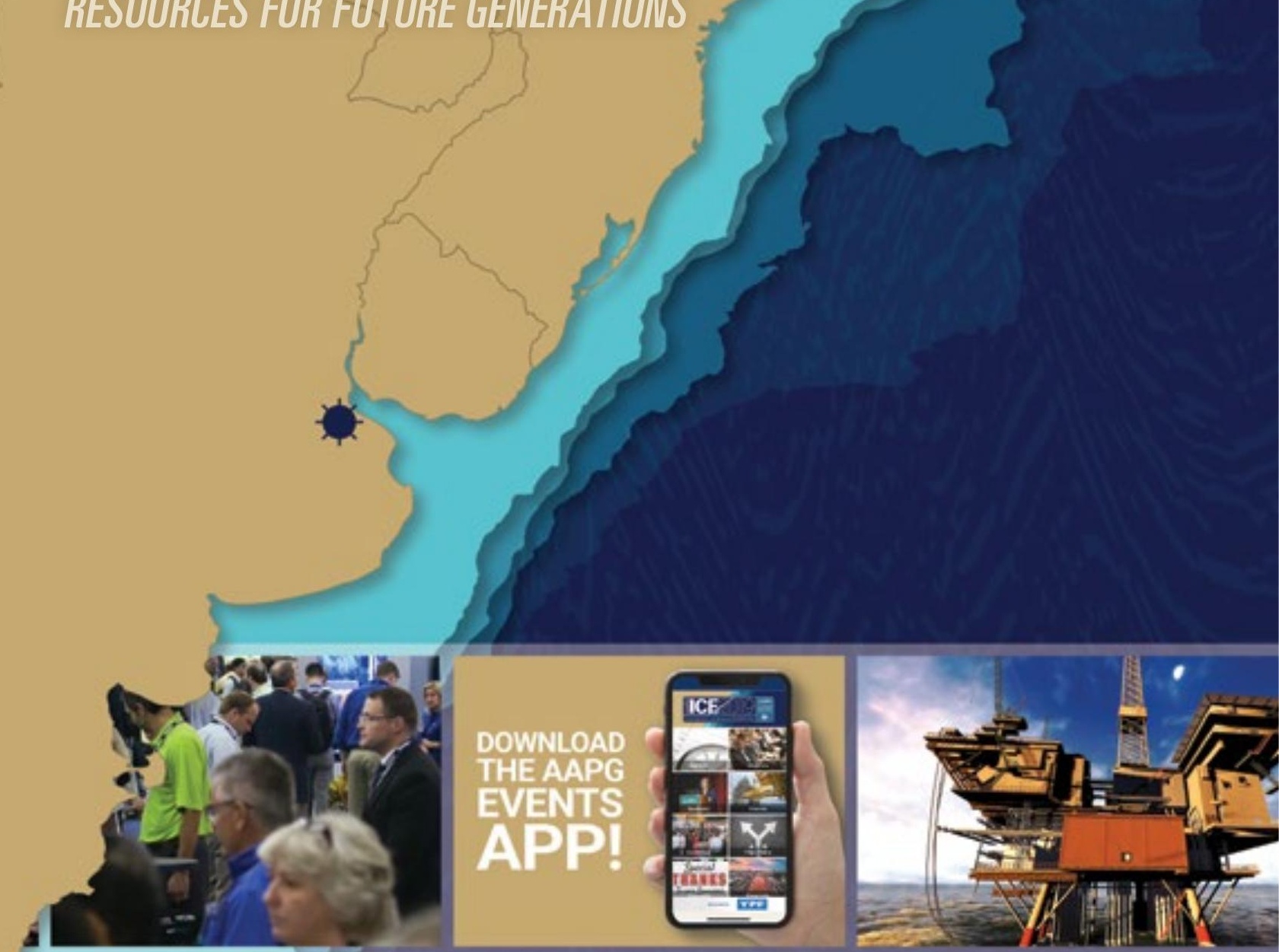

\section{OFFICIAL PROGRAM \\ [ ICEevent.org]}

Program Book Sponsored by: 
10:55 Tectonostratigraphic Evolution of the Southwestern South Atlantic During the Cretaceous: P. R. Kress, R. L. Gerster, N. D. Bolatti, G. Flores, S. Arismendi, J. P. Lovecchio

11:15 Huge Mass Transport Complexes in the Argentina Basin, Offshore South America: Morphology and Seismic Facies: S. Arismendi, G. Flores, P. Kress, R. Gerster, N. Bolatti

11:35 Synrift and Sag Plays in the Southern South Atlantic: Key Elements and Uncertainties: O. R. Lopez-Gamundi, H. de Santa Ana, B. Conti, E. Morales

11:55 Regional Multi 3-D Volume Sculpting Attributes That Tell the Geological Story of Deep-Water Mexico: Z. Ahmadi, V. Brito, C. Luysterburg, E. Manning

Theme 8: Energy Projects and the Environment: Challenges and Proposals for a Better Future

Co-Chairs: G. Garcia y Morales and J. Fasano

Location: Level -2, Atlántico A

08:25 Introductory Remarks

08:30 Comparing Carbon Intensity of Unconventional and Latin American Oil Plays: D. N. Meehan, N. Jenvey

08:50 Energy, Resource Efficiency, and Sustainability: A Road Map for the Oil and Gas Industry: E. Morettini, J. P. Freijo, D. F. Maqui, J. Mahdjoubian Diaz Cano

09:10 The Potential of Medicago Sativa for Microbial-Enhanced Phytoremediation of Diesel Fuel Contaminated Sites: M. O. Eze, S. C. George, G. Hose

09:30 Geohazards Identification and Operational Assurance - Molusco-1 Well Offshore Colombia (Guajira Basin): F. E. Malagon Rojas, H. Niño, C. Rubio*

\section{HISTORY OF PETROLEUM GEOLOGY}

Co-Chairs: E. Gomez and M. L. Rodriquez

Location: Level -2, Atlántico A

10:50 Introductory Remarks

10:55 A Century of Exploration in the Neuquén Basin, Argentina: Jorge Hechem

11:15 History of E\&P Industry in Mexico: Alfredo Guzman

11:35 Historical Overview-Peru Oil and Gas Industry Perspective and Exploration Potential: Pedro Alarcon Medina

11:55 A Short Tale of Colombia Offshore Exploration-History in the Making: Victor Ramirez

\section{Theme 2: Rock and Fluid Characterization of}

\section{Unconventional Reservoirs}

Co-Chairs: E. Morettini and L.B. Smith

Location: Level -2, Atlántico B

08:25 Introductory Remarks

08:30 Shale Porosity and Organic Content from Delaware Wells: J. Walls, G. Davalos, B. Driskill, M. Durand

08:50 Petrophysical Techniques for Unconventional Analysis, Targeting the Wolfcamp Formation in the Permian Basin: R. E. Moreland

09:10 Semi-Quantitative SEM Analysis of the Vaca Muerta Formation, Neuquén Basin, Argentina: L. B. Smith, F. Gonzalez Tomassini, M. J. Rodriguez, C. Bernhardt

09:30 Composition Effects on Pore Structure of Transitional Shale: Q. Zhang, P. Liang, X. Li

10:10 Refreshment Break

10:55 Particularity of Fractal Dimension of Porous Shale and Its Significance for Shale Reservoir Research: X. Wei, J. Zhang, W. Dang, X. Tang
11:15 Investigation of Clay Content as being a Cause for Suppression of Pyrolysis Tmax Maturity Data in the Wolfcamp B: N. Svihlik, A. Maende, M. Riley

11:35 Geochemical Characterization of In-Situ Combustion Process on a Heavy Oil Reservoir from Liaohe Basin, Northeast China: Y. Liu, $H$. Huang, H. Cheng, W. Cheng

11:55 Isotope Stratigraphy and Geochemistry Data from the Upper Jurassic-Lower Cretaceous Vaca Muerta-Quintuco Mixed Depositional System (Neuquén Basin): G. Godino, E. Morettini*

\section{Theme 1: Emerging Basin and New Plays in Mature Basins}

Co-Chairs: N. D. Bolatti and A. Melli

Location: Level -2, Atlántico C

08:25 Introductory Remarks

08:30 Impact of Remote Hydrocarbon Saturation Assessment in a Frontier Basin: J. Rasmussen, E. Nerland, P. T. Gabrielsen, 0 . J. Birkeland

08:50 A Revised Interpretation of Argentina's Offshore Austral and Malvinas Basins and Petroleum Play Analysis: K. R. Reuber, B. W. Horn, D. Allinson

09:10 Unlocking New Hydrocarbon Opportunities in the Lower Cretaceous Section of the Guiana Basin: C. P. Griffith

09:30 Biostratigraphy and Paleoenvironmental Evolution of the Colorado Basin, South Atlantic Ocean: J. P. Perez Panera, D. I. Ronchi, G. N. Angelozzi, J. P. Lovecchio, L. Calvo Marcilese, L. Hiriart, L. Tortora, N. Calaramo, D. Cuciniello, G. Ottone

09:50 Methodology Used in the Exploration of a Frontier Area Located in the Northeast of the Rio Negro Province, Argentina: M. Rodriguez Raising, M. Mendez, J. M. Martinez Lampe

10:10 Refreshment Break

10:55 Assessing the Hydrocarbon Exploration Potential of the Jurassic Cuyo Goup, Southwest Neuquén Basin, Through Outcrop Analog Studies: J. F. Iñigo, R. Gutierrez, R. J. Steel, C. Olariu

11:15 Pre-Salt Plays in West Iberia: R. P. Reis, N. Pimentel, R. Fainstein

11:35 Opening New Plays in the Austral Basin: Frontier Scale, De-Risked Exploration: J. Bessa, P. Malmborg, B. Dewhirst

11:55 Reservoir Characterization of Chachil Formation, Neuquén Basin Data Integration from Rocks to Models: D. E. Velo, H. De Simone

\section{COUNTRY SESSION: BOLIVIA}

Co-Chairs: J. Esquivel and A-M. Goncalves Location: Level 5, Quebracho

08:25 Introductory Remarks

08:30 Luis Alberto Sánchez, Ministry of Hydrocarbons and Energy

08:50 Oscar Barriga, YPFB Corporation

09:20 Tomás Zapata, Repsol

09:40 Claudia Cronenbold Harnés, Bolivian Chamber of Hydrocarbons (CBHE)

10:10 Questions and answers with chairs and panelists

\section{COUNTRY SESSION: COLOMBIA}

Co-Chairs: V. Vega and J. Calvache Location: Level 5, Quebracho

10:50 Introductory Remarks

10:55 Luis Miguel Morelli, ANH Colombia

11:15 Jorge Calvache, Ecopetrol

11:35 Richard Herbert, Frontera Energy

11:55 Francisco Lloreda, Colombian Petroleum Association (ACP) 